\title{
Design of Test Loops for Forced Convection Heat Transfer Studies at Supercritical State
}

\author{
By \\ Masih N. Balouch \\ A thesis submitted to \\ the Faculty of Graduate Studies and Research \\ in partial fulfillment of \\ the requirements for the degree of \\ Master of Applied Science \\ Ottawa-Carleton Institute for Mechanical and Aerospace Engineering \\ Department of Mechanical and Aerospace Engineering \\ Carleton University \\ Ottawa, Ontario \\ Canada
}

August 2011우 
Library and Archives

Canada

Published Heritage

Branch

395 Wellington Street

Ottawa ON K1A ON4

Canada
Bibliothèque et

Archives Canada

Direction du

Patrimoine de l'édition

395 , rue Wellington

Ottawa ON K1A ON4

Canada
Your file Votre référence

ISBN: 978-0-494-87813-2

Our file Notre référence

ISBN: $978-0-494-87813-2$

\section{NOTICE:}

The author has granted a nonexclusive license allowing Library and Archives Canada to reproduce, publish, archive, preserve, conserve, communicate to the public by telecommunication or on the Internet, loan, distrbute and sell theses worldwide, for commercial or noncommercial purposes, in microform, paper, electronic and/or any other formats.

The author retains copyright ownership and moral rights in this thesis. Neither the thesis nor substantial extracts from it may be printed or otherwise reproduced without the author's permission.
AVIS:

L'auteur a accordé une licence non exclusive permettant à la Bibliothèque et Archives Canada de reproduire, publier, archiver, sauvegarder, conserver, transmettre au public par télécommunication ou par l'Internet, prêter, distribuer et vendre des thèses partout dans le monde, à des fins commerciales ou autres, sur support microforme, papier, électronique et/ou autres formats.

L'auteur conserve la propriété du droit d'auteur et des droits moraux qui protege cette thèse. $\mathrm{Ni}$ la thèse ni des extraits substantiels de celle-ci ne doivent être imprimés ou autrement reproduits sans son autorisation.
In compliance with the Canadian Privacy Act some supporting forms may have been removed from this thesis.

While these forms may be included in the document page count, their removal does not represent any loss of content from the thesis.
Conformément à la loi canadienne sur la protection de la vie privée, quelques formulaires secondaires ont été enlevés de cette thèse.

Bien que ces formulaires aient inclus dans la pagination, il n'y aura aucun contenu manquant. 
The undersigned recommend to

the Faculty of Graduate Studies and Research

acceptance of the thesis,

\title{
Design of Test Loops for Forced Convection Heat Transfer Studies at Supercritical State
}

\author{
submitted by \\ Masih N. Balouch \\ in partial fulfillment of the requirements for the degree of \\ Master of Applied Science \\ Dr. Metin I. Yaras, Thesis Supervisor \\ Chair, Department of Mechanical and Aerospace Engineering \\ Carleton University \\ 2011
}




\section{ABSTRACT}

Worldwide research is being conducted to improve the efficiency of nuclear power plants by using supercritical water (SCW) as the working fluid. One such SCW reactor considered for future development is the CANDU-Supercritical Water Reactor (CANDUSCWR). For safe and accurate design of the CANDU-SCWR, a detailed knowledge of forced-convection heat transfer in SCW is required. For this purpose, two supercritical fluid loops, i.e. a SCW loop and an R-134a loop are developed at Carleton University.

The SCW loop is designed to operate at pressures as high as $28 \mathrm{MPa}$, temperatures up to $600{ }^{\circ} \mathrm{C}$ and mass fluxes of up to $3000 \mathrm{~kg} / \mathrm{m}^{2} \mathrm{~s}$. The R-134a loop is designed to operate at pressures as high as $6 \mathrm{MPa}$, temperatures up to $140^{\circ} \mathrm{C}$ and mass fluxes in the range of $500-6000 \mathrm{~kg} / \mathrm{m}^{2} \mathrm{~s}$. The test loops designs allow for up to $300 \mathrm{~kW}$ of heating power to be imparted to the fluid. Both test loops are of the closed-loop design, where flow circulation is achieved by a centrifugal pump in the SCW loop and three parallelconnected gear pumps in the R-134a loop, respectively. The test loops are pressurized using a high-pressure nitrogen cylinder and accumulator assembly, which allows independent control of the pressure, while simultaneously dampening pump induced pressure fluctuations. Heat exchangers located upstream of the pumps control the fluid temperature in the test loops. Strategically located measuring instrumentation provides information on the flow rate, pressure and temperature in the test loops. 
The test loops have been designed to accommodate a variety of test-section geometries, ranging from a straight circular tube to a seven-rod bundle, achieving heat fluxes up to $2.5 \mathrm{MW} / \mathrm{m}^{2}$ depending on the test-section geometry. The design of both test loops allows for easy reconfiguration of the test-section orientation relative to the gravitational direction. All the test sections are of the directly-heated design, where electric current passing through the pressure retaining walls of the test sections provides the Joule heating required to heat up the fluid to supercritical conditions. A high-temperature dielectric gasket isolates the current carrying parts of the test section from the rest of the assembly. Temperature and pressure drop data are collected at the inlet and outlet, and along the heated length of the test section.

The test loops and test sections are designed according to American Society of Mechanical Engineers (ASME) Pressure Piping B31.1, and Boiler and Pressure Vessel Code, Section VIII-Division 1 rules. The final test loops and test sections assemblies are certified by Technical Standards and Safety Authority (TSSA). Every attempt is made to use off-the-shelf components where possible in order to streamline the design process and reduce costs. Following a rigorous selection process, stainless steel Types 316 and $316 \mathrm{H}$ are selected as the construction materials for the test loops, and Inconel 625 is selected as the construction material for the test sections.

This thesis describes the design of the SCW and R-134a loops along with the three test-section geometries (i.e., tubular, annular and bundle designs). 


\section{ACKNOWLEDGMENTS}

First and foremost, I thank Prof. Glenn McRae, my initial supervisor, without whose unending support, this thesis work would not have been possible. His guidance and expertise were invaluable throughout my thesis work. I also thank Prof. Metin I. Yaras, my second supervisor, for giving me the opportunity to continue my thesis research work on the design of the test loops. His efforts to manage such a complex project while handling the responsibilities of being the Chair of the Mechanical and Aerospace Department are remarkable and inspiring.

I thank and acknowledge the contributions of my colleagues, Anne Mason, Yi-Li Jin and Rubicel G. Alena, whose assistance and hard work were significant for the success of this project. Chukwudi Azih's involvement and helpful comments are also noteworthy. I thank Theo Melburn, Andrew Wright and Ron Raaflaub of Swagelok ${ }^{\text {TM }}$ Ottawa for their expert consultation and help in the construction of the R-134a loop.

I can't thank enough my parents and my siblings for their understanding, care and support. My friends have been another great source of support, who kept me smiling through some of the toughest times during the project. Especially, I thank Mario, Majed, and Einalem.

Finally, I would like to extend my appreciation to the Government of Canada, Province of Ontario and AECL for the financial support of this project. 


\section{CONTENTS}

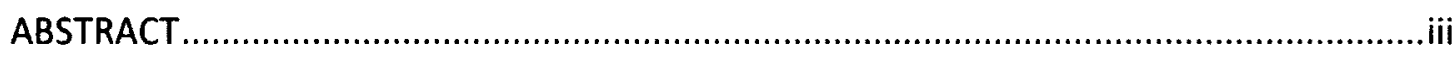

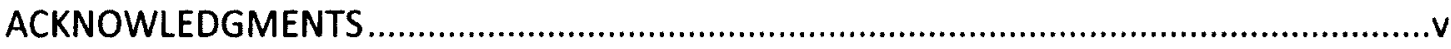

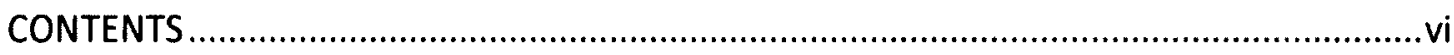

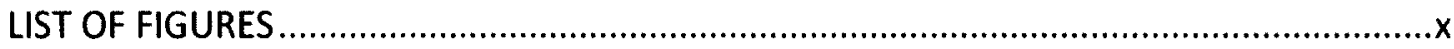

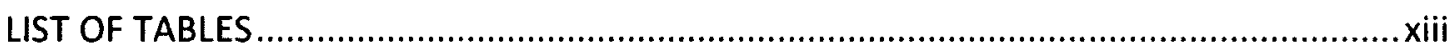

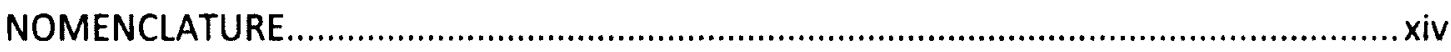

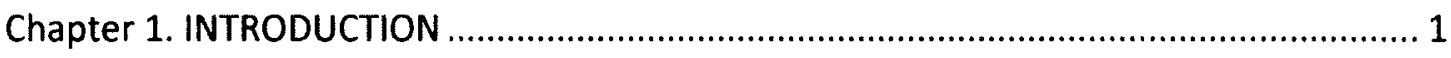

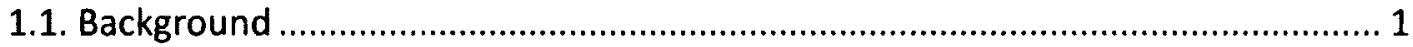

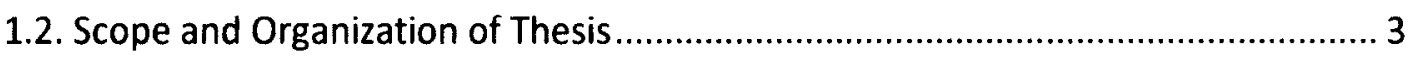

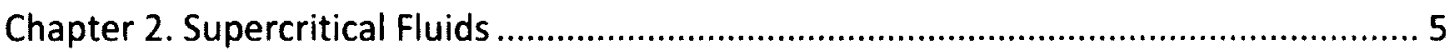

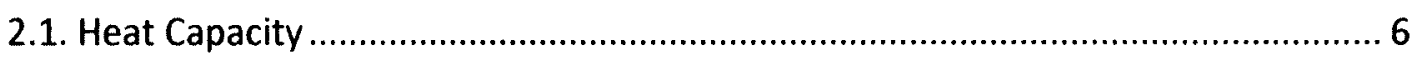

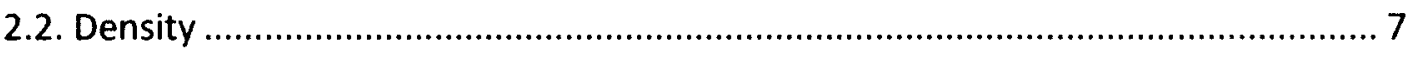

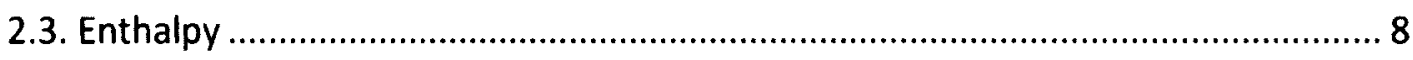

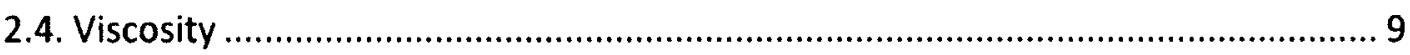

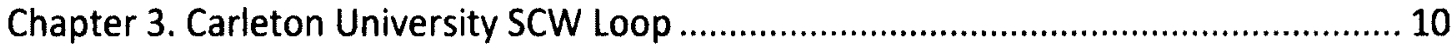

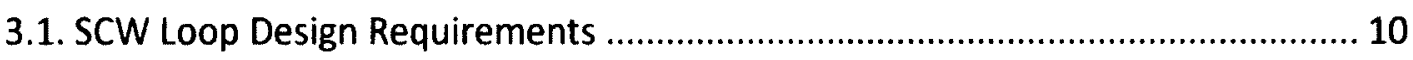

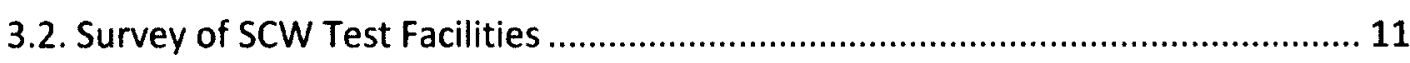

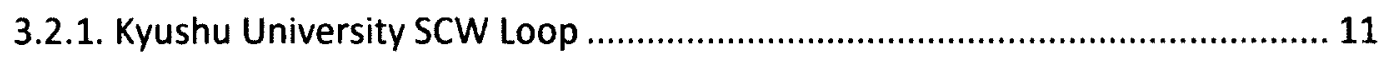

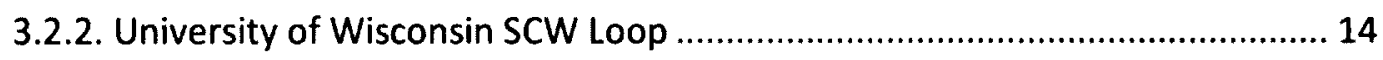

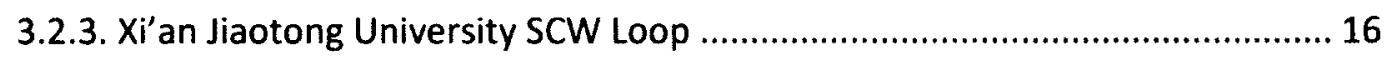

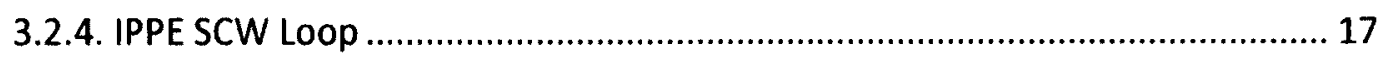

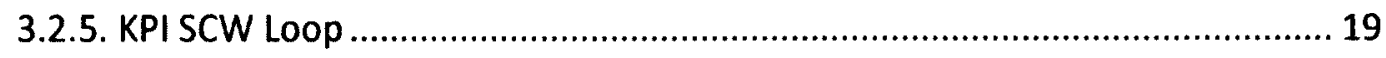

3.3. Design of the Carleton University SCW Loop .................................................... 21

3.3.1. Design Overview ....................................................................................... 21 
3.3.2. Sizing and Selection of the Carleton SCW Loop Piping Components ............. 23

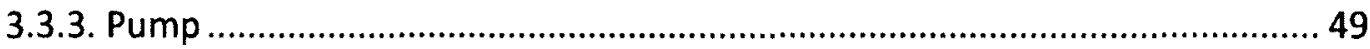

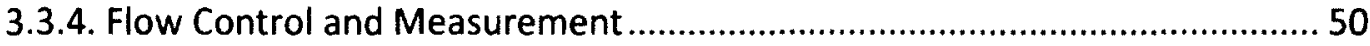

3.3.5. Temperature Control and Measurement ................................................5 57

3.3.6. Pressure Control and Measurement....................................................... 103

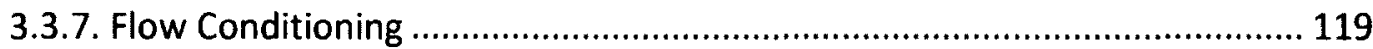

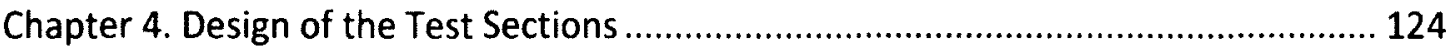

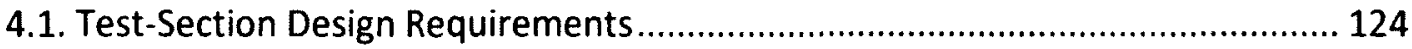

4.2. Survey of Test Sections Used in SCW Experiments ....................................... 126

4.2.1. Kyushu University SCW Loop Test Section................................................. 126

4.2.2. University of Wisconsin SCW Loop Test Section....................................... 128

4.2.3. Xi'an Jiaotong University SCW Loop Test Sections ................................. 132

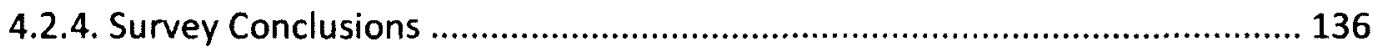

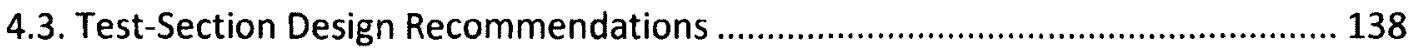

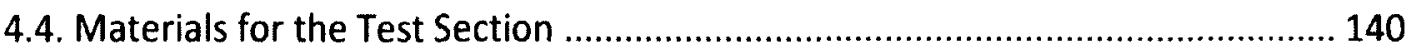

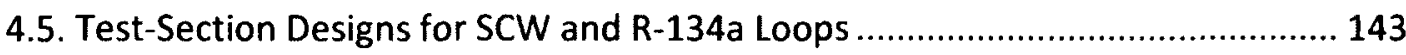

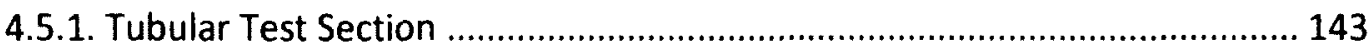

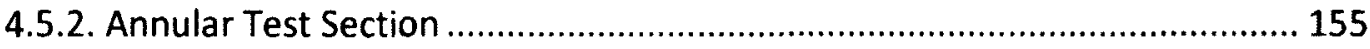

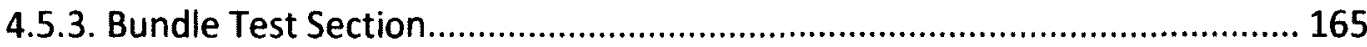

4.6. Design of the Pre-Heater for the SCW Loop .............................................. 174

4.6.1. Pre-heater Heating Element …........................................................... 176

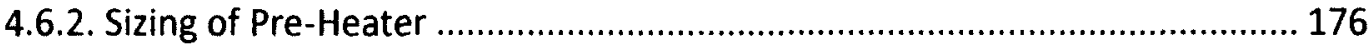

4.6.3. Design and Installation of Pre-Heater Heating Elements ........................... 178

Chapter 5. Carleton University R-134a Loop ............................................................ 179

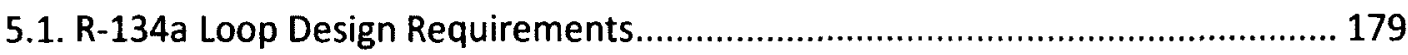

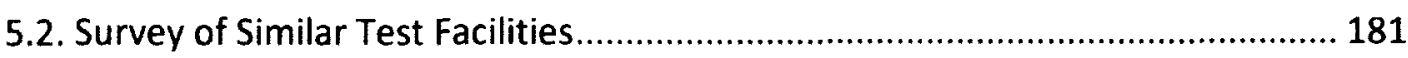

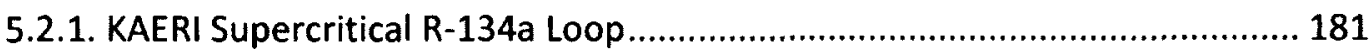

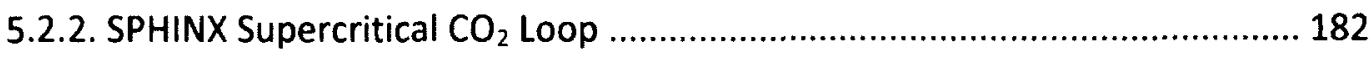

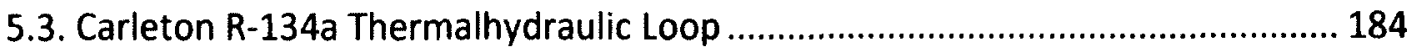

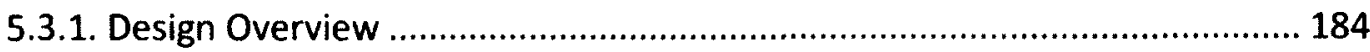

5.3.2. Sizing and Selection of the Carleton R-134a Tubing Components ............... 189 


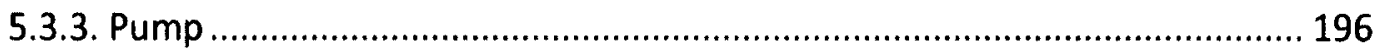

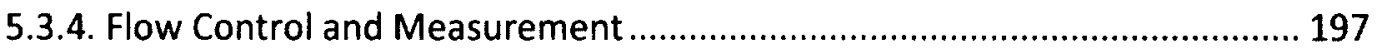

5.3.5. Temperature Measurement and Control .................................................... 199

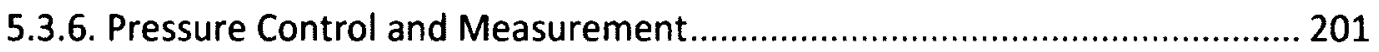

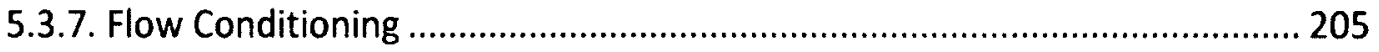

5.4. Design of the Pre-Heater for the R-134a Loop ............................................... 206

Chapter 6. Corrosion Issues and Mitigation ................................................................. 207

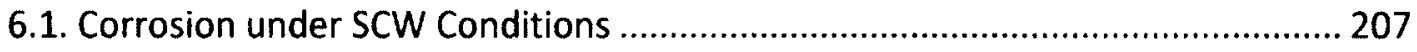

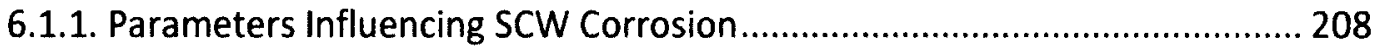

6.1.2. Water Treatment Strategies to Minimize SCW Corrosion ............................. 210

6.1.3. Corrosion Rate of Stainless Steel Type 316 under SCW Conditions ............. 212

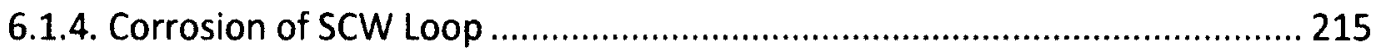

Chapter 7. Conclusions and Recommendations ......................................................... 216

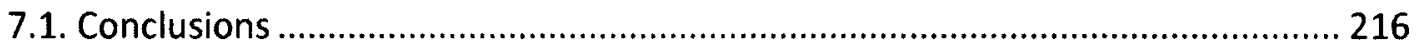

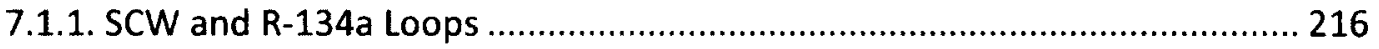

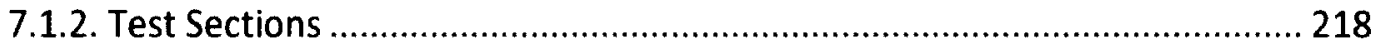

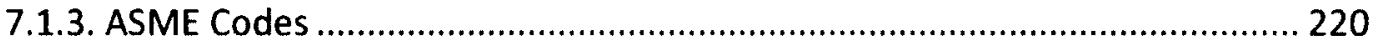

7.1.4. Materials and Materials Costs .................................................................. 220

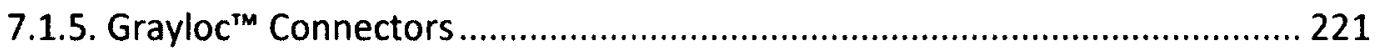

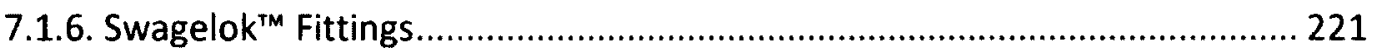

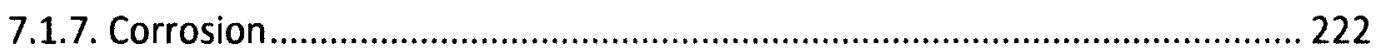

7.1.8. Experimental Capabilities ....................................................................... 222

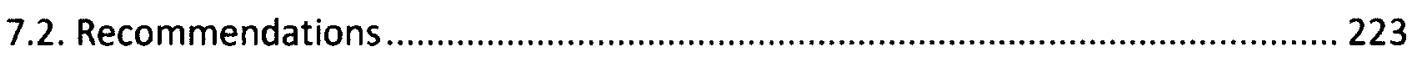

7.2.1. Test-Section Power Regulation ............................................................. 223

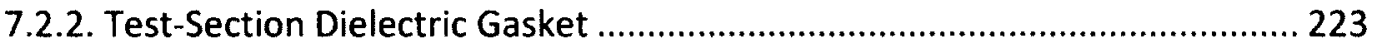

7.2.3. Filter/Strainer Dielectric Gasket .............................................................. 224

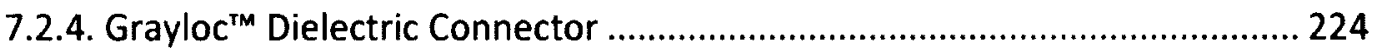

7.2.5. SCW Loop Pre-Heater ............................................................................. 224

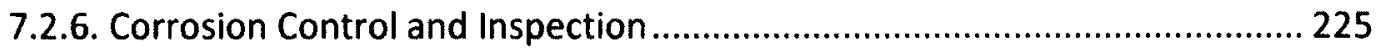

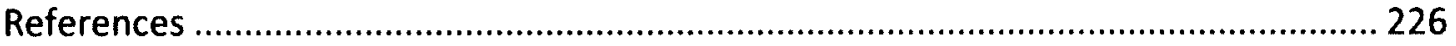


APPENDIX A: Supercritical Fluid Heat Transfer Facility.......................................... 232

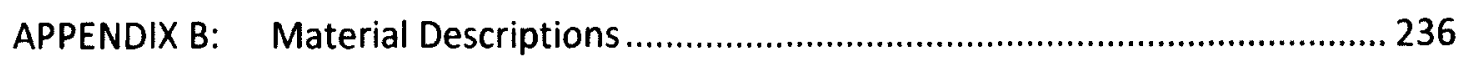

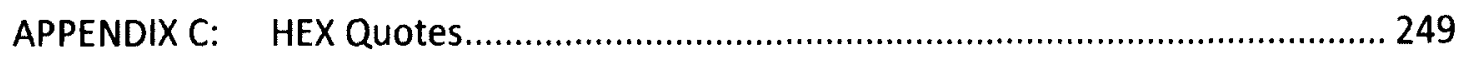

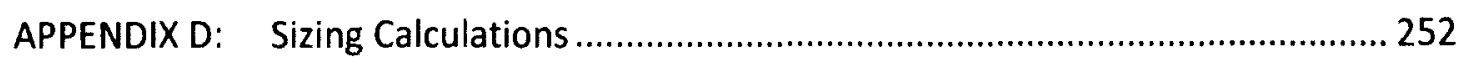

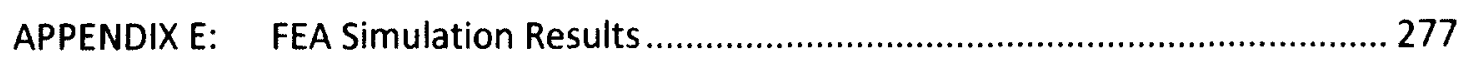

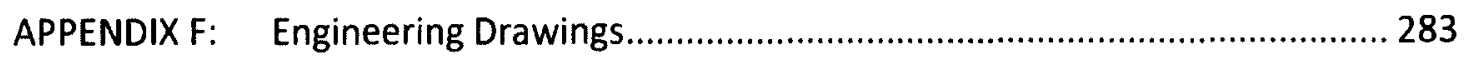




\section{LIST OF FIGURES}

Figure 2.1: Specific heat of water as a function of temperature.................................... 6

Figure 2.2: Density of water as a function of temperature ........................................ 7

Figure 2.3: Specific enthalpy of water as a function of temperature ............................... 8

Figure 2.4: Dynamic viscosity of water as a function of temperature ............................. 9

Figure 3.1: Cross-sections of the three test-section geometries................................... 10

Figure 3.2: Kyushu University SCW experimental apparatus ....................................... 13

Figure 3.3: University of Wisconsin SCW heat transfer loop................................... 15

Figure 3.4: Xi'an Jiaotong University SCW heat transfer loop ................................. 17

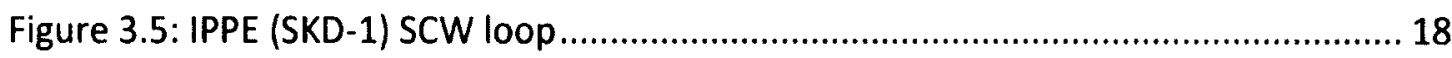

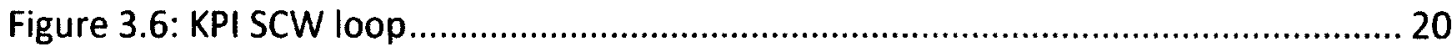

Figure 3.7: Layout and major components of the Carleton SCW loop .......................... 23

Figure 3.8: Piping and instrumentation diagram of the Carleton SCW loop ................... 24

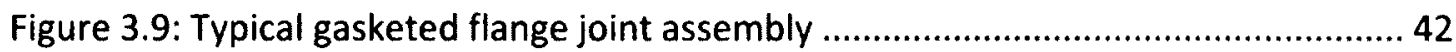

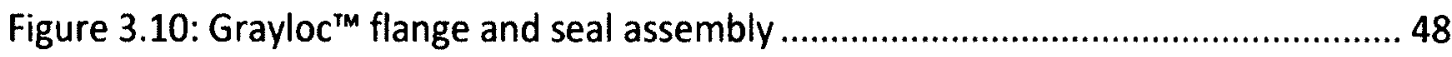

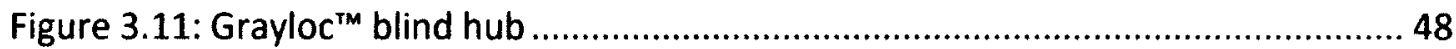

Figure 3.12: Typical calibration curve for a turbine flow meter ................................... 53

Figure 3.13 Recommended turbine flow meter installation pipework ........................ 54

Figure 3.14: Values of swirl velocity ratio, Ks, for various piping configurations............ 56

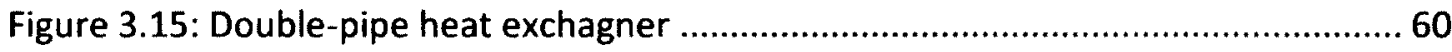

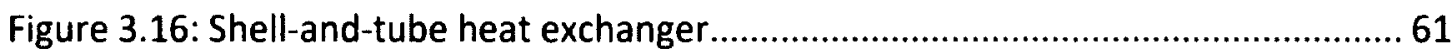

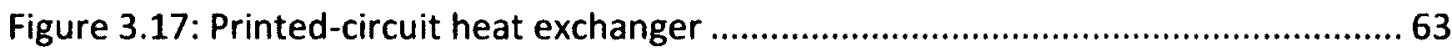

Figure 3.18: (a) Gasketed pate; (b) spiral plate; (c) lamella heat exchanger.................... 65

Figure 3.19: Heat transfer coefficient of SCW at $23 \mathrm{MPa}$ as a function of temperrature 68

Figure 3.20: Internal layout of double-pipe heat exchanger ....................................... 70

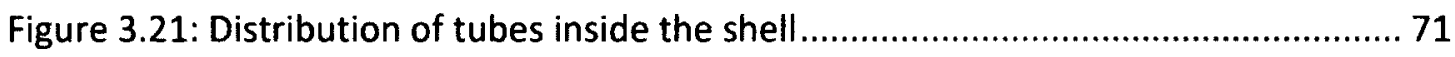


Figure 3.22: List of components that need to be sized ............................................... 90

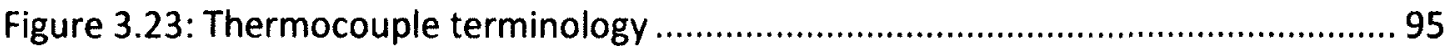

Figure 3.24: The Seebeck coefficient as a function of temperature ............................... 96

Figure 3.25: Thermocouple measuring junction designs........................................... 97

Figure 3.26: Expansion loop for thermal expansion in furnace applications ................. 100

Figure 3.27: Construction of piston back pressure regulator ................................... 105

Figure 3.28: Accumulator and gas cylinder assembly.............................................. 111

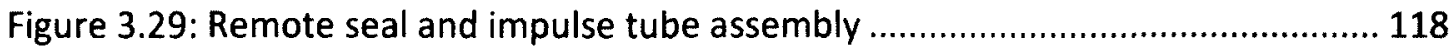

Figure 4.1: Cross-sections of the three test-section geometries............................... 125

Figure 4.2: Kyushu University $10 \mathrm{~mm}$ internal diameter test section ........................ 127

Figure 4.3: University of Wisconsin circle and square annular test-section configurations

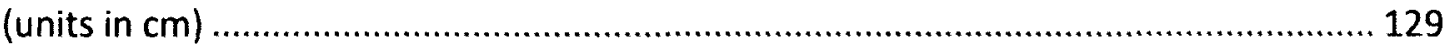

Figure 4.4: University of Wisconsin heater rod schematic ..................................... 130

Figure 4.5: Pressure boundary allowing for differential thermal expansion ................ 131

Figure 4.6: Fixed pressure boundary heater connection design ................................. 131

Figure 4.7: Xi'an Jiaotong University test section and thermocouple arrangement...... 133

Figure 4.8: Xi'an Jiaotong University square annular test section (units in $\mathrm{mm}$ ) ........... 134

Figure 4.9: Leak-proof seal and insulation structure of the test section....................... 136

Figure 4.10: Effect of temperature on the electrical resistivity of various materials .... 140

Figure 4.11: Electrical resistivity of superalloys as a function of temperature ............. 142

Figure 4.12: Heat transfer coefficient of SCW as function of fluid bulk temperature ... 146

Figure 4.13: Allowable stresses for solution annealed Inconel 625 seamless tube/pipe as

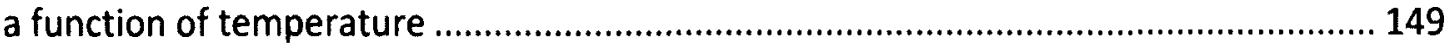

Figure 4.14: Required wall thickness as a function of wall temperature ..................... 151

Figure 4.15: Tubular test section overview ........................................................... 154

Figure 4.16: Predicted heat transfer coefficient of SCW as a function of fluid bulk

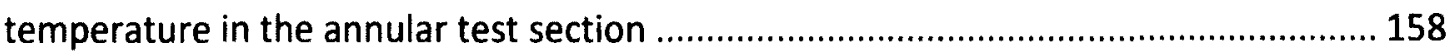

Figure 4.17: Annular test-section overview........................................................... 163 
Figure 4.18: Sealing block assembly 165

Figure 4.19: Predicted heat transfer coefficient of SCW as a function of fluid bulk temperature in the $7.4 \mathrm{~mm}$ bundle test section 169

Figure 4.20: Seven-rod bundle test-section overview 172

Figure 4.21: Sealing block assembly for bundle test section 173

Figure 4.22: Pre-heater locations 175

Figure 4.23: Pre-heater heating element installation 178

Figure 5.1: Schematic diagram of KAERI supercritical R-134a loop. 182

Figure 5.2: Schematic diagram of SPHINX test facility 184

Figure 5.3: Layout and major components of the Carleton R-134a loop.... 185

Figure 5.4: Piping and instrumentation of the Carleton R-134a loop 186

Figure 5.5: Anatomy of a swage fitting..... 195

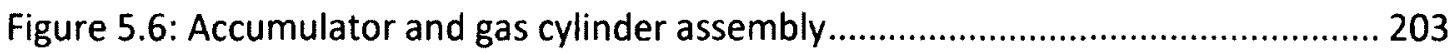

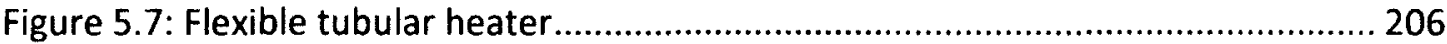

Figure 6.1: Physical properties of water at different temperatures and pressures ....... 208

Figure 6.2: Oxide layer thickness versus time for a number of materials ..................... 212

Figure 6.3: Weight gain versus time for Type 316 when exposed to SCW at $600{ }^{\circ} \mathrm{C} \ldots . .214$ Figure 6.4: Weight gain rate versus temperature for Type 316 at various dissolved oxygen concentrations 214 


\section{LIST OF TABLES}

Table 1.1: Operating parameters in various reactor designs ....................................... 2

Table 3.1: Operating parameters of the supcritical water test sections .......................... 11

Table 3.2: Typical design velocities for liquid water flowing through pipes ................... 29

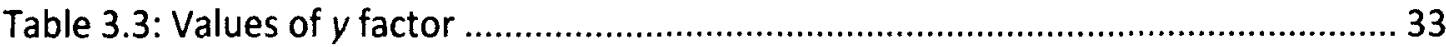

Table 3.4: Ceiling pressure ratings in bars for ASME B16.5 flanges for any material ...... 40

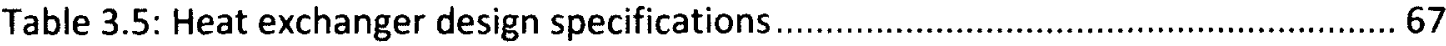

Table 3.6: Heat transfer coefficient values of SCW at $23 \mathrm{MPa}, 0.126 \mathrm{~kg} / \mathrm{s}$ flow rate and

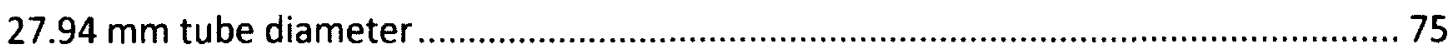

Table 3.7: Properties of propylene glycol and water at 1 bar and $25^{\circ} \mathrm{C} \ldots \ldots \ldots \ldots \ldots \ldots \ldots . . . . . . . . . . . . .76$

Table 3.8: Thermophysical properties of the cooling fluid mixture ................................ 78

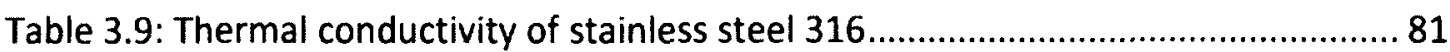

Table 3.10: Summary of sizing results for the hairpin heat exchanger desgin ( $23 \mathrm{MPa}$ and

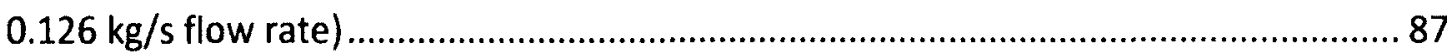

Table 3.11: Standard thermocouple types and tolerances ........................................... 96

Table 3.12: Upper temperature limit vs. wire diameter................................................ 99

Table 3.13: Upper temperature limit vs. sheath diameter.......................................... 99

Table 3.14: Filter element types and characteristics .................................................. 121

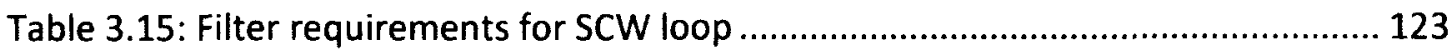

Table 4.1: Proposed design requirements for the test sections................................... 126

Table 5.1: Operating parameters of the supercritical R-134a loop............................ 180 


\section{NOMENCLATURE}
A $\quad\left[m^{2}\right] \quad$ Heat transfer surface area, or
Cross-sectional area of flow conduit
A
$A_{i}$
$A_{C}$
$A_{5}$
ASME
$A / P$
B
C
$C_{p}$
c
CANDU $U^{\text {TM }}$
D
$D_{e} \quad[\mathrm{~mm}$

$D_{h}$
$D_{i}$
Do
$d$
$d_{i}$
A factor determined from Chart $G$ in ASME Section II, Part D Subpart 3
Coefficients used in the aqueous propylene glycol solution
$\left[\mathrm{m}^{2}\right]$ Cross-sectional area of the electrical conductor, or
Cross-sectional area of the flow conduit
$\left[\mathrm{m}^{2}\right] \quad$ Conductor heat transfer surface area
American Society of Mechanical Engineers
Absolute pressure
A factor determined from applicable material chart in ASME Section II, Part D Subpart 3, or
Virial coefficient
Factor determined according to UG-39(d)(1), ASME Section VIII, Div.1, or
Virial coefficient
Specific heat capacity
An empirical dimensional constant to determine erosional velocity
CANada Deuterium Uranium
[mm] Outside diameter of the tube/inner $\operatorname{rod}(\mathrm{s})$, or
Nominal flow meter diameter, or
Diameter
[mm] Hydraulic diameter
[mm] Internal diameter of outer tube/shell, or
Internal diameter of flow conduit
[mm] External diameter of outer tube
[mm] Inner diameter of the tubular test section
$[\mathrm{mm}]$ Internal diameter of inner tube 


\begin{tabular}{|c|c|c|}
\hline$d_{0}$ & {$[m m]$} & External diameter of inner tube \\
\hline$D / P$ & & Differential pressure \\
\hline$E$ & & Joint efficiency (for seamless construction $E=1$ ) \\
\hline$F$ & {$[N]$} & Load \\
\hline & & Cyclic stress range factor, or \\
\hline$f$ & & Friction coefficient \\
\hline FEA & & Finite Element Analysis \\
\hline$h$ & {$\left[\frac{W}{m^{2} K}\right]$} & Heat transfer coefficient \\
\hline$h_{i}$ & {$\left[\frac{W}{m^{2} K}\right]$} & Heat transfer coefficient of fluid inside the inner tube \\
\hline$h_{m}$ & {$\left[\frac{W}{m^{2} K}\right]$} & Mean heat transfer coefficient \\
\hline$h_{o}$ & {$\left[\frac{W}{m^{2} K}\right]$} & Heat transfer coefficient of the fluid outside the inner tube \\
\hline HEX & & Heat exchanger \\
\hline 1 & {$[A]$} & Electric current \\
\hline$K_{S}$ & & Dimensionless swirl velocity ratio \\
\hline$k$ & {$\left[\frac{W}{m K}\right]$} & Coefficient of thermal conductivity \\
\hline$L$ & {$[m]$} & Length of the heater rod(s), or \\
\hline & & Required length of upstream straightening pipe, or \\
\hline & & Length of flow path \\
\hline M & & Number of segments for the calculation of GMTD \\
\hline$\dot{m}$ & {$\left[\frac{k g}{s}\right]$} & Mass flow rate \\
\hline$\dot{m}_{f l u x}$ & {$\left[\frac{\mathrm{kg}}{\mathrm{m}^{2} s}\right]$} & Fluid mass flux \\
\hline$\dot{m}_{c}$ & {$\left[\frac{k g}{s}\right]$} & Mass flow rate of the cold fluid \\
\hline$\dot{m}_{h}$ & {$\left[\frac{k g}{s}\right]$} & Mass flow rate of the hot fluid \\
\hline$n$ & & Exponent used in Dittus-Boetler Equation \\
\hline $\mathrm{Nu}$ & & Nusselt number \\
\hline$P$ & {$[\mathrm{~mm}]$} & Flow conduit wetted perimeter \\
\hline$P$ & {$[\mathrm{~Pa}]$} & Pressure or Internal design pressure \\
\hline
\end{tabular}




\begin{tabular}{|c|c|c|}
\hline$P$ & {$[W]$} & Electrical power \\
\hline$P_{a 1}$ & {$[\mathrm{~Pa}]$} & $\begin{array}{l}\text { Maximum allowable pressure than can be accommodated for a } \\
\text { given wall thickness }\end{array}$ \\
\hline$P_{a 2}$ & {$[\mathrm{~Pa}]$} & $\begin{array}{l}\text { Maximum allowable pressure than can be accommodated for a } \\
\text { given wall thickness }\end{array}$ \\
\hline$P_{x}$ & & $\begin{array}{l}\text { Function describing various properties of aqueous propylene } \\
\text { glycol solution }\end{array}$ \\
\hline $\operatorname{Pr}$ & & Prandtl number \\
\hline $\operatorname{Pr}_{b}$ & & Prandtle number calculated at bulk temperature \\
\hline $\operatorname{Pr}_{w}$ & & Prandtle number calculated at wall temperature \\
\hline PWR & & Pressurized Water Reactor \\
\hline$\Delta p_{b}$ & {$[P a]$} & Pressure drop in bends \\
\hline$\Delta p_{c}$ & {$[\mathrm{~Pa}]$} & Pressure drop in the cold-side fluid \\
\hline$\Delta p_{f}$ & {$[\mathrm{~Pa}]$} & Pressure drop in straight pipes \\
\hline$\Delta p_{h}$ & {$[P a]$} & Pressure drop in the hot-side fluid \\
\hline$\Delta p_{m}$ & {$[\mathrm{~Pa}]$} & Pressure drop due to momentum change \\
\hline$Q$ & {$[W]$} & Time rate of heat transfer \\
\hline$Q_{s}$ & {$[W]$} & Heat transfer at a node for the calculation of GMTD \\
\hline$q$ & $\left\lceil\frac{k W}{m^{2}}\right]$ & Heat flux \\
\hline$R$ & {$[\mathrm{~mm}]$} & Internal radius of the test section \\
\hline$R$ & {$\left[\frac{\mathrm{J}}{\mathrm{mol} \mathrm{K}}\right]$} & Molar gas constant \\
\hline$R$ & {$[\Omega]$} & Ohmic resistance \\
\hline $\operatorname{Re}$ & & Reynolds number \\
\hline$R e_{b}$ & & Reynolds number calculated at bulk temperature \\
\hline$r_{i}$ & {$[\mathrm{~mm}]$} & Internal radius of inner tube \\
\hline$r_{0}$ & {$[m m]$} & External radius of inner tube \\
\hline \multirow[t]{2}{*}{$S$} & {$[\mathrm{~Pa}]$} & $\begin{array}{l}\text { Allowable stress value in applicable tables of ASME B31.1 for } \\
\text { internal pressure sizing, or }\end{array}$ \\
\hline & & $\begin{array}{l}\text { Allowable stress value determined according to UG-28(c)(2), } \\
\text { Section VIII, Division } 1 \text { for external pressure sizing }\end{array}$ \\
\hline$S_{A}$ & {$[\mathrm{~Pa}]$} & Allowable stress for displacement stress range per ASME B31.1 \\
\hline
\end{tabular}




\begin{tabular}{|c|c|c|}
\hline$S_{c}$ & {$[P a]$} & $\begin{array}{l}\text { Material allowable stress from Appendix A, ASME B31.1 at the } \\
\text { minimum metal temperature expected }\end{array}$ \\
\hline$S_{h}$ & {$[\mathrm{~Pa}]$} & $\begin{array}{l}\text { Material allowable stress from Appendix A, ASME B31.1 at the } \\
\text { maximum metal temperature expected }\end{array}$ \\
\hline$S_{f}$ & {$[P a]$} & $\begin{array}{l}\text { Allowable design stress for material of the pipe/tube at design } \\
\text { temperature as given in ASME Section II, Part D }\end{array}$ \\
\hline$S_{f a}$ & {$[\mathrm{~Pa}]$} & $\begin{array}{l}\text { Allowable design stress for material of flange at design } \\
\text { temperature (operating condition) or atmospheric temperature } \\
\text { (gasket seating), as may apply }\end{array}$ \\
\hline$S C W$ & & Supercritical Water \\
\hline SCWR & & Supercritical Water Reactor \\
\hline$T$ & {$\left[{ }^{\circ} \mathrm{C}\right]$} & Temperature or temperature of the mixture \\
\hline$T_{b}$ & {$\left[{ }^{\circ} \mathrm{C}\right]$} & Fluid bulk temperature \\
\hline$T_{\mathrm{c} 1}$ & {$\left[{ }^{\circ} \mathrm{C}\right]$} & Inlet temperature of the cold-side \\
\hline$T_{c 2}$ & {$\left[{ }^{\circ} \mathrm{C}\right]$} & Outlet temperature of the cold-side \\
\hline$T_{h 1}$ & {$\left[{ }^{\circ} \mathrm{C}\right]$} & Inlet temperature of the hot-side \\
\hline$T_{h 2}$ & {$\left[{ }^{\circ} \mathrm{C}\right]$} & Outlet temperature of the hot-side \\
\hline$T_{w}$ & {$\left[{ }^{\circ} \mathrm{C}\right]$} & Temperature of the tube wall \\
\hline$t$ & {$[\mathrm{~mm}]$} & Design minimum wall thickness or wall thickness \\
\hline$t_{a}$ & {$[\mathrm{~mm}]$} & Available wall thickness \\
\hline$t_{\text {blind }}$ & {$[\mathrm{mm}]$} & Thickness of the flat head or blind flange/hub \\
\hline$t_{e_{-} \text {tubular }}$ & {$[\mathrm{mm}]$} & $\begin{array}{l}\text { Required wall thickness based on electrical resistivity for tubular } \\
\text { test section }\end{array}$ \\
\hline$t_{e_{-} a n n u l a r}$ & {$[\mathrm{~mm}]$} & $\begin{array}{l}\text { Required wall thickness based on electrical resistivity for annular } \\
\text { test section }\end{array}$ \\
\hline TSSA & & Technical Standards and Safety Authority \\
\hline$\Delta T$ & {$\left[{ }^{\circ} \mathrm{C}\right]$} & Temperature difference \\
\hline$\Delta \bar{T}$ & {$\left[{ }^{\circ} \mathrm{C}\right]$} & Generalized mean temperature difference (GMTD) \\
\hline$\Delta T_{j}$ & {$\left[{ }^{\circ} \mathrm{C}\right]$} & Temperature difference at a node for calculation of GMTD \\
\hline$\Delta T_{m}$ & {$\left[{ }^{\circ} \mathrm{C}\right]$} & Mean temperature difference (MTD) \\
\hline$U$ & {$\left[\frac{W}{m^{2} K}\right]$} & Overall heat transfer coefficient \\
\hline
\end{tabular}




$\begin{array}{lll}V & {\left[\frac{m}{s}\right]} & \text { Average velocity } \\ V & {\left[m^{3}\right]} & \text { Volume } \\ V_{e} & {\left[\frac{m}{s}\right]} & \text { Fluid erosional velocity } \\ y & & \text { Dimensionless factor used in internal pressure sizing } \\ Z & & \text { A factor based on stress ratio } \\ w_{L} & {[m m]} & \text { Dimension of the fillet weld leg }\end{array}$

\section{Greek Symbols}

$\xi$ Value of mass fraction

$\delta$

Wall thickness manufacturing tolerance $( \pm 12.5 \%$ for pipe and $\pm 10 \%$ for tube, respectively)

$\rho \quad\left[\frac{\mathrm{kg}}{\mathrm{m}^{3}}\right] \quad$ Density

$\rho \quad[\Omega m] \quad$ Resistivity

$\rho_{\text {mix }} \quad$ Gas/liquid mixture density for determination of

$\mu \quad$ [Pas $]$ Viscosity 


\section{Chapter 1. INTRODUCTION}

\subsection{Background}

Worldwide research is ongoing to develop advanced nuclear power plants with higher thermal efficiency and better fuel cycle capabilities to improve their economical competitiveness and long-term sustainability. Many international R\&D collaborative organizations, such as the Generation IV International Forum (GIF), have been established with Canada participating in several of them [1]. The CANDU-Supercritical Water Reactor (CANDU-SCWR) is one of the concepts considered by GIF for international cooperative development [2].

The CANDU-SCWR uses light water at supercritical conditions as coolant and heavy water as the moderator [2]. The coolant at $25 \mathrm{MPa}$ enters the fuel channel at a temperature of $350^{\circ} \mathrm{C}$ and exits the fuel channel at a temperature of about $625^{\circ} \mathrm{C}$ at the outlet. The proposed pressure and exit temperature of the coolant are considerably higher than the current CANDU reactors. Table 1.1 gives an overview of the parameters for the CANDU-SCWR, CANDU-6 and Pressurized Water Reactor (PWR) summarized by Khartabil et al. [2].

For the safe and accurate design of CANDU-SCWR reactors, detailed knowledge of supercritical water (SCW) heat transfer properties is required. The heat transfer properties of SCW are still under investigation and no one definitive correlation to 
predict the complete heat transfer coefficient spectrum of SCW exists [3]. Carleton University has taken the lead to address the uncertainties associated with SCW heat transfer properties with proposed experiments involving a number of test-section geometries.

Table 1.1: Operating parameters in various reactor designs

\begin{tabular}{|l|c|c|c|c|c|c|c|}
\hline Parameter & Unit & \multicolumn{2}{|c|}{ CANDU-SCWR } & \multicolumn{2}{c|}{ CANDU-6 } & \multicolumn{2}{c|}{ PWR } \\
\hline Pressure & $\mathrm{MPa}$ & \multicolumn{2}{|c|}{25} & \multicolumn{2}{c|}{10.5} & \multicolumn{2}{c|}{15} \\
\hline Temperature & ${ }^{\circ} \mathrm{C}$ & Inlet & Outlet & Inlet & Outlet & Inlet & Outlet \\
\cline { 3 - 8 } & & 350 & 625 & 265 & 310 & 290 & 325 \\
\hline Density & $\mathrm{kg} / \mathrm{m}^{3}$ & 625.5 & 67.58 & 782.9 & 692.4 & 745.4 & 664.9 \\
\hline Enthalpy & $\mathrm{k} / \mathrm{kg}$ & 1624 & 3567 & 1159 & 1410 & 1285 & 1486 \\
\hline Specific heat & $\mathrm{J} / \mathrm{kg} \cdot \mathrm{K}$ & 6978 & 2880 & 4956 & 6038 & 5257 & 6460 \\
\hline Expansion Coefficient & $1 / \mathrm{K}$ & $5.17 \cdot 10^{-3}$ & $1.74 \cdot 10^{-3}$ & $2.09 \cdot 10^{-3}$ & $3.71 \cdot 10^{-3}$ & $2.54 \cdot 10^{-3}$ & $4.36 \cdot 10^{-3}$ \\
\hline Thermal conductivity & $\mathrm{W} / \mathrm{m} \cdot \mathrm{K}$ & 0.481 & 0.107 & 0.611 & 0.530 & 0.580 & 0.508 \\
\hline Dynamic viscosity & $\mathrm{Pa} \cdot \mathrm{s}\left(\times 10^{-5}\right)$ & 7.28 & 3.55 & 10.12 & 8.24 & 9.23 & 7.81 \\
\hline Kinematic viscosity & $\mathrm{m}^{2} / \mathrm{s}\left(\times 10^{-9}\right)$ & 11.63 & 52.47 & 12.93 & 11.90 & 12.38 & 11.75 \\
\hline Prandt/ number & - & 1.06 & 0.96 & 0.82 & 0.94 & 0.84 & 0.99 \\
\hline Reynolds number $\left(\times 10^{6}\right)$ & - & 0.946 & 1.940 & 0.680 & 0.835 & 0.745 & 0.881 \\
\hline Nusselt number & - & 1418 & 2425 & 985 & 1225 & 1068 & 1308 \\
\hline Heat transfer coefficient & $\mathrm{W} / \mathrm{m}^{2} \cdot \mathrm{K}$ & 8527 & 3228 & 7522 & 8114 & 7744 & 8303 \\
\hline
\end{tabular}

The Carleton University test facility (Appendix $A$ ) is being designed to house a SCW loop and a supercritical R-134a loop for forced-convection heat transfer experiments. The test sections will be interfaced with either of the supercritical fluid loops depending on the type of experiment being performed.

The working fluid R-134a in the corresponding loop is used to identify fluid-to-fluid modelling correlations between the heat transfer properties of SCW and supercritical R-134a. The use of supercritical R-134a as a modeling substitute for SCW is driven by its 
lower critical pressure and temperature resulting in a simpler experimental apparatus design with shorter development and commissioning times, and a safer testing environment while simultaneously reducing the cost of the experimental facility.

\subsection{Scope and Organization of Thesis}

As mentioned in the Background section, Carleton University has embarked on a project to study the forced-convection heat transfer properties of SCW and R-134a. When the author joined the project team, only a preliminary conceptual design for the R-134a loop existed. The R-134a loop was completely redesigned based on the same design philosophy as the SCW loop. This thesis work focuses on the design of the SCW and R-134a loops, and the three test-section geometries utilized to characterize the heat transfer properties of SCW and R-134a.

Chapter 2 discusses the definitions of the critical point of a fluid and the supercritical state. In particular, it focuses on SCW as it is one of the fluids used in the experiments and its critical point occurs at much higher pressure and temperature compared to other fluids.

Chapter 3 starts with a description of the design requirements for the SCW loop, followed by a literature survey of existing similar test loops around the world. Based on the information gathered from the surveyed SCW loops and the present loop design requirements, the design of the Carleton University SCW loop is discussed. 
The three test-section designs, namely the tubular, annular and bundle are explained in Chapter 4 . The chapter starts with a survey of similar test sections, and moves on to describe the pressure sizing and the method of power transmission to the heated parts of the test sections. Also discussed in the chapter is the pressure sealing method used in the annular and bundle test-section designs to allow access for the sliding temperature probe traverse system to the interior of the test-section heater rod(s).

Following the same design philosophy as for the SCW loop, the redesigned R-134a loop is discussed in Chapter 5 . The chapter begins with an outline of the design requirements for the R-134a loop, followed by a short survey of similar relatively low-pressure and low-temperature loops. As the next step, the redesign of the R-134a loop is carried out based on the design requirements, the information gathered from the surveyed loops and the design philosophy used in the design of the SCW loop.

Corrosion under supercritical fluid conditions, in particular for water as the working fluid, is the main contributing factor limiting the life cycle of the supercritical fluid loops. Chapter 6 deals with possible corrosion mechanisms and corrosion mitigation schemes for the SCW loop.

Chapter 7 concludes the thesis with the conclusions drawn from this research work. The recommendations for future work are also contained in this chapter. 


\section{Chapter 2. Supercritical Fluids}

As the temperature of a liquid in equilibrium with its vapour phase is increased under constant volume, the vapour phase becomes denser as a result of increasing pressure and the liquid phase becomes less dense as a result of increasing temperature. Ultimately, at a specific pressure and temperature known as the critical point, the density difference between the two phases disappears and the fluid becomes a onephase fluid [3]. The critical point of water occurs at a pressure of $22.06 \mathrm{MPa}$ and a temperature of $373.9^{\circ} \mathrm{C}$, whereas the critical point of $\mathrm{R}-134 \mathrm{a}$ occurs at a pressure and temperature of $4.06 \mathrm{MPa}$ and $101.1^{\circ} \mathrm{C}$, respectively [3]. At pressures and temperatures above the critical point, the fluid is said to be a supercritical fluid [3].

The supercritical fluid cannot be described as a gas or a liquid, however, its behaviour resembles that of a perfect gas. As such, attempts have been made to express the behaviour of fluids at and above the critical point using virial equations of state with semi-empirical compressibility factor $(z)$ of the form [3]:

$$
z=\frac{p V}{R T}=1+\frac{B}{V}+\frac{C}{V^{2}}+\cdots
$$

where $p$ is the pressure, $V$ is the volume, $R$ is the molar gas constant, $T$ is the temperature and $B, C, \ldots$, are the second and third virial coefficients, which are functions of temperature only. 
In the vicinity of the critical point, the thermophysical properties of fluids undergo dramatic changes [3]. In the following subsections, water is used as the representative fluid to illustrate the behaviour of some of the thermophysical properties of fluids at and above the critical point.

\subsection{Heat Capacity}

The heat capacity of water as a function of temperature is shown in Figure 2.1. As the temperature nears the critical temperature, the heat capacity experiences an abrupt increase and at the critical point, its value reaches a maximum before dropping again.

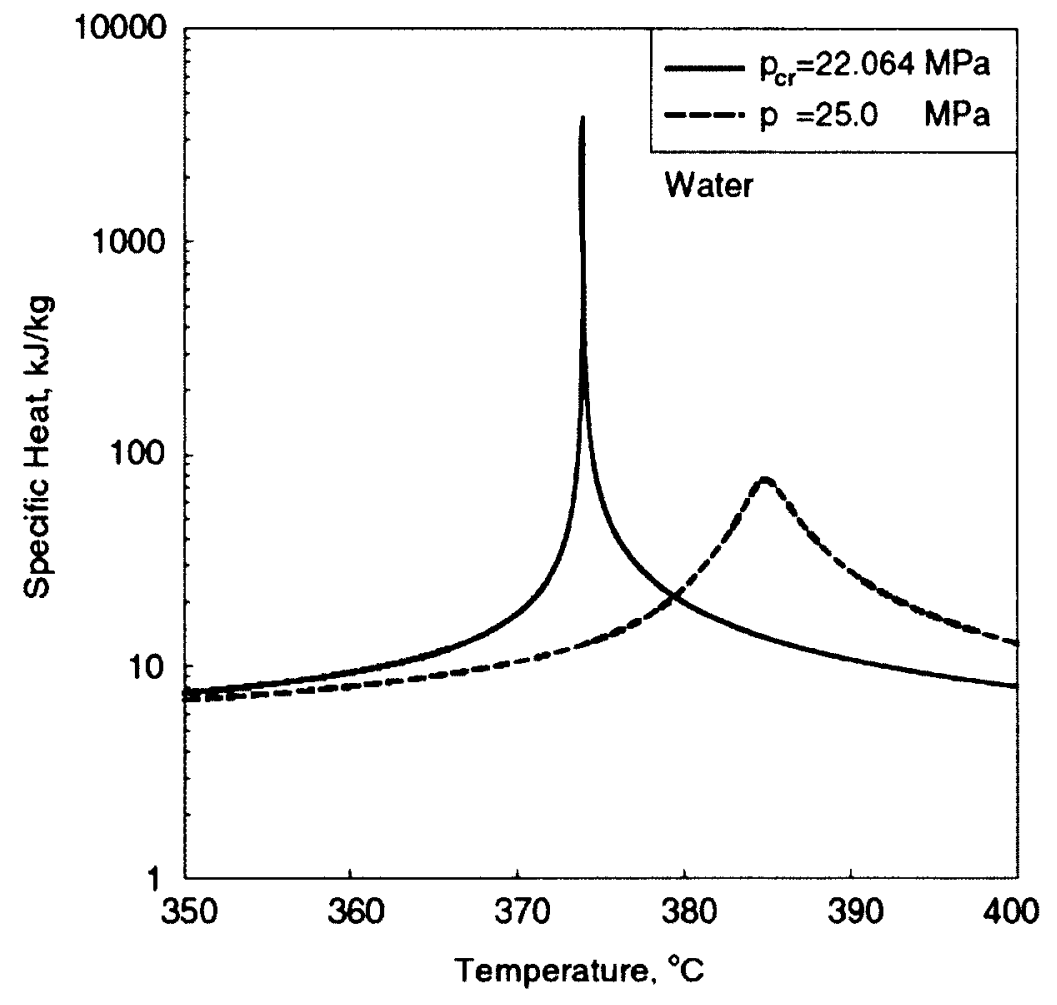

Figure 2.1: Specific heat of water as a function of temperature [3] 
At pressures above the critical pressure, the maximum heat capacity occurs at higher temperatures. In supercritical pressure range, the temperature at which the maximum heat capacity occurs is called the pseudo-critical temperature. The line connecting the maximum values of heat capacities is called the pseudo-critical line.

\subsection{Density}

One of the key distinguishing factors of SCW from ambient water is its density. As discussed previously, at the critical point, the distinction between liquid phase and vapour phase disappears; the two phases become one and the same.

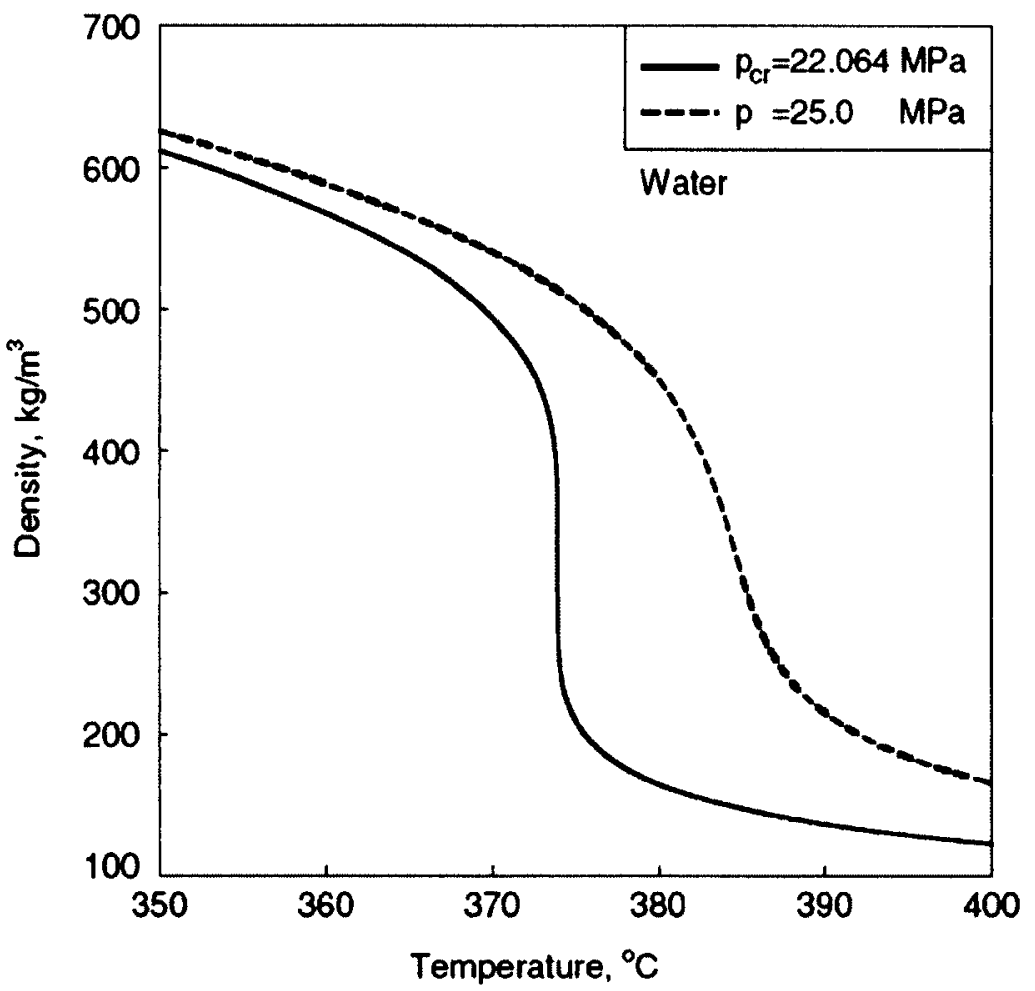

Figure 2.2: Density of water as a function of temperature [3] 
In Figure 2.2, the density of water is plotted against temperature. It can be seen that the density undergoes an almost vertical drop at the critical point. The drop at the pseudocritical temperature for $25 \mathrm{MPa}$ pressure is not as steep. At even higher pressures, the density becomes a smoothly decreasing function of temperature.

\subsection{Enthalpy}

The enthalpy of water versus temperature is shown in Figure 2.3. It is evident from the figure that the enthalpy is an increasing function of the temperature. However, if the temperature is kept constant and the pressure is varied, the enthalpy decreases with increasing pressure.

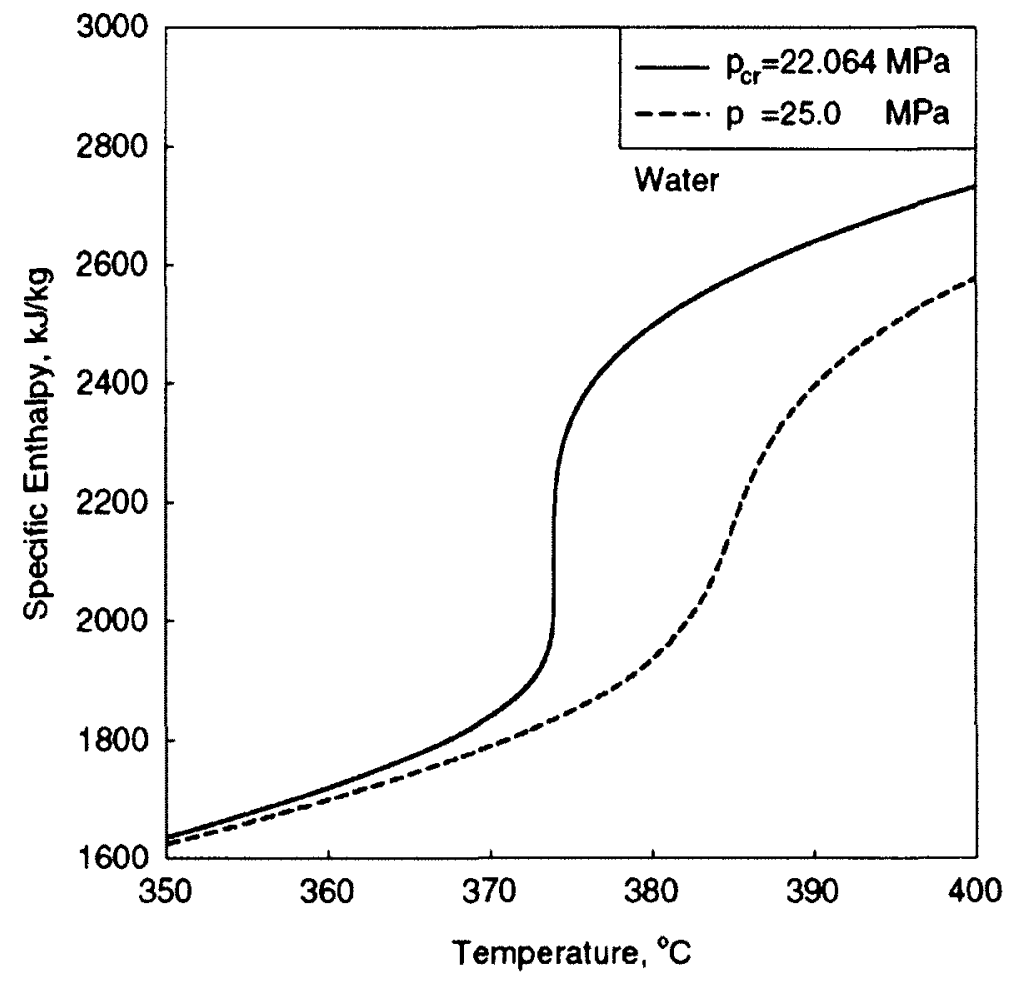

Figure 2.3: Specific enthalpy of water as a function of temperature [3] 


\subsection{Viscosity}

For all pressures, the viscosity decreases with increasing temperature and reaches a minimum value at the critical temperature (Figure 2.4). Further raising the temperature causes the viscosity to gradually start increasing. Increasing the pressure, on the other hand, increases the viscosity for all temperatures.

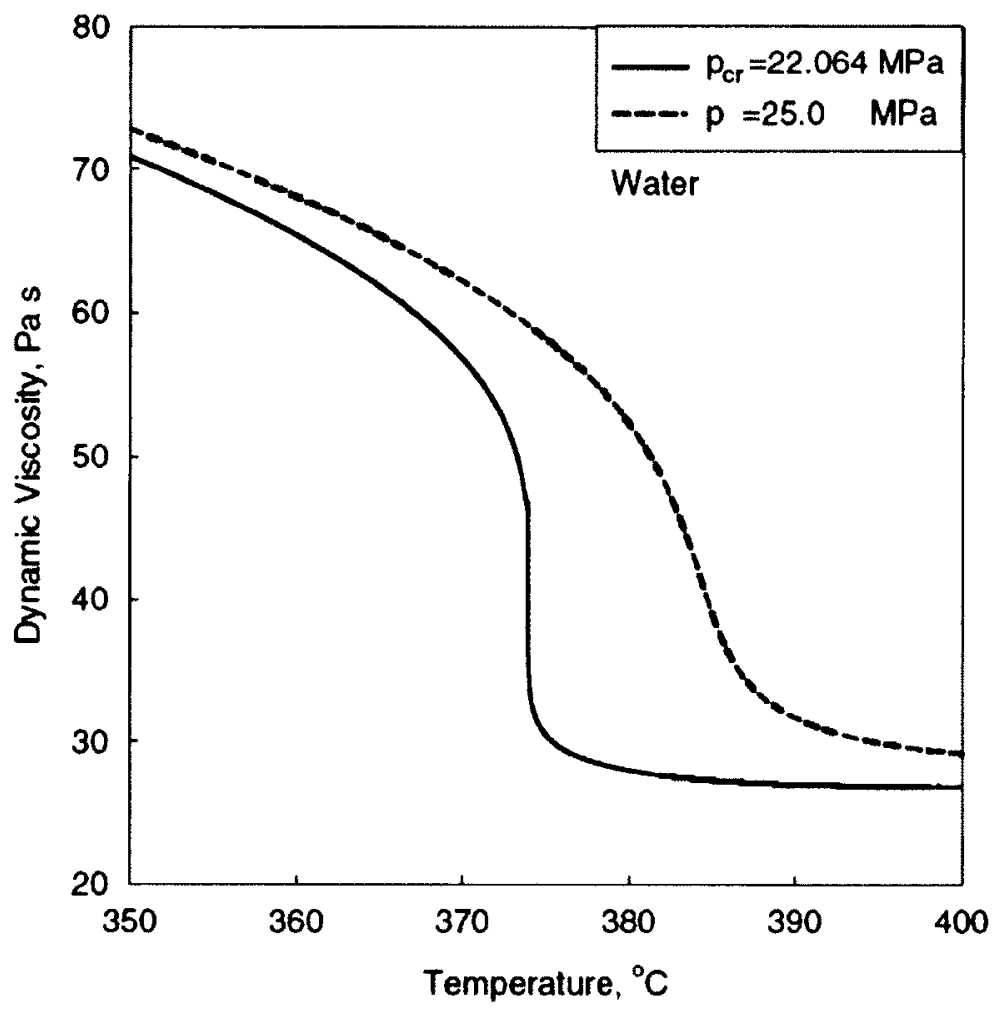

Figure 2.4: Dynamic viscosity of water as a function of temperature [3]

The thermal conductivity follows a similar trend as the heat capacity, whereas the behaviour of the dielectric constant resembles that of the density or dynamic viscosity [3]. 


\section{Chapter 3. Carleton University SCW Loop}

\subsection{SCW Loop Design Requirements}

As mentioned in the introduction to this thesis, the SCW loop is used to investigate forced-convection heat transfer properties of water under supercritical conditions. Three different test-section geometries, the cross-sections of which are schematically shown in Figure 3.1, are considered for the experiments. The annular and bundle designs are used to simulate the CANDU-SCWR fuel pin and fuel bundle arrangements, respectively, while the tubular configuration is used as a commissioning test-section to validate the overall accuracy of the experimental setup in comparison to data available from other research facilities.

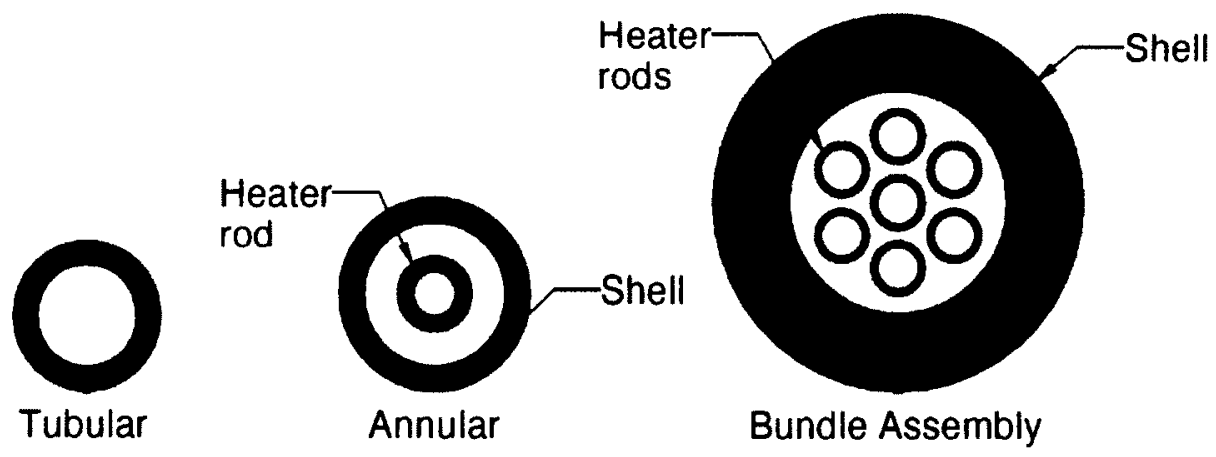

Figure 3.1: Cross-sections of the three test-section geometries

Table 3.1 lists the intended test-section operating conditions. As noted in this table, the test sections are required to operate at temperatures and pressures of $260-600^{\circ} \mathrm{C}$ and 23-27 MPa, respectively. As such, the loop is designed to operate at pressures up to $27 \mathrm{MPa}$. 
Table 3.1: Operating parameters of the supcritical water test sections

\begin{tabular}{|l|c|c|}
\hline Parameter & \multicolumn{2}{|c|}{ SCWLoop } \\
\hline Pressure & \multicolumn{2}{|c|}{$23-27 \mathrm{MPa}$} \\
\hline \multirow{2}{*}{ Temperature } & Inlet & Outlet \\
\cline { 2 - 3 } & $260-380^{\circ} \mathrm{C}$ & $380-600^{\circ} \mathrm{C}$ \\
\hline Mass Flux & \multicolumn{2}{|c|}{$500-3000 \mathrm{~kg} / \mathrm{m}^{2} \mathrm{~s}$} \\
\hline
\end{tabular}

The temperature limits of pumps that can circulate water through the test section at the desired flow rates and the noted loop operating pressure dictate the use of a heat exchanger downstream of the test section to reduce the fluid temperature to a maximum level of $260^{\circ} \mathrm{C}$ before entering the pump. This heat exchanger, the fluidcirculation pump and the test section constitute the primary components of the loop. Numerous other smaller components are needed on the loop to control the operating conditions, ensure safe operation, and acquire various health-monitoring and test data.

\subsection{Survey of SCW Test Facilities}

A literature survey was conducted to learn from existing best practices in the design of test facilities for forced-convection heat transfer involving supercritical fluids. The results of this survey are summarized in the following subsections.

\subsubsection{Kyushu University SCW Loop}

The SCW loop at Kyushu University is a high-pressure once-through monotube test loop [4]. Figure 3.2 shows a schematic of the loop. The loop has a maximum circulating 
mass flux of $1830 \mathrm{~kg} / \mathrm{m}^{2} \mathrm{~s}$ and a maximum system pressure of $30 \mathrm{MPa}$. Maximum fluid bulk temperatures up to $540^{\circ} \mathrm{C}$ can be achieved in the stainless steel (AISI Type 316) test section. Water pressurized with a triple-connected plunger type circulating pump (13) is heated in a two step method, first by the primary (15) and then by the secondary (17) heaters up to the required test-section inlet temperature before reaching the test section. Once the water leaves the test section, it is further heated to $600{ }^{\circ} \mathrm{C}$ by the rear heater (23) and its pressure is throttled to the atmospheric pressure by a throttle valve (24). The pressure reduced steam is passed through a cooler (26), a condenser (27) and a flow measuring device (28) before leading it is returned to the tank (5). The water is then sent to a hydrazine tank (8) and an injector pump system (9) where the $\mathrm{pH}$ of water is monitored and adjusted as required. Before reaching the recirculating pump, the water is cleansed of its particulate contaminants by a polisher (7) and deaerated by a deaeration system (10).

The secondary and the rear heaters are electrical furnaces containing spiral water tubes. The heat load regulation of the secondary heaters is carried out by autotransformers (18). The primary heater derives its heating source from the saturated steam produced by a $10 \mathrm{MPa}$ steam generator (4). Also, part of the condensed water exiting the primary heater is directed to the deaerator, where it is used as the heating source for the deaerator operation. Flow through the loop is provided by a triple connected plunger pump, with continuous regulation capability to the one-third of the maximum by speed control. In order to reduce the pressure pulsations created by the 
plunger pump, an accumulator (14) is installed at the pump's discharge. The throttle valve is a $1 / 4$ in globe valve and it automatically adjusts to maintain the pressure at the test-section inlet at a preset value.

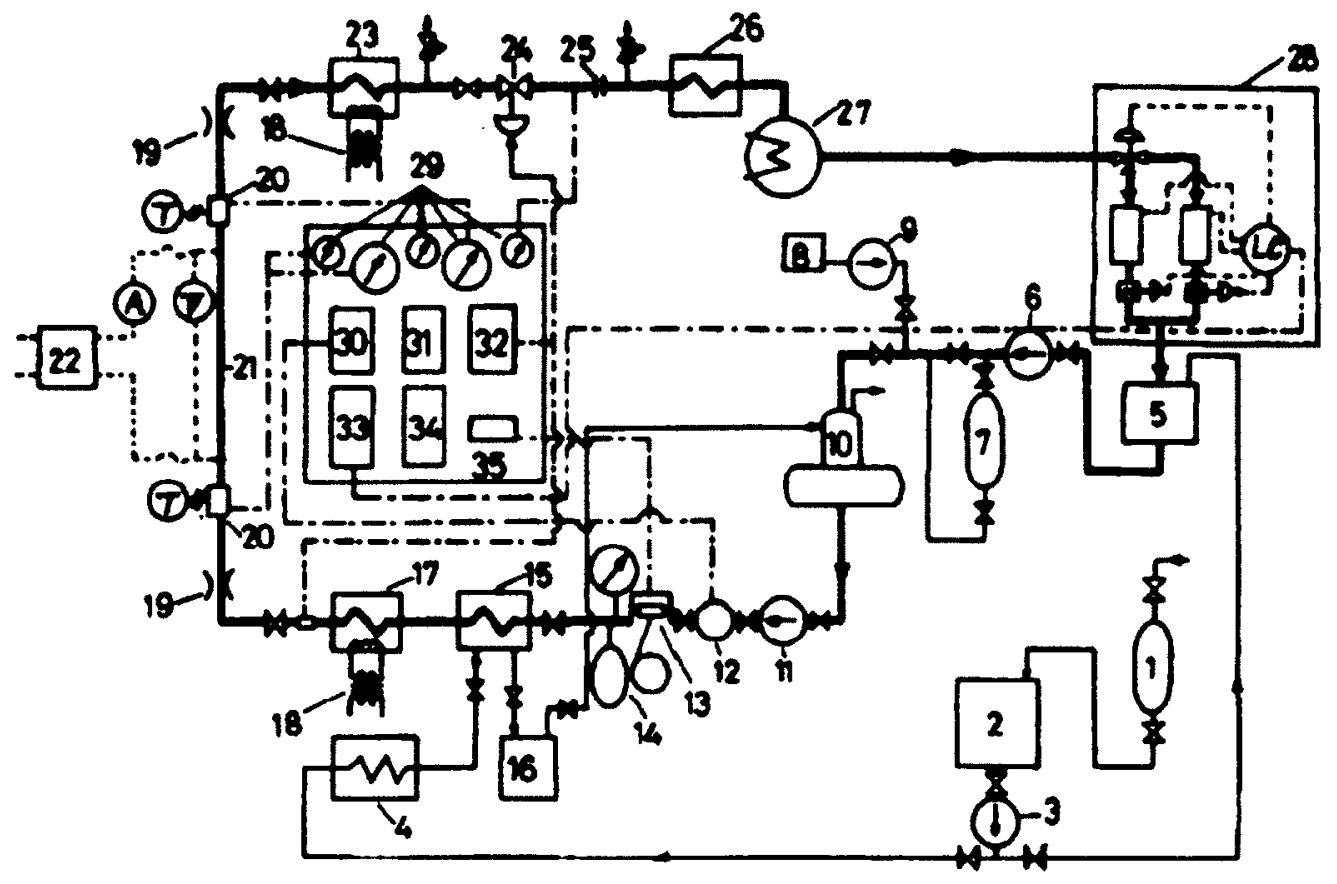

1. Water parifier

2 Purifial waves tank

3. Supply pump

4. Sionem remeralor

5. Drain tank

G. Prousure pump

7. Poliaber

8. Hydruxine tank

9. Injector pomp

10. Deserator

11. Boomer puanp

12. Flow neter

13. Creulatins pump

14. Accumulator

15. Primary boater

16. Flush tank

17. Secoudary beater

18. Auto-trandormet
19. Venturi tube

20. Mixim chamber

21. Test rection

22. Mechanical rectifier

23. Rear bealer

24. Throtile valve

25. Electrically insulated nange

26. Cooler

27. Coodeneer

23. Flow measuring lovice

29. Presure panes

30. Flow recorder

31. Temperature reconder

32. Precuere recordar-costroller

33. Flow recorder

34. Temperature recorder

35. Flow rezulutor

Figure 3.2: Kyushu University SCW experimental apparatus [4] 
It is also of interest that the test section is directly heated by a high-current DC power source (22). In order to isolate the electrical current from leaking into other parts of the loop, an electrically insulating flange (25) is installed downstream of the throttle valve.

\subsubsection{University of Wisconsin SCW Loop}

The University of Wisconsin SCW loop is a closed-loop forced flow heat transfer facility using circular annular and square annular test sections at a pressure of $25 \mathrm{MPa}$ [5]. Mass fluxes up to $2000 \mathrm{~kg} / \mathrm{m}^{2} \mathrm{~s}$ and temperatures up to $400{ }^{\circ} \mathrm{C}$ are achievable in the test section. The loop is made of $42.9 \mathrm{~mm}$ inner diameter and $60.3 \mathrm{~mm}$ outer diameter Inconel 625 piping with overall dimensions of approximately $2 \mathrm{~m}$ width and $3 \mathrm{~m}$ height. The main components of the loop are illustrated in Figure 3.3.

Degassed and de-ionized water is circulated by an impeller-type pump (1) capable of operating at a maximum pressure of approximately $25 \mathrm{MPa}$ (3600 psi) and a maximum temperature of $593^{\circ} \mathrm{C}$. In order to cover a large range of flow rates, a bypass (2) directs part of the flow back to the inlet of the pump. Flow rates in the test-section leg are controlled with orifice plates (3) and a variable frequency drive, which regulates the pump speed. Before flowing through the test section, wrap-type pre-heaters (4) increase and maintain the water temperature to the desired test-section inlet temperature. The right leg of the loop, which is used as the test section (5), is equipped with a $3.3 \mathrm{~m}$ long heater rod (6) with a diameter of $10.7 \mathrm{~mm}$ at its centre. Up to $50 \mathrm{~kW}$ 


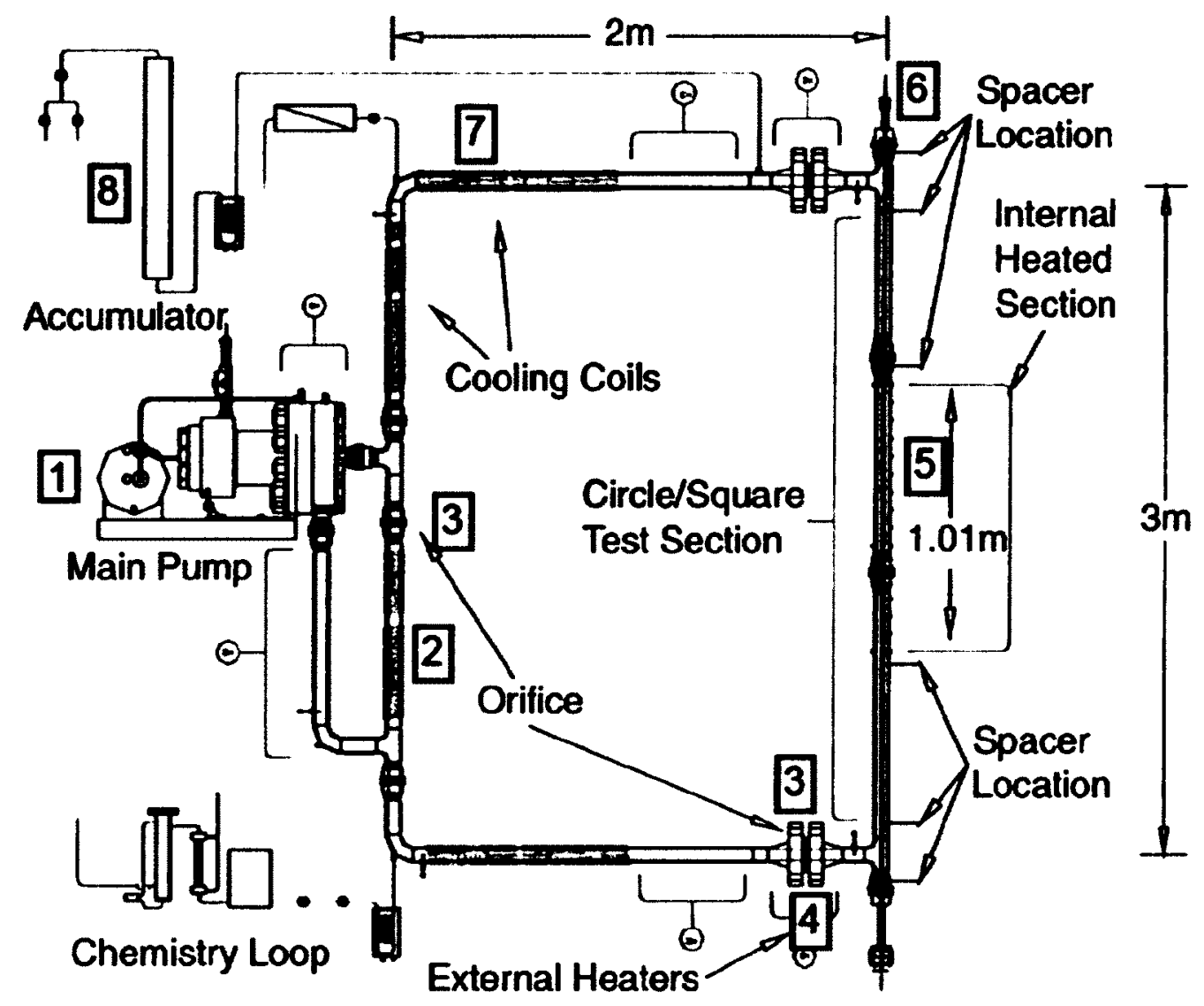

Figure 3.3: University of Wisconsin SCW heat transfer loop [5]

of power can be generated with the heater rod, resulting in a maximum heat flux of $1.5 \mathrm{MW} / \mathrm{m}^{2}$. The length of the right leg permits a $760 \mathrm{~mm}$ entrance length for both upward and downward flow studies. After passing through the test section, part of the heat added to the water in the test section is removed with the help of copper cooling coils (7) before returning to the pump. The copper cooling coils are tightly wrapped around the Inconel piping and they are supplied with cooling water from building water supply. The cooling coils are divided into sections, with independent flow-rate regulation. The desired amount of heat removal is achieved by simply controlling the 
number of coils receiving cooling water and controlling their respective flow rates. The pressure in the loop is sustained using a bladderless accumulator (8) maintained at room temperature. The accumulator is connected to a high-pressure $40 \mathrm{MPa}$ (6000 psi) argon gas cylinder. The accumulator is sized to have the same amount of volume as the loop, and the level of water and pressure in the accumulator are monitored using a differential and an absolute pressure gauge, respectively.

\subsubsection{Xi'an Jiaotong University SCW Loop}

The heat transfer test loop at Xi'an Jaiotong University is a high-pressure, hightemperature pumped loop for heat transfer studies of SCW [6][7]. The schematic diagram of the experimental loop is shown in Figure 3.4. The loop is used for experiments involving pressures as high as $30 \mathrm{MPa}$ and mass fluxes up to $1200 \mathrm{~kg} / \mathrm{m}^{2} \mathrm{~s}$. Experiments with maximum fluid bulk temperatures of $460{ }^{\circ} \mathrm{C}$ have been reported. Distilled and de-ionized water from the water tank (1) passes through a filter (2) before reaching the high-pressure plunger pump (3). The high-pressure plunger pump is capable of operating at up to $40 \mathrm{MPa}$. A combination of valves (4) and orifices (5) is used to control and measure the pressure and water flow rate in the stainless steel (1Cr18Ni9Ti) test section. Before flowing into the test section, the water is pre-heated in a regenerative heat exchanger (6) and a pre-heater (7). The pre-heater and the test section (8) are directly heated by $A C$ power supplies with maximum heating capacities of $760 \mathrm{~kW}$ and $180 \mathrm{~kW}$, respectively. The pre-heater gives an effective control over the water bulk temperature at the inlet of the test section. 


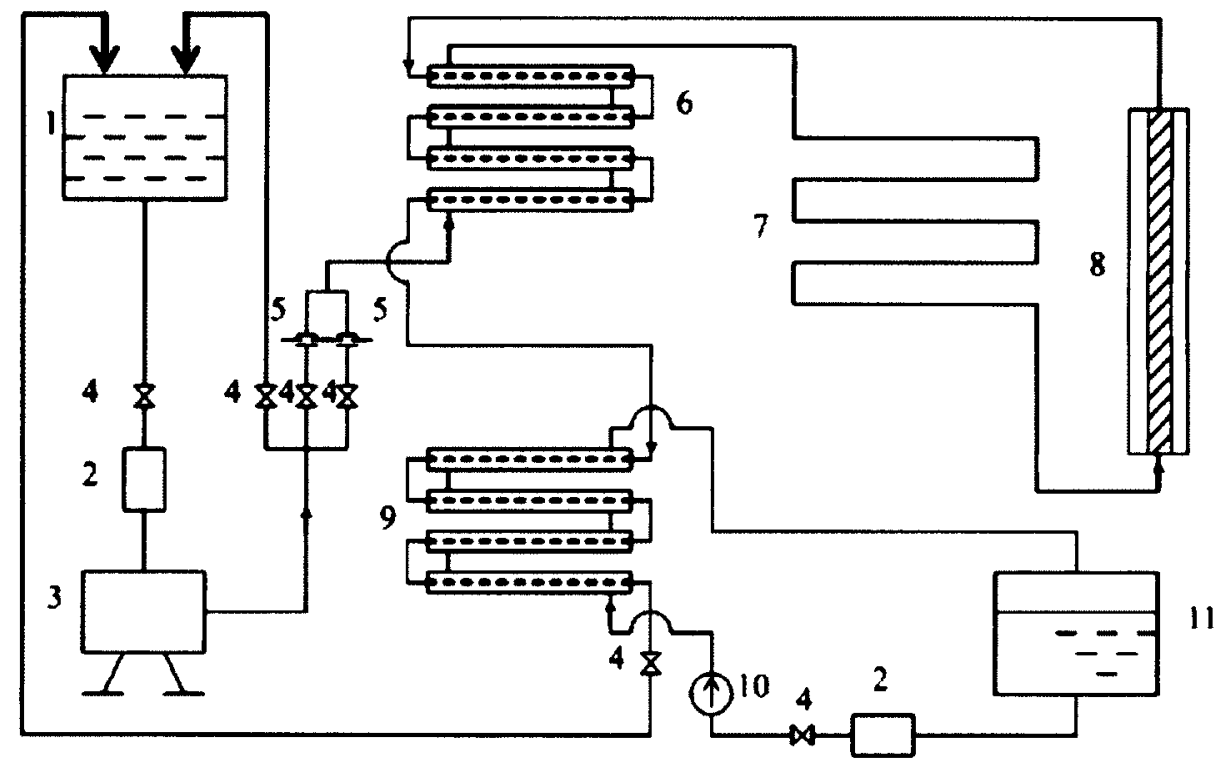

Figure 3.4: Xi'an Jiaotong University SCW heat transfer loop [6]

The heat imparted in the test section is removed after the test section discharge by first passing the water through the regenerative heat exchanger, where part of the heat is imparted to the water flowing to the test section and then passing the water through a condenser (9). The cooling water to the condenser is boosted by a circulating cooling water pump (10) from and to a large tank (11). The mass flux through the test section is regulated by adjusting a bypass valve (4).

\subsubsection{IPPE SCW Loop}

The SKD-1 is a high-temperature, high-pressure forced flow loop located at the Institute of Physics and Power Engineering, in Obninsk, Russia [3]. The loop can be operated at pressures up to $28 \mathrm{MPa}( \pm 0.25 \%)$ and outlet temperatures up to $500^{\circ} \mathrm{C}\left( \pm 3.0^{\circ} \mathrm{C}\right)$. The mass flux ranges from 200 to $1500 \mathrm{~kg} / \mathrm{m}^{2} \mathrm{~s}( \pm 1.5 \%)$. Figure 3.5 illustrates the loop design. 


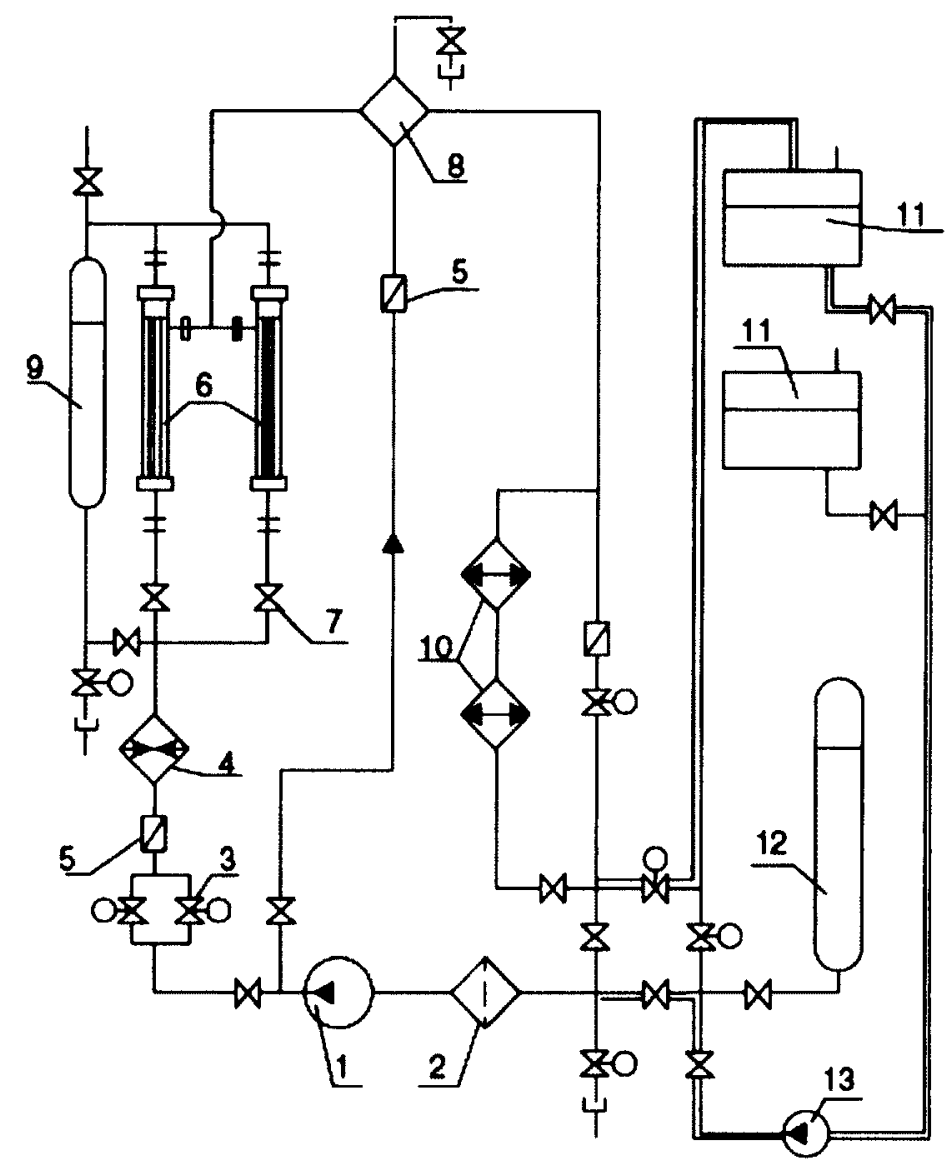

Figure 3.5: IPPE (SKD-1) SCW loop [3]

De-ionized and distilled water from the tank is directed to the main circulating pump (1) after passing through a mechanical filter (2). The water flow to the test section is regulated with valves (3) and the flow rate is measured with a calibrated orifice (5). Before reaching the stainless steel (12Cr18Ni10Ti-similar composition to SS304) test section (6), the water is heated using a pre-heater (4). The high-temperature water leaving the test section is successively cooled in the mixer-cooler (8) and main loop heat exchangers (10). Once the fluid temperature has been lowered, it flows back to the feedwater tank (11) from where it is redirected to the main circulating pump (1) with 
the help of a feedwater pump (13). A volume compensator (12) is used to sustain a steady flow of water to the circulating pump. The pressurization of the loop is achieved with a high-pressure gas $\left(\mathrm{N}_{2}\right)$ charged accumulator (9).

The water in the test section is heated by a $600 \mathrm{~kW}( \pm 1 \%) \mathrm{AC}$ power supply. As mentioned before, partial cooling of water that exits the test section is accomplished just downstream of the test section using the mixing cooler. A large amount of heat is removed using the main loop heat exchangers in the discharge circuit of the pump.

\subsubsection{KPI SCW Loop}

The Kiev Polytechnic Institute SCW loop is an open stainless steel loop operating at pressures up to $28 \mathrm{MPa}( \pm 0.22 \%)$ and test-section outlet temperatures as high as $600{ }^{\circ} \mathrm{C}$ $( \pm 0.21 \%)[3]$. Mass fluxes up to $500 \mathrm{~kg} / \mathrm{m}^{2} \mathrm{~s}( \pm 2.28 \%)$ are achievable in the loop. Figure 3.6 shows a general schematic of the loop.

Water is first passed through an electro-distillator (1) and then through an ion-filter (2) to achieve a pH of 7.2 and average hardness of $0.2 \mu \mathrm{g} / /$ and is stored in the accumulator reservoir (3). A booster (4) pressurizes the water from the accumulator reservoir, which is exposed to atmospheric pressure, to $0.2 \mathrm{MPa}$ and leads it to the plunger pumps (5). Each plunger pump can increase the pressure of the water up to $70 \mathrm{MPa}$. To reduce pressure pulsations, the water from the plunger pumps is dumped into damping reservoirs (8) from where it passes through a set of regulating valves (7) and a flow meter (9) before passing through two pre-heaters. A tube-in-tube pre-heater (10) uses 
some of the heat from the water exiting the test section to pre-heat the water and an electrical pre-heater (11) raises the temperature of water to the desired test-section inlet temperature. The electrical power to the pre-heater is supplied by a generator (12). In the stainless steel (1Cr18Ni9Ti) test section (13), heat is added to the water by a 120 or $90 \mathrm{~kW}( \pm 1.15 \%$ to $\pm 2.40 \%)$ DC power supply (17). After exiting the test section, the water flows into another damping reservoir (15). It passes through the tube-in-tube regenerative heat exchanger (10) and a main heat exchanger (18) before being throttled (19) back to atmospheric pressure and returned to the reservoir. Pressure at the inlet of the test section is controlled using a throttling valve (14) and flow rate of water is monitored using a turbine-type flow meter.

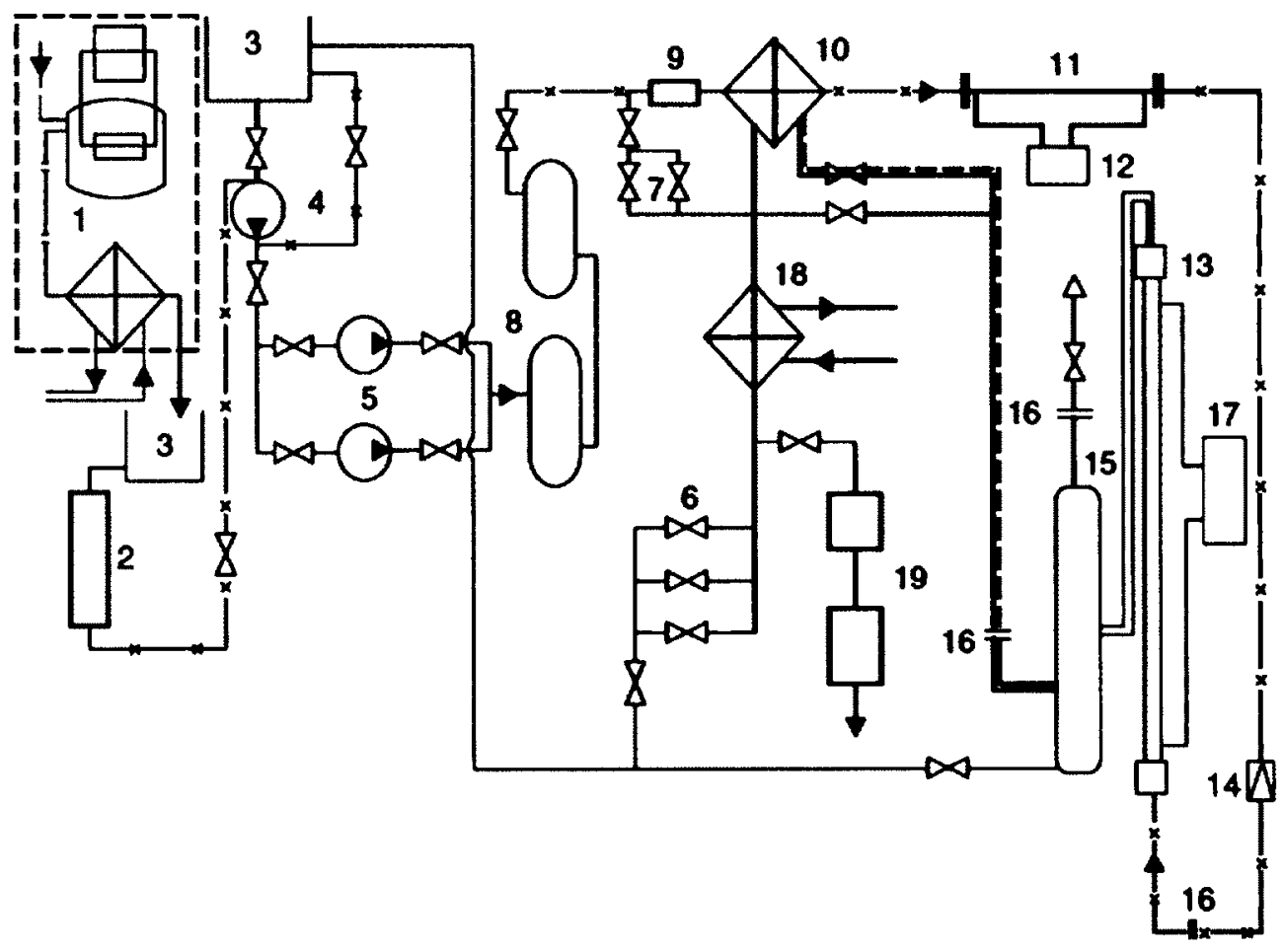

Figure 3.6: KPI SCW loop [3] 


\subsection{Design of the Carleton University SCW Loop}

Based on the information gathered from the surveyed SCW loops and the present loop design requirements outlined previously, a SCW loop is designed. The following sections discuss the design of the Carleton University SCW loop and its components.

\subsubsection{Design Overview}

Figure 3.7 shows the layout and major components of the Carleton SCW loop, and the piping and instrumentation diagram is illustrated in Figure 3.8. The loop occupies a volume that is approximately $2.5 \mathrm{~m}$ wide, $3.5 \mathrm{~m}$ long and $2.5 \mathrm{~m}$ high when the test section is in the vertical position. The test section can be easily reconfigured to the horizontal position, in which case the loop has the dimensions of $2.5 \mathrm{~m}$ width and $6 \mathrm{~m}$

length. The loop piping is of nominal size 1.5 in schedule XXS made of stainless steel 316 or $316 \mathrm{H}$ with outer and inner diameters of $48.26 \mathrm{~mm}(1.9 \mathrm{in})$ and $27.94 \mathrm{~mm}(1.1 \mathrm{in})$, respectively. Pipe and component connections are made with either Grayloc ${ }^{\top M}$ connectors or standard Class 2500 ASME flanges.

The test-section leg of the loop is designed such that different test sections can be easily interfaced with the loop using the provided inlet/outlet connections. The test sections are expected to be approximately $2.3 \mathrm{~m}$ long. Heat is imparted to the water flowing through the test section through Joule heating of the heater rod(s) or the test-section wall. Up to $300 \mathrm{~kW}$ of heat can be transferred to the water from the high-current DC power supply. 
A centrifugal pump capable of operating at a maximum pressure of $28 \mathrm{MPa}$ at $260^{\circ} \mathrm{C}$ generates flow rates in the range of 0.4 to $1.6 \mathrm{~kg} / \mathrm{s}$. For better flow control, a bypass line is provided which diverts part of the pump discharge back to the pump inlet.

The water flow rate is regulated by two globe valves and the speed of the pump. One globe valve is located on the bypass line and the other is located on the main line. The valves are rated for up to $27.5 \mathrm{MPa}$ at $260^{\circ} \mathrm{C}$. The flow of water is monitored by a turbine-type flow meter with a flow range of $0.34 \mathrm{~m}^{3} / \mathrm{hr}$ to $7.9 \mathrm{~m}^{3} / \mathrm{hr}(1.5$ to $35 \mathrm{GPM})$. The turbine flow meter has a pressure rating of $27.5 \mathrm{MPa}$ at $260^{\circ} \mathrm{C}$.

A heat exchanger downstream of the test section lowers the temperature of water to meet the temperature rating requirements of components on the loop and achieve the desired test-section inlet temperature. The heat exchanger is designed to lower the water temperature to $260^{\circ} \mathrm{C}$ by extracting heat rates of up to $300 \mathrm{~kW}$. The heat exchanger is rated for operation at $30 \mathrm{MPa}$ and $630^{\circ} \mathrm{C}$.

Before the water returns to the pump, it is passed through a Y-type filter/strainer to protect the centrifugal pump from debris that may be dislodged from the piping, in particular the test section where direct Joule heating of the tubes is carried out, and other components on the loop due to corrosion and/or erosion. The filter has a 400 micron stainless steel mesh element. 


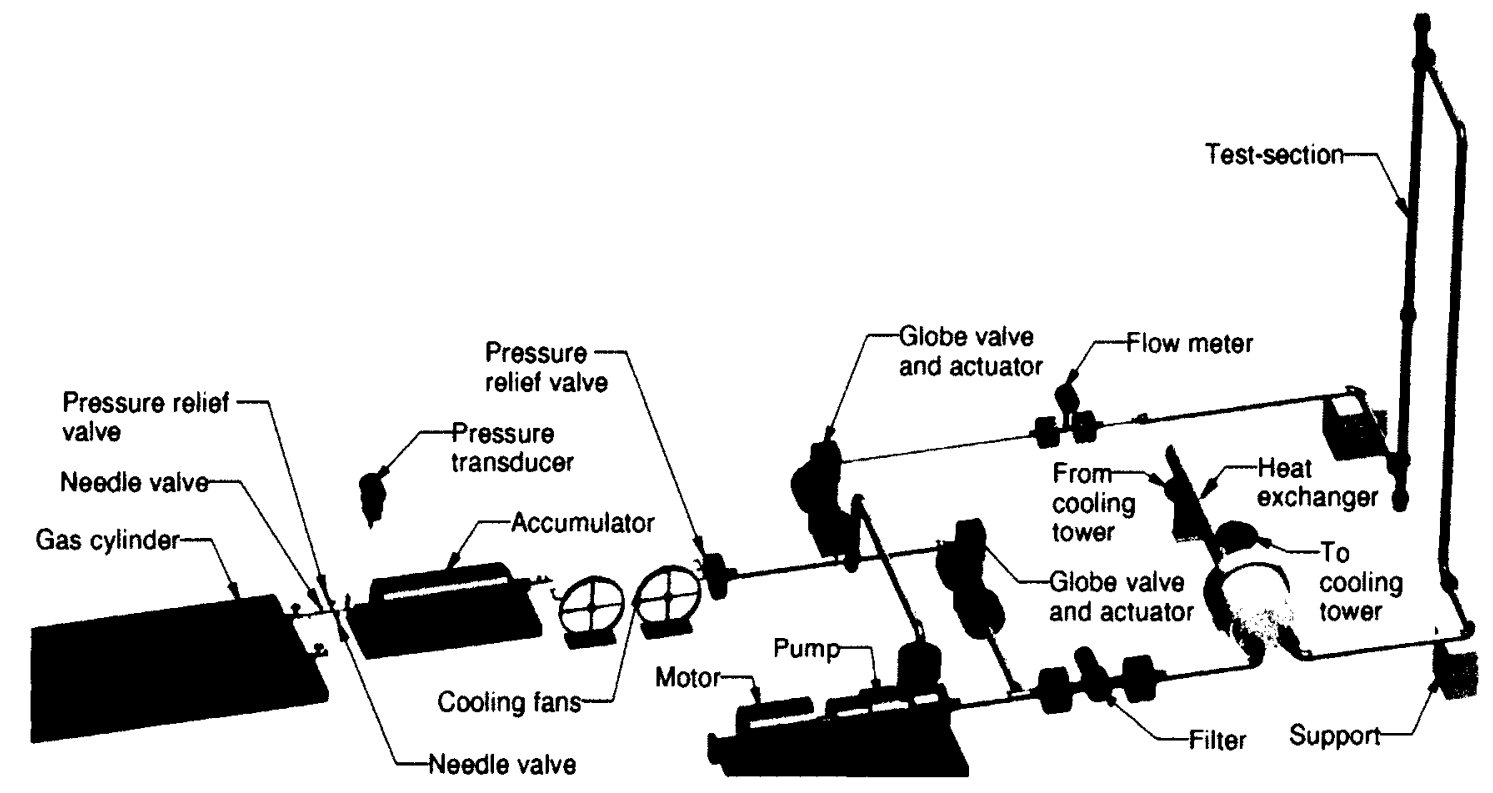

Figure 3.7: Layout and major components of the Carleton SCW loop

Pressurization of the water is achieved with a high-pressure bladder accumulator. The accumulator is also used to dampen the pressure oscillations created by the pump. The accumulator is connected to a high-pressure nitrogen cylinder and the pressure in the loop is regulated by allowing nitrogen gas to flow into the accumulator or by venting it off to the atmosphere.

The following sections discuss the design of the SCW loop and its components in detail.

\subsubsection{Sizing and Selection of the Carleton SCW Loop Piping Components}

The piping components used on the Carleton SCW loop are designed based on the rules stipulated by ASME B31.1 piping code [8] and the final assembly is certified by TSSA. To supplement the design code, an FEA simulation of the final assembly is performed by Rubicel Alena, a member of the project, results of which are discussed in Appendix E. 


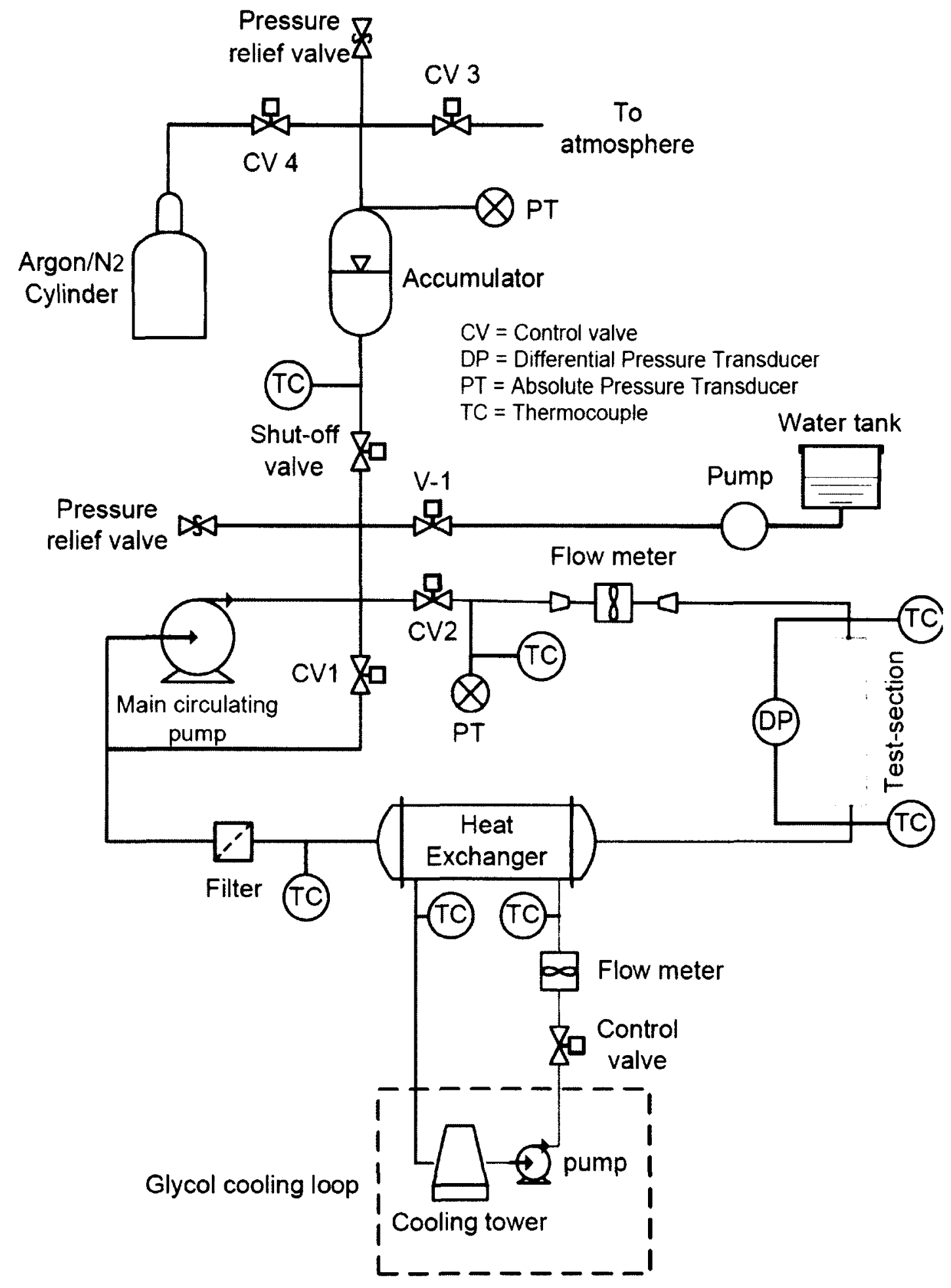

Figure 3.8: Piping and instrumentation diagram of the Carleton SCW loop 
The ASME B31.1 Code is one of several sections of the American Society of Mechanical Engineers (ASME) Code for Pressure Piping, B31. ASME B31.1 specifically deals with the design of piping typically found in electric power generating stations, in industrial plants, and central and district heating and cooling systems. Another similar piping code, B31.3 Process Piping Code, deals with the design of piping typically found in petroleum refineries, and chemical processing plants [9]. ASME B31.1 is selected as the design code due to the similarities of the current application with power generating stations.

The piping components are selected and sized in a number of steps. The first step is to select a material suitable for use at the expected operating conditions of the test loop. Secondly, the size of the straight pipe that can sustain the internal pressure is determined and a standard pipe size meeting or exceeding the determined size is selected. The selected pipe size then forms the basis on which other piping components, such as fittings and flanges, are selected.

The following subsections describe this process in detail.

\subsubsection{Materials Selection}

As described in Section 3.1, the SCW loop will contain very high pressures of up to $27 \mathrm{MPa}$ and the operating temperature of parts of the loop will be as high as $600^{\circ} \mathrm{C}$. Therefore, it is important that the material has very good high temperature strength. The strength of the material at elevated temperatures plays a crucial role in the bulk size of the test loop. It determines the thickness of the pressure retaining pipe wall, the 
size of the flanges and any other pressure boundary components. Since the pressurized fluid flowing through a portion of the loop is SCW, the corrosion resistance of the material under $\mathrm{SCW}$ conditions is also a significant factor. Another less important factor is the density of the material. A relatively low density will result in a lighter loop structure and will make reconfiguration of the loop easier. Keeping these criteria in mind, a number of materials, such as stainless steel Types 316 and 316H, Inconel 625 , Hastelloy C-276, are investigated. The reader may refer to the appendices for the full material descriptions.

The maximum allowable stresses for the materials are listed in ASME B31.1 [8]. The basis for establishing the maximum allowable stresses is the same as those in the ASME Boiler and Pressure Vessel Code, Section II, Part D. The maximum stress values as listed in the ASME code are determined for various temperatures taking into account creep and stress rupture properties of the material. The ASME-established maximum allowable stress for a material is the lowest of either the tensile strength of the material at the design temperature divided by 3.5 or $67 \%$ of the average stress to cause rupture in 100,000 hours at the design temperature [10]. Therefore, the maximum allowable stress for a material at the design temperature is substantially lower than the maximum tensile strength of the material at the design temperature.

The high tensile strength at elevated temperatures and the ease of machinability with good forging and weldability properties along with the ease of availability make stainless 
steel Type 316 an attractive option. Stainless steel Type $316 \mathrm{H}$ is a modified version of Type 316, specifically designed for high temperature applications where creep strength and stress rupture properties are important. Inconel 625 has a very high tensile strength at high temperatures and very good corrosion resistance under SCW conditions. This material has been extensively used in the paper and pulp industry where high temperature steam and in some cases, SCW is used. It has also been used in the construction of autoclaves that operate at very high temperatures and pressures. Alloy C-276 has very good high temperature strength and excellent corrosion properties. It has been approved by ASME for use in high-temperature high-pressure vessels.

Stainless steel Type 316 is not recommended for use in temperatures above $538^{\circ} \mathrm{C}$, unless the carbon content is $0.04 \%$ or higher [9], and inconel 625 becomes very brittle at room temperatures after exposure to temperatures in the range of $538^{\circ} \mathrm{C}$ and $760^{\circ} \mathrm{C}$, and it is also an expensive material [8][9][10]. Although there is no such limitation on the use of Alloy $\mathrm{C}-276$, it is a rather expensive superalloy. Type $316 \mathrm{H}$ has been modified for use in temperatures where the application of Type 316 is not recommended.

Therefore, the materials selected for the SCW loop piping applications are stainless steel Type 316 and Type $316 \mathrm{H}$. Components that are not subjected to severe temperatures, such as the sections after the heat exchanger, are constructed from Type 316 and components that come into contact with the high temperature SCW, such as the parts after the test section leading to the heat exchanger, are constructed of Type $316 \mathrm{H}$. 


\subsubsection{Pressure Sizing of Pipes}

The sizing of pipes is performed in three steps. First, an inner diameter is selected; then, a wall thickness is calculated based on the selected inner diameter, and the design pressure and design temperature of the fluid that needs to be contained. Finally, once these dimensions are determined, they are compared with the standard nominal pipe sizes and the next-larger nominal pipe size meeting the calculated wall thickness is selected.

\subsection{Determination of the Inner Diameter}

The inner diameter is determined such that it will accommodate the design flow rate while maintaining the flow velocity and hence the pressure drop within reasonable limits. In most cases, the flow velocity is limited by the available pump head and/or erosional velocity of the piping [11]. In the current design, the pump will be sized to compensate for the flow induced pressure drop in the piping. Therefore, the inside diameter of the pipe is not restricted by the capabilities of a particular commerciallyavailable pump. Since there are no established limits for the flow velocity in the current design, the inner diameter needs to be determined based on the accepted industry pipe flow velocities. Table 3.2 gives some flow velocities that are typical for many industrial applications determined such that the pressure drop in the piping is kept at a reasonable level. Industrially accepted flow velocities for superheated and saturated steam are an order of magnitude larger than the ones given for liquid flow [11]. 
Table 3.2: Typical design velocities for liquid water flowing through pipes [11]

\begin{tabular}{lc}
\hline Service condition & Reasonable velocity $(\mathrm{m} / \mathrm{s})$ \\
\hline Boiler feed & $2.5-4.6$ \\
Pump suction and drain lines & $1.2-2.1$ \\
General service & $1.2-3.0$ \\
City water & to 2.1 \\
\hline
\end{tabular}

Flow velocity limits have also been established below which the erosion of the piping material due to direct flow is considered to be low. For liquid water, velocities up to about $10 \mathrm{~m} / \mathrm{s}$ can be safely used in stainless steel piping [11]. Velocities of $30 \mathrm{~m} / \mathrm{s}$ to $100 \mathrm{~m} / \mathrm{s}$ can be safely used with saturated and superheated steam at pressures above $0.35 \mathrm{MPa}$ and $1.36 \mathrm{MPa}$, respectively [11]. The recommended velocity for saturated steam at low pressures up to 0.1 MPa ranges between $20-30 \mathrm{~m} / \mathrm{s}$ [11].

The API standard recommends the following formula for determining the erosional velocity of two-phase gas/liquid mixtures [12]:

$$
V_{e}=\frac{c}{\sqrt{\rho_{\text {mix }}}}
$$

where, $V_{e}$ is the fluid erosional velocity, $c$ is an empirical dimensional constant and $\rho_{\text {mix }}$ is the gas/liquid mixture density at fluid's pressure and temperature. Industry experience has shown that for solid-particle-free fluids, values of $c=100$ to 200 may be used for continuous service. 
A flow velocity, which establishes the basis for determining the size of the pipe inner diameter, must be selected/evaluated. First, it should be determined whether to base the flow velocity on liquid, gas or two-phase fluid. The water in the SCW loop behaves more like a gas at the exit of the test section where it has its lowest density. Downstream of the heat exchanger the density of water in the SCW loop is close to that of water under atmospheric conditions and hence, at locations after the heat exchanger, it behaves like a liquid. Pseudo-two-phase flow is expected only in the test section and inside the heat exchanger. Therefore, it is unnecessary to size the piping based on two-phase flow because it is does not occur in the piping. On the other hand, sizing the pipes based on steam and erosional velocities results in relatively large pressure drop in the piping. Thus, the inside diameter of the pipe is conservatively sized based on the liquid water flow velocities given in Table 3.2.

The flow velocity for the boiler feed is used and the value corresponding to the lower end of the given range, $2.5 \mathrm{~m} / \mathrm{s}$, is selected. The maximum mass flow rate $(\dot{m})$ is determined based on the maximum mass flux $\left(\dot{m}_{f l u x}\right)$ given in Table 3.1 and the largest cross-sectional area $\left(A_{C}\right)$ of the three proposed test section configurations. The temperature of the water on the cooler part of the loop is expected to be $260{ }^{\circ} \mathrm{C}$ and therefore the density of water at this temperature and a pressure of $23 \mathrm{MPa}$ will be used to determine the pipe inner diameter. At $260{ }^{\circ} \mathrm{C}$, the density of water in the supercritical pressure range is nearly constant between 23 and $27 \mathrm{MPa}$ [13]. 


$$
\begin{aligned}
& \dot{m}_{f l u x}=3000 \frac{\mathrm{kg}}{\mathrm{m}^{2} \mathrm{~s}} \\
& A_{C}=3.46 \times 10^{-4} \mathrm{~m}^{2} \quad \begin{array}{l}
\text { (initial estimate for the } \\
\text { bundle test section) }
\end{array}
\end{aligned}
$$

Therefore, $\quad \dot{m}=\frac{\dot{m}_{\text {flux }}}{A_{C}}=1.038 \frac{\mathrm{kg}}{\mathrm{s}}$

The required inner diameter of the pipe can be calculated as follows [14]:

$$
\dot{m}=\rho V \frac{\pi D_{i}^{2}}{4}
$$

In this formula, $\rho$ is the density of water at $260^{\circ} \mathrm{C}$ and $23 \mathrm{MPa}$ and it is equal to $805 \mathrm{~kg} / \mathrm{m}^{3}$ [13], $V$ is the flow velocity selected from Table 3.2 and it equals $2.5 \mathrm{~m} / \mathrm{s}$ and $D_{i}$ is the inner diameter of the pipe. Substitution of these values into Equation (3.2) results in a pipe inner diameter of $25.6 \mathrm{~mm}$.

\subsection{Determination of the Wall Thickness}

Before the sizing of the pipe wall thickness is carried out, it is important to establish the design pressure and design temperature of the pipe.

ASME B31.1 states that the design pressure shall not be less than the maximum sustained operating pressure within the piping system including the effects of static head [8]. In a similar manner, the design temperature is defined as the maximum sustained temperature in the pipe metal [8]. The design pressure and design temperature as described by the Code stipulate the minimum conditions to determine 
the minimum required pipe wall thickness. For added safety, a design pressure of 28.35 MPa and a design temperature of $625^{\circ} \mathrm{C}$ are selected. The selected design pressure is $5 \%$ higher than the maximum expected operating pressure of $27 \mathrm{MPa}$ and the selected design temperature is $25^{\circ} \mathrm{C}$ higher than the maximum expected operating temperature of $600^{\circ} \mathrm{C}$.

A number of pipe-wall-thickness design formulae exist for evaluating the required wall thickness of a pipe under internal pressure. The ASME piping codes have adopted Equations (3.3) and (3.4) for thick walled pipes [8].

$$
\begin{aligned}
& t=\frac{P D_{0}}{2(S E+P y)} \\
& t=\frac{P D_{i}}{2(S E+P y-P)}
\end{aligned}
$$

In these equations, $t$ represents the design minimum wall thickness required to ensure pressure integrity, $P$ is the design pressure, $D_{0}$ and $D_{i}$ signify the outer and inner diameters of pipe, respectively, $S$ is the allowable stress tabulated in ASME B31.1 Appendix $A, E$ stands for the weld joint efficiency factor and $y$ is a dimensionless factor which varies with temperature. Table 3.3 lists $y$ factors for three classes of materials at various temperatures.

The design temperature of the loop $\left(625^{\circ} \mathrm{C}\right)$ falls between the temperature values stated in Table 3.3. Therefore, a linear interpolation between the temperatures $621^{\circ} \mathrm{C}$ 
and $649^{\circ} \mathrm{C}$ is performed to obtain the right $y$ factor for the design temperature of the loop. Performing the interpolation for austenitic steels, the selected piping material, the $y$ factor is determined to be 0.7 .

Table 3.3: Values of $y$ factor [8]

\begin{tabular}{lcccccccc}
\hline $\begin{array}{c}\text { Temperature } \\
\left({ }^{\circ} \mathbf{C}\right)\end{array}$ & $\begin{array}{c}\mathbf{4 8 2} \\
\text { and } \\
\text { below }\end{array}$ & $\mathbf{5 1 0}$ & $\mathbf{5 3 8}$ & $\mathbf{5 6 6}$ & $\mathbf{5 9 3}$ & $\mathbf{6 2 1}$ & $\mathbf{6 4 9}$ & $\begin{array}{c}\mathbf{6 7 7} \\
\text { and } \\
\text { above }\end{array}$ \\
\hline Ferritic steels & 0.4 & 0.5 & 0.7 & 0.7 & 0.7 & 0.7 & 0.7 & 0.7 \\
Austenitic steels & 0.4 & 0.4 & 0.4 & 0.4 & 0.5 & 0.7 & 0.7 & 0.7 \\
Nickel alloys & 0.4 & 0.4 & 0.4 & 0.4 & 0.4 & 0.4 & 0.5 & 0.7 \\
\hline
\end{tabular}

The joint efficiency, $E$, is a derating factor applied to allowable stress values of welded joints based on the level of radiographic examination [8]. The necessary joint efficiency factors are accounted for in the allowable stress values given in Appendix A of ASME B31.1. It is expected that the piping will be of seamless construction (for seamless pipe/tube, $E=1$ ) and therefore, the corresponding allowable stress value for stainless steel Types $316 \mathrm{H}$ and 316 at $625^{\circ} \mathrm{C}$ is $65.5 \mathrm{MPa}$ (9.8 ksi).

Substituting these values into Equation (3.4) to determine the wall thickness based on the previously calculated pipe inner diameter yields:

$$
\begin{aligned}
& t=\frac{28.4 \times 10^{6} \mathrm{~Pa} \cdot 25.6 \times 10^{-3} \mathrm{~m}}{2\left(65.5 \times 10^{6}+28.4 \times 10^{6} \cdot 0.7-28.4 \times 10^{6}\right) P a} \\
& t=6.4 \times 10^{-3} \mathrm{~m}=6.4 \mathrm{~mm}
\end{aligned}
$$


Therefore, the minimum required wall thickness to withstand the internal design pressure at the design temperature is $6.4 \mathrm{~mm}$.

\subsection{Determination of Wall Thickness for Piping Before and After Flow Meter}

For the purpose of flow rate measurement, a commercially-available turbine flow meter with an inner diameter of $14.2 \mathrm{~mm}(0.56 \mathrm{in}$ ) has been selected (detailed information on the flow meter is available in Section 3.3.4.2.3). For accurate measurement of flow rate, it is important that the flow entering the flow meter is free of swirl and has a close-tofully-developed velocity profile. This is achieved by using a sufficiently long straight pipe section upstream of the flow meter. The pipe segment immediately downstream of the turbine flow meter maintains the flow diameter of the turbine flow meter. As such, it is necessary to calculate the required wall thickness of these pipe sections for the given inner diameter of $14.2 \mathrm{~mm}$.

Again, using Equation (3.4) and substituting for the new inner diameter:

$$
\begin{aligned}
& t=\frac{28.4 \times 10^{6} \mathrm{~Pa} \cdot 14.2 \times 10^{-3} \mathrm{~m}}{2\left(65.5 \times 10^{6}+28.4 \times 10^{6} \cdot 0.7-28.4 \times 10^{6}\right) P a} \\
& t=3.5 \times 10^{-3} \mathrm{~m}=3.5 \mathrm{~mm}
\end{aligned}
$$

The required wall thickness is thus determined to be $3.5 \mathrm{~mm}$. 


\subsection{Pipe Sizing Conclusion}

To provide ample corrosion allowance and extra wall thickness for factors such as piping dead weight, thermally induced stresses, and pressure excursions due to possible water hammering, a wall thickness of $10 \mathrm{~mm}$ is selected. Comparing the determined factors such as wall thickness and internal diameter with standard nominal pipe sizes listed in ASME B36.19-Stainless Steel Pipe, it is found that the dimensions of NPS 1.5 schedule XXS meet the required wall thickness and internal diameter. NPS 1.5 schedule XXS has an internal diameter of $27.94 \mathrm{~mm}(1.1 \mathrm{in})$ and a wall thickness of $10.16 \mathrm{~mm}$ (0.4 in) [15]. The selected pipe size provides an extra wall thickness of approximately $2 \mathrm{~mm}(25 \%)$ when corrected for the larger internal diameter and manufacturing tolerance at the selected design temperature of $625^{\circ} \mathrm{C}$.

For the smaller diameter pipe segments upstream and downstream of the flow meter, it is found that pipe with a nominal size of $3 / 4$ in and Schedule 160 wall thickness has the closest inside diameter as the turbine flow meter while satisfying the determined wall thickness requirement. NPS 3/4 schedule 160 has an internal diameter of $15.6 \mathrm{~mm}$ (0.614 in) and a wall thickness of $5.5 \mathrm{~mm}(0.218 \mathrm{in})$ [15]. This wall thickness provides a $1.0 \mathrm{~mm}$ ( $25 \%$ extra wall thickness after accounting for manufacturing tolerance) allowance for corrosion at the selected design temperature of $625^{\circ} \mathrm{C}$.

It should be noted that the pipe is sized for a design temperature of $625^{\circ} \mathrm{C}$. As discussed earlier, some parts of the loop will not be exposed to temperatures higher than $260^{\circ} \mathrm{C}$. 
The required wall thickness at this temperature is relatively small compared to the one required at $625^{\circ} \mathrm{C}$. However, in order to simplify the design and selection of piping components, and for added safety in case of unexpected temperature excursions, it is decided to use the same selected design temperature and the resulting pipe sizes for the entire loop.

\subsubsection{Selection of Pipe Fittings}

Pipe fittings are utilized to accomplish a change in direction of piping, a change in diameter of pipe, or to branch from the main pipe run [16]. Since pipe fittings are part of the piping system, they are manufactured such that they match closely in specification and rating to the pipe to which they are joined. Pipe fittings are commonly divided into butt-welding, screwed, socket-welding, flanged and compression fittings [8].

ASME B31.1 imposes limitations on the use of threaded joints in the main piping. Threaded joints are restricted to a maximum pressure of $10.35 \mathrm{MPa}$ and a maximum temperature of $496{ }^{\circ} \mathrm{C}$ [8]. Furthermore, socket welds are not recommended for piping joints where temperature or pressure cycling or severe vibration is expected to occur, or where accelerated crevice corrosion is expected [8]. Therefore, due to the SCW loop operating conditions, butt-welding fittings are the only appropriate type of fittings.

Butt-welding fittings belong to a family of fittings where attachment of fittings to the mating piping is accomplished by forming circumferential butt-welding joints. They are 
used in conjunction with ASME/ANSI pipe and are available in the same size range, but there are fewer wall thicknesses of fittings than there are wall thicknesses of pipe [16].

Austenitic stainless steel butt-welding pipe fittings conform to the requirements of ASTM A403 [17]. ASTM A403 requires that fittings be manufactured with equivalent chemical and physical properties as those of the mating pipe. A403 specifies four categories of fittings, namely WP-S, WP-W, WP-WX and WP-WU.

WP-S refers to seamless fittings made from seamless pipe to ASTM A312. WP-W refers to welded pipe fittings manufactured from welded pipe to ASTM A312. Fittings made to ASTM A312 are not required to be radiographically examined unless a manufacturer's weld has been introduced or there are welds made with the addition of filler metal. WP-WX describes butt-welding fittings of welded construction where all welds must be $100 \%$ radiographed and last but not least, WP-WU defines fittings of welded construction where all welds must be $100 \%$ examined by ultrasonic examination.

ASTM A403 butt-welding pipe fittings are manufactured to the dimensional and tolerance requirements of ASME B16.9 [17]. ASME B16.9 requires that the pressuretemperature rating of the butt-welding fitting meet or exceed that of the mating pipe of the similar material and nominal size [18]. ASME B16.9 pipe fittings include elbows, tees, crosses, caps, reducers, saddles, lap-joint stub ends and laterals. 


\subsection{Pipe Fitting Selection Conclusion}

$90^{\circ}$ elbows are employed in the construction of the loop to achieve changes in the direction of the flow. Elbows at locations with temperatures higher than $538^{\circ} \mathrm{C}$ are of grade $316 \mathrm{H}$ and at locations with expected fluid temperatures lower than $538^{\circ} \mathrm{C}$ are of grade 316. All elbows are of type WP-S A403 with nominal pipe size of 1.5 in schedule XXS.

An equal cross (with all four sides of equal dimensions) is used to make a two-way branch connection from the main line. The cross is of type WP-S A403, grade 316 with 1.5 in nominal pipe size and schedule XXS.

Two concentric reducers are required to reduce the line size from NPS 1.5 schedule XXS to NPS $3 / 4$ schedule 160 upstream of the flow meter and to enlarge the line size from NPS $3 / 4$ schedule 160 back to NPS 1.5 schedule XXS downstream of the flow meter. Reducers are of type WP-S A403, grade 316 with nominal pipe size $1.5 \mathrm{in} \times 3 / 4$ in and schedule 160 wall thickness.

\subsubsection{Selection of Flanged Joints}

Flanges are used to mechanically connect piping segments to other pipe sections, components and equipment [19]. Proper selection of flanged joints plays an important role in the integrity and reliability of the piping system. 
Flanges are commonly identified by the flange facing and the type of flange. The three most widely used flange faces are flat face, raised face and ring-type joint, and the most widely used flange types are threaded, socket weld, slip-on, lap-joint and welding neck.

\subsection{Pressure Rating of Flanges}

Pressure rating of a flange is defined as the maximum pressure allowed by the applicable code for the specific temperature at which the flange will be operating [16]. Flanges are sized according to pressure ratings established by ASME B16.5. These pressure ratings are divided into seven categories for forged flanges [16]. They are 150\#, $300 \#, 400 \#, 600 \#, 900 \#, 1500 \#$ and $2500 \#$, commonly referred to as Class 150, Class 300 and so on. These ratings when combined with temperature are used to select the appropriate size, rating and type of flange. The maximum pressure rating for ASME B16.5 flanges for any material is given in Table 3.4.

For flanged joints with pressure-temperature ratings that fall outside the limits of ASME B16.5, the rules for design of flanged joints with ring type gaskets, as given in ASME Boiler and Pressure Vessel (BPV) Code Section VIII, Division 1, Appendix 2, are used.

Alternatively, API flanges with metallic ring gaskets can be used within their pressuretemperature limitations to substitute for ASME B16.5 flanges whenever the operating conditions of the joint exceed the ratings of ASME B16.5 flanges. 
Table 3.4: Ceiling pressure ratings in bars for ASME B16.5 flanges for any material [20]

\begin{tabular}{|c|c|c|c|c|c|c|c|}
\hline \multirow[b]{2}{*}{ Remperatures } & \multicolumn{7}{|c|}{ cluss } \\
\hline & $\begin{array}{l}\text { Cans } \\
130\end{array}$ & $a_{300}$ & Class & ans & Class & $\begin{array}{l}\text { Chss } \\
1500\end{array}$ & anses \\
\hline-291030 & 20.0 & $\$ 1.7$ & 64.9 & 103.4 & 155.1 & 258.6 & 430.9 \\
\hline & 19.5 & 31.7 & 60.9 & 103.4 & 155.1 & 258.6 & 430.9 \\
\hline 100 & 17.7 & 31.5 & 60.7 & 103.0 & 154.6 & 257.6 & 429.4 \\
\hline 150 & 15.8 & so.3 & 66.8 & 100.3 & 150.6 & 250.8 & 418.2 \\
\hline 200 & 13.8 & 48.6 & 64.8 & 97.2 & 145.8 & 243.4 & $\cos .4$ \\
\hline 250 & 12.1 & 46.3 & 61.7 & 92.7 & 139.0 & 231.8 & 306.2 \\
\hline 300 & 10.2 & 42.9 & 57.0 & 85.7 & 128.6 & 214.4 & 357.1 \\
\hline 325 & 9.3 & 41.4 & 35.0 & 22.6 & 124.0 & 206.6 & 34.3 \\
\hline 350 & 84 & 40.1 & $\$ 3.6$ & ea.4 & 120.7 & 201.1 & 335.3 \\
\hline 375 & 7.4 & 38.9 & $\$ 1.6$ & 17.6 & 116.5 & 19.1 & 323.2 \\
\hline 100 & 6.5 & 36.5 & 4.9 & 13.3 & 109.8 & 183.1 & 304.9 \\
\hline 425 & 5.5 & 35.2 & $\$ 6.3$ & 70.0 & 105.1 & 173.1 & 291.6 \\
\hline 450 & 4.6 & 33.7 & As.1 & 67.7 & 101.4 & 169.0 & 281.8 \\
\hline 475 & 3.7 & 31.7 & 42.3 & 63.4 & 93.1 & 158.2 & 263.9 \\
\hline 500 & 2.8 & 28.2 & 37.6 & 56.5 & 4.7 & 160.9 & 235.0 \\
\hline 525 & 1.9 & 23.8 & 34.4 & $\$ 1.6$ & 77.4 & 129.0 & 214.9 \\
\hline 530 & 1.4 & 25.2 & 33.4 & 50.0 & 73.2 & 125.5 & 206.9 \\
\hline sso & (1) & 25.0 & 33.3 & 49.8 & 70.8 & 124.9 & 208.0 \\
\hline 375 & (1) & 20.0 & 31.9 & 47.9 & 71.8 & 319.7 & 199.5 \\
\hline 600 & (1) & 21.6 & 28.6 & 42.9 & 64.2 & 107.0 & 178.5 \\
\hline 625 & (1) & 18.3 & 24.3 & 36.6 & 54.9 & 91.2 & 152.0 \\
\hline 650 & (1) & 14.1 & 18.9 & $2 \times 1$ & 42.5 & 70.7 & 117.7 \\
\hline ass & (1) & 12.4 & 16.9 & 25.2 & 37.6 & 62.7 & 104.5 \\
\hline 200 & (1) & 10.1 & 13.4 & 20.0 & 29.8 & 49.7 & 83.0 \\
\hline 725 & (1) & 7.9 & 10.5 & 15.4 & 23.2 & 38.6 & 64.4 \\
\hline 750 & (1) & 5.9 & 7.9 & 11.7 & 17.6 & 29.6 & 49.1 \\
\hline 775 & (1) & 4.6 & 6.2 & 9.0 & 13.7 & 22.8 & $\mathbf{3 8 . 0}$ \\
\hline$\infty 00$ & (1) & 3.5 & 4.8 & 7.0 & 10.5 & 17.4 & 29.2 \\
\hline 816 & (1) & 2.8 & 3.8 & 5.9 & 8.6 & 14.1 & 23.8 \\
\hline
\end{tabular}

note:

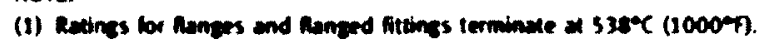

\subsection{Flange Selection Conclusion}

As noted earlier, the pressure and temperature rating of ASME B16.5 flanges are limited due to their standardized design. Referring to ASME B16.5 ceiling pressure ratings, it can be concluded that the use of these flanges is restricted only to the low temperature regions of the SCW loop. It is further concluded that ASME B16.5 Class 2500 flanges are suitable for use at the SCW pressures encountered during the operation of the loop $\left(27 \mathrm{MPa}\right.$ and $\left.260^{\circ} \mathrm{C}\right)$. 
As discussed previously, ASME B31.1 restricts the use of threaded and socket-weld joints to low pressures and joints not subject to thermal or pressure cycling. Therefore, the only flange type suitable for the conditions of the SCW loop is the welding neck flange. Based on the foregoing discussion on flange facings, raised face facing is selected for the flanges used on the loop.

Hence, two standard ASME B16.5 flange sizes, NPS 1.5 schedule XXS and NPS $3 / 4$ schedule 160, are selected. The flanges are welding neck with raised face made to SA 182 grade F316.

In order to accurately determine the flow rate of water in the SCW loop, it is necessary to measure the pressure of the water at a location close to the flow meter. The simplest way to connect the pressure transducer to the piping is through a pressure tap hole on the flange, as in orifice flanges. However, orifice flanges come in standard sizes NPS 1 and larger, whereas the mating flow meter flange is of size NPS $3 / 4$. Therefore, to simplify the design, an NPS 1.5 orifice flange with $1 / 2$ in NPT pressure tap holes is installed upstream of the flow meter (mating with the globe valve). A second orifice flange is mated with the strainer for bulk temperature measurement purposes.

For high temperature locations, where the use of standard ASME B16.5 flanges is not viable and flange designs based on ASME BPV Code and API would result in bulky flanged joints, a proprietary piping connector (Grayloc ${ }^{\top M}$ connector) is selected. More detail on Grayloc $^{T M}$ connectors is provided in Section 3.3.2.7. 


\subsubsection{Selection of Gaskets}

A gasket is a material or combination of materials placed between two separable members of a mechanical joint to create a static seal between the two members of a mechanical assembly and maintain that seal under all design and operating conditions [21][22]. Figure 3.9 shows a typical flange assembly with a gasket as the sealing component. Sealing in a gasket is achieved with sufficient seating force such that the pressure is resisted by the stored energy within the gasket. Thus proper initial seating load plays a crucial role in the sealing capability of a gasket.

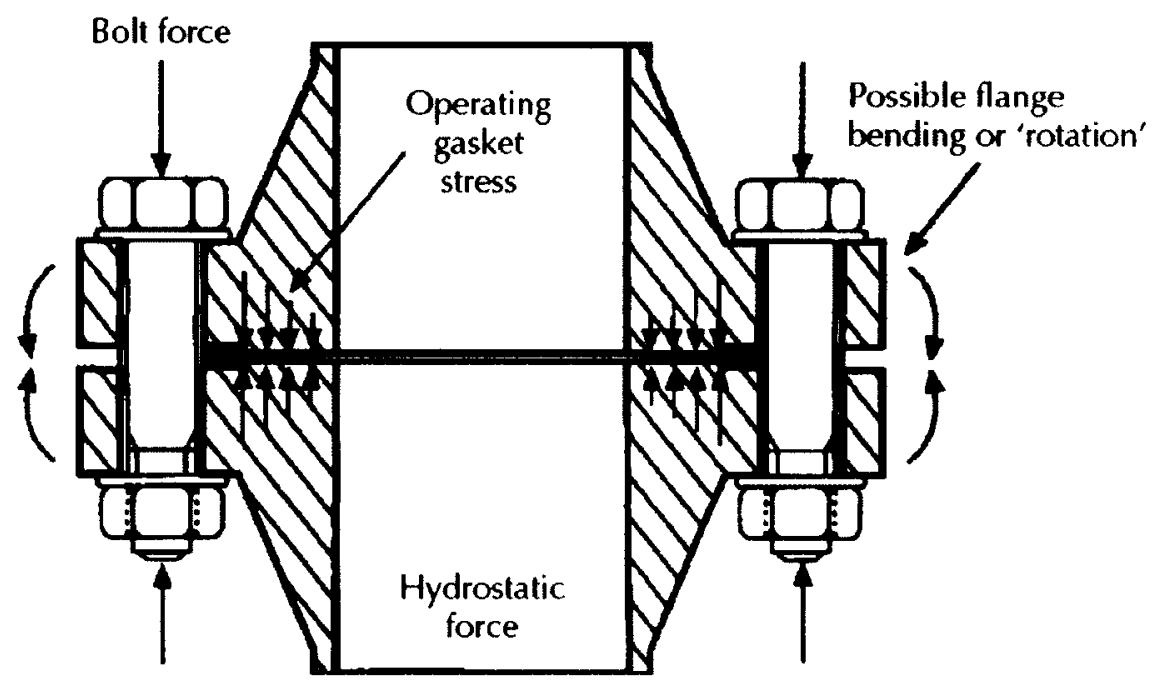

Figure 3.9: Typical gasketed flange joint assembly [21]

Gaskets are selected based on a number of factors, such as design temperature, design pressure, corrosion resistance, compressibility, robustness, creep and handleability. In most applications, the properties of the fluid that needs to be sealed also require special consideration [22]. The materials used in the construction of gaskets not only determine 
the temperature and pressure applicability of gaskets, but also determine the flange surface finish requirement [21]. The flange surface finish requirement of compressed fibre and elastomeric gaskets is less demanding relative to that of metallic or semimetallic gaskets [22].

Materials used in the construction of gaskets fall into three fundamental types [21]:

- Non-metallic (flat rubber, elastomers, graphite, cork, compressed fibres, Teflon, etc.) used at -40 to $450^{\circ} \mathrm{C}$ and 10 to 110 bar.

- Semi-metallic or composite (spiral wound, jacketed, kammprofile, dielectric isolating gaskets, etc.) used at -200 to $1050^{\circ} \mathrm{C}$ and 100 to 300 bar.

- Metallic (soft iron, stainless steel ring, Monel, etc.) utilized in applications involving very high temperatures and pressures up to 1380 bar.

\subsection{Gasket Selection Conclusion}

The high temperatures and pressures encountered during the operation of the SCW loop preclude the use of non-metallic gaskets. Non-metallic gaskets are limited to relatively low pressures and temperature.

Most semi-metallic and all metallic gaskets can be used at the conditions encountered during the operation of the loop where the ASME B16.5 flanges are to be installed. Metallic gaskets require very large seating loads and are used in extremely highpressure and high-temperature applications. The operating temperature of the loop does not warrant the use of metallic gaskets. Semi-metallic gaskets can be utilized as they are suitable for use at temperatures encountered during operation of SCW loop. 
A semi-metallic gasket that meets the pressure requirement can be selected. Both spiral wound and kammprofile gaskets are suitable for use on the SCW loop. Therefore, any one of the two gaskets can be selected, but the kammprofile gasket requires less seating load relative to spiral wound and also has a better leak tightness capability. Therefore, a kammprofile gasket is selected for flanged joint connections.

The selected gaskets are NPS 1.5 and NPS $3 / 4,3.175 \mathrm{~mm}(1 / 8$ in) thick kammprofile gaskets.

There may be a need to electrically isolate at least one of the flanged joint connections in order to avoid inadvertent heating of the rest of the entire loop during the Joule heating of the test sections. However, as discussed earlier, insulating gaskets have limited temperature range applicability. The lowest expected temperature during the operation of the SCW loop is $260^{\circ} \mathrm{C}$, whereas the maximum temperature at which, for example, Pikotek ${ }^{\top M}$ insulating gasket can be used is $200^{\circ} \mathrm{C}[23]$. Therefore, should it be required to use an electrically insulating gasket on the loop, caution must be exercised that the particular flanged joint does not exceed the maximum temperature limit of the insulating gasket.

\subsubsection{Selection of Bolts, Nuts and Washers}

Bolts and nuts are used for clamping of the flange and gasket components [11]. Studbolts are commonly utilized for bolting of flanges and pressure-containment purposes. The screwed threads used on studbolts are commonly defined by ASME B1.1 
(Unified Inch Screw Threads) [11]. Bolts for use with ASME B16.5 flanges are made to ASTM materials standards. The most commonly used standards are ASTM A193 and A320. ASTM A193 is a materials specification for bolts made of stainless steel and highalloy steel [20]. Various bolt grades exist for specific applications. Some most commonly used grades are B7, B8 Class 1 and B8 Class 2. Grade B7 is used for high strength bolting, Grade B8 Class 1 is used for low strength bolting and Grade B8 Class 2 is used for intermediate strength bolting [20].

Heavy series nuts are usually used with bolts in pressure-containing applications [11]. The bolt material specification generally states the proper matching nut specification to be used. For example, A193 states that nuts should conform to ASTM A194. However, it does not specify the exact grade of the material. For high temperature applications exceeding $480^{\circ} \mathrm{C}$, ferrous nuts should be of the same steel alloy material as the bolts. Non-ferrous nuts conforming to the requirements of BPV Code Section VIII, Division 1, UNF-13 may be used with ferrous bolts.

Washers, used optionally, are utilized principally to reduce embedment of the nut and to help ease torquing [11]. ASME B18.22.1 standard stipulates the manufacturing requirements of washers. Material requirements for washers are covered by various ASTM standards and hardened washers, which are used in high-torque applications, are covered by ASTM F436. For high temperature applications exceeding $480^{\circ} \mathrm{C}$, when used with ferrous nuts, the washers should be of an equivalent steel alloy material. Non- 
ferrous washers conforming to the requirements of BPV Code Section VIII, Division 1, UNF-13 may be used.

\subsection{Selection Conclusion}

ASME B16.5 specifies studbolts of diameter $1-1 / 8$ in $(28.5 \mathrm{~mm})$ for class 2500 , NPS 1.5 flanges. The selected studs are of Type 316 made to ASTM A193 specification, grade B8M-Cl.1, UNC Series Class 2A with a length 170 mm (1 1/8-UNC-2A-316-SA193-B8MCl.1). Corresponding nuts for these studbolts are heavy hex nuts, Type 316 made to ASTM A194 specification, grade B8M, UNC Series Class 2B with 1-1/8 in diameter (1 1/8UNC-2B-316-A194-B8M). Washers, if used, are of Type 316 made to ASME B18.22M of nominal size 30 , narrow series, hardened.

Similarly, for class 2500 , NPS $3 / 4$ flanges, the selected studs are 3/4-UNC-2A-316-SA193B8M-Cl.1 and the corresponding nuts are 3/4-UNC-2B-316-A194-B8M. Washers, if used, are of Type 316 made to ASME B18.22M of nominal size 20 , narrow series, hardened.

\subsubsection{Grayloc ${ }^{\top M}$ Connector}

As concluded in the flange selection section, the temperature-pressure rating of the SCW loop flanged joints falls outside the limits of ASME B16.5 at locations where the expected operating temperature is as high as $600^{\circ} \mathrm{C}$. Flanged joints designed according to the rules stipulated in ASME BPV Code Section VIII, Division 1 or made from API flanges result in bulky and heavy-joint assemblies. The heavy size of the conventional flanges is required to apply the gasket seating load and maintain that positive pressure 
on the gasket under the high internal pressure and high temperature of the SCW. In order to reduce the bulky size of the flanges, as an alternative to the conventional flange design, a proprietary flange design can be used for the flanged connections. One such proprietary flange design is a Grayloc ${ }^{\mathrm{TM}}$ connector. As will be discussed below, Grayloc $^{\mathrm{TM}}$ connectors have the advantage of complete rotational freedom. This is quite important since the SCW loop is required to accommodate test sections for both vertical and horizontal arrangements. The following is a brief description of the Grayloc ${ }^{\mathrm{m}}$ connector, as given in [24].

A Grayloc ${ }^{\top M}$ connector is an assembly of three components: a metal seal ring, two hubs and a clamp assembly (Figure 3.10). The seal ring has a " $T$ " cross-section and the leg of the " $T$ " forms a rib that is held between the two hub faces as the connection is made. The two arms form lip seals that make an area of sealing surface with the inner surface of the hub. This seal is further strengthened with the help of the internal pressure.

The clamp fits over the two hubs and pushes them against the seal ring rib. As the hubs are pulled together by the clamp assembly, the ensuing force causes the seal ring lips to deflect against the inner sealing surfaces of the hubs. The deflection elastically loads the seal ring against inner sealing surface of the hub thereby forming a self-energizing seal.

The clamp assembly is designed to provide almost $360^{\circ}$ clamping contact with the hubs. One of the advantages of such a clamp assembly is that no specific circumferential orientation is required during installation. 

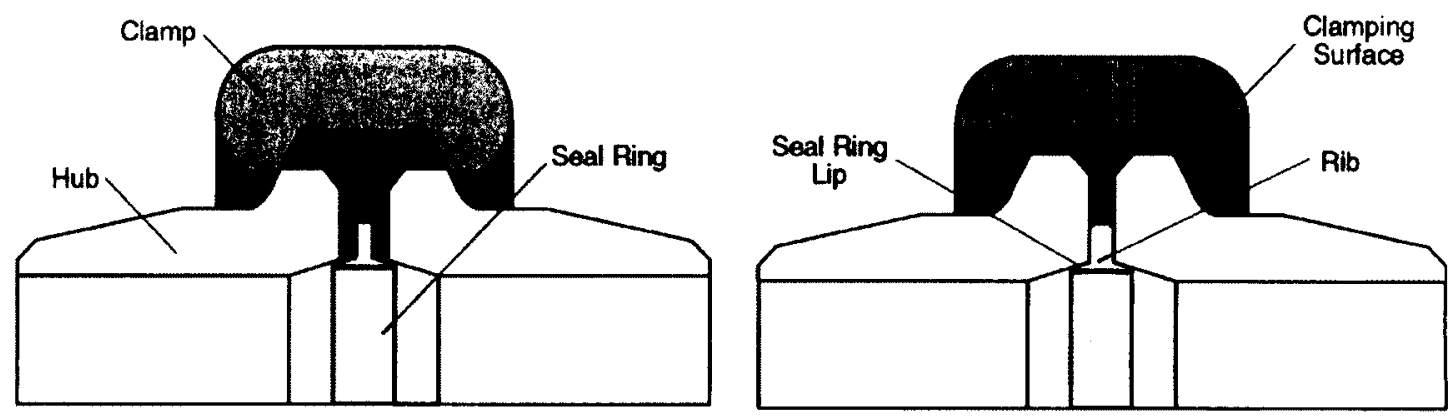

Figure 3.10: Grayloc ${ }^{\mathrm{m}}$ flange and seal assembly [24]

Grayloc $^{\top m}$ connectors can withstand severe service situations, such as vibration, thermal shock, pressures up to $400 \mathrm{MPa}(60,000 \mathrm{psi})$ and temperatures up to $926^{\circ} \mathrm{C}\left(1700^{\circ} \mathrm{F}\right)$.

Compared to conventional ASME designed flanges, the Grayloc ${ }^{T M}$ connector is significantly lighter and smaller. The clamp may be rotated a full $360^{\circ}$ around the hub to orient the bolts so the connectors can be assembled and disassembled in confined spaces with minimal clearance.

Grayloc $^{\mathrm{TM}}$ blind hubs can be drilled or machined to accommodate various penetrations or connections. The blind hub is intended for use in pressure and temperature instrumentation. A schematic of a blind hub is shown in Figure 3.11.

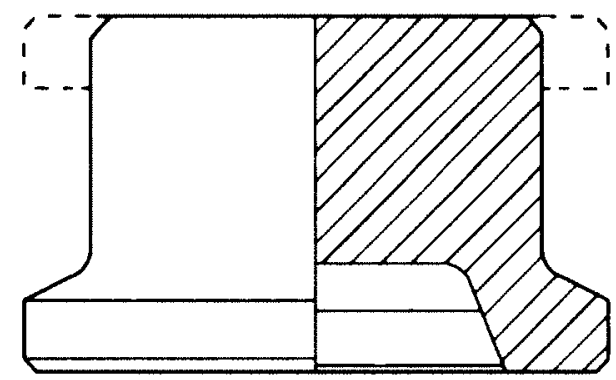

Figure 3.11: Grayloc ${ }^{\mathrm{TM}}$ blind hub [24] 


\subsubsection{Pump}

A pump is required to circulate the water in the Carleton SCW loop compensating for the flow induced pressure losses. The pump must be capable of operating at the highpressure high-temperature conditions encountered during the operation of the SCW loop.

Preliminary sizing of the pump was performed by Yi-Li Jin, another graduate student in the research group, and Klaus Union ${ }^{\mathrm{TM}}$, Inc. was contracted to design and manufacture the pump. This company has chosen a centrifugal-type design driven at a nominal rotational speed of $1750 \mathrm{rpm}$ through a magnetic drive. This pump, identified by the model number SLM HVHO 040-025-160-09T02, is capable of providing the pressure rise and flow rate ranges for the Carleton SCW loop while withstanding pressures up to 28 $\mathrm{MPa}$ and temperatures up to $260^{\circ} \mathrm{C}$. The pressure retaining parts are made of stainless steels 316 and $316 \mathrm{Ti}$. The pump has a $160 \mathrm{~mm}(6.3 \mathrm{in})$ diameter impeller powered by a $1.12 \mathrm{~kW}(1.5 \mathrm{HP})$ squirrel cage induction motor. A variable frequency drive (VFD) is used to control the speed of the motor and hence the pump. The pump has a flow rate ranging from 1.8 to $7.3 \mathrm{~m}^{3} / \mathrm{hr}(7.9$ to $32 \mathrm{GPM})$ or in terms of mass flow rate at $23 \mathrm{MPa}$ and $260{ }^{\circ} \mathrm{C}$, from 0.4 to $1.6 \mathrm{~kg} / \mathrm{s}$. The minimum flow rate of the pump approximately corresponds to the maximum flow rate desired for the test loop. Operation of the test loop at less than maximum flow rate is therefore realized by the use of a bypass line as was described earlier. The suction and discharge connections utilize NPS 1.5 class 2500 RF ASME flanges. 


\subsubsection{Flow Control and Measurement}

The flow of water in the SCW loop can be regulated in two ways: by adjusting the speed of the pump and/or the port opening of control valves. The adjustability range of the pump speed is limited since the minimum pump flow rate is approximately equal to the maximum required flow rate for experimental purposes. Therefore, it is decided to operate the pump at an optimum speed and regulate the flow by adjusting two control valves, one on the main line leading to the test section and the other on the bypass line.

Accurate measurement of water flow rate in the test section is critical for purposes of experimental data deduction. The flow meter must provide for the measurement of the required flow rate range $\left(0.56 \mathrm{~m}^{3} / \mathrm{hr}-1.8 \mathrm{~m}^{3} / \mathrm{hr}\right.$ or $\left.2.5 \mathrm{GPM}-7.9 \mathrm{GPM}\right)$.

\subsubsection{Control Valves Selection}

Unlike regular valves, control valves are part of an automated control system responding to commands from a controller thereby regulating the process flow [11]. A number of valve types, such as globe valve, angle valve, rotary plug valve, ball valve and butterfly valve are researched.

Pressure rating and construction of valves are addressed by ASME B16.34 [25]. The constructional aspects of valves covered by the ASME code include dimensions, tolerances, materials, non-destructive examination requirements, testing and marking. Similar to ASME B16.5, ASME B16.34 divides the pressure ratings of valves into seven categories. They are listed as $150 \#, 300 \#, 600 \#, 900 \#, 1500 \#, 2500 \#$ and $4500 \#$. These 
pressure ratings when combined with temperature give the correct class of the valve to be employed in a particular application.

Considering the merits and disadvantages of various valves, two globe valves are selected as the control valves. To be consistent with the selection of material for other components on the loop, the valve material is selected to be stainless steel Type 316 . Referring to ASME B16.34, class 2500 valve has a pressure-temperature rating of 27.5 $\mathrm{MPa}$ at $260^{\circ} \mathrm{C}$. The valve connection method is selected to be raised face flanged connection of size NPS 1.5. Specifically, globe type control valves made of stainless steel Type 316, grade CF8M, NPS 1.5 class 2500 manufactured by Severn Glocon ${ }^{\mathrm{TM}}$ Ltd. (models SAREX12-LTU12-4 and SAREX25-LTU25-5.6) are procured by Yi-Li Jin, another graduate student in the research group. The valves will be controlled with the help of electric actuators.

\subsubsection{Flow Sensor Selection}

A wide range of flow meters are available for almost any application. Some most commonly used flow meters include differential pressure type, electromagnetic meter, turbine meter, ultrasonic and mass flow meters [26].

A few of the flow measurement methods can be used on the Carleton SCW loop. The simplest flow rate measurement can be achieved with a differential pressure flow meter, such as an orifice plate. In order to measure the differential pressure, two pressure taps are required through the pressure boundary. Also, differential pressure 
flow meters have a small turndown ratio of 3:1 [26]. For the accurate measurement of flow rate for the current application, at least two calibrated orifice plates are required. Besides, the orifice plates would have to be calibrated under atmospheric conditions, which are not representative of water properties at 23-27 MPa and $260^{\circ} \mathrm{C}$.

A Coriolis mass flow meter would perform the flow rate measurement very well (within $\pm 0.2 \%$ of reading [26]), but such a flow meter is expensive when customized for the operating conditions of $27 \mathrm{MPa}$ and $260^{\circ} \mathrm{C}$, assuming that a Coriolis flow meter can be customized for the noted conditions.

An ultrasonic flow meter can be used to measure the fluid flow rate. However, ultrasonic flow meters are expensive and they suffer from relatively low accuracy readings ( $1 \%$ of actual reading to $2-5 \%$ of full scale [26]) compared to other methods of flow measurement. One advantage of an ultrasonic flow meter is that the sensors may be clamped on the outside of the pipe. This method of installation can be very useful in high-pressure applications, such as the current loop, because the need for a pressure boundary breach is avoided.

Thus, the one economical flow meter with reasonable accuracy that is readily available in the pressure-temperature rating range required for the Carleton SCW loop is the turbine flow meter. With a turndown ratio of 10:1, the turbine flow meter would be able to detect the entire required flow range [26]. 


\subsection{Turbine Flow Meter Sizing}

Turbine flow meters are sized based on the volumetric flow rate [26]. When sizing a turbine flow meter, it is recommended that the maximum flow rate of the application should fall at approximately 70 to $80 \%$ of the maximum specified flow rate for the flow meter [26]. It is recommended to avoid the lower $30 \%$ of the flow meter range for improved linearity. This point is better understood when looking at a typical calibration curve for a turbine flow meter (Figure 3.12). The linearity tolerance is typically $\pm 0.25 \%$ of actual reading over a turndown ratio of 10:1. However, this value can be improved if the lower $30 \%$ of the calibration range is avoided.

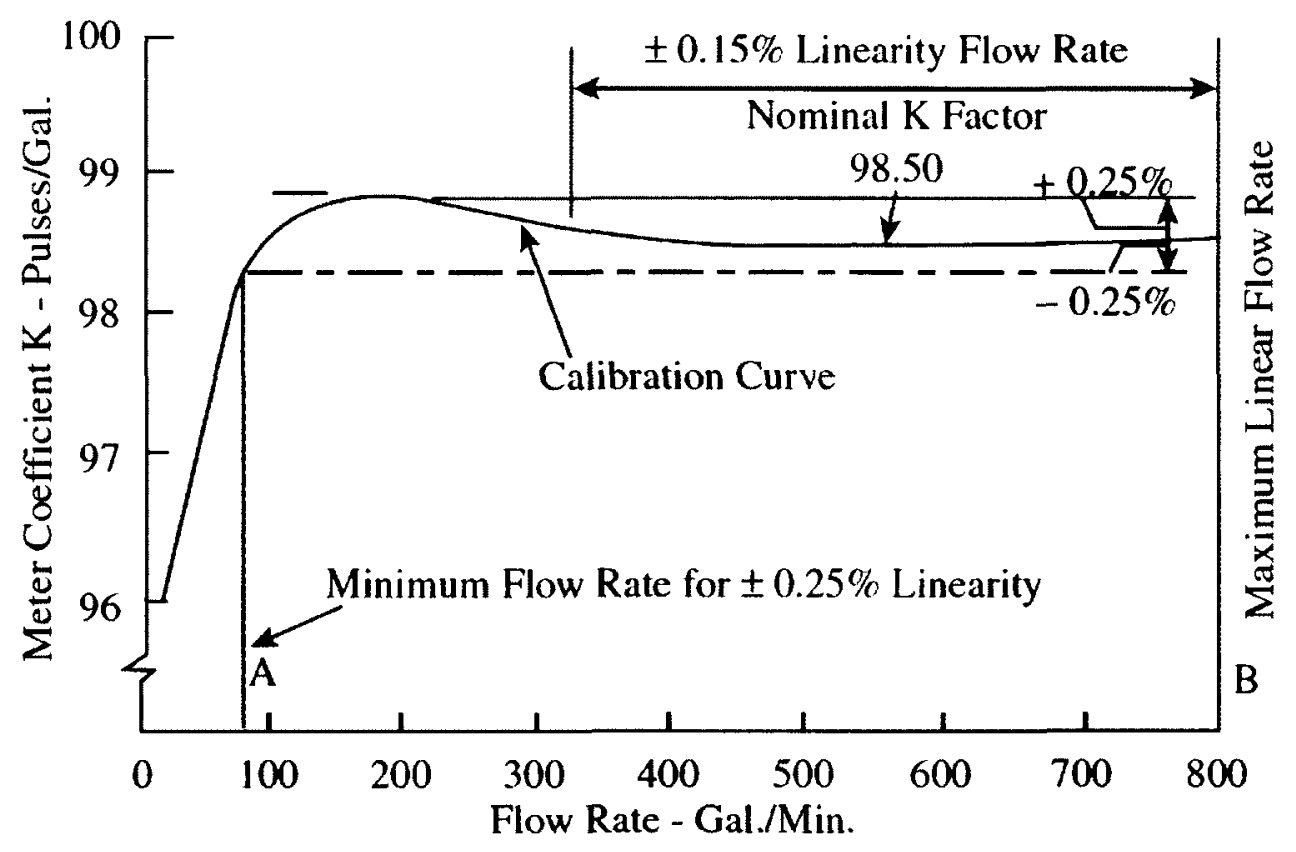

Figure 3.12: Typical calibration curve for a turbine flow meter [26] 


\subsection{Turbine Flow Meter Installation}

To maintain the high accuracy of turbine flow meters, it is important that the flow reaching the meter is free of disturbances and swirl. Flow disturbances are usually caused by bends, valves or filters and if they are present upstream of a turbine flow meter, the flow meter's linearity and $K$ factor (defined in Figure 3.12) will be affected.

In order to mitigate the adverse effects of flow disturbances, sections of straight pipe are installed upstream and downstream of the flow meter. Depending on the degree of upstream disturbance, the required length of straight upstream pipe could be as long as 50 times the nominal meter diameter [26]. To avoid excessively long straight pipe sections, a flow straightening element can be installed upstream of the flow meter. The flow straightener reduces the required upstream straight pipe length to 10 times the nominal meter diameter. The required downstream straight pipe length is 5 times the nominal meter diameter. Figure 3.13 illustrates the installation requirements of the flow meter for optimal accuracy.

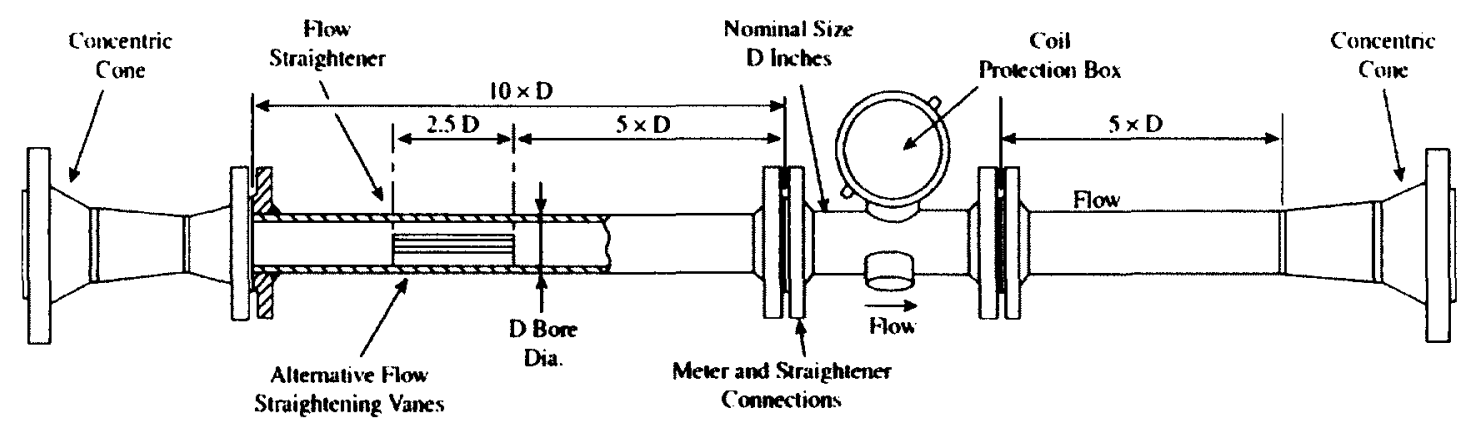

Figure 3.13 Recommended turbine flow meter installation pipework [26] 
As an alternative, the American Petroleum Institute recommends straightening pipe lengths of 20 times the nominal flow meter diameter upstream and 5 times the nominal flow meter diameter downstream of the flow meter under ideal conditions [27]. However, it recommends that the required length of upstream piping be verified according to the following equation [27]:

where,

$$
L=(0.35 D)\left(\frac{K_{s}}{f}\right)
$$

$$
\begin{aligned}
& L=\text { required length of upstream straightening pipe } \\
& D=\text { nominal flow meter diameter } \\
& K_{s}=\text { dimensionless swirl velocity ratio } \\
& f=\text { Pipe friction factor }
\end{aligned}
$$

Values for the swirl velocity ratio, $K_{s}$, for a number of piping configurations are shown in Figure 3.14. The current application is similar to a combination of subfigures $C-1, C-2$ and $\mathrm{C}-5$. The swirl velocity ratio for this arrangement can be determined by adding the ratios of the three subfigures resulting in 4.25 . Using an average friction factor of 0.022 , calculated based on Haaland's approximation of the Colebrook-White equation [14], the required length of the straight pipe segment is determined to be approximately 68 times the nominal diameter. 


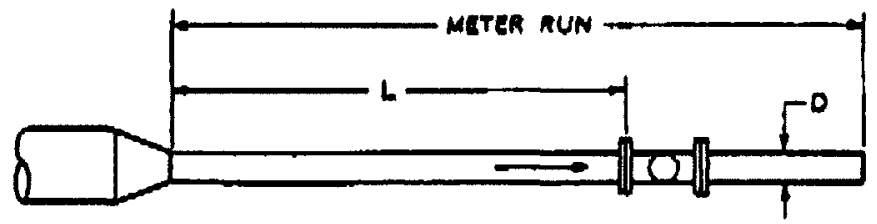

concentmic neoucen meceone mater RUN $\ldots K_{8}=0.75$

FIG. C.L

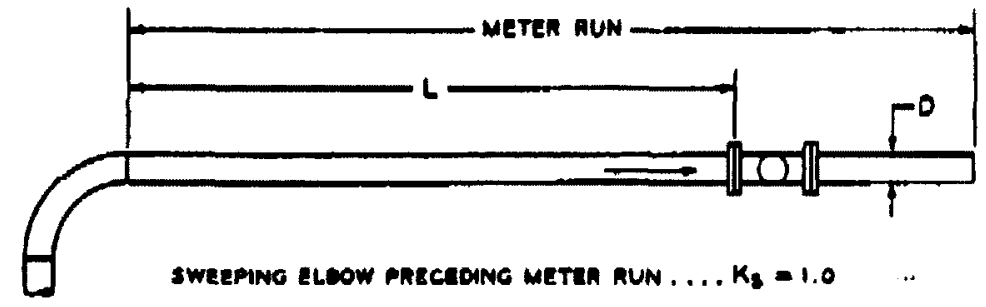

FIG. C.2

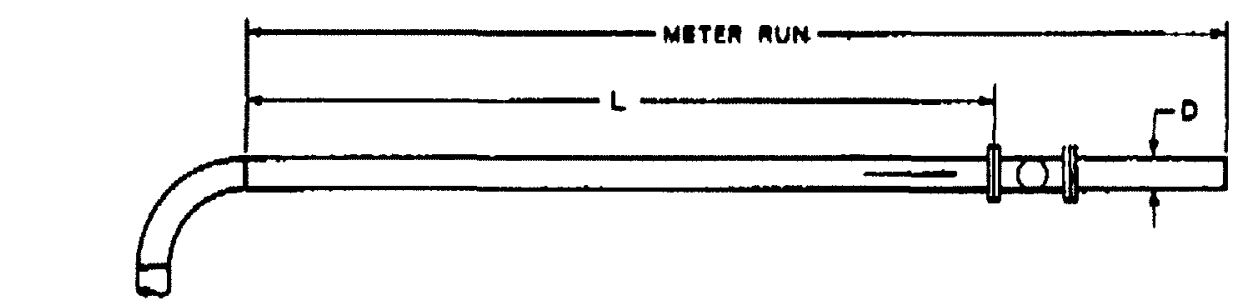

Two sweeping eloows maceoine MrTen RUN .... Ms: 1.28

FIG. C.3

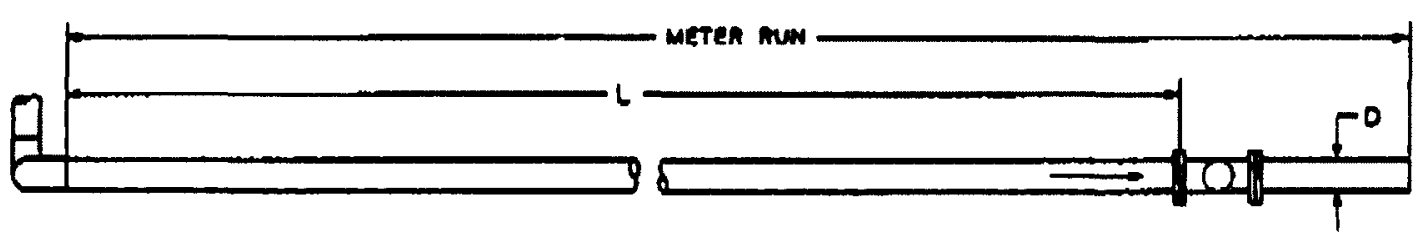

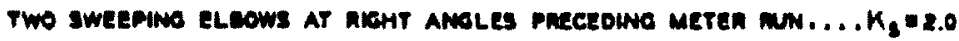

FIC. $\mathrm{C}-4$

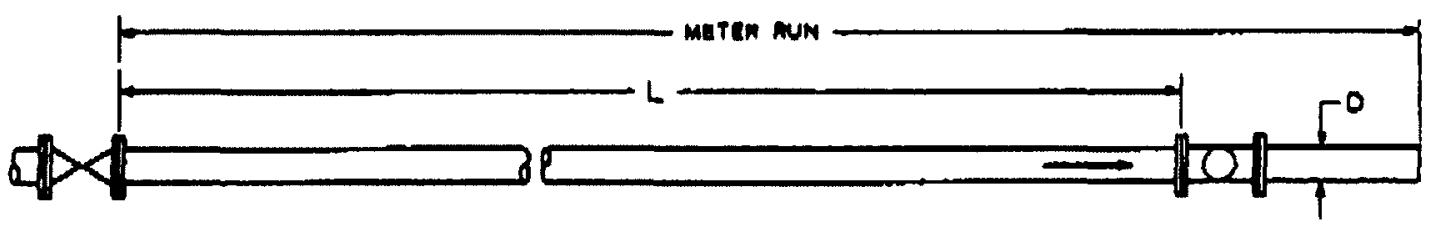

eully open valve pagegoing meten nUN ...... K, 1.0

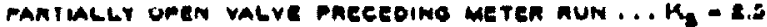

FIG. C.5

Figure 3.14: Values of swirl velocity ratio, Ks, for various piping configurations [27] 


\subsection{Flow Meter Selection Conclusion}

Based on the foregoing discussion, a turbine flow meter with $3 / 4$ in nominal size manufactured by FTI Flow Technology ${ }^{\mathrm{TM}}$ (model FT-12C6XWBLED-6-FT-I SERIES TURBINE) was initially sourced. However, the flow meter lacked the proper CRN (Canadian Registration Number) number for use in the province of Ontario. Therefore, a second turbine flow meter of similar specifications as the FTI flow meter and with the appropriate CRN number manufactured by Hoffer Flow Controls ${ }^{\mathrm{TM}}$ (HO 3/4X3/4-2.5-29TC-1MX8S-F25SS-CE) is selected. The flow meter has a linear flow rate range of $2.5-29$ GPM with a repeatable flow rate range of 1.5-35 GPM. The flow meter is equipped with a magnetic pick-up sensor rated to $454^{\circ} \mathrm{C}$. For better high-temperature performance, tungsten carbide is selected as the bearing material. The interfacing of the flow meter with the rest of the SCW loop piping is achieved by NPS $3 / 4$ class 2500 raised face flanges. The flow meter is rated to $27.4 \mathrm{MPa}$ at $260{ }^{\circ} \mathrm{C}$. The required upstream straightening pipe length is determined through Equation (3.5) and it is found that a $1300 \mathrm{~mm}$ long pipe (68 diameters) is sufficient.

\subsubsection{Temperature Control and Measurement}

Experimental conditions in the supercritical region call for test-section outlet temperatures to be as high as $600^{\circ} \mathrm{C}$. To meet the temperature ratings of the pump and several other components on the loop, the temperature of the water must be lowered downstream of the test section. The lowering of the fluid temperature is achieved with the help of a heat exchanger. Additionally, the heat exchanger is required to lower the 
temperature of the fluid to the desired test-section inlet temperature to be able to steadily impart heat to the working fluid in the test section thus allowing measurements of this energy transfer process. Design requirements for the heat exchanger are that it must be capable of operating at high temperatures and pressures of $260-600^{\circ} \mathrm{C}$ and 23 $27 \mathrm{MPa}$, respectively. Lowering the fluid temperature to $260{ }^{\circ} \mathrm{C}$ from various testsection outlet temperatures, ranging from $380-600^{\circ} \mathrm{C}$ and realizing this over the flow rate range of $0.403 \mathrm{~kg} / \mathrm{s}$ to $0.126 \mathrm{~kg} / \mathrm{s}$, requires the heat exchanger to be sized for $300 \mathrm{~kW}$ maximum heat exchange capability, i.e. the maximum possible amount of heat energy imparted to the fluid in the test section.

Initially, it was intended to design the heat exchanger in-house and have it fabricated by a certified high-pressure high-temperature fabricator. Hence, a large body of work, ranging from thermal to mechanical design and analyses of the heat exchanger, was carried out in this regard. Although eventually it was decided to contract a heat exchanger manufacturing company to design and build the heat exchanger for the SCW loop, the results of the in-house design were used to verify the heat exchanger company's thermal and structural analyses since the heat exchanger company did not have experience with heat exchanger designs involving supercritical fluids, in particular SCW. Therefore, this section delves into the design and selection of the heat exchanger in more detail. 
Measurement of temperature along the loop is essential for health monitoring and for the study of the heat transfer process in the test section. The measured temperature ranges along the loop span by hundreds of degrees. It is necessary that the temperature sensing devices are capable of accurate temperature measurement throughout this temperature range. It is also necessary that the temperature sensors are capable of withstanding the operating environments of the locations where they are used.

\subsubsection{Heat Exchanger}

Heat exchangers are devices that facilitate the flow of thermal energy between two or more fluids at different temperatures [28]. Heat exchangers are extensively used in applications such as power generation, waste heat recovery, manufacturing industry, environmental engineering, air-conditioning and refrigeration. Heat exchangers are classified based on the type (recuperators and regenerators), heat transfer process (direct contact and indirect), heat transfer mechanisms (single phase and two phase), geometry or construction (tubes, plates, extended surfaces and regenerative) and flow arrangements (parallel, counter and cross flows) [28]. Commonly, however, heat exchangers are referred to by their type of construction.

\subsection{Types of Heat Exchanger}

\section{Double-Pipe Heat Exchanger}

A double-pipe heat exchanger essentially consists of two concentric pipes [28]. The double-pipe heat exchanger is the simplest of all heat exchanger types, where one fluid 
flows in the inner pipe and the other fluid flows in the annulus between the two pipes (Figure 3.15). In some configurations, a U-bend is incorporated into the design to make the heat exchanger more compact and a number of heat exchanger units can be connected in parallel or series to achieve the required heat duty. This has the advantage of flexibility because the capability of the heat exchanger can be increased or reduced as necessary. In certain designs, the outside surface of the inner tube is furnished with longitudinal fins to enhance heat transfer to the fluid flowing in the annulus. Doublepipe heat exchangers are preferred when one or both of the fluids are under very high pressure since it is less costly to contain pressure in small diameter tubes/pipes than in large diameter shells.

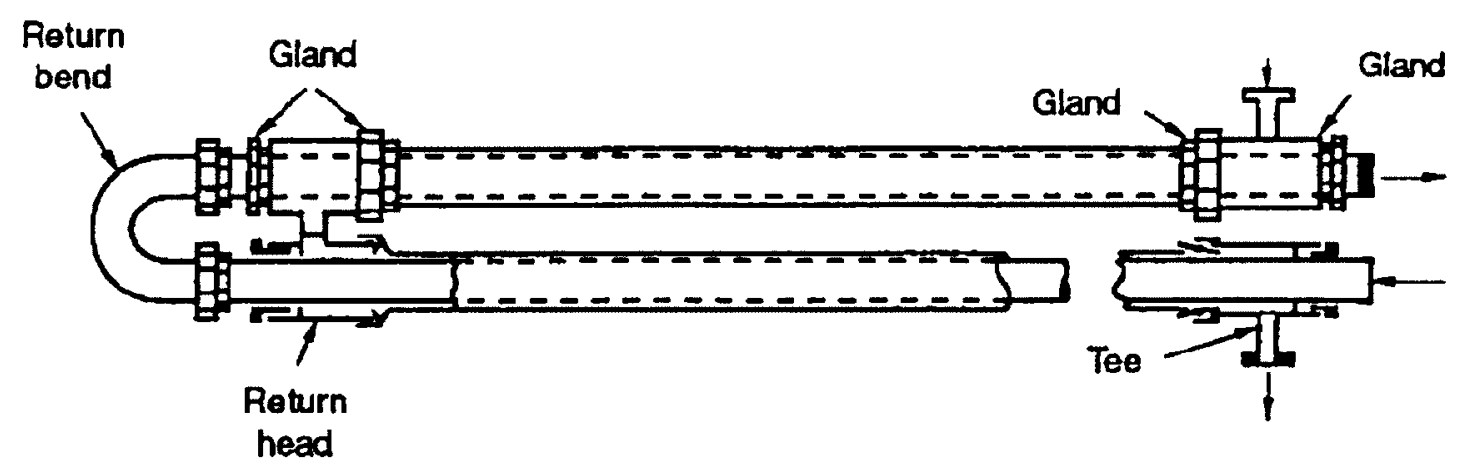

Figure 3.15: Double-pipe heat exchagner [29]

Double-pipe heat exchangers are used in small-duty applications where the required heat transfer surface area does not exceed $50 \mathrm{~m}^{2}$ [29]. A variant of double-pipe heat exchangers consisting of a bundle of tubes inside a small diameter pipe (less than $150 \mathrm{~mm}$ ) is called a hairpin heat exchanger [29]. 


\section{Shell-and-Tube Heat Exchanger}

Shell-and-tube heat exchanger consists of a bundle of round tubes mounted inside a baffled cylindrical shell (Figure 3.16) [29]. One of the fluids flows inside straight tubes, whereas the other flows between and around those tubes, within an all-confining shell. The flow of the fluid in the shell-side is guided in its path by baffles. The baffles also serve to hold the tubes apart, so that the shell-side fluid can flow between them, and provide structural support for the tubes. Shell-and-tube heat exchangers are the most widely used industrial heat exchanger [30].

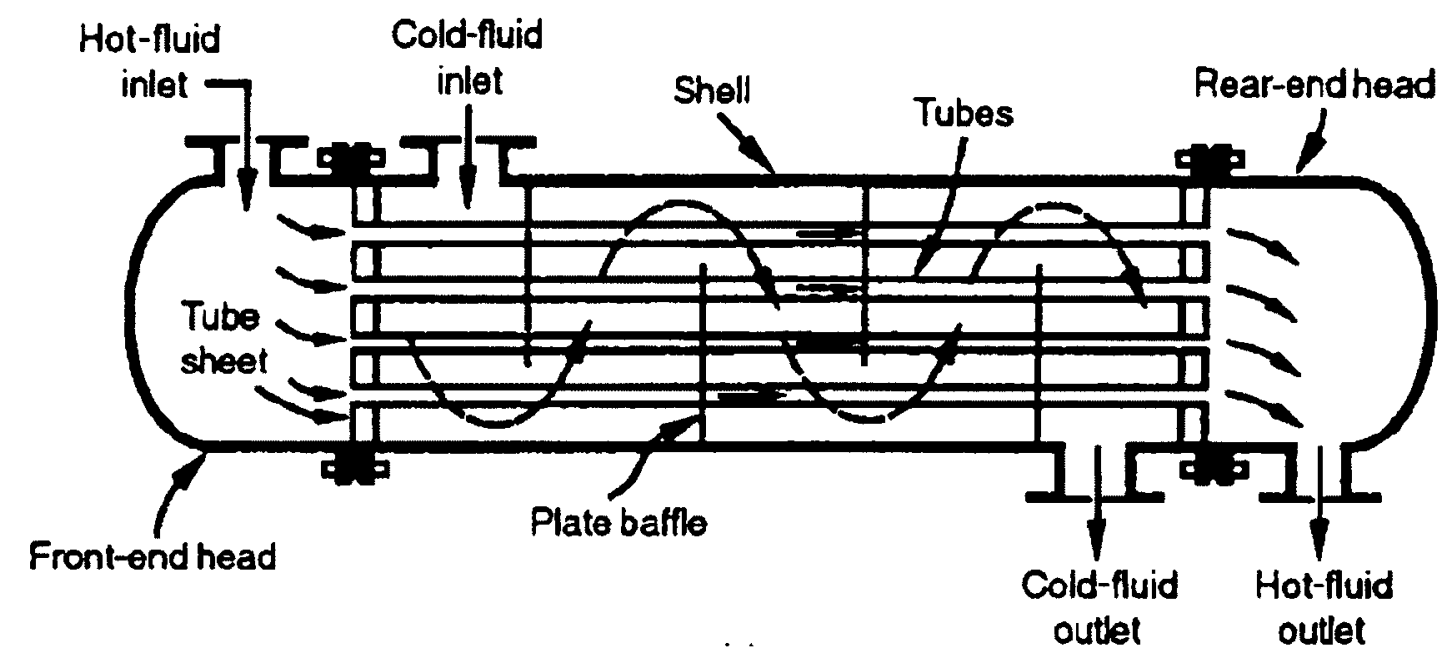

Figure 3.16: Shell-and-tube heat exchanger [29]

Shell-and-tube type heat exchangers are very versatile. They are used in applications with pressures as low as vacuum to ultrahigh pressures of up to $100 \mathrm{MPa}$, from cryogenics to high temperatures of up to $1100{ }^{\circ} \mathrm{C}$, from small sizes of $0.1 \mathrm{~m}^{2}$ to giant 
exchangers with surface areas up to $10^{5} \mathrm{~m}^{2}$, and any pressure and temperature differences between the fluids, limited only by the materials of construction [29].

\section{Coiled Tube Heat Exchanger}

The design of this heat exchanger involves winding a large number of small-diameter ductile tubes in helix fashion around a central core tube [30]. Each heat exchanger unit can contain many layers of tubes along both the principal and radial axes. Coiled tube heat exchangers are used extensively for liquefaction systems [30].

The high pressure fluid flows through the small-diameter tubes, while the low pressure fluid flows in the annular space between the inner central core and the outer shell across the outside surface of the small-diameter tubes. Due to the spiralling of the small-diameter tube, a considerable amount of heat transfer surface area can be accommodated. Because of the small-diameter tubes, cleaning is almost impossible and therefore, the heat exchanger is expected to handle clean fluids that do not cause fouling [30].

\section{Printed-Circuit Heat Exchanger}

Printed-circuit exchangers are considered a form of plate-type heat exchanger because similar to plate exchangers there are only primary heat transfer surfaces [29]. The design of printed-circuit heat exchanger employs the same technique used in making electronic printed circuit boards. Flow channels are chemically etched onto plates and the etched plates are diffusion bonded to make the heat exchanger (Figure 3.17) [29]. 
Multiple passes and multiple fluid streams can be created in a single block and several blocks are welded together for large heat duty applications.

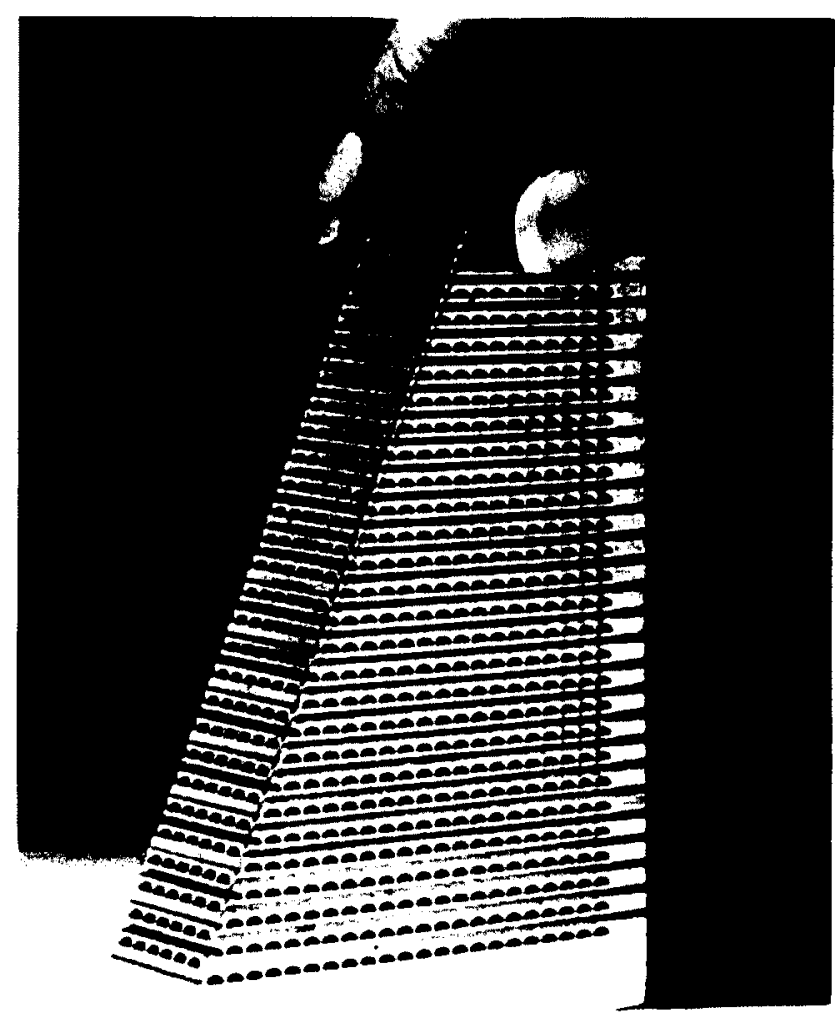

Figure 3.17: Printed-circuit heat exchanger [29]

Printed-circuit exchangers are used in applications involving clean fluids due to the fine nature of the flow channels. These exchangers are very compact and high surface area densities of up to $1300 \mathrm{~m}^{2} / \mathrm{m}^{3}$ are achievable for operating pressures 10 to $50 \mathrm{MPa}$ and temperatures 150 to $800^{\circ} \mathrm{C}[29]$. 
Printed-circuit exchanger costs more than other exchangers due to the precision and labour intensity required in the design and manufacture of printed-circuit heat exchangers [31].

\section{Pate-Type Heat Exchanger}

Plate heat exchangers are built with thin metal plates arranged parallel to one another. The plates are often corrugated or modified in some other fashion to impart mechanical strength to the plates to prevent collapse of the channel under external pressure and to increase the effective plate surface area [29]. One fluid flows through one set of channels and the other fluid flows through the immediately adjacent channels. Generally, plate-type exchangers consist of only primary heat transfer surfaces, as they do not entertain any extra heat transfer surfaces, such as fins commonly used in tubular heat exchangers [29]. The three configurations (Figure 3.18) are the gasketed plate, the spiral plate and the lamella heat exchanger.

Plate-type heat exchangers are commonly utilized in relatively low pressure applications

of up to $3.45 \mathrm{MPa}$ and maximum temperatures up to $500{ }^{\circ} \mathrm{C}$ [29]. However, recently developed extended surface plate-type heat exchangers can take pressures exceeding $35 \mathrm{MPa}$. 


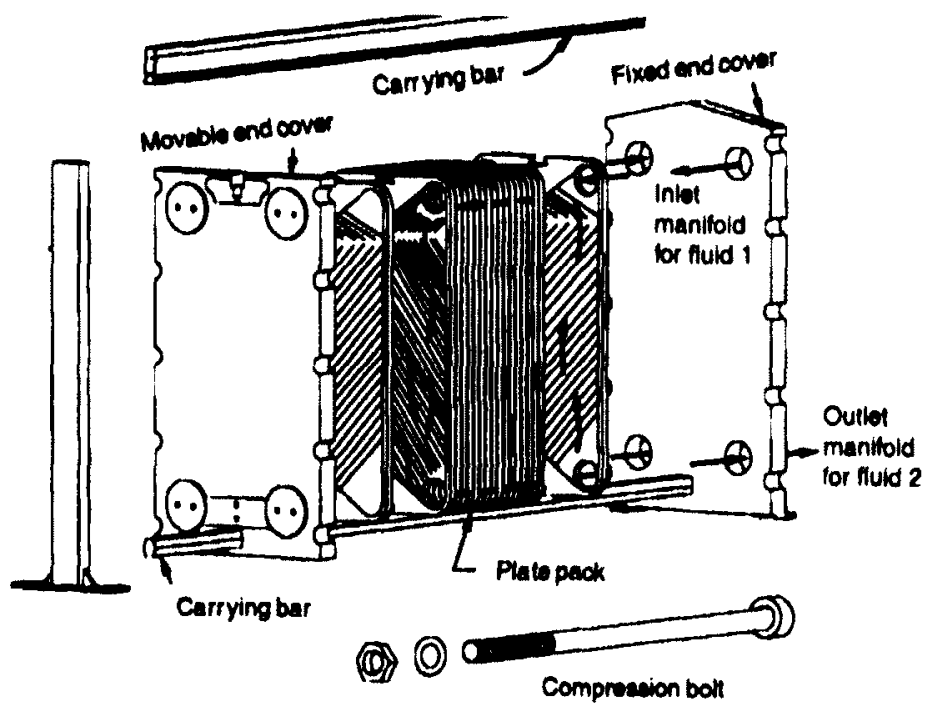

(a)

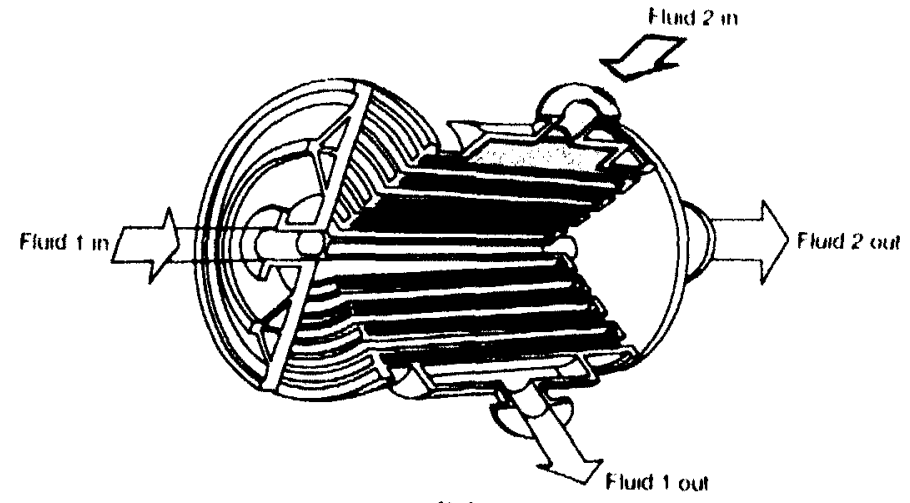

(b)

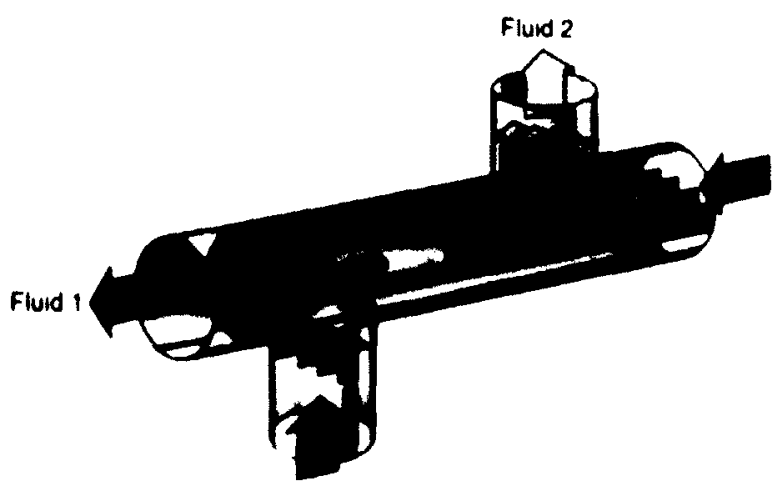

(c)

Figure 3.18: (a) Gasketed pate; (b) spiral plate; (c) lamella heat exchanger [29] 


\subsection{Heat Exchanger Selection}

Selection of a heat exchanger is dependent on a number of factors, such as the type of fluids to be handled, operating pressures and temperatures, heat duty and cost [30]. For the current application, factors of critical importance in the selection of the heat exchanger are the operating pressure and temperature, and the cost.

From the foregoing discussion on the different types of heat exchangers, it can be concluded that the two suitable types of heat exchanger for the current application are double-pipe and shell-and-tube heat exchangers. Both heat exchangers are recommended for applications where one or both fluids are under high pressures and temperatures. Other types of heat exchangers are generally limited to the pressure range of 0.1-3.45 MPa. Although recently developed plate-type heat exchangers can be used at pressures up to $35 \mathrm{MPa}$, their use for the current application brings up thermalhydraulic design issues which have not been successfully resolved yet. Heat transfer to SCW is still under investigation and to this date no one definitive correlation to predict the SCW heat transfer coefficient exists. Many of the existing correlations are for circular tube geometries and thus, from a thermalhydraulic design perspective, the selection of the current heat exchanger is limited to tubular heat exchangers. Printedcircuit heat exchangers are very well suited for the current application. However, they are many folds more costly than any other type of heat exchanger. 
From a mechanical design and construction point of view, the simplest heat exchanger design is that of a double-pipe heat exchanger. As a result of the simplified design, double-pipe heat exchangers are also less costly compared to shell-and-tube heat exchangers.

\subsection{Thermalhydraulic Design of the Heat Exchanger}

Thermalhydraulic design (sizing) of a heat exchanger is concerned with the determination of the dimensions, in particular the required heat transfer surface area, to meet the specified inlet and outlet temperatures of the hot and cold fluids, flow rates and pressure drop requirements [28].

Table 3.5 lists the exact design requirements for the SCW loop heat exchanger. As noted, the heat exchanger will be operating at very high temperatures and pressures of $260-600^{\circ} \mathrm{C}$ and $23-27 \mathrm{MPa}$. Additionally, the heat exchanger must be capable of transferring $300 \mathrm{~kW}$ of heat duty.

Table 3.5: Heat exchanger design specifications

\begin{tabular}{|l|c|l|c|}
\hline \multicolumn{2}{|c|}{ Hot Side } & \multicolumn{2}{c|}{ Cold Side [32] } \\
\hline Fluid in $\left(T_{h 1}\right)$ & $600^{\circ} \mathrm{C}$ & Fluid in $\left(T_{\mathrm{c} 1}\right)$ & $29.5^{\circ} \mathrm{C}\left(85^{\circ} \mathrm{F}\right)$ \\
\hline Fluid Out $\left(T_{\mathrm{h} 2}\right)$ & $260^{\circ} \mathrm{C}$ & Fluid Out $\left(T_{\mathrm{c} 2}\right)$ & $35^{\circ} \mathrm{C}\left(95^{\circ} \mathrm{F}\right)$ \\
\hline Fluid Medium & $\mathrm{H}_{2} \mathrm{O}$ & Fluid Medium & $50 / 50 \mathrm{Glycol}$ \\
\hline Fluid Flow & $0.126-0.403 \frac{\mathrm{kg}}{\mathrm{s}}$ & Fluid Flow & $25 \frac{\mathrm{kg}}{\mathrm{s}}$ \\
\hline Fluid Pressure & $23 \mathrm{MPa}-27 \mathrm{MPa}$ & Fluid Pressure & $\sim 0.1 \mathrm{MPa}(15 \mathrm{psi})$ \\
\hline
\end{tabular}


The sizing of the heat exchanger for the SCW loop is made complicated due to the highly distributed physical properties of water under the high temperatures and pressures encountered, as well as due to the resulting nonlinear temperature dependence of the heat transfer coefficient of SCW. Figure 3.19 shows the heat transfer coefficient of SCW at $23 \mathrm{MPa}$ as a function of temperature for a fully developed pipe flow.

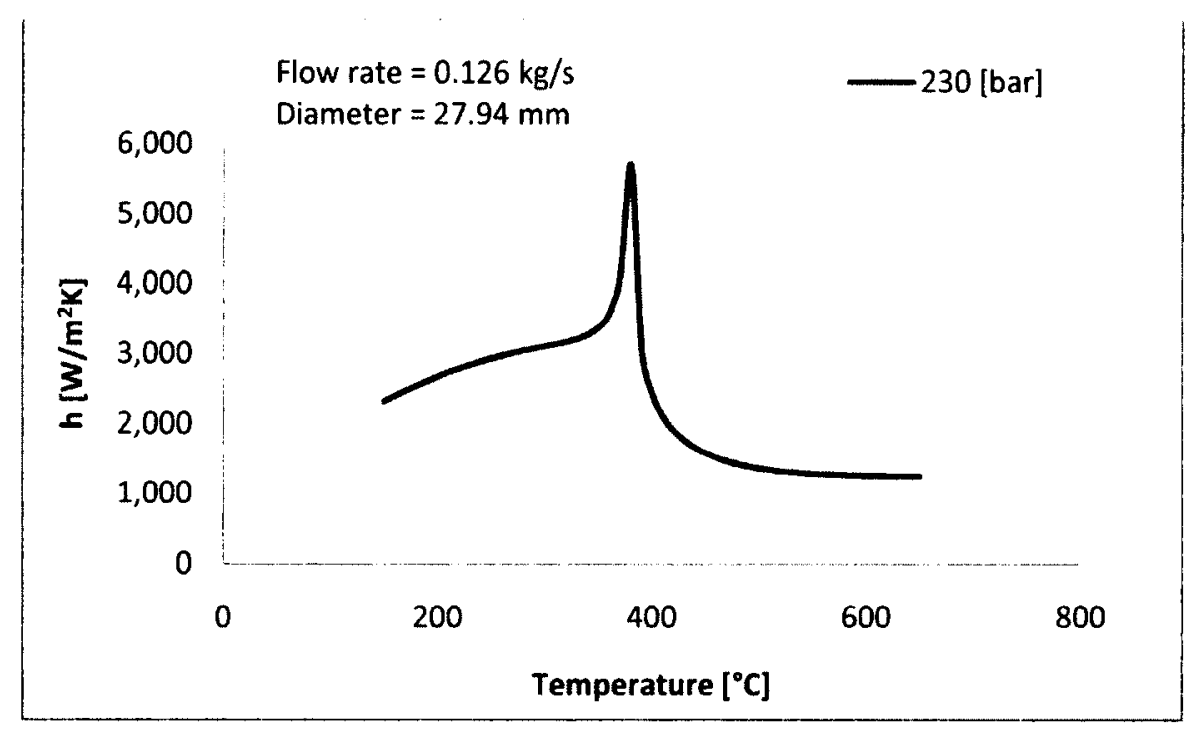

Figure 3.19: Heat transfer coefficient of $\mathrm{SCW}$ at $23 \mathrm{MPa}$ as a function of temperrature

It can be seen from the plot that the heat transfer coefficient of SCW increases as it gets closer to the pseudo-critical temperature and drastically drops immediately after as the temperature is further increased. Hence, there will be regions in the heat exchanger where the heat transfer is enhanced and regions where the heat transfer is deteriorated. As such, it is necessary to determine a mean heat transfer coefficient value to simplify the sizing of the heat exchanger. 
Additionally, the cooling fluid is a mixture of propylene glycol and water [32]. In order to calculate the heat transfer coefficient of the cooling fluid, it is necessary to determine its thermophysical properties. Simple weighted averages of the thermophysical properties of the constituents based on mass fractions have been shown to be of poor quality in their prediction of the real thermophysical properties of mixtures [33][34][35]. Correlations involving cross coefficients have been found to have the least deviation from the actual property values. However, the cross coefficients have to be determined experimentally. Thus, to obtain realistic values for the thermophysical properties of the cooling fluid, correlations specific to propylene glycol and water mixture are required.

\section{scope}

Thermodynamic calculations have shown that the heat exchanger will have two extreme operating conditions. Based on the hot side specifications, one extreme operating condition occurs at $27 \mathrm{MPa}$ with a mass flow rate of $0.403 \mathrm{~kg} / \mathrm{s}$, and inlet and outlet temperatures of $380^{\circ} \mathrm{C}$ and $260^{\circ} \mathrm{C}$. The other occurs at $23 \mathrm{MPa}$ with a mass flow rate of $0.126 \mathrm{~kg} / \mathrm{s}$, and inlet and outlet temperatures of $600^{\circ} \mathrm{C}$ and $260^{\circ} \mathrm{C}$, respectively. Hence, the heat exchanger is sized for these two extreme operating conditions and the larger of the two required heat transfer surface areas is selected.

The heat exchanger is sized for two different designs with counter flow arrangement for the above mentioned two extreme operating conditions. The first design involves a simple concentric double-pipe heat exchanger (Figure 3.20). The internal diameter $\left(d_{i}\right)$ 
of the inner pipe, through which the SCW flows, is selected to be $27.94 \mathrm{~mm}$ (1.1 in). The reason for this selection is due to the fact that this value corresponds to the internal diameter of NPS 1.5 schedule XXS pipe. The wall thickness of this pipe, as will be discussed in the mechanical design section of this thesis, meets the ASME stipulated wall thickness at the design temperature and pressure of the heat exchanger. The internal diameter $\left(D_{i}\right)$ of the outer pipe is selected to be the same as that of NPS 4 schedule 40 , namely $102.26 \mathrm{~mm}$ (4.026 in). There are no specific guidelines as to the selection of $D_{i}$. The main deciding factor in the selection of $D_{i}$ is the frictional pressure drop. The current value is selected based on the pipe size used in the design of one of the heat exchanger quotes received from a leading heat exchanger manufacturer.

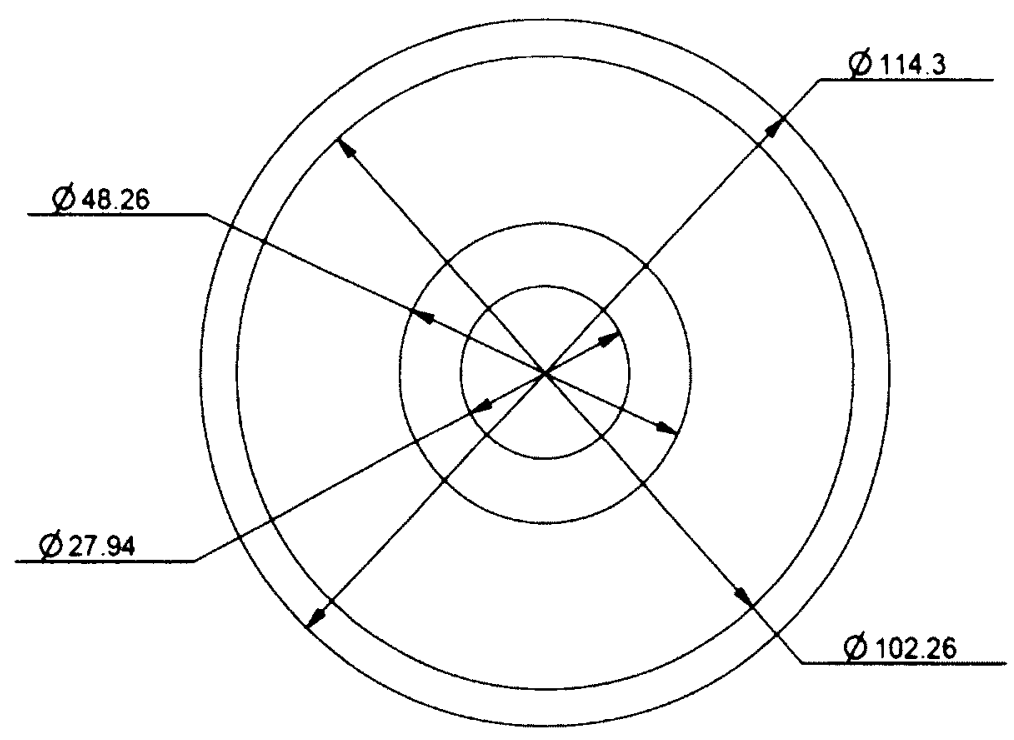

Figure 3.20: Internal layout of double-pipe heat exchanger

The second design involves a variant of a double-pipe heat exchanger, namely a hairpin heat exchanger. Four smaller diameter pipes of size NPS $3 / 4$ with $d_{0}$ of $26.67 \mathrm{~mm}$ 
(1.05 in) are placed inside a larger diameter pipe of size NPS 3.5 (Figure 3.21). The wall thickness used for the smaller pipes is schedule XXS and the wall thickness used for the large diameter pipe is schedule 40 similar to the double-pipe heat exchanger. The wall thickness of schedule XXS meets the ASME required wall thickness, as will be discussed.

There are two reasons for selecting a hairpin heat exchanger with a number of smaller diameter pipes. The first reason is that a smaller pipe diameter results in a thinner pipe wall, which improves the heat conduction through the pipe wall. The second reason is that a number of smaller diameter pipes results in a shorter length for the heat exchanger when translating the required heat transfer surface area to the length of the pipes. However, the construction of a hairpin heat exchanger is more labour intensive compared to that of a simple concentric double-pipe heat exchanger.

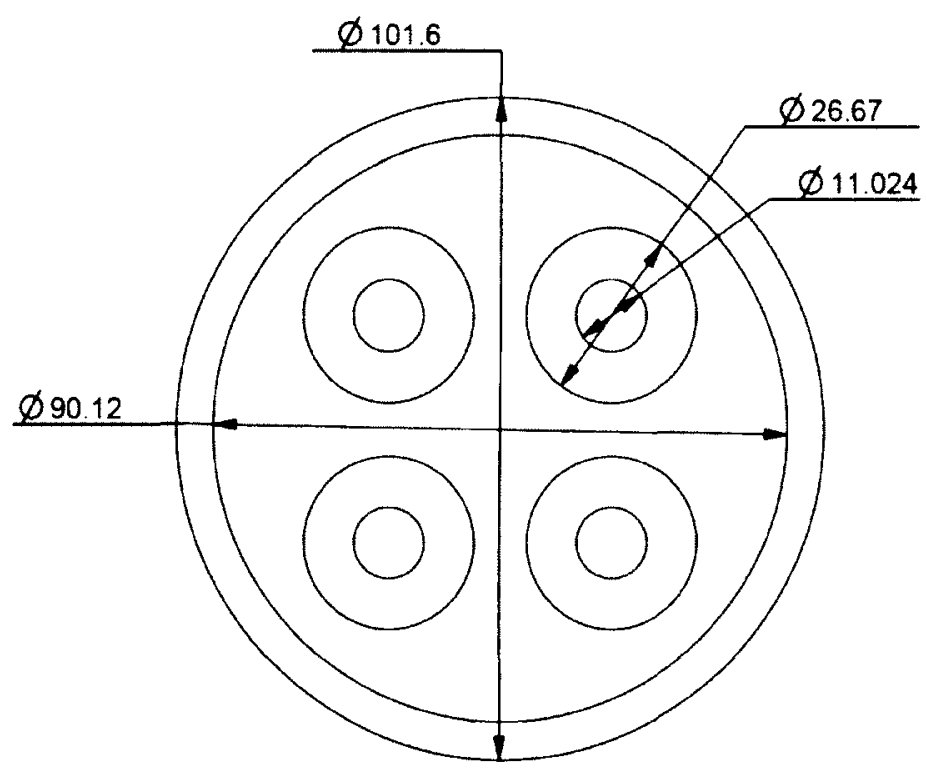

Figure 3.21: Distribution of tubes inside the shell 


\section{Sizing of the Heat Exchanger.}

As mentioned previously, sizing involves determining the needed surface area to meet the heat transfer requirements. In the following, a step-by-step sizing of the double-pipe heat exchanger for the SCW loop is carried out.

The required surface area of the heat exchanger can be calculated using the following equation [28]:

$$
Q=U A \Delta T_{m}
$$

In Equation (3.6), $Q$ is the heat transfer rate, $U$ is the total/overall heat transfer coefficient, $A$ is the required surface area and $\Delta T_{m}$ is the mean temperature difference between the inlet and outlet. The total heat transfer coefficient is given by the following expression [28]:

$$
U=\frac{1}{\frac{r_{0}}{r_{i}} \frac{1}{h_{i}}+\frac{r_{o} \ln \left(\frac{r_{o}}{r_{i}}\right)}{k}+\frac{1}{h_{o}}}
$$

In this equation, $r_{x}(x: i$ or 0$)$ represents the internal and external radii of the tube,

$h_{x}(x: i$ or o $)$ represents the convective heat transfer coefficients of the fluids inside and outside the tube and $k$ is the thermal conductivity of the tube material. The fluid inside the tube is the SCW, and the fluid outside the tube is the cooling fluid consisting of $50 \%$ wt. propylene glycol [32]. 
In order to determine the total heat transfer coefficient, $U$, the heat transfer coefficient of the SCW inside the tube, $h_{i}$, the heat transfer coefficient of the cooling fluid outside the tube, $h_{0}$, and the conductive heat transfer through the tube wall have to be evaluated.

\section{Heat Transfer Coefficient of SCW}

It is evident from Figure 3.19 that the heat transfer coefficient of SCW shows strong dependence on temperature. Between the inlet and outlet temperatures of $600{ }^{\circ} \mathrm{C}$ and $260{ }^{\circ} \mathrm{C}$, respectively, the heat transfer coefficient increases three-fold until the temperature reaches the pseudo-critical point and then drops immediately after. Therefore, in order to simplify the determination of the total heat transfer coefficient, a mean heat transfer coefficient for SCW between the inlet and outlet temperatures is calculated using the following equations:

$$
h_{m}=\frac{1}{\Delta T} \int_{T_{h 1}}^{T_{h 2}} h d T
$$

where,

$$
h=\frac{N u k}{D}
$$


is the local heat transfer coefficient that can be estimated with the nondimensional Nusselt number, $\mathrm{Nu}$, obtained from a correlation for fully developed pipe flows proposed by Dittus-Boetler [36] as follows:

$$
\begin{aligned}
& N u=0.023 \operatorname{Re}^{0.8} \operatorname{Pr}^{n} \\
& n=0.3 \text { for cooling [37] }
\end{aligned}
$$

where, $R e$ is the Reynolds number defined as,

$$
R e=\frac{\rho v D}{\mu}=\frac{4 \dot{m}_{h}}{\mu \pi d_{i}}
$$

and $\operatorname{Pr}$ is the PrandtI number defined as,

$$
\operatorname{Pr}=\frac{\mu C_{p}}{k}
$$

It should be noted that based on these definitions, both $\operatorname{Re}$ and $\operatorname{Pr}$ are dependent on temperature, $T$, and are evaluated at the bulk temperature, $T_{b}$.

Table 3.6 lists the heat transfer coefficient values of SCW as it changes with temperature at $23 \mathrm{MPa}$. The Reynolds number values in Table 3.6 are calculated for a mass flow rate $\left(\dot{m}_{h}\right)$ of $0.126 \mathrm{~kg} / \mathrm{s}$ and a tube internal diameter $\left(d_{i}\right)$ of $27.94 \mathrm{~mm}$. A plot of the heat transfer coefficient values versus temperature is given in Figure 3.19. 
In order to find the mean heat transfer coefficient, $h_{m}$, the area under the curve in Figure 3.19 needs to be calculated. For simplification, the area under the curve is estimated by dividing the curve at 50 evenly spaced points, over the temperature range of $260^{\circ} \mathrm{C}$ to $600^{\circ} \mathrm{C}$, and the arithmetic average of the values is taken. Attempts to establish the "grids independent" solution to the estimation of the area under the curve, by using increasingly smaller intervals, resulted in negligible improvement to the value of the mean heat transfer coefficient when compared to the uncertainty [5] involved in the use of the Dittus-Boetler equation to estimate the heat transfer coefficient of SCW. The mean heat transfer coefficient $h_{m}=h_{i}$ is found to be $2.3 \mathrm{~kW} / \mathrm{m}^{2} \mathrm{~K}$.

Table 3.6: Heat transfer coefficient values of SCW at $23 \mathrm{MPa}, 0.126 \mathrm{~kg} / \mathrm{s}$ flow rate and $27.94 \mathrm{~mm}$ tube diameter

\begin{tabular}{|c|c|c|c|c|c|c|}
\hline $\mathrm{T}\left[{ }^{\circ} \mathrm{C}\right]$ & $\mu[\mathrm{Pa} .5]$ & $\begin{array}{c}k \\
{[\mathrm{~W} / \mathrm{mK}]}\end{array}$ & $\operatorname{Pr}$ & $\operatorname{Re}$ & $\mathbf{N u}$ & $\begin{array}{c}\mathbf{h} \\
{\left[\mathbf{W} / \mathbf{m}^{2} \mathrm{~K}\right]}\end{array}$ \\
\hline 200 & $1.40 \mathrm{E}-04$ & 0.682 & 0.898 & $4.12 \mathrm{E}+04$ & 109.5 & $2.67 \mathrm{E}+04$ \\
\hline 250 & $1.11 \mathrm{E}-04$ & 0.644 & 0.804 & $5.17 \mathrm{E}+04$ & 127.0 & $2.93 \mathrm{E}+04$ \\
\hline 300 & $9.10 \mathrm{E}-05$ & 0.577 & 0.826 & $6.31 \mathrm{E}+04$ & 150.2 & $3.10 \mathrm{E}+04$ \\
\hline 350 & $7.15 \mathrm{E}-05$ & 0.474 & 1.104 & $8.03 \mathrm{E}+04$ & 198.8 & $3.38 \mathrm{E}+04$ \\
\hline 370 & $5.91 \mathrm{E}-05$ & 0.416 & 1.959 & $9.72 \mathrm{E}+04$ & 275.2 & $4.10 \mathrm{E}+04$ \\
\hline 390 & $2.79 \mathrm{E}-05$ & 0.160 & 2.341 & $2.06 \mathrm{E}+05$ & 528.6 & $3.04 \mathrm{E}+04$ \\
\hline 410 & $2.74 \mathrm{E}-05$ & 0.121 & 1.656 & $2.09 \mathrm{E}+05$ & 483.4 & $2.10 \mathrm{E}+04$ \\
\hline 430 & $2.78 \mathrm{E}-05$ & 0.107 & 1.425 & $2.07 \mathrm{E}+05$ & 456.9 & $1.76 \mathrm{E}+04$ \\
\hline 450 & $2.84 \mathrm{E}-05$ & 0.101 & 1.297 & $2.02 \mathrm{E}+05$ & 436.4 & $1.57 \mathrm{E}+04$ \\
\hline 470 & $2.91 \mathrm{E}-05$ & 0.097 & 1.212 & $1.97 \mathrm{E}+05$ & 419.2 & $1.46 \mathrm{E}+04$ \\
\hline 500 & $3.03 \mathrm{E}-05$ & 0.096 & 1.126 & $1.90 \mathrm{E}+05$ & 397.5 & $1.36 \mathrm{E}+04$ \\
\hline 550 & $3.23 \mathrm{E}-05$ & 0.097 & 1.034 & $1.78 \mathrm{E}+05$ & 368.4 & $1.28 \mathrm{E}+04$ \\
\hline 600 & $3.43 \mathrm{E}-05$ & 0.101 & 0.976 & $1.68 \mathrm{E}+05$ & 345.2 & $1.25 \mathrm{E}+04$ \\
\hline 650 & $3.62 \mathrm{E}-05$ & 0.107 & 0.937 & $1.59 \mathrm{E}+05$ & 326.2 & $1.24 \mathrm{E}+04$ \\
\hline
\end{tabular}




\section{Heat Transfer Coefficient of Cooling Fluid}

The cooling fluid consists of $50 \%(\mathrm{w} / \mathrm{w})$ propylene glycol and water [32]. Table 3.7 lists properties of propylene glycol and water under atmospheric pressure and room temperature. Although it is possible to obtain a rough estimate of the effective properties of binary mixtures by calculating the weighted averages of the properties of the constituents, in some cases the estimates are completely unrepresentative of the real mixture properties, in particular of the properties where the constituents interact with each other at the molecular level [33][34][35].

An effort is made to use more appropriate correlations from the literature, obtained either theoretically or empirically, to determine the effective properties of the cooling fluid. Similar to SCW, the heat transfer coefficient of the cooling fluid can be determined using the Dittus-Boelter Equation (3.10). However, for heating of the fluid, the exponent $n$ should be 0.4 [37].

Table 3.7: Properties of propylene glycol and water at 1 bar and $25^{\circ} \mathrm{C}$

\begin{tabular}{|l|c|l|c|}
\hline \multicolumn{2}{|c|}{ Propylene Glycol [38] } & \multicolumn{2}{c|}{ Water [13] } \\
\hline Density $(\rho)$ & $1033 \mathrm{~kg} / \mathrm{m}^{3}$ & Density $(\rho)$ & $998 \mathrm{~kg} / \mathrm{m}^{3}$ \\
\hline Heat capacity $\left(C_{P}\right)$ & $2.51 \frac{\mathrm{kJ}}{\mathrm{kg} \cdot \mathrm{K}}$ & Heat capacity $\left(C_{P}\right)$ & $4.183 \frac{\mathrm{kJ}}{\mathrm{kg} \cdot \mathrm{K}}$ \\
\hline Viscosity $(\mu)$ & $0.0486 \mathrm{~Pa} \cdot \mathrm{s}$ & Viscosity $(\mu)$ & $0.8908 \mathrm{mPa} \cdot \mathrm{s}$ \\
\hline $\begin{array}{l}\text { Thermal } \\
\text { conductivity }(k)\end{array}$ & $0.2061 \frac{\mathrm{W}}{\mathrm{m} \cdot \mathrm{K}}$ & $\begin{array}{l}\text { Thermal } \\
\text { Conductivity }(k)\end{array}$ & $0.6072 \frac{\mathrm{W}}{\mathrm{m} \cdot \mathrm{K}}$ \\
\hline $\operatorname{Pr}$ & 509.5 & $\operatorname{Pr}$ & 6.1 \\
\hline
\end{tabular}


The properties of aqueous solutions of propylene glycol are described by the following two equations [39]:

$$
\begin{array}{r}
P_{x}=A_{1}+A_{2} \xi+A_{3} \frac{273.15}{T}+A_{4} \xi \frac{273.15}{T}+A_{5}\left(\frac{273.15}{T}\right)^{2} \\
\ln \left(P_{x}\right)=A_{1}+A_{2} \xi+A_{3} \frac{273.15}{T}+A_{4} \xi \frac{273.15}{T}+A_{5}\left(\frac{273.15}{T}\right)^{2}
\end{array}
$$

Equation (3.13) is used in the calculation of density, specific heat capacity, and thermal conductivity, whereas Equation (3.14) is used in the calculation of viscosity and Prandtl number. $P_{x}$ represents the property that needs to be predicted, $A_{i}^{\prime}$ 's are the coefficients specific to each property, $T$ is the temperature of the mixture in Kelvin and $\xi$ is the mass fraction of propylene glycol in the solution. Using these two equations, properties of the cooling fluid mixture are determined and the results are listed in Table 3.8. Since the cooling fluid's temperature rises from $29.5{ }^{\circ} \mathrm{C}$ to $35^{\circ} \mathrm{C}$, its properties slightly vary between the inlet and outlet of the heat exchanger. Therefore, the properties at the inlet and outlet conditions are averaged and the resulting values are used in the subsequent calculations.

The Reynolds number can be determined using Equation (3.11). In order to estimate the Reynolds number, the hydraulic diameter $\left(D_{h}\right)$, mass flow rate $\left(\dot{m}_{c}\right)$ and the viscosity $(\mu)$ of the fluid need to be calculated first. The hydraulic diameter is given by Equation (3.15) [28], where $A$ is the cross sectional area and $P$ is the wetted perimeter. 
Table 3.8: Thermophysical properties of the cooling fluid mixture [39]

\begin{tabular}{|c|c|c|c|c|c|}
\hline Coefficient & $\begin{array}{c}\boldsymbol{\mu} \\
{[\mathrm{Pa} \cdot \mathrm{s}]}\end{array}$ & $\begin{array}{c}\boldsymbol{\rho} \\
{\left[\mathrm{kg} / \mathrm{m}^{3}\right]}\end{array}$ & $\begin{array}{c}\mathrm{C}_{\mathbf{p}} \\
{[\mathrm{kJ} / \mathbf{k g} \cdot \mathrm{K}]}\end{array}$ & $\begin{array}{c}\boldsymbol{k} \\
{[\mathbf{W} / \mathbf{m} \cdot \mathrm{K}]}\end{array}$ & $\operatorname{Pr}$ \\
\hline $\mathrm{A} 1$ & -1.028 & 508.411 & 4.476 & 1.189 & 6.661 \\
\hline $\mathrm{A} 2$ & -10.033 & -182.408 & 0.609 & -1.491 & -6.994 \\
\hline $\mathrm{A} 3$ & -19.935 & 965.765 & -0.715 & -0.697 & -18.551 \\
\hline $\mathrm{A} 4$ & 14.658 & 280.291 & -1.939 & 1.136 & 12.046 \\
\hline $\mathrm{A} 5$ & 14.621 & -472.225 & 0.479 & 0.067 & 14.477 \\
\hline$\xi$ & 0.50 & 0.50 & 0.50 & 0.50 & 0.50 \\
\hline$T_{c 1}\left(29.5^{\circ} \mathrm{C}\right)$ & 298.150 & 302.650 & 302.650 & 302.650 & 302.650 \\
\hline$T_{c 2}\left(35^{\circ} \mathrm{C}\right)$ & 308.150 & 308.150 & 308.150 & 308.150 & 308.150 \\
\hline Result @ $T_{c 1}$ & $4.883 \mathrm{E}-03$ & $1.031 \mathrm{E}+03$ & 3.651 & $3.821 \mathrm{E}-01$ & $3.847 \mathrm{E}+01$ \\
\hline Result @ $T_{c 2}$ & $3.245 \mathrm{E}-03$ & $1.026 \mathrm{E}+03$ & 3.664 & $3.822 \mathrm{E}-01$ & $3.102 \mathrm{E}+01$ \\
\hline Average & $4.06 \mathrm{E}-03$ & $1.03 \mathrm{E}+03$ & 3.66 & $3.82 \mathrm{E}-01$ & $3.48 \mathrm{E}+01$ \\
\hline
\end{tabular}

$$
D_{h}=\frac{4 A}{P}
$$

The calculation of the hydraulic diameter requires the external diameter of the inner pipe and the internal diameter of the outer pipe. The external diameter $\left(d_{o}\right)$ of NPS 1.5 is $48.26 \mathrm{~mm}(1.9 \mathrm{in})$ and the internal diameter $\left(D_{i}\right)$ of the outer pipe, NPS 4 schedule 40 is $102.26 \mathrm{~mm}(4.026 \mathrm{in})$.

Application of Equation (3.15) results in the following hydraulic diameter:

$$
D_{h}=\frac{4\left(\frac{\pi}{4} D_{i}^{2}-\frac{\pi}{4} d_{o}^{2}\right)}{\pi D_{i}+\pi d_{0}}=54 \mathrm{~mm}
$$


The mass flow rate of the cooling fluid can be calculated by using the average specific heat capacity from Table 3.8 and performing an energy balance on the heat transferred from the SCW to the cooling fluid. The value of $Q$ is taken as $300 \mathrm{~kW}$.

$$
\begin{aligned}
& Q=\dot{m} c_{P} \Delta T \\
& \Delta T=T_{c 2}-T_{c 1}=5.5 \mathrm{~K}
\end{aligned}
$$

Therefore, the mass flow rate is calculated as follows:

$$
\dot{m}=\frac{Q}{c_{P} \Delta T}=\frac{300 \mathrm{~kW}}{\left(3.657 \frac{\mathrm{kJ}}{\mathrm{kg} \cdot \mathrm{K}}\right)(5.5 \mathrm{~K})}=14.91 \frac{\mathrm{kg}}{\mathrm{s}}
$$

Now, the Reynolds number for an annulus can be calculated as:

$$
\begin{aligned}
& R e=\frac{4 \dot{m} D_{h}}{\mu \pi\left(D_{i}^{2}-d_{o}^{2}\right)} \\
& =\frac{4.0\left(14.91 \frac{\mathrm{kg}}{\mathrm{s}}\right)(0.054 \mathrm{~m})}{\pi\left(4.064 \times 10^{-3} \mathrm{~Pa} \mathrm{~s}\right)\left(0.102^{2}-0.0483^{2}\right) \mathrm{m}^{2}} \\
& =3.5 \times 10^{4}
\end{aligned}
$$

The Nusselt number can be calculated using Equation (3.10).

$$
N u=0.023 \operatorname{Re}^{0.8} \operatorname{Pr}^{0.4}
$$




$$
\begin{aligned}
& N u=0.023\left(3.5 \times 10^{4}\right)^{0.8}\left(3.48 \times 10^{1}\right)^{0.4} \\
& N u=4.1 \times 10^{2}
\end{aligned}
$$

Therefore, the heat transfer coefficient of the cooling fluid can be calculated using Equation (3.9). The diameter $(D)$ in equation (3.9) should be replaced by the equivalent diameter $\left(D_{e}\right)$ given by equation (3.18) [28]:

$$
\begin{gathered}
D_{e}=\frac{4\left(\frac{\pi D_{i}^{2}}{4}-\frac{\pi d_{o}^{2}}{4}\right)}{\pi d_{o}}=\frac{D_{i}^{2}-d_{o}^{2}}{d_{o}} \\
h_{o}=\frac{\left(4.1 \times 10^{2}\right)\left(3.82 \times 10^{-1} \mathrm{~W} / m K\right.}{0.168 m}=9.2 \times 10^{2} \frac{\mathrm{W}}{\mathrm{m}^{2} \mathrm{~K}}
\end{gathered}
$$

\section{Thermal Conductivity of Pipe Material}

Following the same procedure as for the selection of the piping material for the SCW loop, stainless steel $316 \mathrm{H}$ is selected as the material of the inner pipe. Like most metals, the thermal conductivity of stainless steel $316 \mathrm{H}$ increases with increasing temperature. Table 3.9 lists the thermal conductivity of stainless steel 316 at various temperatures ranging from $50^{\circ} \mathrm{C}$ to $600^{\circ} \mathrm{C}$. These thermal conductivity values, although for nominal stainless steel 316 composition, are applicable to stainless steel grade $316 \mathrm{H}$ [10]. For the purpose of determining the overall heat transfer coefficient $U$, the average of the thermal conductivity values between the temperatures of $200^{\circ} \mathrm{C}$ and $600^{\circ} \mathrm{C}$ is calculated as the value to be used in Equation (3.7). 
Table 3.9: Thermal conductivity of stainless steel 316 [10]

\begin{tabular}{|c|c|}
\hline $\mathbf{T}\left[{ }^{\circ} \mathrm{C}\right]$ & $\boldsymbol{k}\left[\frac{\boldsymbol{W}}{m \boldsymbol{K}}\right]$ \\
\hline 50 & 14.6 \\
\hline 100 & 15.4 \\
\hline 200 & 16.8 \\
\hline 300 & 18.3 \\
\hline 400 & 19.7 \\
\hline 500 & 21.2 \\
\hline 600 & 22.6 \\
\hline 700 & 23.9 \\
\hline
\end{tabular}

\section{Overall Heat Transfer Coefficient}

The overall heat transfer coefficient can now be calculated using Equation (3.7). The radii and the heat transfer coefficients along with the thermal conductivity of the tube/pipe material are substituted from the previously determined values. The overall heat transfer coefficient is based either on the internal or external diameter of the inner tube/pipe. It is industry practice to base the overall heat transfer coefficient of a heat exchanger on the external diameter of the inner pipe [28]. 


$$
\begin{aligned}
& U=\frac{1}{\left(\frac{48.26}{27.94}\right)\left(\frac{1}{2.3 \times 10^{3}}\right)+\frac{0.024 \ln \left(\frac{48.26}{27.94}\right)}{19.7}+\frac{1}{9.24 \times 10^{2}}} \\
& U=4.0 \times 10^{2} \frac{W}{m^{2} K}
\end{aligned}
$$

Mean Temperature Difference (MTD)

Generally, the mean temperature difference $\left(\Delta T_{m}\right)$ between the hot and cold fluids is determined by using the log mean temperature difference (LMTD) method, as given by the following equations [28]:

$$
\begin{aligned}
& L M T D=\frac{\Delta T_{1}-\Delta T_{2}}{\ln \left(\frac{\Delta T_{1}}{\Delta T_{2}}\right)} \\
& \Delta T_{1}=T_{h 1}-T_{c 2} \\
& \Delta T_{2}=T_{h 2}-T_{c 1}
\end{aligned}
$$

In these equations, $T_{h 1}$ and $T_{c 1}$, and $T_{h 2}$ and $T_{c 2}$ represent the inlet and outlet temperatures of the hot and cold fluids, respectively. The LMTD method assumes that the fluids' properties do not vary much as they flow through the heat exchanger. However, as discussed previously, properties of SCW vary extremely nonlinearly throughout the heat exchanger. To account for the nonlinear variation of SCW 
properties a so-called generalized mean temperature difference (GMTD) method [40] is employed.

The GMTD method calculates the mean temperature difference by taking the fluid temperature profile as a function of heat load. The total heat duty is expressed by a sum of $M$ sets of heat segment $Q_{s}(=Q / M)$, each of which is sequentially numbered from the hot-side fluid entry. Enthalpies and temperatures at the node on the right edge of the segment are obtained from the heat balance and thermodynamic state equations, and the method is continued until the heat load reaches the heat duty given. At each node, the temperature difference $\left(\Delta T_{j}\right)$ between the hot-side fluid and cold-side fluid is calculated. The GMTD $(\Delta \bar{T})$ is calculated using the nodal temperature differences as follows:

$$
\Delta \bar{T}=\frac{M}{\sum_{j=1}^{M} \frac{2}{\Delta T_{j}+\Delta T_{j+1}}}
$$

The total heat duty of $300 \mathrm{~kW}$ is divided into 1000 segments for the purpose of calculating the mean temperature difference. The GMTD $(\Delta \bar{T})$ is determined to be $353^{\circ} \mathrm{C}$. This value is approximately $5.5 \%$ smaller than the value calculated using the LMTD method. Using the LMTD method would have underestimated the required heat transfer surface area by $5.5 \%$. 


\section{Calculation of the Required Surface Area and Tube Length}

The required heat transfer surface is given by Equation (3.6):

$$
\begin{aligned}
& 300 \times 10^{3} W=A\left(4.0 \times 10^{2} \frac{W}{m^{2} K}\right)(353 K) \\
& A \cong 2.1 \mathrm{~m}^{2}
\end{aligned}
$$

This required heat transfer surface area is very close to what has been determined by leading heat exchanger manufacturers based on their quotations for the heat exchanger (Appendix C). The result of the required surface area can be used to determine the required length $(L)$ of the tube/pipe. The outer surface area of the inner pipe must equal the required heat transfer surface area calculated above.

$$
\begin{aligned}
& A=\pi d_{0} L \\
& L=\frac{2.1 \mathrm{~m}^{2}}{\pi \cdot 0.048 \mathrm{~m}} \cong 14 \mathrm{~m}
\end{aligned}
$$

\section{Pressure Drop}

The total pressure drop on the SCW side $\left(\Delta p_{h}\right)$ can be calculated as the sum of the frictional pressure drop in the straight pipe $\left(\Delta p_{f}\right)$, frictional pressure drop in bends $\left(\Delta p_{b}\right)$, and pressure drop due to momentum change as a result of expansion and/or contraction of the fluid $\left(\Delta p_{m}\right)$. 


$$
\Delta p_{h}=\sum \Delta p_{f}+\sum \Delta p_{b}+\sum \Delta p_{m}
$$

The frictional pressure drop in the straight pipe is defined as follows [3]:

$$
\Delta p_{f}=f \frac{L}{D} \frac{\rho v^{2}}{2}=f \frac{L}{D} \frac{\dot{m}_{f l u x}^{2}}{2 \rho}
$$

where $f$ is the frictional coefficient and for SCW flowing in smooth circular tubes is given as follows [3]:

$$
f=\left(1.82 \log _{10} R e_{b}-1.64\right)^{-2}\left(\frac{P r_{w}}{P r_{b}}\right)^{\frac{1}{3}}
$$

In Equation (3.25), the Reynolds number is evaluated at bulk temperature and the Prandtl number is evaluated both at bulk $\left(P r_{b}\right)$ and wall $\left(P r_{w}\right)$ temperatures. The equation is applicable within the range of $\operatorname{Re}>4000$. Based on Equation (3.25), the friction factor varies throughout the heat exchanger. Similar to the heat transfer coefficient, an average frictional pressure drop is calculated and for the $14 \mathrm{~m}$ hot-side pipe, it is estimated at $1.2 \mathrm{kPa}$.

Currently, there are no correlations for SCW pressure drop in bends. As a first estimate, the equivalent length method used for the determination of isothermal turbulent flow pressure drop in smooth pipe bends can be used. It is expected that the heat exchanger will have two large radius $(R=10 D) 180^{\circ}$ bends to accommodate it in the lab. The 
estimated equivalent length in pipe diameters $\left(L_{e} / D\right)$ for a large radius $180^{\circ}$ bend is 50 [28]. The pressure drop in the bends, using the equivalent length and the previously calculated mean friction factor, is calculated to be $0.23 \mathrm{kPa}$.

The momentum change pressure drop due to the expansion and contraction of the SCW is defined as [3]:

$$
\Delta p_{m}=\rho_{\text {out }} v_{\text {out }}^{2}-\rho_{\text {in }} v_{\text {in }}^{2}=\dot{m}_{\text {flux }}^{2}\left(\frac{1}{\rho_{\text {out }}}-\frac{1}{\rho_{\text {in }}}\right)
$$

Using Equations (3.26), the hot-side pressure drop due to momentum change in the heat exchanger is determined to be $0.60 \mathrm{kPa}$.

Therefore, the total pressure drop in the hot-side fluid is:

$$
\Delta p_{h}=1.2 \mathrm{kPa}+0.23 \mathrm{kPa}+0.60 \mathrm{kPa}=2.0 \mathrm{kPa}
$$

The pressure drop for the cold-side fluid $\left(\Delta p_{c}\right)$ is much more easily calculated. The frictional pressure drop can be calculated using Equation (3.24), however the diameter $(D)$ needs to be replaced by the hydraulic diameter $\left(D_{h}\right)$. The friction factor is calculated using Equation (3.25) by setting the PrandtI number ratio to unity because the properties of cold-side fluid are assumed to be constant. Similar to the hot-side fluid, there are two $180^{\circ}$ turns in the cold-side fluid path and the pressure drop in the turns is estimated by the equivalent length of four $90^{\circ}$ sharp elbows. The equivalent length in pipe diameters $\left(L_{e} / D\right)$ for a sharp $90^{\circ}$ elbow is 60 [28]. There is no substantial 
phase change in the cold-side fluid and hence Equation (3.26) is not applicable. Therefore, the total cold-side fluid pressure drop $\left(\Delta p_{c}\right)$ is determined to be $30 \mathrm{kPa}$.

Similarly, calculations are performed for the other extreme operating condition of $27 \mathrm{MPa}$ and $0.403 \mathrm{~kg} / \mathrm{s}$, and for the hairpin design. It is found that the maximum heat transfer area is required for the $23 \mathrm{MPa}$ and $0.126 \mathrm{~kg} / \mathrm{s}$ operating condition. The following table summarizes the results of the calculations for the hairpin heat exchanger design for $23 \mathrm{MPa}$ and $0.126 \mathrm{~kg} / \mathrm{s}$ operating condition.

Table 3.10: Summary of sizing results for the hairpin heat exchanger desgin (23 MPa and $0.126 \mathrm{~kg} / \mathrm{s}$ flow rate)

$$
\begin{aligned}
& h_{i}=4.0 \frac{\mathrm{kW}}{\mathrm{m}^{2} \mathrm{~K}} \\
& h_{o}=2.5 \frac{\mathrm{kW}}{\mathrm{m}^{2} \mathrm{~K}} \\
& U=6.2 \times 10^{2} \frac{\mathrm{W}}{\mathrm{m}^{2} \mathrm{~K}} \\
& \Delta \overline{\mathrm{T}}=353^{\circ} \mathrm{C} \\
& A \cong 1.4 \mathrm{~m}^{2} \\
& L=4 \times 4.1 \mathrm{~m}
\end{aligned}
$$




$$
\begin{aligned}
& \Delta p_{h}=12 \mathrm{kPa} \\
& \Delta p_{c}=111 \mathrm{kPa}
\end{aligned}
$$

\section{Uncertainty in the Prediction of the Required Heat Transfer Area}

It is important to note that the required heat transfer surface areas are calculated based on the values obtained for the heat transfer coefficients using the Dittus-Boelter equation. It has been shown that the Dittus-Boetler equation underpredicts the heat transfer coefficient of SCW by a factor of as low as 0.5 at low heat fluxes and overpredicts the heat transfer coefficient of SCW by a factor of as high as 2 at high heat fluxes near the pseudo-critical regions, under heating conditions [41]. It is not clear whether a similar phenomenon is present under cooling conditions as is the case in the current sizing application.

Despite the inability of the Dittus-Boetler equation to capture deteriorated or enhanced heat transfer occurring in the pseudo-critical region, the heat transfer coefficient values calculated using the Dittus-Boetler equation have been shown to have good agreement ( $80 \%)$ with experimental results with a $\pm 25 \%$ accuracy [5]. When reducing the calculated mean heat transfer coefficient values of the SCW by $25 \%$ for each combination, the required heat transfer surface area increased by up to $12 \%$. Therefore, it is recommended that the heat exchanger for the SCW loop application should be oversized by this value. 


\subsection{Mechanical Design of the Heat Exchanger}

Mechanical design involves the design of pressure-retaining and non-pressure retaining parts to withstand the design loads and the deterioration in service so that the equipment will function satisfactorily and reliably throughout its life cycle [30]. Mechanical design of heat exchangers is carried out in accordance with established standards and codes. For mechanical design of tubular heat exchangers, the most widely used standard is TEMA Standards (Tubular Exchangers Manufacturers' Association) and the most widely used design code is ASME Boiler and Pressure Vessel Code Section VIII, Division 1.

A number of components need to be sized, which are pointed out in Figure 3.22. A large body of work was carried out to select a design pressure and a design temperature, select the proper type and size the welds based on the location of the weld on the heat exchanger, determine the required tubesheet thickness to withstand the exerted high pressure and the bending stresses due to the tubes, determine the dimensions of the flange according to ASME Section VIII, Division 1 rules, size and select bolts and nuts, select type and size of gasket, calculate the wall thickness of the inner tube(s) under internal pressure, determine the right bending radius for inner tube(s), etc. However, due to constraints on the size of the thesis and to keep the thesis focused on the design of the loops, only the sizing of the internal tube(s) under internal pressure is briefly discussed. 


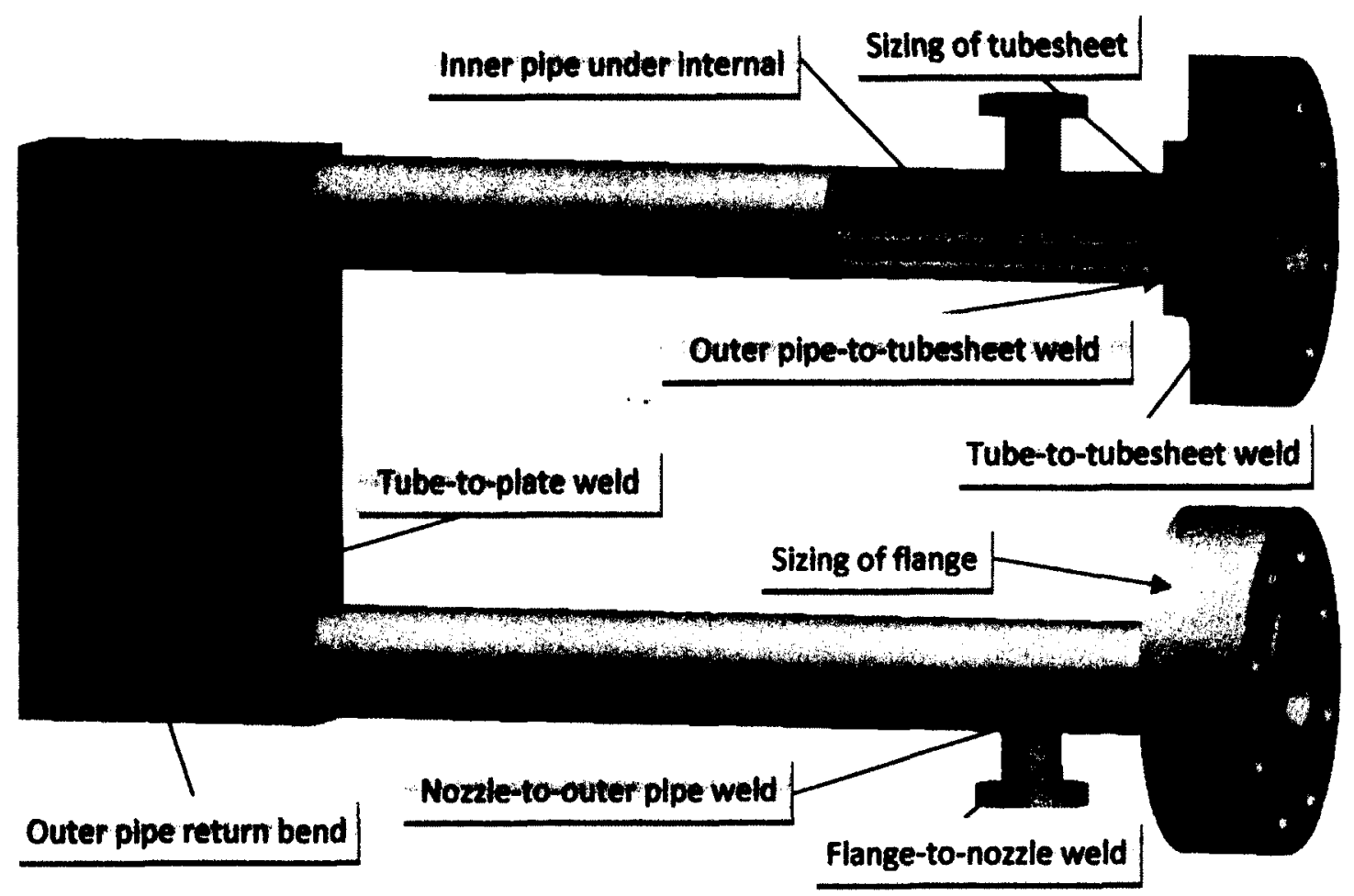

Figure 3.22: List of components that need to be sized

Inner Tube(s) Under Internal Pressure

Design of the inner tube is carried out as per Mandatory Appendix 1 of the ASME BPV Code Section VIII, Division 1 [42]. Based on ASME Code, the thickness of the inner pipe under internal pressure must not be less than that calculated by the following formulae:

$$
\text { For } \begin{aligned}
P>0.385 S_{f} E: \quad t & =R\left(Z^{1 / 2}-1\right) \\
Z & =\frac{S_{f} E+P}{S_{f} E-P}
\end{aligned}
$$


In the above equations, $P$ is the design pressure, $R$ is the internal radius of the pipe, $S_{f}$ is the maximum allowable stress at the design temperature from ASME BPV Code Section II Part D, E is the weld joint efficiency depending on the weld joint type and the level of radiographic examination, and $t$ is the minimum required thickness of the inner pipe at the design temperature and pressure.

Based on a design pressure of $28.35 \mathrm{MPa}$ ( $5 \%$ higher than the maximum operating pressure of $27 \mathrm{MPa})$ and design temperature of $625^{\circ} \mathrm{C}\left(25^{\circ} \mathrm{C}\right.$ higher than the maximum operating temperature of $600^{\circ} \mathrm{C}$ ), the minimum required wall thickness of the inner pipe for the double-pipe heat exchanger is calculated to be $8.2 \mathrm{~mm}(0.32 \mathrm{in})$ and that for the hairpin heat exchanger is calculated to be $3.2 \mathrm{~mm}(0.13 \mathrm{in})$. Detailed calculations are presented in Appendix D.

The wall thickness for NPS 1.5 schedule XXS is $10.2 \mathrm{~mm}(0.400 \mathrm{in})$ and the wall thickness for NPS 3/4 schedule XXS is $7.8 \mathrm{~mm}$ (0.308 in) [43]. Therefore, as discussed previously, the selected pipe sizes and wall thicknesses are appropriate for this application.

\subsection{Heat Exchanger Selection Conclusion}

As mentioned at the beginning of this subsection, it was decided to outsource the design and manufacturing of the heat exchanger. A leading heat exchanger company, Advanced Industrial Components, Inc. (AIC), is contracted to manufacture the heat exchanger. A shell-and-tube heat exchanger rated for a maximum heat exchange capability of $300 \mathrm{~kW}$ with a $1.1 \mathrm{~m}^{2}$ heat transfer area is proposed by AIC for use on the 
Carleton SCW loop. The heat exchanger is made of a combination of stainless steel and Incoloy $800 \mathrm{H}$ rated for operation at $30 \mathrm{MPa}$ and $630^{\circ} \mathrm{C}$. The heat exchanger is interfaced with the loop piping via 1.5 in $\mathrm{Grayloc}^{\mathrm{TM}}$ connectors.

\subsubsection{Temperature Sensor}

As discussed in the introduction to this section, temperature sensors are required to monitor the health of the SCW loop for any unexpected temperature excursions, and for the purposes of studying the heat-transfer process in the test section. The selected temperature sensors must have measurement ranges comparable to those expected on the loop and they must be able to withstand the operating environments at their installed locations. With these criteria in mind, a wide variety of temperature sensors are researched.

Some of the most commonly used temperature sensors include non-electric sensors, such as filled system thermometers and bimetallic thermometers, and electronic sensors, like thermocouples, resistance temperature detectors (RTD's), radiation pyrometers and ultrasonic thermometers [26].

Nonelectric temperature sensors are mostly of filled system construction involving glass tubes and glass bulbs that cannot be directly used under high pressures [26]. On the other hand, bimetallic thermometers take advantage of the difference in the thermal expansion coefficients of dissimilar metals, where a change in temperature causes the movement of a coil, which in turn moves a pointer over a dial scale thus indicating the 
temperature [26]. Therefore, the filled system thermometers, as well as the bimetallic thermometer due to its working mechanism, cannot be used to measure the bulk temperature of the fluid by crossing the pressure boundary and being in direct contact with the fluid. The use of nonelectric thermometers is also limited for the temperature measurement of the loop outside the pressure boundary. In the design of the nonelectric temperature sensors, the measured temperature is interpreted from the physical changes in the properties of the temperature sensor fill fluids or elements in the form of mechanical movements of indicators. For purposes of data acquisition in the current experimental setup, the physical changes of the fill fluids and sensor elements have to be translated to electrical signals, which create a secondary potential source of error. As a result, nonelectric temperature sensors are deemed unsuitable for the present application.

The electronic temperature sensors mentioned previously can be used to measure the temperature of the fluid or the wall temperature of the piping, depending on the type of the temperature sensor. For example, radiation pyrometry can be used to measure the wall temperature of the piping at select locations, where no piping insulation is present. However, it cannot be used to measure the fluid bulk temperature unless a window through the pressure boundary allows for direct line-of-sight access to the fluid. Acoustic thermometers that use the fluid as the sound conductor result in average temperature measurements, which might be suitable for SCW loop health monitoring purposes. Acoustic thermometers that use an immersable rod to conduct the sound 
waves have a more precise local temperature measurement; nonetheless the results are affected by temperature variations along the length of the rod. Furthermore, they possess a relatively low accuracy and are quite expensive compared to other temperature measurement systems [26]. RTDs are the most accurate of all temperature sensors [26]. Only platinum RTD can cover the entire temperature range $\left(0-600{ }^{\circ} \mathrm{C}\right)$ encountered on the SCW loop. Although accurate, RTDs have a slower response time compared to thermocouples because of their larger size. They also have a higher cost compared to thermocouples and are rather fragile, which makes their use at locations subjected to a lot of mechanical stresses, such as tension, twisting and vibration unsuitable. On the other hand, thermocouples, although not as accurate as RTDs, cover a wide temperature range with reasonable error limits. They are quite rugged with relatively fast response time. Both RTDs and thermocouples are prone to errors associated with EMI and RFI, whereas RTDs suffer from added error associated with selfheating [26].

Therefore, based on the above discussion, thermocouples are selected as the suitable temperature sensor for the SCW loop application. The following sections discuss the selection of the right type(s) of thermocouples.

\subsection{Thermocouple Type and Size Selection}

A thermocouple is constructed of two dissimilar metals joined at one end to make a measuring junction normally referred to as the hot junction [26]. The free ends of the 
two wires are connected to a measuring instrument forming a closed electrical loop through which current can flow. The wire junction inside the measuring instrument is referred to as the cold junction [26]. This configuration is schematically shown in Figure 3.23 .

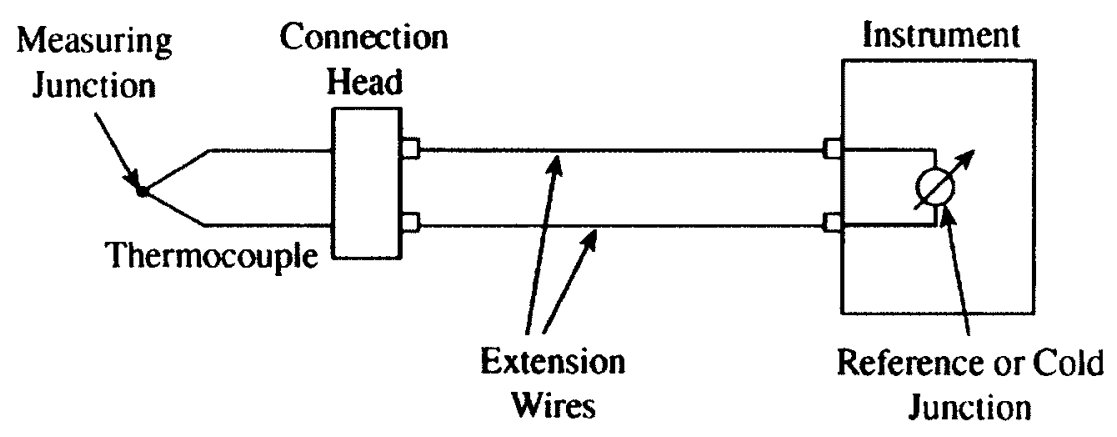

Figure 3.23: Thermocouple terminology [26]

The amount of current generated is dependent on the temperature difference between the hot and cold junctions, and the combination of the dissimilar metals. Heating the measuring junction of the thermocouple produces a voltage or EMF which is greater than the voltage across the cold junction. The difference between the two voltages can be measured with the help of a voltmeter.

There are a number of thermocouple types based on the combination of dissimilar metals. Each particular combination affects a thermocouple's properties, such as temperature range, maximum application temperature, stability, repeatability, accuracy, application environment and cost [26]. Standard thermocouple types and temperature ranges along with accuracies are given in Table 3.11 and Figure 3.24 shows 
a graph of voltage output as a function of temperature also known as the Seebeck coefficient for most commonly used commercially available thermocouple types.

Table 3.11: Standard thermocouple types and tolerances [44]

\begin{tabular}{cccc}
\hline $\begin{array}{c}\text { Thermocouple } \\
\text { code }\end{array}$ & Material Combination & Range & $\begin{array}{c}\text { Special Limits } \\
\text { Accuracy }\end{array}$ \\
\hline $\mathrm{J}$ & $\mathrm{Fe}$ and $\mathrm{Cu}-\mathrm{Ni}$ & $>0$ to $750^{\circ} \mathrm{C}$ & $1.1^{\circ} \mathrm{C}$ or $0.4 \%$ \\
$\mathrm{~K}$ & $\mathrm{Ni}-\mathrm{Cr}$ and $\mathrm{Ni}-\mathrm{Al}$ & $>0$ to $1250^{\circ} \mathrm{C}$ & $1.1^{\circ} \mathrm{C}$ or $0.4 \%$ \\
$\mathrm{~T}$ & $\mathrm{Cu}$ and $\mathrm{Cu}-\mathrm{Ni}$ & $>0$ to $350^{\circ} \mathrm{C}$ & $0.5^{\circ} \mathrm{C}$ or $0.4 \%$ \\
$\mathrm{E}$ & $\mathrm{Ni}-\mathrm{Cr}$ and $\mathrm{Cu}-\mathrm{Ni}$ & $>0$ to $900^{\circ} \mathrm{C}$ & $1.0^{\circ} \mathrm{C}$ or $0.4 \%$ \\
$\mathrm{~N}$ & $\mathrm{Ni}-\mathrm{Cr}-\mathrm{Si}$ and $\mathrm{Ni}-\mathrm{Si}-\mathrm{Mg}$ & $>0$ to $1300^{\circ} \mathrm{C}$ & $1.1^{\circ} \mathrm{C}$ or $0.4 \%$ \\
$\mathrm{R}, \mathrm{S}$ & $\mathrm{Pt}-\mathrm{Rh}$ and $\mathrm{Pt}$ & $>0$ to $1400^{\circ} \mathrm{C}$ & $0.6^{\circ} \mathrm{C}$ or $0.1 \%$ \\
$\mathrm{~B}$ & $\mathrm{Pt}-30 \% \mathrm{Rh}$ and $\mathrm{Pt}-6 \% \mathrm{Rh}$ & $>0$ to $1700^{\circ} \mathrm{C}$ & Not Established \\
\hline
\end{tabular}

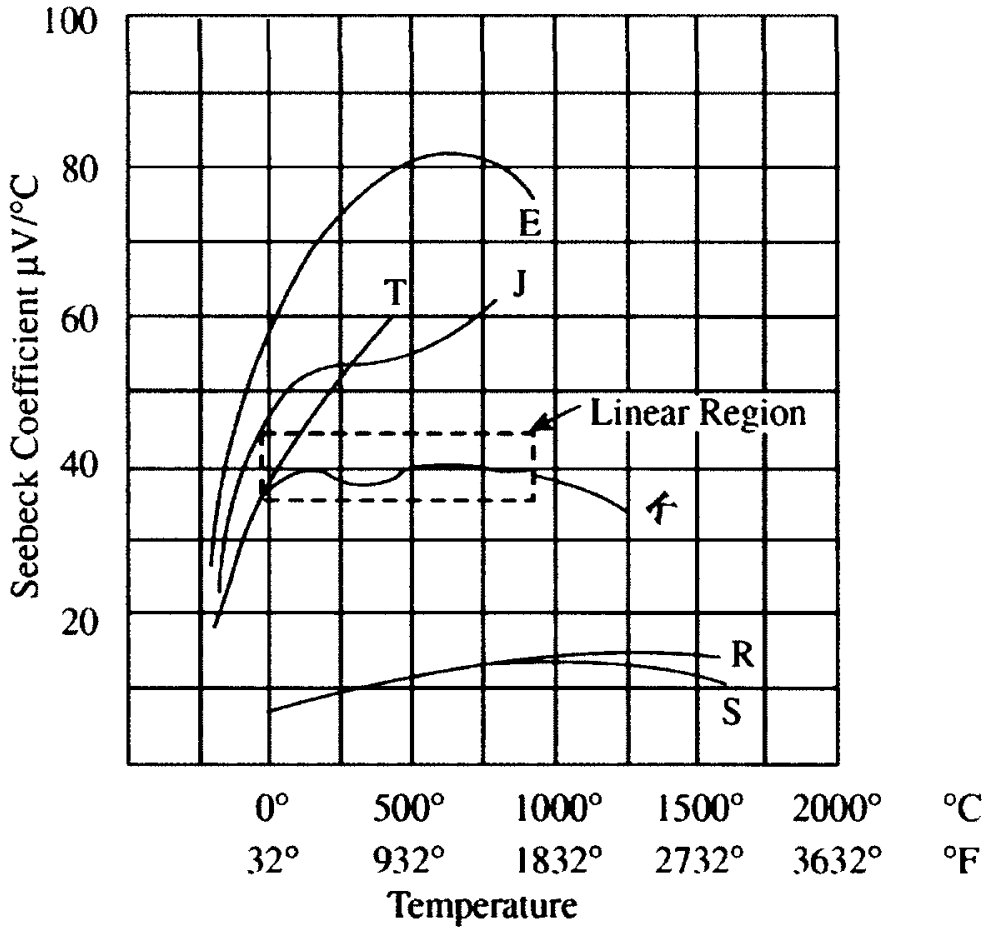

Figure 3.24: The Seebeck coefficient as a function of temperature [26] 


\section{Measuring Junction Designs}

In order to protect the thermocouple wire from the aggressive environments in which it is used, the wire is usually covered by a thermal insulation and a sheath for mechanical protection. The purpose of this design is to expose only the measuring junction of the thermocouple to the temperature of the process. There are three different thermocouple measuring junction designs (exposed, ungrounded and grounded) to achieve this, as shown in Figure 3.25.

The exposed thermocouple junction design has the best response time, but it cannot be used in environments that are corrosive to the thermocouple wires.

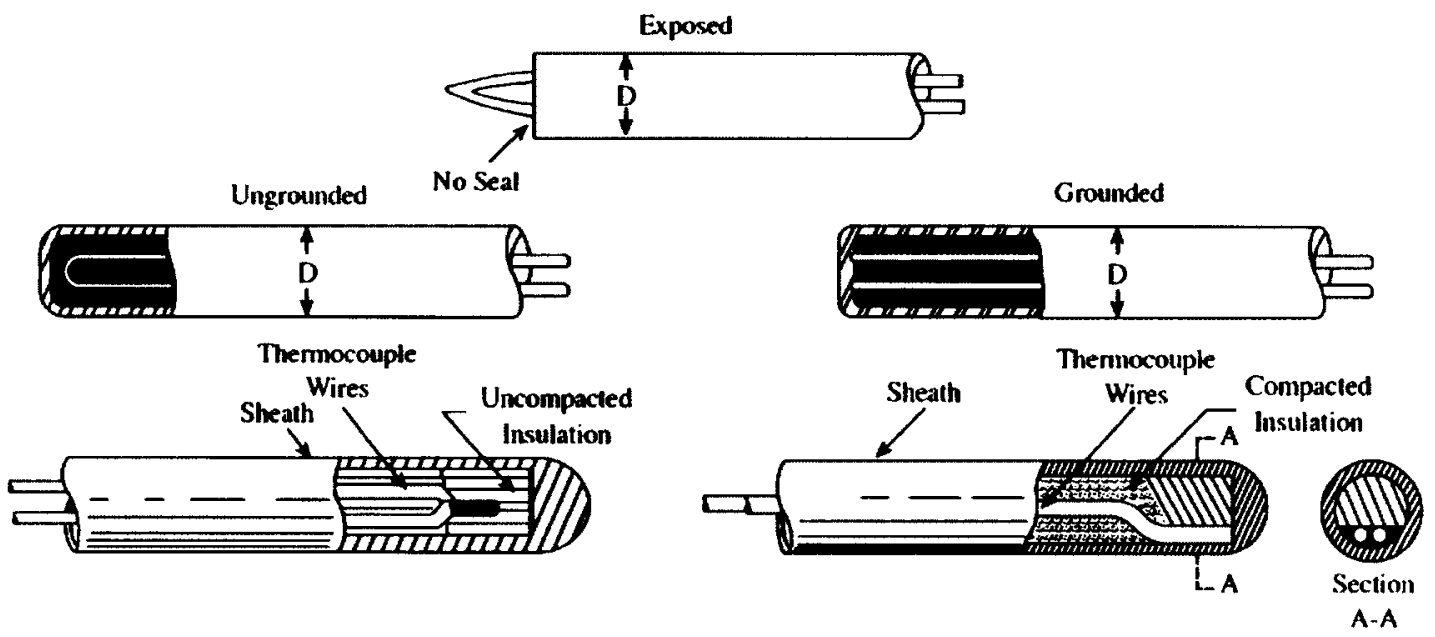

Figure 3.25: Thermocouple measuring junction designs [26]

In ungrounded-junction thermocouples, the thermocouple junction is protected by a thermally conductive sheath. Mineral insulation electrically isolates the protective sheath from the thermocouple junction and wires. The ungrounded junction design has 
a relatively long response time, but it is particularly useful in applications where high levels of electrical noise are present.

The grounded-junction design is different from the ungrounded-junction in that the thermocouple junction is electrically connected to the protective sheath. Grounded thermocouples possess faster response time compared to the ungrounded thermocouples due to the direct contact between the thermally conductive protective sheath and the thermocouple junction. A disadvantage of grounded-junction thermocouples is the susceptibility to ground loop problems, which are quite difficult to solve in thermocouples, due to low voltages.

\section{Upper Temperature Limits}

Although thermocouples may not be visibly affected by an environment, the EMF produced by the thermocouple might be substantially degraded [45]. Slight modifications to the dissimilar wires that make up the thermocouple can change the EMF dramatically. The properties of dissimilar metals can be degraded by use for a long period of time, at extreme temperatures and in adverse environments [45]. This degradation manifests itself as instability or drift in the thermocouple output. Although the absolute upper temperature range of thermocouples is determined by the melting points of the dissimilar metal wires, there are a multitude of application limits, below this value, at which stability of thermocouples might be substantially reduced [45]. 
Table 3.12: Upper temperature limit vs. wire diameter [44]

\begin{tabular}{|c|c|c|c|c|c|c|c|}
\hline Diameter (mm) & 0.13 & 0.25 & 0.33 & 0.51 & 0.81 & 1.6 & 3.3 \\
\hline Type & \multicolumn{7}{|c|}{ Temperature Limit $\left({ }^{\circ} \mathrm{C}\right)$} \\
\hline J & 315 & 320 & 370 & 370 & 480 & 590 & 760 \\
\hline $\mathrm{K}$ & 590 & 760 & 870 & 870 & 980 & 1090 & 1260 \\
\hline $\mathrm{E}$ & 320 & 370 & 430 & 430 & 540 & 650 & 870 \\
\hline$T$ & - & 150 & 200 & 200 & 260 & 370 & 370 \\
\hline $\mathrm{N}$ & - & 870 & 980 & 980 & 980 & 1090 & 1260 \\
\hline$R X / S X$ & - & 150 & 200 & 200 & 200 & 200 & 200 \\
\hline
\end{tabular}

The rate at which a thermocouple degrades is dependent on the cross-section of the thermocouple wires. Thermocouples of smaller cross-section degrade more quickly compared to the ones with larger cross-sections. Omega, a leading thermocouple manufacturer, lists upper temperature limits both based on the bare thermocouple wire diameter (Table 3.12) and the thermocouple sheath diameter (Table 3.13).

Table 3.13: Upper temperature limit vs. sheath diameter [44]

\begin{tabular}{|c|c|c|c|c|c|c|c|c|}
\hline & $0.020^{\prime \prime}$ & $0.032^{\prime \prime}$ & $0.040^{\prime \prime}$ & $0.062^{\prime \prime}$ & $0.093^{\prime \prime}$ & $0.125^{\prime \prime}$ & $0.188^{\prime \prime}$ & $0.250^{\prime \prime}$ \\
\hline Diar & $0.5 \mathrm{~mm}$ & $0.8 \mathrm{~mm}$ & $1.0 \mathrm{~mm}$ & $1.6 \mathrm{~mm}$ & $2.4 \mathrm{~mm}$ & $3.2 \mathrm{~mm}$ & $4.8 \mathrm{~mm}$ & $6.3 \mathrm{~mm}$ \\
\hline
\end{tabular}

\begin{tabular}{ccccccccc} 
Type & \multicolumn{7}{c}{ Temperature Limit $\left({ }^{\circ} \mathrm{C}\right)$} \\
\hline J & 260 & 260 & 260 & 440 & 480 & 520 & 620 & 720 \\
K \& N & 700 & 700 & 700 & 920 & 1000 & 1070 & 1150 & 1150 \\
E & 300 & 300 & 300 & 510 & 580 & 650 & 730 & 820 \\
T & 260 & 260 & 260 & 260 & 260 & 315 & 370 & 370 \\
\hline
\end{tabular}




\section{Thermocouple Installation}

When installing thermocouples, it is important that the thermocouple wires are not subjected to mechanical strain and excessive vibrations. Such stresses result in inhomogeneity of thermocouple wires, which manifests itself as drift in thermocouple measurements [26]. In applications where the thermocouple is constrained to the target object/surface by welding, it is necessary to account for thermal expansion and remedy it by providing expansion loops, as shown in Figure 3.26 .

Like most electronic transducers, thermocouples are prone to uncertainties resulting from electromagnetic (EMI) and radio frequency (RFI) interferences, and/or from capacitive secondary grounds [26]. Errors due to stray currents resulting from EMI and RFI enter both thermocouple wires and are easier to remove compared to ground loop errors, which enter only one of the thermocouple lead wires.

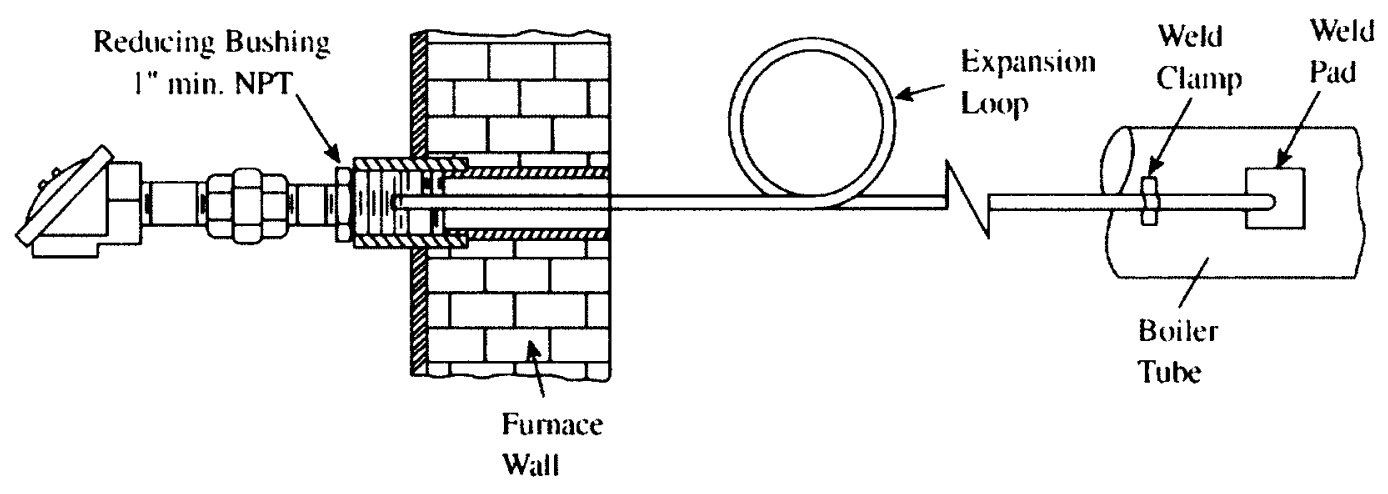

Figure 3.26: Expansion loop for thermal expansion in furnace applications [26]

Errors from EMI and RFI result when thermocouple lead wires are situated in the proximity of electrical wiring, pumps, radio transmitters, etc. One of the simplest 
methods to eliminate errors associated with EMI and RFI noise is to use twisted wire leads. Other means of noise reduction include connecting the thermocouple protective sheath (if shielded thermocouple) to the guard surrounding the measurement instrument and using harmonic noise filters [26].

Ground loop noise, on the other hand, is not as easy to remove as the EMI and RFI noise. It arises in situations where the thermocouple junction is in direct contact with a noise source, such as the heating element of an electric heater, and where the measurement instrument shares the same ground as the noise source [26]. Ground loop can be eliminated by avoiding any common grounds between the noise source and the measurement instrument/thermocouple. One of the simplest ways to avoid common grounds is to use ungrounded shielded thermocouples.

\subsection{Thermocouple Selection Conclusion}

Based on the foregoing discussion, it can be concluded that a number of thermocouple types (Table 3.11) can be used on the Carleton SCW loop, albeit with restrictions particular to each thermocouple type. For example, type $E$ thermocouple provides the highest EMF of any thermocouple and hence has excellent sensitivity to temperature change. However, referring to the tables that specify the upper temperature limits of the thermocouples based on the sheath diameter or thermocouple wire diameter, type $E$ thermocouples require relatively larger thermocouple diameters and as a consequence larger sheath diameters to withstand the same temperature range as type 
$\mathrm{K}$ or $\mathrm{N}$ thermocouples. Types $\mathrm{K}$ and $\mathrm{N}$ have the highest upper temperature limits of any commonly used thermocouples, for the same thermocouple wire or sheath diameter. However, type $\mathbf{N}$ is considered an improved version of type $\mathrm{K}$ because it possesses relatively better stability at higher temperatures. Other thermocouple types either have limited temperature ranges (e.g. type T) or relatively low Seebeck coefficients (e.g. types $S$ and $R$ ) making them suitable below or above certain temperatures.

Since the SCW loop application involves high pressures and high temperatures, it is recommended to use sheathed thermocouples. The sheath provides added protection to the thermocouple wires in the extreme environments encountered in the SCW loop. To minimize ground loops and other errors associated with grounded-junction construction, an ungrounded junction is recommended for the thermocouples used on the SCW loop.

The sheath diameter is determined by the maximum application temperature and the length of time that the thermocouple is expected to operate before it suffers from irreparable inhomogeneity and other errors associated with prolonged usage at high temperatures. Since in many instances the thermocouple must penetrate the pressure boundary to measure the fluid bulk temperature, it is desirable that the thermocouple sheath diameter is as small as possible to achieve better pressure sealing. Additionally, smaller sheath diameters improve the time response of ungrounded thermocouples. 
In conclusion, $1.5 \mathrm{~mm}(1 / 16 \mathrm{in})$ stainless steel and Inconel sheathed thermocouples are selected for use on the SCW loop. Type E thermocouple is selected for the temperature measurement close to the flow meter. Type $\mathrm{N}$ thermocouple is selected for temperature measurement at other locations on the SCW loop.

For health monitoring purposes, thermocouples are spot-welded or clamped on the outer surface of the piping at select locations. For the study of heat transfer process, fluid bulk temperatures are measured at a number of locations. At a location upstream of the flow meter, a thermocouple is fitted through a Swagelok ${ }^{\mathrm{TM}}$ fitting to measure the fluid bulk temperature. Similarly, at the inlet and outlet of the test section, thermocouples fitted through Swagelok ${ }^{\mathrm{TM}}$ fittings measure the fluid bulk temperature.

\subsubsection{Pressure Control and Measurement}

The SCW loop will be used for experiments in the pressure range of $23-27 \mathrm{MPa}$. Additionally, the temperature of the water within the loop varies with the extent of heating in the test section, with this heating causing both temporal and spatial temperature gradients in the loop. This combination of high pressure and changing temperature requires a pressure control system that can accommodate the expanding fluid volume contained in the loop while maintaining a constant pressure. Accurate pressure control is particularly important in the lower pressure range, close to the critical pressure, where the properties of SCW are inextricably dependent on pressure. 
There are a number of ways which can be employed to raise the fluid pressure and maintain a steady pressure for experimentation.

Accurate measurement of pressure in the Carleton SCW loop is required for the purposes of measuring the heat transfer process in the test section and operatingcondition/health monitoring. The absolute pressure of the water in the loop is required to determine the properties of water in conjunction with temperature and to ensure that the pressure in the SCW loop does not exceed its maximum allowable limit. The pressure drop across the length of the test section is required for studying the heat transfer and flow development in the test section. The pressure in the SCW loop ranges from atmospheric to $28 \mathrm{MPa}$. Therefore, it is necessary that the pressure sensing devices are capable of accurate pressure measurement throughout the required range, while withstanding the operating environments of the locations where they are used.

\subsubsection{Methods of Pressurization and Control}

\subsection{Back Pressure Regulator}

A back pressure regulator provides one of the simplest ways to maintain the pressure of a system at a predetermined level. Unlike a pressure reducing valve, which controls the outlet pressure, a back pressure regulator controls the inlet pressure [46]. Back pressure regulators are very similar in operation to relief valves and are often used as pressure relief valves (Figure 3.27). 


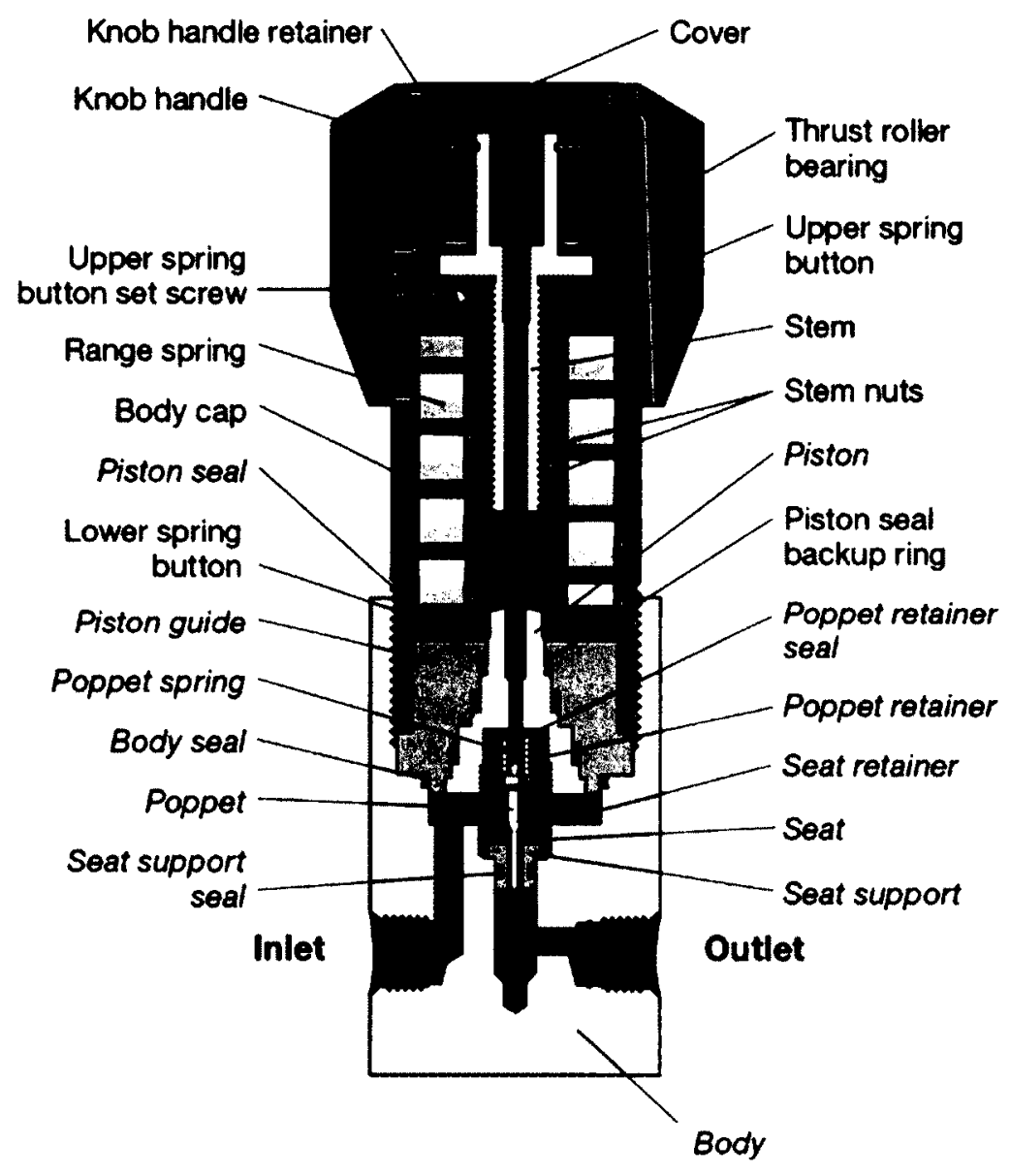

Figure 3.27: Construction of piston back pressure regulator [46]

They are sometimes referred to as a "precise pressure relief valve" [46]. As such, a back pressure regulator maintains a constant pressure upstream of the valve. A back pressure regulator is a normally-closed valve and it opens up to allow excess fluid volume to discharge from the system when the pressure of the process fluid exceeds the set spring force in the valve.

Initial pressurization of the SCW loop can be achieved by adding heat to the fluid in the test section. Once the fluid pressure reaches the back pressure regulator set pressure, 
the regulator will prevent further increase in the system pressure by venting off some of the working fluid until steady state conditions are achieved.

Most back pressure regulators are spring loaded and the required back pressure (upstream pressure) can be set by turning the control knob to either increase or decrease the spring force on the regulator seat. Although back pressure regulators can be used in applications involving very high pressures ( $\sim 100 \mathrm{MPa})$, their operating temperature is rather limited [46][47]. Two factors contribute to the operating temperature limitation of back pressure regulators, namely the temperature rating of the seat material and the effect of higher temperatures on the spring constant of the spring-loaded regulators. At higher pressures, the operating temperature of back pressure regulators ranges from -40 to $176^{\circ} \mathrm{C}$ [48].

\subsection{Piston/Plunger Pump}

Piston/plunger pumps are particularly employed in applications requiring high system pressures. Piston pumps can raise the system pressure up to $70 \mathrm{MPa}$ [49]. They also offer unlimited pumping capacity and good volumetric efficiencies. In general, piston pumps are designed for high pressure only at the discharge port of the pump and the discharge flow is invariably pulsating in nature.

Using piston or plunger pumps to increase the system pressure is limited by a number of factors, the most critical of them being the facts that the pump can be used for high pressure applications only at the discharge and the pulsating flow generated by the 
pump. As a result, application of piston pumps is restricted only to open loop system configurations, where the inlet fluid pressure is much lower compared to the required discharge pressure. For this very reason, the SCW loops described in Sections 3.2.1, 3.2.3 and 3.2.5 are of open loop design. In all three designs, the fluid pressure is reduced to atmospheric pressure before being redirected to the plunger pumps. Flow pulsations generated by a piston or plunger pump can be mitigated by use of a pulsation dampener. Pulsation dampeners are generally situated immediately after the discharge of the pump.

\subsection{Thermal Pressure Control}

Thermal pressure control is a well established method to pressurize and control the pressure of a system. Thermal pressure control has been proposed for supplying constant pressure for a series of applications, ranging from hydraulic presses [50] to fine pressure control for an ultrahigh-pressure laboratory gas triaxial cell [51].

The working principle of thermal pressure control involves generation of gaseous vapours within an auxiliary pressure vessel or by adjusting the pressure of a gas contained in the pressure vessel. The rate of vapour generation or the pressure of the gas is controlled by regulating the temperature of the vessel contents.

A supercritical $\mathrm{CO}_{2}$ experimental loop, located at AECL Chalk River Labs (Ontario), is pressurized and its pressure regulated by means of thermal pressure control [3]. A pressure vessel several times larger than the loop total internal volume is used as the 
pressurizer. The inside of the pressurizer is equipped with electrically heated elements, which are used to increase the temperature and hence the pressure of the $\mathrm{CO}_{2}$ gas contained in the pressurizer. The pressurizer has been used to increase the pressure in the loop up to $10.3 \mathrm{MPa}$.

\subsection{Accumulator}

Accumulators have been used as a source of pressure and stored fluid volume very extensively in hydraulic systems [52]. They are employed to compensate for pressure changes due to temperature variations by delivering or receiving some amount of the process fluid, thereby maintaining a constant system pressure. Accumulators can operate at pressures as high as $136 \mathrm{MPa}(20,000 \mathrm{psi})$ [53]. The operating temperature of barrier type accumulators is limited to about $100{ }^{\circ} \mathrm{C}$ by the polymeric material used in the design of the barrier [53]. On the other hand, the operating temperature of nonseparated accumulators is limited only by the design temperature of the accumulator vessel.

Both the Wisconsin SCW loop and the SKD-1 loop described in Sections 3.2.2 and 3.2.4, respectively, use accumulators to pressurize and regulate the pressure of the loops. In the Wisconsin SCW loop, the accumulator is sized to have the same volume as the internal volume of the loop. The pressure to the accumulator is supplied by a highpressure gas cylinder. This arrangement is found to provide an independent control of 
pressure in the SCW loop, while adequately dampening pressure oscillations generated by the pump.

\subsection{Pressurization and Control Method Selection}

Each pressurization and control method discussed above has its advantages and disadvantages. The back pressure regulator method is advantageous as this method of pressurization and pressure control is quite simple. However, as mentioned, back pressure regulators have a relatively low operating temperature and their use for application on the SCW loop requires cooling of the fluid before it reaches the back pressure regulator. The final system pressure is set on the back pressure regulator before the system is pressurized. Therefore, the back pressure regulator cannot be used to change the system pressure during operation.

The Carleton SCW loop is of closed-loop design and a centrifugal pump has been chosen to circulate the water through the loop with minimal pulsation. Thus, the piston/plunger method is not applicable to the Carleton SCW loop.

Thermal pressure control is a viable solution for the purposes of pressure control in the Carleton SCW loop. However, it requires a pressure vessel many times larger than the total internal volume of the SCW loop and the pressure vessel must provide for the means (most probably electrical) to internally increase the temperature of the gas in the vessel. Experience has shown that such a relatively large high-pressure pressure vessel 
with electrical wiring breaching the pressure boundary would be quite costly to manufacture.

Pressurization and pressure control via an accumulator is a tried and proven method, as is evidenced by its use on the two SCW loops discussed previously. The accumulator method gives independent control over the pressure in the loop. The volumetric size of the accumulator can be similar to that of the internal volume of the loop. As a result, it eliminates the need for a very large pressure vessel, as needed for thermal pressure control. Pressurization of the accumulator can be achieved by an auxiliary gas cylinder, which is relatively inexpensive to obtain.

Therefore, considering the cost, controllability and ease of installation, the accumulator method is selected as the suitable method of pressurization and pressure control for the Carleton SCW loop.

\subsubsection{Accumulator and Gas Cylinder Assembly}

To have absolute control of the pressure in the SCW loop, it is essential that the auxiliary gas cylinder supplying gas for pressurization is continuously connected to the accumulator. Accordingly, the accumulator and gas cylinder assembly shown in Figure 3.28 is used to pressurize and control the pressure of the Carleton SCW loop.

A high-pressure gas cylinder is connected to an accumulator via a cross manifold that interfaces with two control valves and a pressure relief valve. The electrically actuated 
control valves are used to regulate the pressure in the accumulator and as an extension the pressure in the SCW loop. Regulating CV4 increases the pressure in the accumulator, whereas regulating $C V 3$ reduces the pressure in the accumulator. A pressure transducer measures the pressure of the accumulator and the measured pressure is used as a feedback to either increase the pressure by opening CV4 and allowing more highpressure gas to flow into the accumulator or decrease the pressure by opening $\mathrm{CV} 3$ and allowing some of the gas to vent off to the atmosphere.

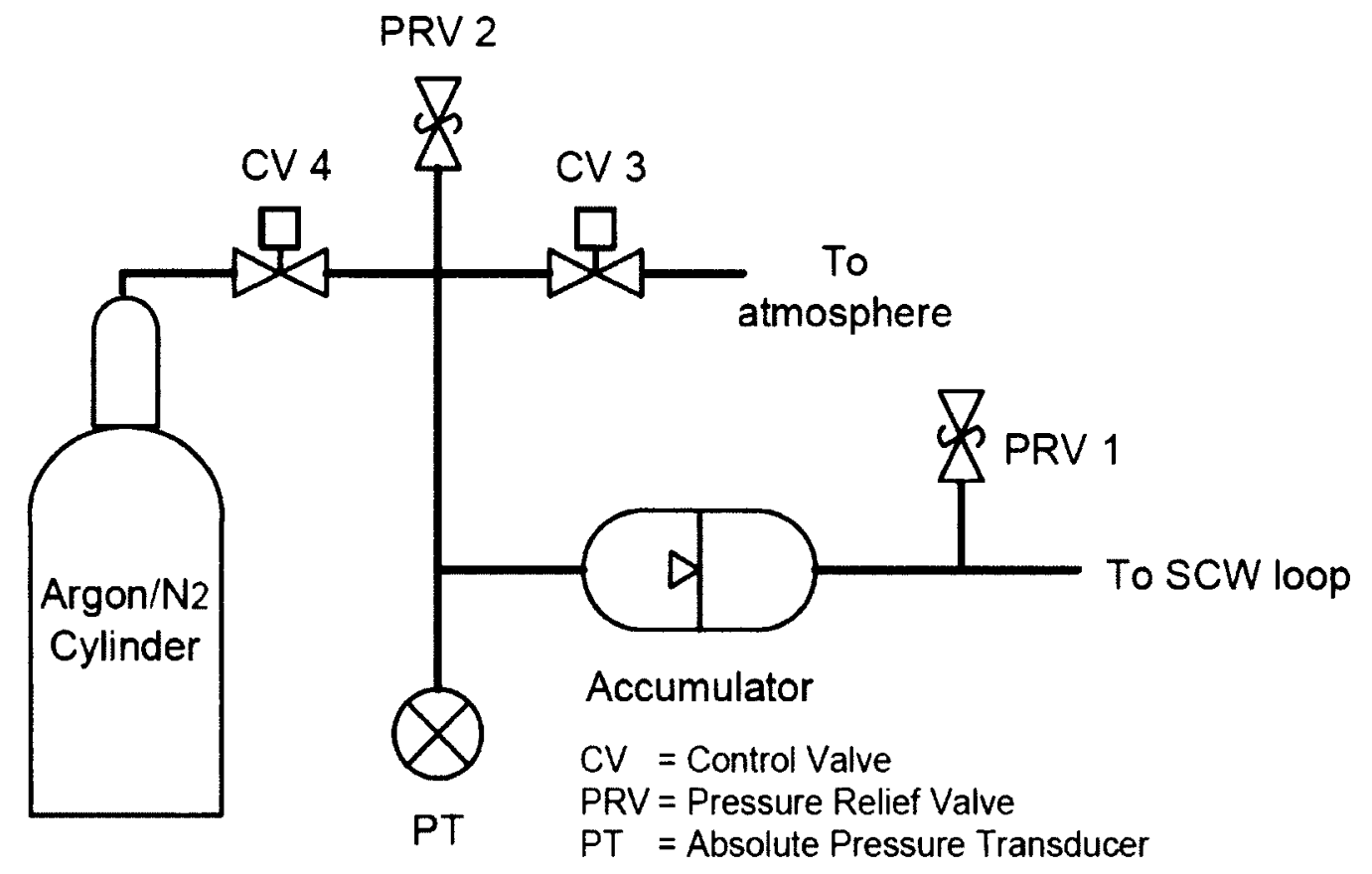

Figure 3.28: Accumulator and gas cylinder assembly

The accumulator and gas cylinder assembly is designed to operate at room temperature. The accumulator is selected to have similar size as the total internal volume of the Carleton SCW loop. A pressure relief valve ensures that the pressure in the accumulator 
does not exceed its design pressure. The connections among various parts in the assembly are achieved with the help of Swagelok ${ }^{\mathrm{TM}}$ threaded and compression type fittings. The interfacing of the assembly with the SCW loop is facilitated by a Swagelok ${ }^{\mathrm{TM}}$ to-flange adapter (SS-400-F24-2500). More information on Swagelok ${ }^{\mathrm{TM}}$ fitting can be found in Chapter 5 .

\subsection{Auxiliary Gas Cylinder Selection}

The auxiliary gas cylinder connected to the accumulator helps to dynamically regulate the pressure of the SCW loop. The gas cylinder serves two purposes, namely to precharge the accumulator and to supply the accumulator with additional high-pressure gas during the operation of the SCW loop should the experimental conditions require so. Furthermore, the gas cylinder should be able to supply the SCW loop with the required precharge and control gas pressure for a number of start-up cycles. Therefore, a gas cylinder with adequate volume and a high pressure rating is required for the Carleton SCW loop application.

The largest standard high-pressure gas cylinder size is approximately 50 litres (type $\mathrm{K}$ ) and these cylinders can contain gas pressures up to $41.3 \mathrm{MPa}$ (6000 psi) [54]. Simple ideal gas calculations have shown that two cylinders used together can precharge the accumulator half a dozen times, while maintaining a pressure higher than $28 \mathrm{MPa}$ to fine tune the pressure in the system. 
Therefore, two 41.3 MPa, 50 litre gas cylinders supplied by Praxair Ottawa are combined together and connected to the accumulator. The gas cylinders interface with the accumulator via 1/4 in female NPT ports. A Praxair Type 4092 high-pressure regulator at the outlet of the gas cylinder is used to manually shut off or open the cylinder port.

\subsection{Accumulator Selection}

A suitable accumulator for the Carleton SCW loop is selected by evaluating the merits of various commercially available standard accumulators, such as piston, bladder and diaphragm accumulator. Yi-Li Jin, another graduate student in the research group, performed the selection of the accumulator, and a standard bladder accumulator manufactured by Accumulators, Inc. (model A5TBG61001XS) with a volumetric size of approximately 19 litres (5 US gallons) and a maximum operating pressure of $41 \mathrm{MPa}$ (6000 psi) is selected. The interfacing of the accumulator with the other pressure control assembly components shown in Figure 3.28 is achieved through $1 / 4$ in and $1-1 / 4$ in female NPT threaded ports. The selected accumulator makes provisions for the protection of the bladder against extrusion into the fluid port or the gas port. A poppet prevents extrusion of the bladder into the fluid port and a transfer barrier is installed in the gas section to protect the bladder against extrusion into the gas port. The interior of the accumulator shell is coated with a phenolic compound to provide protection against corrosion. 


\subsection{Control Valves Selection}

The flow of nitrogen gas in and out of the accumulator is controlled using two control valves. Precise control of the flow from the high-pressure gas cylinder to the accumulator and from the accumulator to the atmosphere requires small-flow valves. Needle valves are generally used in applications requiring accurate throttling and in applications involving high pressure and/or high temperatures [11]. Therefore, electrically actuated needle valves manufactured by Swagelok ${ }^{\text {TM }}$ are selected. The valves are connected to the gas cylinder and bladder accumulator assembly through $1 / 8$ in Swagelok $^{\text {TM }}$ compression type connections. To have precise control over the gas flow rate, the smallest readily available needle valve flow coefficient $\left(C_{v}\right.$ of 0.09$)$ was selected.

\subsection{Pressure Relief Valve Selection}

ASME Code requires that the SCW loop is protected against overpressurization [8][9]. Protection against overpressurization is achieved by installing pressure relief devices. Two pressure relief valves are integrated into the loop to prevent overpressurization. As shown in Figure 3.28, the first pressure relief valve is installed between the accumulator and the SCW loop to protect the loop and the second pressure relief valve is installed between the high-pressure gas cylinder and the accumulator to protect the accumulator against overpressurization. $1 / 2$ in ASME certified pressure relief (safety) valves are considered for the SCW loop. 


\subsection{Tubing Selection}

The selected tube for connecting the accumulator to the SCW loop and to the highpressure gas cylinder is $6.4 \mathrm{~mm}$ (1/4 in) outer diameter stainless steel 316, A213 tubing. The selected wall thickness of $1.2 \mathrm{~mm}(0.049 \mathrm{in})$ can withstand internal pressures up to $52 \mathrm{MPa}$, at room temperature. Temperature at the interface between the accumulator assembly and the SCW loop can be as high as $260^{\circ} \mathrm{C}$. At this temperature, the selected tube wall thickness can withstand an internal pressure of $44.5 \mathrm{MPa}$. The pressure rating of the tube is determined based on the formulae given in ASME B31.1 [8].

The tubes will be connected to the accumulator, valves and the gas bottle with the help of compression-type fittings manufactured by Swagelok ${ }^{\mathrm{TM}}$.

\subsubsection{Pressure Sensor}

As discussed in the introduction to Section 3.3.6, pressure sensors are required to monitor the health of the SCW loop to ensure its maximum allowable operating pressure is not exceeded, and for the purposes of measuring the flow development in the test section. The selected pressure sensors must have measurement ranges comparable to those expected on the SCW loop and they must be able to withstand the operating environments of the locations where they are used on the loop. With these criteria in mind, a number of pressure sensors are researched. 
Some of the most commonly used pressure sensors include non-electric sensors, such as Bourdon and bellows-type gauges, and electronic sensors, like capacitive and piezoresistive transducers [26].

Non-electric pressure sensors, such as the bellows type, are used only for low pressure applications with maximum pressure limits of $14 \mathrm{MPa}$ [26]. The Bourdon pressure sensor meets the pressure requirement of the application (applicable for high pressures up to $690 \mathrm{MPa}$ [26]), but the sensor gives a mechanical output in the form of the movement of an indicator. For the purposes of data acquisition in the present application, electrical output signal is preferred because it can be easily interfaced with the data acquisition system. It is possible to convert the mechanical output of a Bourdon pressure sensor in the form of a potentiometric transducer by connecting its wiper arm to a potentiometer; however, this transformation potentially affects the accuracy of the pressure readings and is beyond the scope of the loop design effort.

Electronic pressure sensors can be used for application on the Carleton SCW loop. Either capacitive or piezoresistive pressure transducer can be selected because both meet the measurement pressure range requirement of the application (35 MPa and $41.1 \mathrm{MPa}$ for capacitive and piezoresistive, respectively) and both possess relatively high accuracies (0.1 to $0.5 \%)$ [26]. Piezoresistive pressure sensors are the most widely used pressure transducers and as a result they cost less in comparison to capacitive pressure transducers. Hence, piezoresistive pressure transducers are selected for the SCW loop. 


\subsection{Pressure Transducer Selection}

A student member of the research group, Ms. Anne Mason, helped procure two Rosemount 2088 pressure transducers for absolute pressure measurements. The Rosemount 2088 utilizes a polysilicon pressure sensor with $316 \mathrm{~L}$ isolating diaphragms. The absolute pressure $(\mathrm{A} / \mathrm{P})$ transducer has a measurement range of $1.4-27.6 \mathrm{MPa}$ and a maximum operating temperature of $85{ }^{\circ} \mathrm{C}$. The Rosemount 2088 transducer has a maximum line pressure limit of $55.2 \mathrm{MPa}$. The transducer makes use of 1-5Vdc HART low power communication protocol for transmitting pressure readings as an analogue electrical signal to the data acquisition system.

A Rosemount 3051CD differential pressure (D/P) transducer (also procured by group member Anne Mason) is used to measure the pressure drop in the test section. This transducer is rated for a maximum line pressure of $31 \mathrm{MPa}$ with a pressure range of -250 to $+250 \mathrm{kPa}$. This pressure range is compatible with the maximum pressure drop of $69.3 \mathrm{kPa}$ expected in the three test sections. The operating temperature of the $\mathrm{D} / \mathrm{P}$ transducer is limited to $85^{\circ} \mathrm{C}$. Similar to the $\mathrm{A} / \mathrm{P}$ transducer, the $\mathrm{D} / \mathrm{P}$ transducer transmits the differential pressure readings via 1-5Vdc HART protocol.

\subsection{Pressure Transducer Installation}

It is intended to install two absolute pressure transducers, one on the accumulator (Figure 3.28) to monitor its pressure and for redundancy a second one on the loop (Figure 3.8 ) to directly monitor the pressure of the loop. The differential pressure 
transducer will be installed on the test section (Figure 3.8) to detect the test-section pressure drop. The temperature of the accumulator will be kept at the same level as the room temperature and therefore, the pressure transducer can be directly installed on the accumulator. However, the temperature at the location of the second absolute pressure transducer is expected to be as high as $260^{\circ} \mathrm{C}$ and for the $\mathrm{D} / \mathrm{P}$ transducer, the fluid temperature will reach $600^{\circ} \mathrm{C}$. As described in the preceding section, the operating temperature of the selected transducers is limited to maximum $85^{\circ} \mathrm{C}$. To accommodate the pressure transducers, a combination of a "remote seal" and impulse tubing is used (Figure 3.29).

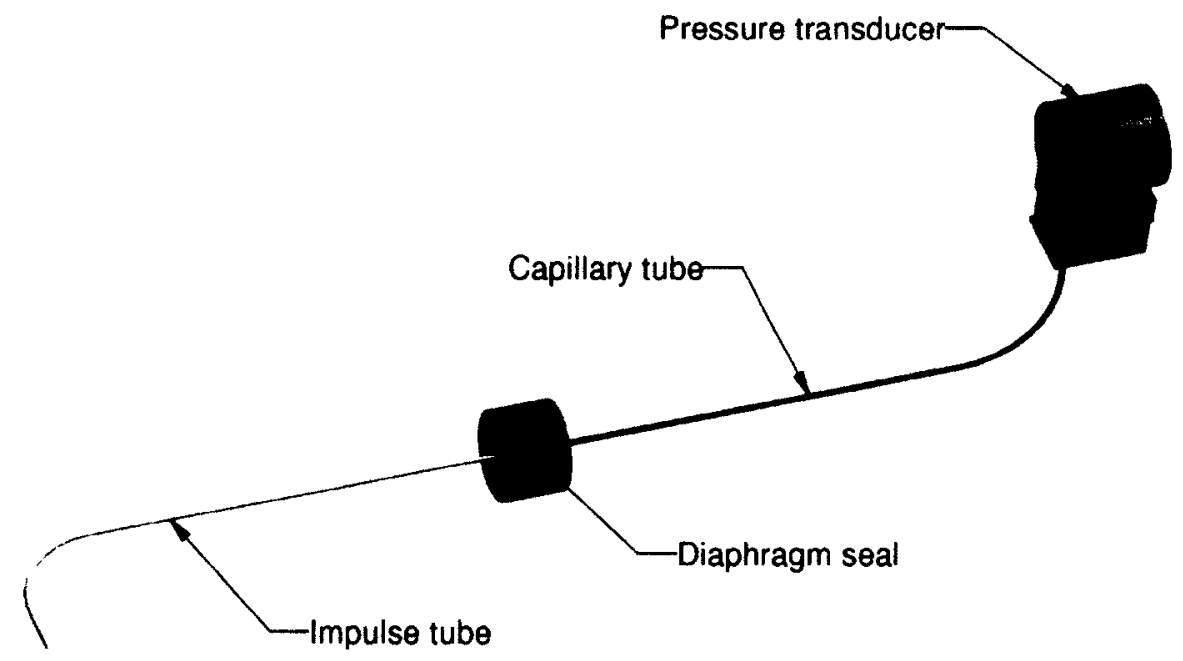

Figure 3.29: Remote seal and impulse tube assembly

The remote seal consists of the diaphragm seal and the capillary tube with the capillary tube connecting the diaphragm seal to the pressure transducer. This arrangement can increase the operating temperature of the pressure transducer installation to $320^{\circ} \mathrm{C}[55]$. 
For the second $A / P$ transducer, the remote seal by itself is adequate, as the temperature rating of the remote seal is above the temperature expected at the location of installation. For the $\mathrm{D} / \mathrm{P}$ pressure transducer, however, the remote seal cannot be directly connected to the test section because the expected fluid temperature, at the test-section outlet is as high as $600^{\circ} \mathrm{C}$. Therefore, an impulse tube is connected to the test section to lower the temperature of the fluid to $320^{\circ} \mathrm{C}$ before connecting the remote seal to the impulse tube. The impulse tube is of $6.4 \mathrm{~mm}(1 / 4 \mathrm{in})$ OD stainless steel Type 316 tubing with a wall thickness of $1.2 \mathrm{~mm}(0.049 \mathrm{in})$. The impulse tube is connected to the loop and the pressure transducer(s) via 1/4 in Swagelok ${ }^{\top M}$ fittings.

Numerical simulations have shown that a $0.5 \mathrm{~m}$ long impulse tube can reduce the temperature of the stagnant fluid in the impulse tube to well below $320^{\circ} \mathrm{C}$ through natural convective heat exchange with the environment. Details on the simulation are given in Appendix E.

\subsubsection{Flow Conditioning}

The operation of high pressure systems calls for the system components such as the pumps and control valves to have very close tolerances. This combination of high pressure and reduced clearances requires the elimination of particles from the system, which could cause clogging and damage and hence necessitates protection by filters. The purpose of a filter (strainer) is to reduce or remove impurities or contaminants present in the system to an acceptable or predetermined level [11]. 
The most damaging contaminants to the high pressure system components are the nonsoluble and abrasive contaminants, commonly referred to as particulate contamination [49]. Hard or abrasive particulate contamination can lead to high rates of wear and erosion in parts of the system with high fluid velocities and tight tolerances. Particulate contaminants are measured in "microns", i.e. in millionths of a meter.

\subsubsection{Filter/Strainer}

\subsection{Filter/Strainer Performance and Rating}

Generally, the performance of a filter/strainer is evaluated based on its contaminantholding capacity, pressure drop and filtration efficiency, expressed in terms of a so called "beta ratio" [52]. The contaminant-holding capacity of a filter is found by measuring the amount of contaminant that can be captured by the filter before the pressure drop becomes too large. The efficiency of a filter is determined by measuring the particle concentration upstream of the filter and downstream of the filter and expressed as a ratio.

\section{Nominal Rating}

The nominal filter rating is an arbitrary micrometer value given by the filter manufacturer and expressed in terms of percentage retention by weight of a specified contaminant size (usually glass beads) [49][56]. The percentage term represents the nominal efficiency of the filter. For example, a $10 \mu \mathrm{m}$ filter at $90 \%$ efficiency nominal 
ratings describe a filter capable of removing $90 \%$ by weight of particulate contamination larger than $10 \mu \mathrm{m}$ in size.

\section{Absolute Rating}

The absolute filter rating is determined by the diameter of the largest hard spherical particle that will pass through a filter element under specific conditions [56]. This method of filter rating gives an indication of the largest hole in the filter element. The corresponding efficiency of a filter is determined by measuring the concentration of particles larger than a specified size upstream and downstream of the filter and expressing the result in terms of a so-called beta ratio.

\subsection{Filter/Strainer Element Media}

The filter/strainer element medium is the part that captures the contaminants for subsequent removal. Filter element media can be made of cellulose (paper and fabric types), metals (woven stainless steel cloth and sintered porous metal) or synthetic fibre (microglass) [49][56]. Each filter element medium has its advantages and drawbacks.

Table 3.14 lists the characteristics of the most commonly used filter element media.

Table 3.14: Filter element types and characteristics [49][56]

\begin{tabular}{ccccccc}
\hline $\begin{array}{c}\text { Element } \\
\text { Medium }\end{array}$ & $\begin{array}{c}\text { Filtration } \\
\text { Range }\end{array}$ & Efficiency & $\begin{array}{c}\text { Dirt Holding } \\
\text { Capacity }\end{array}$ & $\begin{array}{c}\text { Flow Rate } \\
\text { Capacity }\end{array}$ & $\begin{array}{c}\text { Mechanical } \\
\text { Strength }\end{array}$ & $\begin{array}{c}\text { Overall } \\
\text { Cost }\end{array}$ \\
\hline Cellulose & $10-20 \mu \mathrm{m}$ & Poor & Average & Moderate & Poor & Low \\
Microglass & $3 \mu \mathrm{m}$ & Excellent & Excellent & High & Low & Moderate \\
Wire Mesh & $10 \mu \mathrm{m}$ & Excellent & Moderate & Moderate & High & High \\
\hline
\end{tabular}




\subsection{Filter/Strainer Type}

There are four main types of filters - pressure-line filters, return-line filters, suction filters and bypass or off-line filters [49][56]. Generally, filters are of pressure-line type located on the pressure side of the pump. A filter on the suction side of the pump should be of a large size and with a relatively high flow rate to avoid the possibility of restricted flow starving the pump and causing cavitation [49].

\subsection{Filter/Strainer Requirements for the SCW Loop}

The SCW loop operates at very high pressures and temperatures of up to $28 \mathrm{MPa}$ and $600^{\circ} \mathrm{C}$. However, the filter is located after the heat exchanger and therefore, it is not subjected to temperatures higher than $260^{\circ} \mathrm{C}$. Due to the combination of high pressure and temperature encountered in the SCW loop, flanged type connections are required on the filter. Based on the discussion of various filter element media in the previous sections, a stainless steel wire mesh filter element medium is the suitable filter element medium for the SCW loop. The manufacturer of the centrifugal pump for the Carleton SCW loop recommends a 500 micron filter element. Since the SCW loop is of the closed loop design, the location/type of the filter falls between a suction type and a return-line filter type. Therefore, the filter must be able to accommodate the varying flow conditions required for different experimental conditions. Cavitation is not a concern since the pump has a bypass loop and only a fraction of the total flow passes through the filter. The filter requirements for the SCW loop are tabulated in Table 3.15. 
Table 3.15: Filter requirements for SCW loop

\begin{tabular}{ll}
\hline Fluid & Water \\
\hline Maximum Pressure & $28 \mathrm{MPa}$ \\
Maximum Temperature & $260^{\circ} \mathrm{C}$ \\
Maximum Flow Rate & $2.3 \mathrm{~m}^{3} / \mathrm{hr}(10 \mathrm{GPM})$ \\
Micron Rating & 500 \\
Material of construction & Stainless steel 316 \\
Connection Type & Class 2500 Flange \\
Line Size & NPS 1.5, SCH XXS \\
\hline
\end{tabular}

\subsubsection{2, Filter/Strainer Selection}

Initially, a Norman Tee-type filter was selected to protect the centrifugal pump from debris that may be dislodged from the tubing, in particular the test section where direct Joule heating of the tubes is carried out, and other components on the loop due to corrosion and/or erosion. However, due to improper CRN for the filter, an alternative filter/strainer is selected.

The selected strainer is of Y-type with standard Class 2500 RF ASME flanges manufactured by Sure Flow Equipment, Inc. It is custom fabricated from stainless steel 316. Filtration is achieved with a Mesh 40 (400 micron) stainless steel wire mesh element. 


\section{Chapter 4. Design of the Test Sections}

This part of the thesis outlines and discusses the designs as well as the limitations and challenges involved in the development of the test sections. The test sections are designed such that they are interchangeable between the SCW and R-134a loops. Since the SCW experiments impose the most stringent requirements on the design of the test sections, hereafter reference is made only to SCW as the working fluid. However, the test section designs are fully compatible with both the SCW and R-134a loops.

\subsection{Test-Section Design Requirements}

The test sections are used to measure the heat transfer properties of water in the subcritical, near-critical and supercritical regimes. Three different test-section geometries, whose cross-sections are shown in Figure 3.1 and reproduced here as Figure 4.1, are planned for the experiments. The annular and bundle designs are used to simulate the proposed CANDU-SCWR fuel pin and fuel bundle arrangements, respectively, while the tubular configuration is used to study the convective heat transfer phenomenon in a more fundamental setting and to quantify the overall accuracy of the experimental facility/setup in comparison with the established data.

Table 4.1 lists the proposed test sections' design requirements. The test sections are required to operate at very high temperatures and pressures of $260-600^{\circ} \mathrm{C}$ and 23 $27 \mathrm{MPa}$. They must be capable of imparting up to $300 \mathrm{~kW}$ of heating power to the fluid 
by direct Joule heating. Depending on the test-section geometry, heating of the working fluid is achieved by Joule heating of either the internal pipe(s) or the pressure containing outer pipe. For the annular and bundle geometries, the inner pipe(s) are heated, whereas for the tubular test section the pressure retaining pipe itself is heated. The transmission of electrical power to the heating pipe(s) must take place in a manner that is electrically isolated from the rest of the test section and the test loop at large.

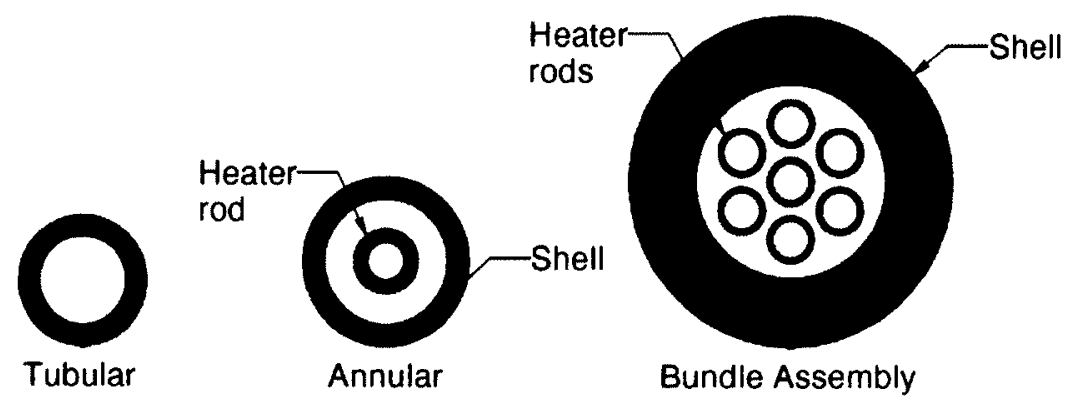

Figure 4.1: Cross-sections of the three test-section geometries

The flow path of the test sections, in particular that of the annular test section, must be easily accessible. This is because one of the experimental tasks calls for testing the effects of spacers, as found on CANDU fuel bundles, on the heat transfer in the working fluid. It is also of importance to be able to inspect the interior of the test sections for corrosion and other safety compromising damages and when possible carry out the necessary repairs.

The test sections should be designed to use off-the-shelf components whenever possible without undermining safety or operational capacity. 
Table 4.1: Proposed design requirements for the test sections

\begin{tabular}{|l|c|c|c|c|}
\hline \multicolumn{1}{|c|}{ Parameter } & Units & Tubular & Annular & $\begin{array}{c}\text { Bundle } \\
\text { Assembly }\end{array}$ \\
\hline System pressure & $\mathrm{MPa}$ & $23-27$ & $23-27$ & $23-27$ \\
\hline Inlet temperature & ${ }^{\circ} \mathrm{C}$ & 260 & 260 & 260 \\
\hline Outlet temperature & ${ }^{\circ} \mathrm{C}$ & $380-600$ & $380-600$ & $380-600$ \\
\hline Mass flux & $\mathrm{kg} / \mathrm{m}^{2} \mathrm{~s}$ & $500-3000$ & $500-3000$ & $500-3000$ \\
\hline Hydraulic diameter (close to) & $\mathrm{mm}$ & 8 & 8 & 8 \\
\hline Heated length (up to) & $\mathrm{mm}$ & 2000 & 2000 & 2000 \\
\hline Power & $\mathrm{kW}(\mathrm{DC})$ & 300 & 300 & 300 \\
\hline Available voltage & $\mathrm{V} \mathrm{(DC)}$ & $0-150$ & $0-150$ & $0-150$ \\
\hline Available current & $\mathrm{A}$ & $0-2000$ & $0-2000$ & $0-2000$ \\
\hline
\end{tabular}

\subsection{Survey of Test Sections Used in SCW Experiments}

A number of heat transfer experiments with SCW have been carried out over the years. Many of the experiments employed the method of direct Joule heating of the test sections with high-current electrical power sources. The following sections give a brief survey of examples of the test sections used in these experiments.

\subsubsection{Kyushu University SCW Loop Test Section}

Yamagata et al. [4] performed heat transfer experiments involving SCW on the Kyushu University's SCW loop. Two different test section sizes were employed. The test sections were made from AISI Type 316 stainless steel tubes of $7.5 \mathrm{~mm}$ and $10 \mathrm{~mm}$ internal diameters with heated lengths of $1500 \mathrm{~mm}$ and $2000 \mathrm{~mm}$, respectively. The total length of test sections, excluding the mixing chambers, were a little over $3000 \mathrm{~mm}$. Figure 4.2 depicts the $10 \mathrm{~mm}$ internal diameter test section. The test sections were heated by an 
$80 \mathrm{~kW}$ direct current low voltage power supply. Mixing chambers were located at the inlet and outlet of the test sections, where the fluid inlet and outlet temperatures and pressures were measured. Up to eighteen chromel-alumel (type K) thermocouples were arc-welded to the surfaces of the test sections at regular axial intervals on diametrically opposite sides of the tubes (top and bottom of the tube for horizontal test section) to measure the outside wall temperature of the test sections. Two sheathed thermocouples, one at the inlet and one at the outlet of the test section, were inserted into the mixing chambers to measure the fluid bulk temperature.

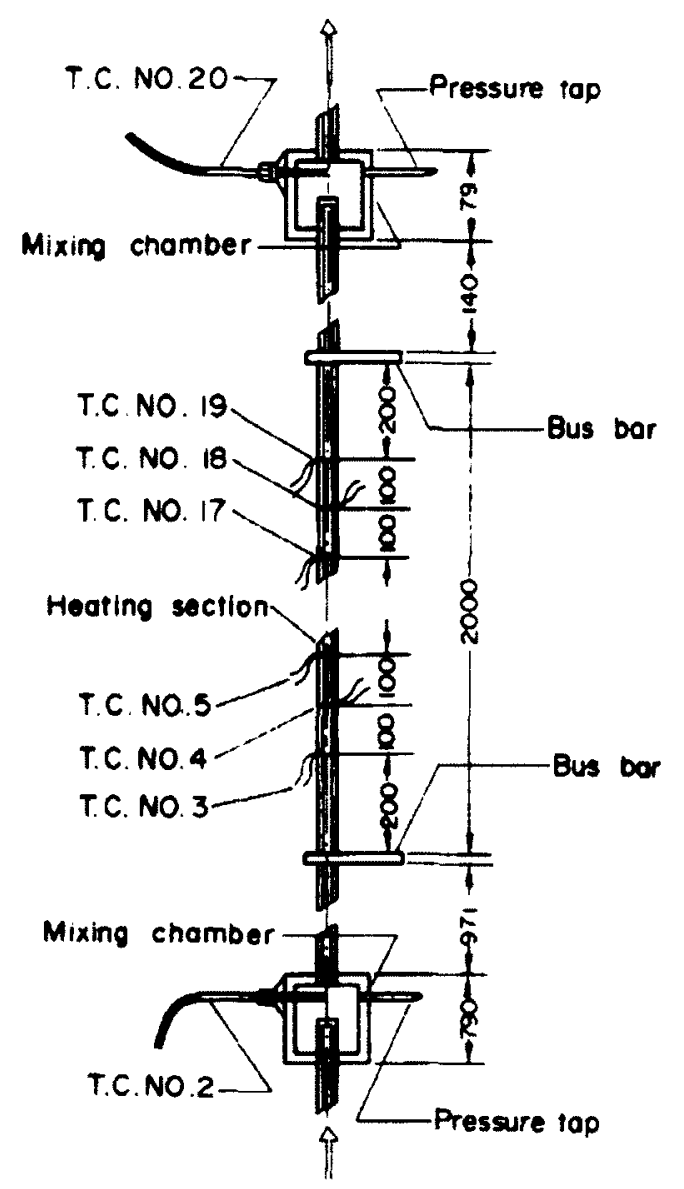

Figure 4.2: Kyushu University $10 \mathrm{~mm}$ internal diameter test section [4] 
In order to prevent the electric power supplied to the test sections from leaking out, one of the flanges in the low pressure region of the loop was electrically isolated. To avoid electrical conduction through water, the feed water was purified by a mixed-bed deionizer to a high resistivity of $3 \times 10^{6} \Omega \mathrm{m}$.

The pressure in Yamagata's experiments ranged from 22.6 MPa to $29.4 \mathrm{MPa}$ and the fluid bulk temperature in the test section varied between 230 and $540^{\circ} \mathrm{C}$. Based on the data presented by Yamagata et al., the fluid bulk temperature never exceeded $500^{\circ} \mathrm{C}$. The heat flux ranged from 116 to $930 \mathrm{~kW} / \mathrm{m}^{2}$ and it was adjusted relative to the mass flux $\left(310-1830 \mathrm{~kg} / \mathrm{m}^{2} \mathrm{~s}\right)$ to ensure the outside tube wall did not exceed $700^{\circ} \mathrm{C}$.

\subsubsection{University of Wisconsin SCW Loop Test Section}

Licht et al. [5] performed heat transfer experiments with SCW using circular annular and square annular test sections on the University of Wisconsin SCW loop. The test sections were approximately $3000 \mathrm{~mm}$ long and the heated length of the test sections was limited to $1010 \mathrm{~mm}$. The heating of the fluid was accomplished with the help of a 10.7 $\mathrm{mm}$ diameter heater rod located within the $\mathbf{4 2 . 9} \mathrm{mm}$ diameter flow channel in case of the circular annular test section. The square annular geometry incorporated the heater rod within a $28.8 \mathrm{~mm}$ wide square channel. Figure 4.3 shows the cross-sectional views of the two test-section configurations. The heater rod was centred within the flow channel using six spacers with three situated on either side of the heated length of the heater rod. Two of the spacers were located $5 \mathrm{~cm}$ from either end of the heated section. 

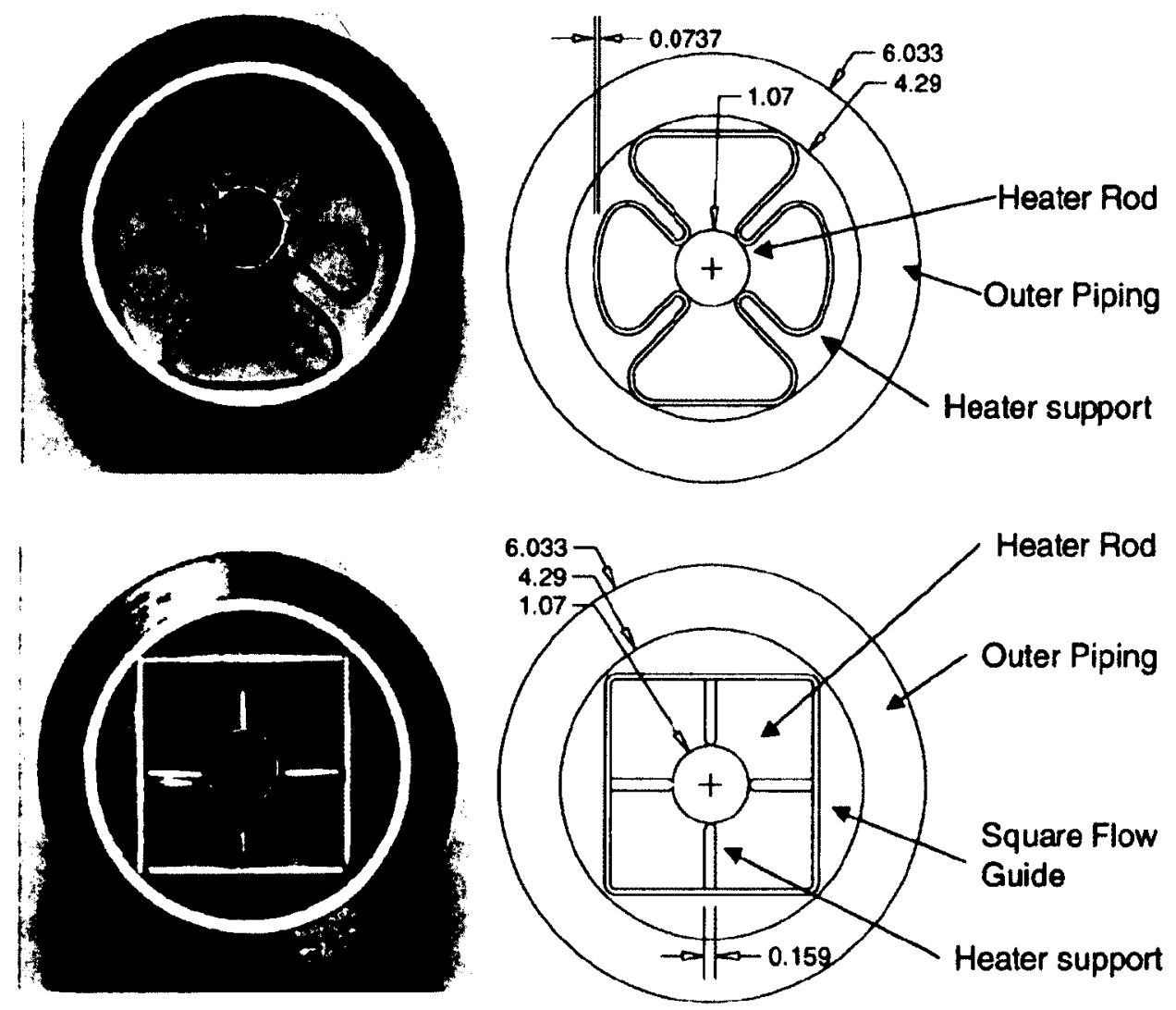

Figure 4.3: University of Wisconsin circle and square annular test-section configurations (units in $\mathrm{cm}$ ) [5]

The heater could generate up to $50 \mathrm{~kW}$, giving a maximum heat flux of $1.5 \mathrm{MW} / \mathrm{m}^{2}$. For high mass fluxes, the heat flux was varied from $250 \mathrm{~kW} / \mathrm{m}^{2}$ to $1 \mathrm{MW} / \mathrm{m}^{2}$, whereas for low mass fluxes, the heat flux was varied from $125 \mathrm{~kW} / \mathrm{m}^{2}$ to $650 \mathrm{~kW} / \mathrm{m}^{2}$. The fluid mass flux was varied between 350 and $1425 \mathrm{~kg} / \mathrm{m}^{2} \mathrm{~s}$. The inlet temperature was varied between 300 and $400^{\circ} \mathrm{C}$ with a bulk temperature rise across the heated section varying from less than $1^{\circ} \mathrm{C}$ to a maximum of $15^{\circ} \mathrm{C}$. All the experiments were carried out at a pressure of $25 \mathrm{MPa}$. 
The heater rod was not directly heated. Instead, a heating filament made of Monel K500 with an outside diameter of $6.325 \mathrm{~mm}$ was placed inside the heater rod sandwiched between layers of boron nitride electrical insulation. The filament and insulation were enclosed within a two-piece cladding consisting of an inner sheath and outer wall cladding, both made of Inconel 600. Sixteen thermocouples equally spaced axially along the heated section were placed between the cladding and the sheath. The temperature of the heater rod was limited to a maximum of $600^{\circ} \mathrm{C}$. Figure 4.4 shows the internal structure of the heater rod.

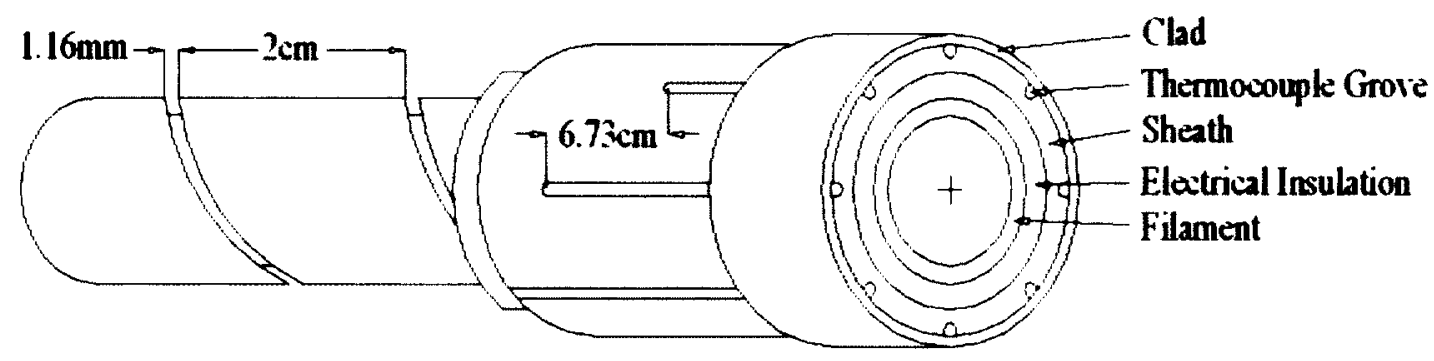

Figure 4.4: University of Wisconsin heater rod schematic [5]

The lead wires for the heating filament and the thermocouple wires all exited out the heater rod at both ends. This required that one end of the heater rod was free to move in order to make provision for thermal expansion. This was achieved by first reducing the diameter of the test-section conduit connecting to the heater rod and lowering its temperature with cooling coils. Then a Viton O-ring and a urethane Backup-ring were used to form a seal between the flange and the heater rod. Figure 4.5 shows this arrangement. 


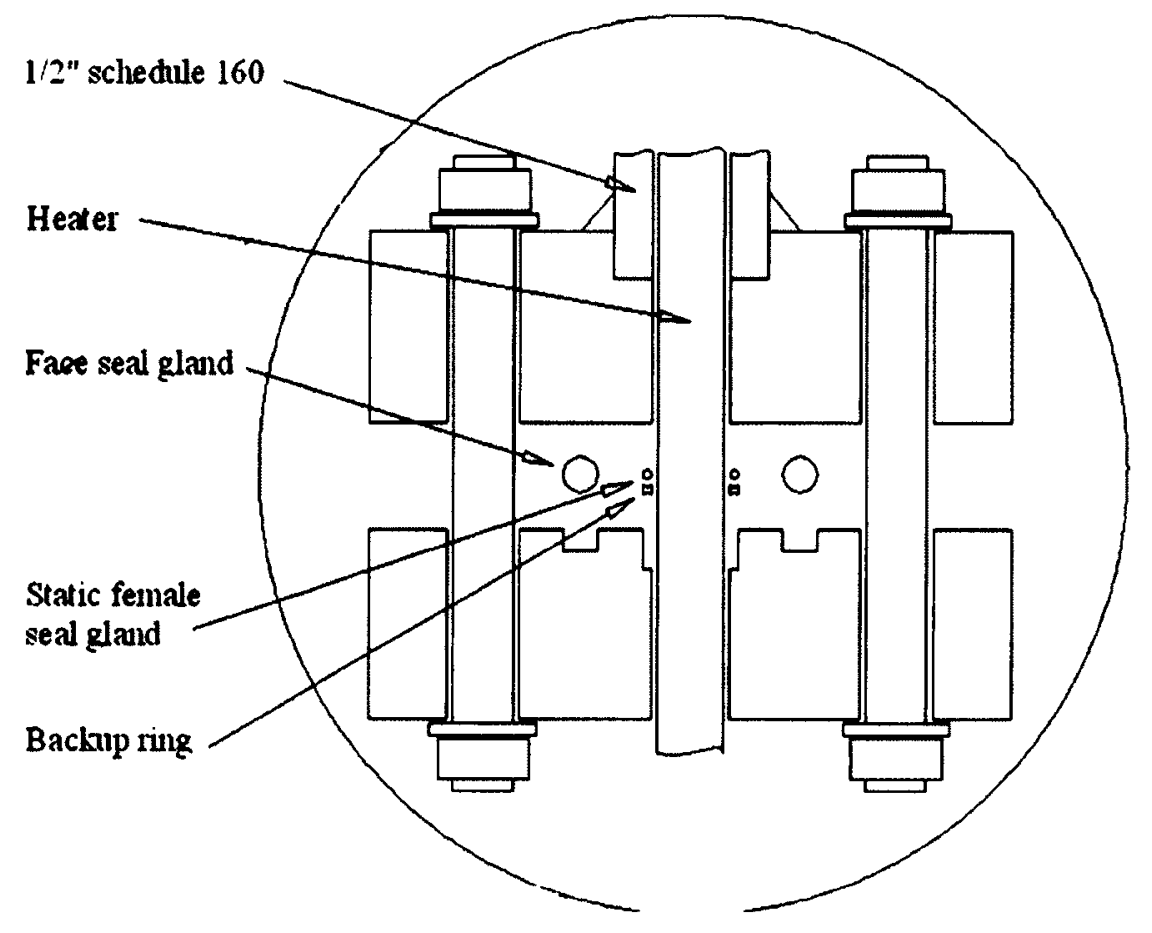

Figure 4.5: Pressure boundary allowing for differential thermal expansion [5]

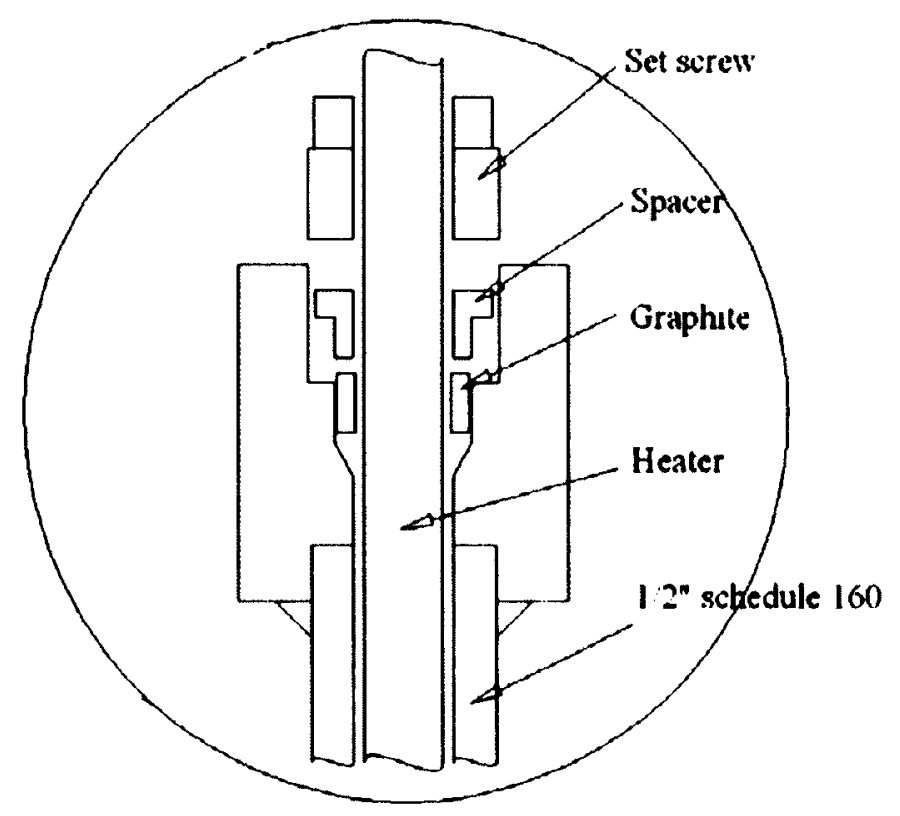

Figure 4.6: Fixed pressure boundary heater connection design [5] 
The other end of the heater was fixed with respect to the test section and the pressure sealing action was achieved with the help of a graphite compression type fitting. First the diameter of the pipe connecting with the heater rod was reduced and the temperature of the fluid was lowered with copper cooling coils. Then a screw bolt was used to compress a washer, which in turn compressed packed-graphite into the heater rod and fitting wall, effectively forming a fixed pressure barrier. This arrangement is shown in Figure 4.6.

\subsubsection{Xi'an Jiaotong University SCW Loop Test Sections}

Heat transfer to SCW in horizontally- and vertically-oriented test sections has been performed by many investigators [3]. To investigate heat transfer to SCW in intermediate orientations, Yin et al. [7] performed experiments in an upward-inclined test section.

The test section was made of $1 \mathrm{Cr} 18 \mathrm{Ni9Ti}$ stainless steel tube with an outer diameter of $32 \mathrm{~mm}$ and an inner diameter of $26 \mathrm{~mm}$. The $3 \mathrm{~mm}$-thick tubular test section had a heated length of $2000 \mathrm{~mm}$ with an overall length of $2120 \mathrm{~mm} .96$ type $\mathrm{K}$ thermocouples were installed at 14 cross-sections along the heated length of the test section to identify changes in the wall temperature, and two thermocouples each at the inlet and outlet of the test section were used to measure the fluid bulk temperature. A schematic of the test section depicting its dimensions and the locations of the thermocouples is shown in Figure 4.7. 


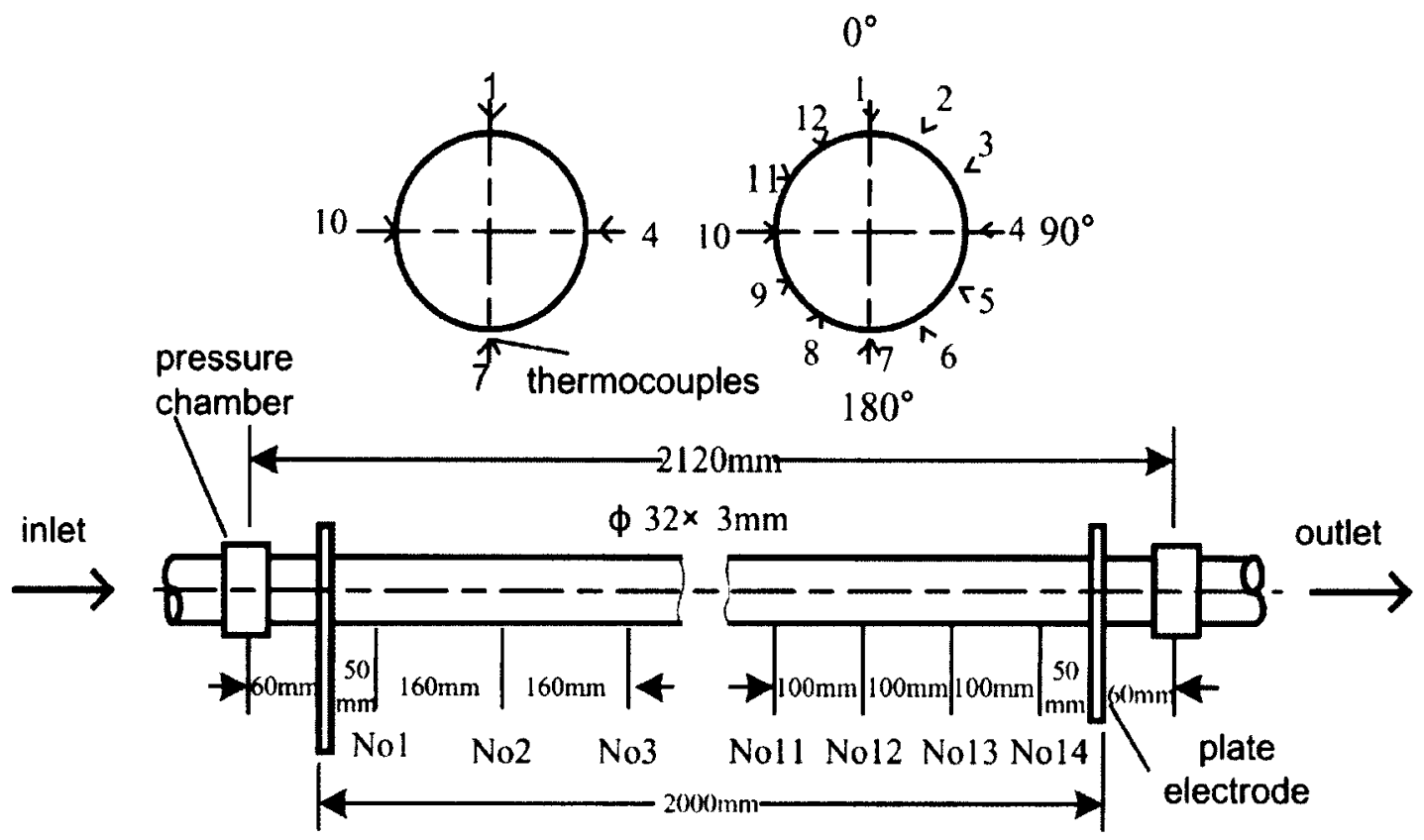

Figure 4.7: Xi'an Jiaotong University test section and thermocouple arrangement [7]

The test section was directly heated as a resistance element by alternating current. The test section could deliver up to $180 \mathrm{~kW}$ of heating power to the working fluid. However, the heat flux used in the experiments was limited to a range of $200-600 \mathrm{~kW} / \mathrm{m}^{2}$ based on the internal surface area of the test section. Experiments were performed for pressures up to $30 \mathrm{MPa}$ and mass fluxes between 600 and $1200 \mathrm{~kg} / \mathrm{m}^{2} \mathrm{~s}$. Based on the published data, the wall temperature of the test section was limited to a maximum of approximately $575{ }^{\circ} \mathrm{C}$. The limitation on the wall temperature allowed maximum fluid bulk temperatures as high as $475^{\circ} \mathrm{C}$, depending on the mass flux, heat flux and fluid temperature at the test-section inlet.

Laurien et al. [6] studied the effects of a wrapped wire around the heating rod on the Xi'an Jiaotong SCW loop. Their test section consisted of a circular pipe (1Cr18Ni9Ti) with 
a $10 \mathrm{~mm}$ outer diameter and a wall thickness of $2.5 \mathrm{~mm}$ placed inside a square channel with $15 \mathrm{~mm}$ side dimensions. A schematic of the test section is shown in Figure 4.8 .

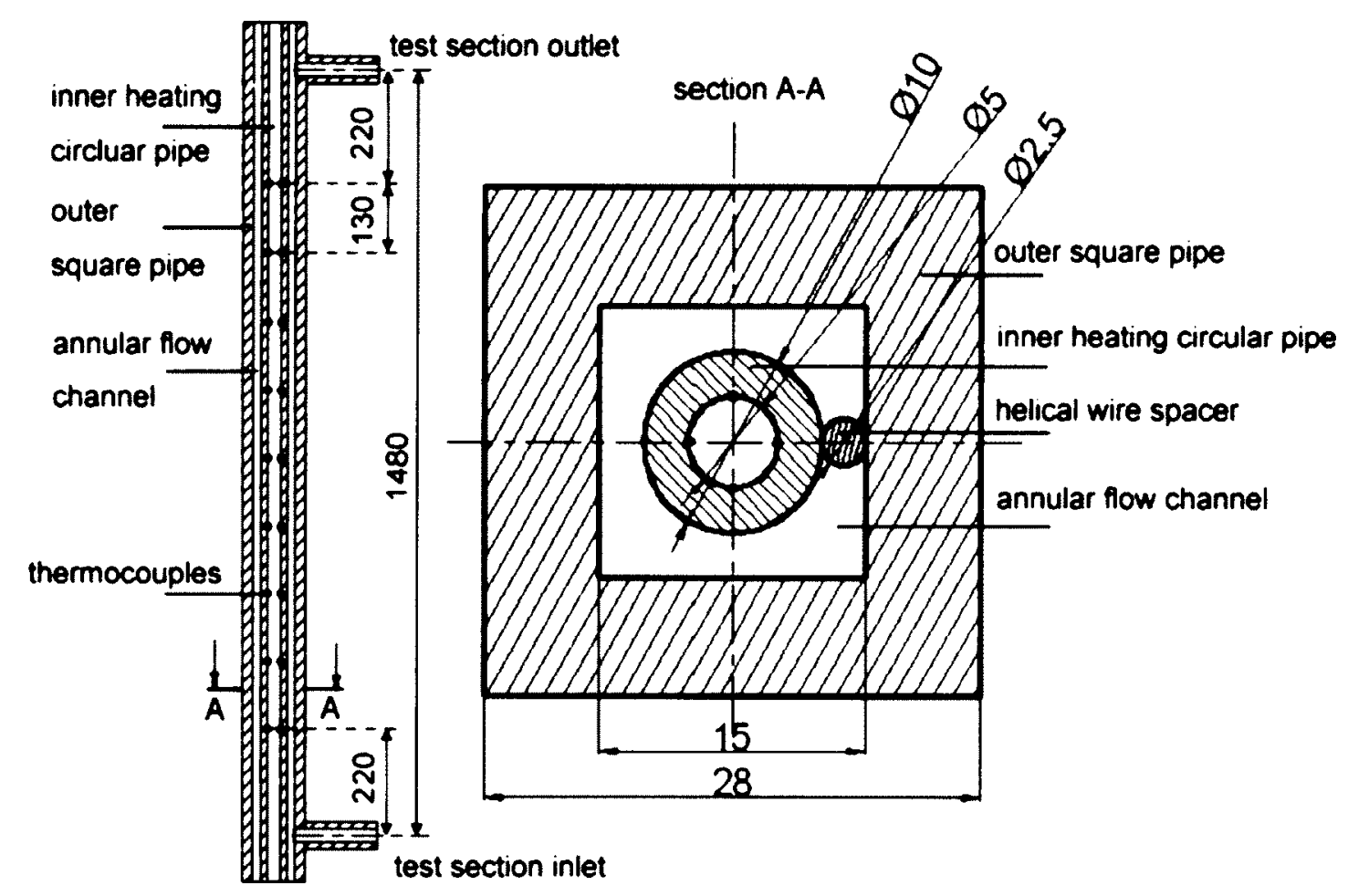

Figure 4.8: Xi'an Jiaotong University square annular test section (units in $\mathrm{mm}$ ) [6]

The heated test section is approximately $1500 \mathrm{~mm}$ long from the inlet to the outlet. Up to 18 thermocouples (type $\mathrm{K}$ and $0.2 \mathrm{~mm}$ sheath diameter) were evenly spaced along the internal wall of the circular pipe to measure the wall temperature. Similar thermocouples were used to measure the fluid bulk temperature at the inlet and outlet of the test section. To simulate helical wire-wrapped fuel pin spacers, a string of small ceramic tubes ( $2.5 \mathrm{~mm}$ diameter) were wrapped around the heated circular pipe in a helical manner. 
The test section was subjected to pressures in the range of 23-25 MPa and the testsection heat flux was varied from 200 to $800 \mathrm{~kW} / \mathrm{m}^{2}$. The heat flux allowed for a temperature rise ranging from less than $1^{\circ} \mathrm{C}$ to a maximum of $13^{\circ} \mathrm{C}$ across the length of the test section, depending on the fluid temperature at the test-section inlet and the fluid mass flux. The inlet temperature of the fluid was varied between 300 and $400{ }^{\circ} \mathrm{C}$ while the mass fluxes varied between 500 and $1200 \mathrm{~kg} / \mathrm{m}^{2} \mathrm{~s}$. Based on the published data, the wall temperature of the heated inner pipe was maintained below $500{ }^{\circ} \mathrm{C}$, however, under deteriorated heat transfer conditions, localized wall temperatures as high as $620^{\circ} \mathrm{C}$ were recorded.

In this test section, the inner circular pipe itself was directly heated by passing current through it and the thermocouples were installed on the inside of the heated rod. This requires that the current flowed only through the inner pipe and that the thermocouple wires exited out of the heater rod. Both objectives were achieved by using an insulated leak-proof seal as shown in Figure 4.9. This particular method of insulated sealing required cooling of the flanges, but did allow for the use of an electrically-insulating gasket between the flanges. 


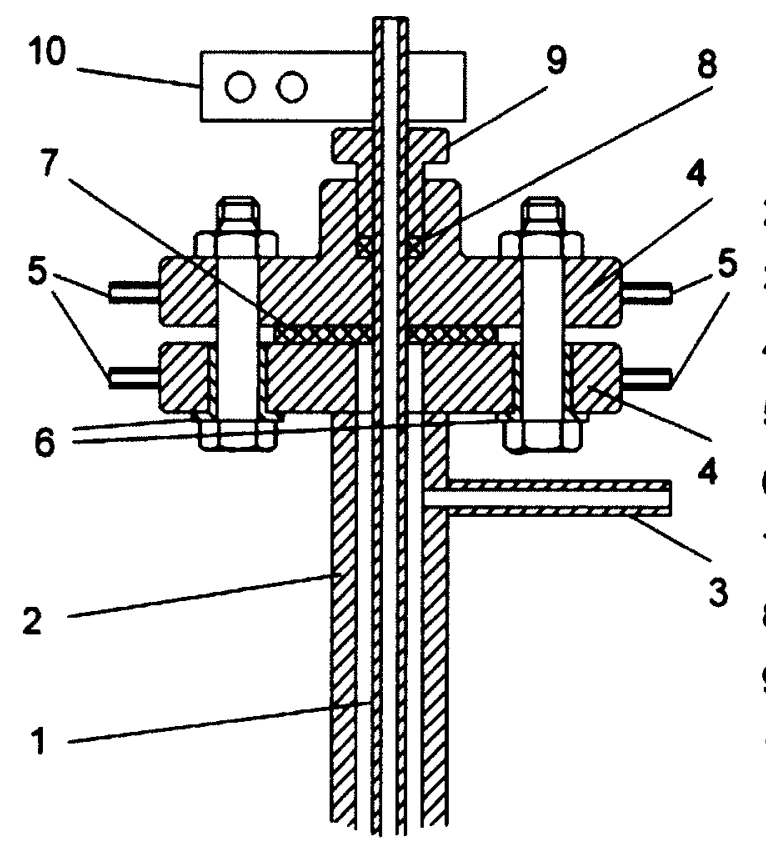

1. inner heating circular pipe

2. outer square pipe

3. test section outlet

4. flange

5. cooling piping for flange

6. insulation sleeve

7. gasket seal

8. gasket material

9. hold-down bolt

10. copper electrode plate

Figure 4.9: Leak-proof seal and insulation structure of the test section [6]

\subsubsection{Survey Conclusions}

The surveyed test sections involve three design philosophies. The tubular test-section design, where the pressure containing wall is directly heated by Joule heating and the heat transfer to the fluid takes place in the radially inwards direction, is the simplest design and for that reason the most widely used in heat transfer experiments involving SCW. Joule heating of the test section is achieved by connecting electrical power clamps at two desired locations on the test section. To avoid inadvertently heating up the rest of the loop, the continuous connection of the loop piping is dielectrically broken at least in one location outside the test section. Further, the measurement of test-section wall temperature for heat transfer study is carried out under atmospheric pressure by directly connecting thermocouples to the test-section outer surface. This method of 
gathering data for heat transfer is relatively simple and does not require any special considerations. This test section type needs to be designed for mechanical stresses as well as for Joule heating requirements.

The internally heated test-section design poses some challenges as far as the transmission of electrical power to the heated section and the measurement of relevant wall temperatures are concerned. In this design, it is important that only the internallylocated element of the test section that is used as the heater is heated and not the outer shrouding wall. To achieve this, two different heater element designs as discussed in Sections 4.2.2 and 4.2.3 are employed. In the first design, the heater rod is indirectly heated by Joule heating of a heating filament located inside the heater rod and electrically insulated from the heater rod outer clad. Thermocouples are positioned inside the heater rod between the heating filament and outer cladding for heat transfer studies. This heater rod type is simpler to use as it is electrically insulated from the outer test-section shroud by virtue of its design. Furthermore, since it is compacted with ceramic insulation on the inside, it does not require any special consideration regarding mechanical stresses due to the external pressure of the fluid.

In the second design, the Joule heating of the heater rod is accomplished by passing current directly through the heating rod itself. This poses the challenge of electrically insulating the heater rod from the outer shroud. It is achieved by using insulating gaskets. However, insulating gaskets are generally limited to a maximum temperature of 
$200{ }^{\circ} \mathrm{C}$ and therefore, the flanged connection that contains the insulating gasket must be cooled. This heater rod design is hollow, so it must be designed for both mechanical stresses and Joule heating requirements.

\subsection{Test-Section Design Recommendations}

A number of recommendations regarding design of a test section are provided in reference [3].

\section{Recommendation 1}

It is unlikely that a test section can fully simulate the thermalhydraulic behaviour of the actual fuel channel geometry. However, it is recommended that the test section hydraulic diameter is chosen close to the hydraulic-equivalent diameter of the average fuel channel. The hydraulic diameter of the 43-element fuel bundle that is considered for use in the CANDU-SCWR is approximately $8 \mathrm{~mm}$.

\section{Recommendation 2}

It is recommended that the electrical resistance of the heated part should be equal to or at least to be close to the nominal electrical resistance of the power supply. Only then the nominal power rating of the power supply can be applied to the test section. Otherwise, the power input to the test section will be limited by the nominal voltage of the power supply if the electrical resistance of the test section is larger than the internal resistance of the power supply or it will be limited by the nominal current of the power 
supply if the electrical resistance of the test section is lower than the internal resistance of the power supply.

\section{Recommendation 3}

The test section should be wrapped with thermal insulation to minimize heat loss. In case of circular insulation, the optimal insulation thickness value should be determined.

\section{Recommendation 4}

For heat transfer studies it is necessary to measure the fluid bulk temperature at the inlet and outlet of the test section. Mixing chambers together with sheathed thermocouples should be used immediately downstream and upstream of the test section for this purpose. Also, a flow stabilization zone with the same diameter as the test section should be installed between the inlet mixing chamber and the test section. The length of this stabilization zone is generally about 20 to 50 times the local diameter.

\section{Recommendation 5}

Electrical resistivity of material for directly heated test-section designs should be nearly independent of the material temperature. This ensures that the local heat flux remains uniform along the test section in spite of variable wall temperature if the test-section diameter and wall thickness are constant along the heated length. It is also desirable for the material to possess a relatively high value of specific electrical resistivity. This provides more flexibility for changing the test-section wall thickness and heated length. 
For these reasons, high nickel alloys, such as Inconel 718 are recommended for use in directly heated test-section designs (Figure 4.10).

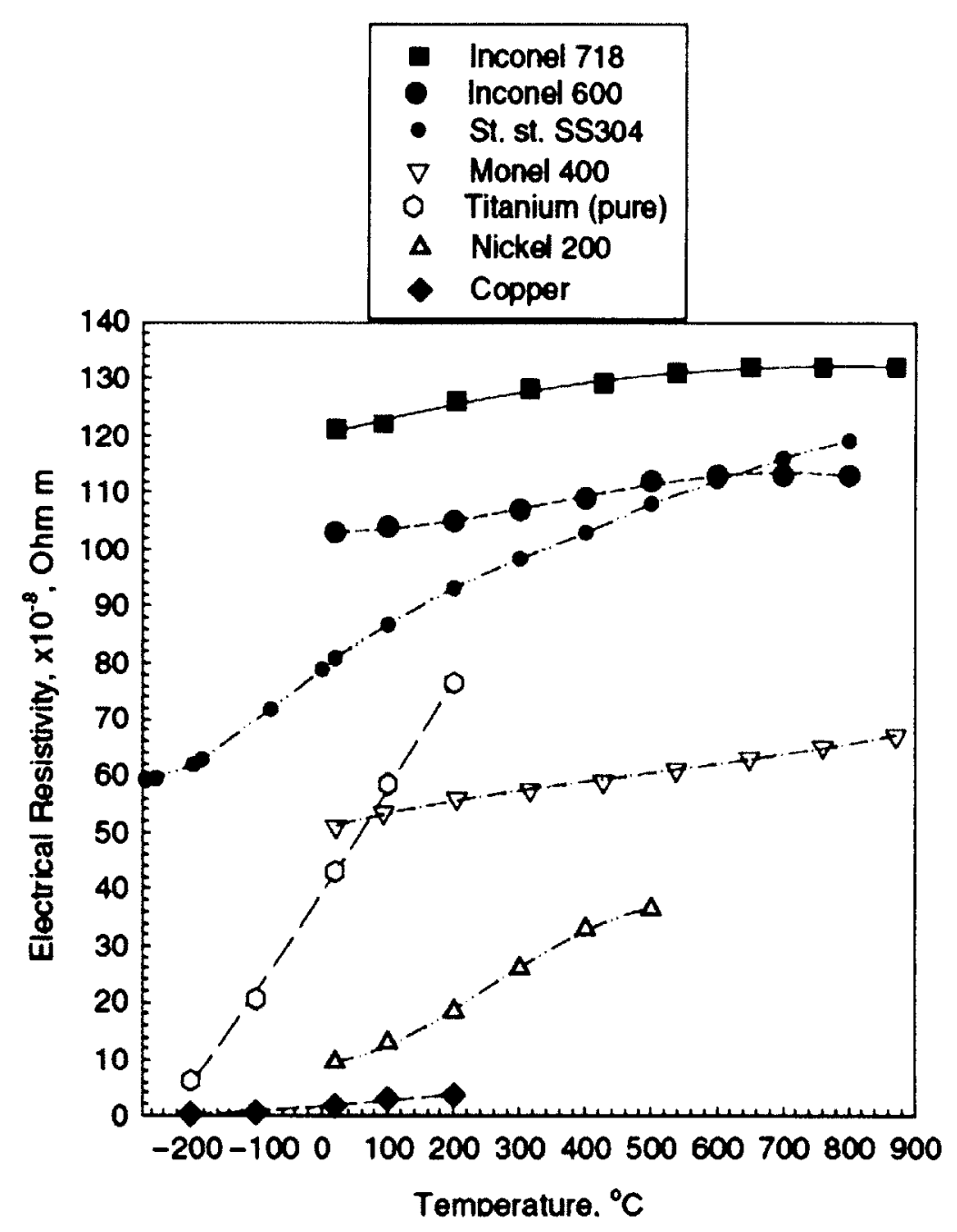

Figure 4.10: Effect of temperature on the electrical resistivity of various materials [3]

\subsection{Materials for the Test Section}

As described in Section 4.1, the test section will contain very high pressures of up to $27 \mathrm{MPa}$ and the fluid bulk temperature at the test-section outlet will be as high as 
$600^{\circ} \mathrm{C}$. As will be shown later, the test-section wall temperature will be higher than the fluid bulk temperature. Therefore, it is important that the test-section material has excellent high-temperature strength. The strength of the material at elevated temperatures plays a crucial role in facilitating the application of the nominal power rating of the power supply to the test section. Since the test section will be subjected to high temperatures in the presence of SCW, the corrosion resistance of the material under SCW conditions is also a significant factor. Additional characteristics affecting the selection of a suitable material for the test section are the physical properties of the material, such as the electrical resistivity, thermal conductivity and heat capacity. It is desirable for these material properties to be nearly independent of temperature. Also, since the test sections are designed according to the rules of the applicable ASME Codes, it is important that the material selected for the test sections is recognized by the ASME Codes to make the certification process of the test sections easier. These criteria reduce the pool of applicable materials for the test section.

Three nickel based superalloys, namely Inconel 625, Inconel 617 and Inconel N06230 are investigated for use as test-section material (for full description and properties of the materials, the reader is referred to Appendix B). All three ASME recognized materials have excellent high-temperature strength and corrosion properties. Furthermore, as evidenced by the graph of electrical resistivity versus temperature in Figure 4.11 , the electrical resistivity of each material is relatively stable over the temperature range expected during the operation of the test sections. Thus, any of the investigated 
materials can be used for the design of the test sections. However, there are some minor limitations, which are discussed below.

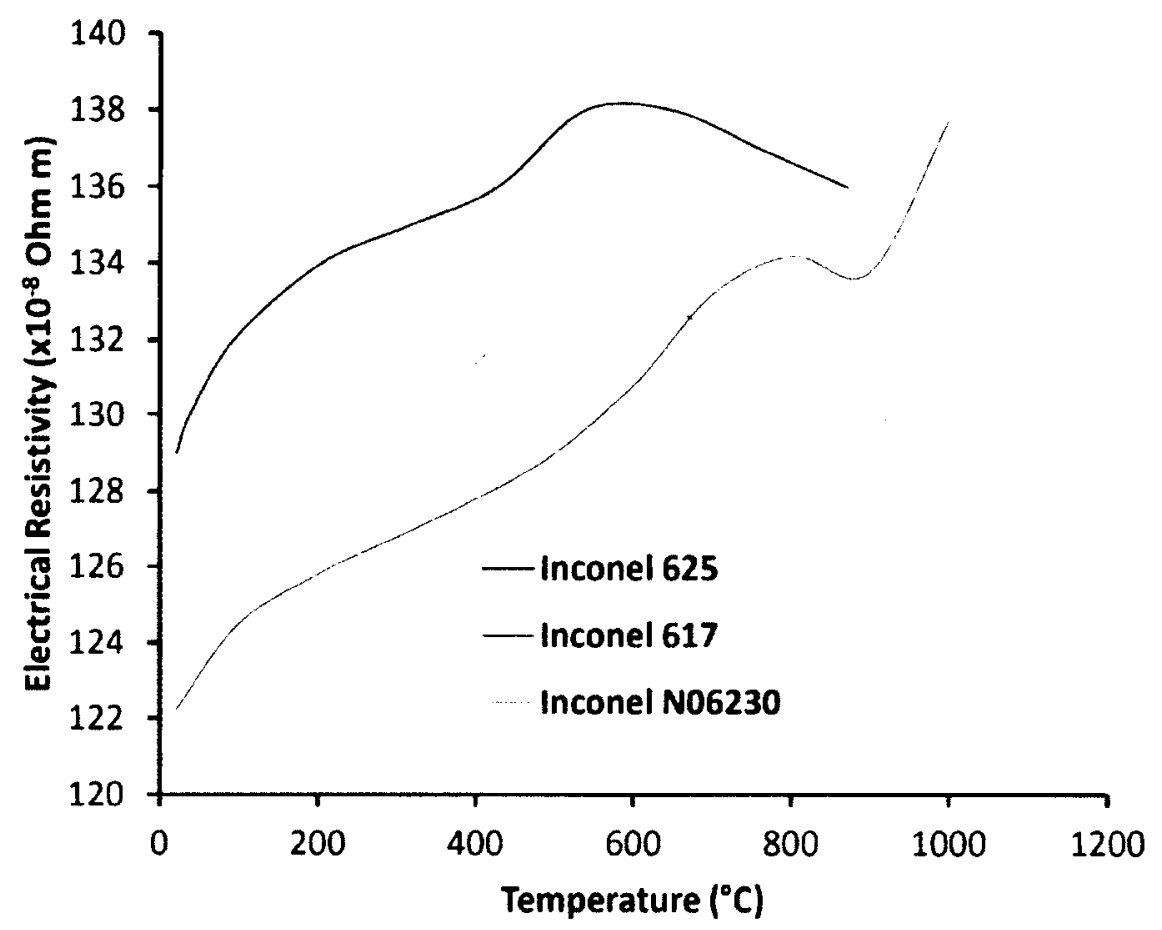

Figure 4.11: Electrical resistivity of superalloys as a function of temperature [57]

Based on its function, the test section can be considered an unfired pressure vessel as defined in ASME Boiler and Pressure Vessel Code, Section VIII, Division 1 (ASME VIII, Div. 1) [42]. As such, it may be designed based on the rules stipulated in the ASME code. Based on the maximum allowable stress values (ASME Section II, Part D) in the temperature range 600 to $850^{\circ} \mathrm{C}$, Inconel N06230 has the highest allowable stress for any of the three materials, followed by Inconel 617 and Inconel 625 . Both Inconel N06230 and Inconel 617 have a maximum allowable temperature of $982{ }^{\circ} \mathrm{C}$, whereas Inconel 625 is limited to a maximum temperature of $871^{\circ} \mathrm{C}[10]$. However, both 
Inconel 617 and Inconel N06230 are rather exotic materials with costs 2-3 times that of Inconel 625 and are not readily available. Therefore, for the heated parts of the test sections, Inconel 625 is selected as the preferred material of construction. The selection of Inconel 625 for the annular and bundle test-section designs is also driven by its relatively high compressive strength at the expected wall temperature range of the test section.

\subsection{Test-Section Designs for SCW and R-134a Loops}

\subsubsection{Tubular Test Section}

The wall thickness, in most cases, is a compromise between the required wall thickness to withstand the internal pressure of the fluid at the expected maximum test-section wall temperature and the wall thickness required to apply the nominal rating of the power supply to the test section. To calculate an optimal wall thickness, it is necessary to specify the heated length of the test section and the inner or outer diameter of the test section tube.

Based on the design of the Carleton SCW and R-134a loops, the maximum length between the inlet and outlet of the test section is approximately $2380 \mathrm{~mm}$. However, this entire length cannot be used as the heated length in case of the tubular test section due to the presence of Grayloc ${ }^{\mathrm{TM}}$ connectors. Therefore, a length of $2000 \mathrm{~mm}$ is selected for the heated part of the test section. The inner diameter (along with the wall thickness) of the test section is determined by an iterative process, where a compromise 
is struck among the heat transfer coefficient, pressure drop and power input to the test section, as will be discussed later. As a starting point, an inner diameter of $8 \mathrm{~mm}$ is selected. This inner diameter is close to the hydraulic diameter of the CANDU-SCWR fuel bundle and is therefore a suitable choice.

\subsubsection{Wall Thickness Sizing for Nominal Power Input}

The power supply has a nominal power rating of $300 \mathrm{~kW}(2000 \mathrm{~A}$ and $150 \mathrm{~V})$. In order to apply the nominal rating of the power supply to the test section, the internal electrical resistance of the power supply must be determined.

The relationship between electrical power $(P)$, electric current $(/)$ and Ohmic resistance $(R)$ is given by Joule's Law [58]:

$$
P=I^{2} R
$$

Substituting the values of power and current into the equation results in an internal resistance of $0.075 \Omega$.

Using the resistivity of Inconel 625 and the heated length of the test section, a crosssectional area with an equivalent resistance as the internal resistance of the power supply is calculated. The relationship between a conductor's cross-sectional area $\left(A_{C}\right)$, length (L), resistivity $(\rho)$ and resistance is given by the following equation [59]: 


$$
R=\rho \frac{L}{A_{C}}
$$

As shown in Figure 4.11, the electrical resistivity of Inconel 625 varies slightly between room temperature and a maximum of $1000{ }^{\circ} \mathrm{C}$. Therefore, an average resistivity of $134.5 \times 10^{-8} \Omega \cdot m$ over this temperature range is used in the above equation.

Substituting the known values yields:

$$
\begin{aligned}
& A_{C}=134.5 \times 10^{-8} \Omega \cdot m \frac{2 m}{0.075 \Omega} \\
& A_{C}=35.9 \times 10^{-6} \mathrm{~m}^{2}
\end{aligned}
$$

Since the inner diameter $(d)$ of the test-section tube is known, the determined crosssectional area can be translated to the required wall thickness ( $t_{e_{-}}$tubular $)$to apply the nominal power of the power supply to the heated length of the test section.

$$
\begin{aligned}
& t_{e_{-} \text {tubular }}=\sqrt{\frac{A_{C}}{\pi}+\left(\frac{d}{2}\right)^{2}}-\frac{d}{2} \\
& t_{e_{-} \text {tubular }}=1.20 \mathrm{~mm}
\end{aligned}
$$

\subsubsection{Wall Thickness Sizing for Internal Pressure}

Once the required wall thickness for the power supply nominal input power has been determined, it must be checked against the required wall thickness to withstand the 
internal pressure of the fluid. To determine the required wall thickness for internal pressure, the maximum test-section wall temperature must be evaluated.

The maximum test-section wall temperature depends on the heat flux input to the test section and the fluid mass flux, which in turn determines the fluid heat transfer coefficient. The input heat flux is determined from the power input to the test section and the inner surface area of the test-section heated length. The heat-transfer coefficient of SCW can be predicted with reasonable accuracy using the Dittus-Boetler correlation given in Equation (3.10). It is predicted that the minimum fluid heat transfer coefficient occurs at the minimum mass flow rate of $0.126 \mathrm{~kg} / \mathrm{s}$ (mass flux of 2500 $\mathrm{kg} / \mathrm{m}^{2} \mathrm{~s}$ based on $8 \mathrm{~mm}$ inner diameter test section). Figure 4.12 depicts the heat transfer coefficient $(h)$ of SCW as a function of fluid bulk temperature.

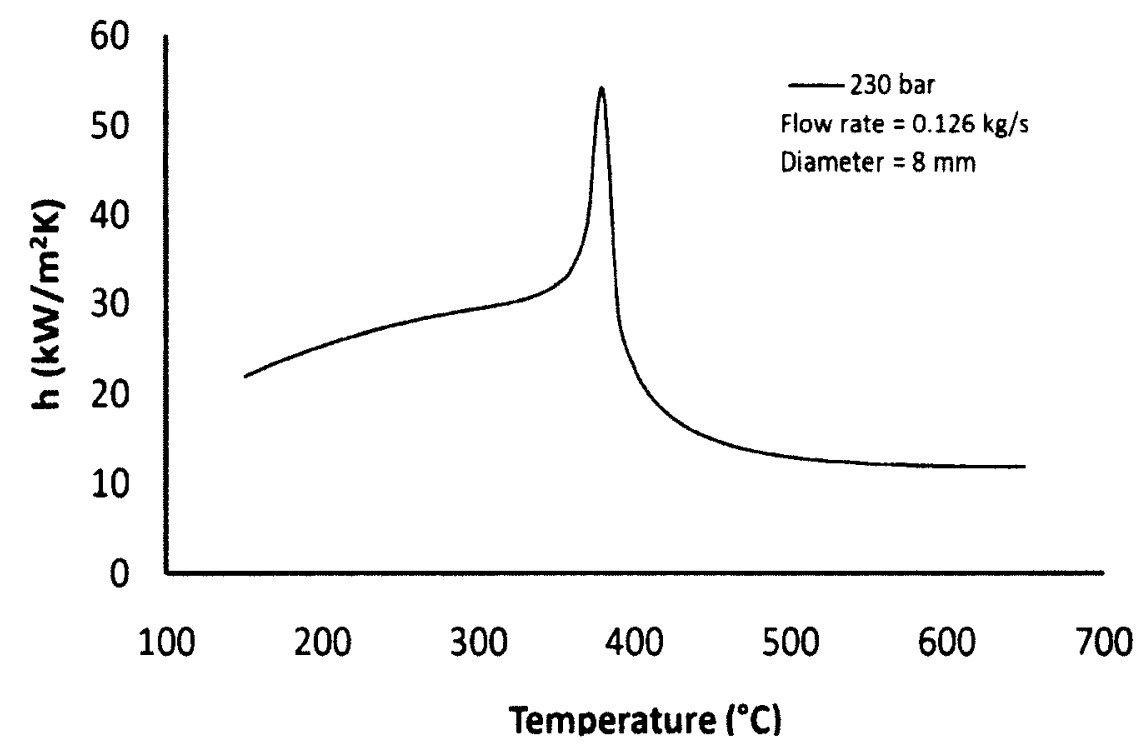

Figure 4.12: Heat transfer coefficient of SCW as function of fluid bulk temperature 
Based on Figure 4.12, it can be concluded that the maximum test-section wall temperature will occur at the test-section outlet where the fluid bulk temperature is $600^{\circ} \mathrm{C}$ and the fluid heat transfer coefficient has its minimum value.

Assuming an input power (Q) of $300 \mathrm{~kW}$ to the test section, the heat flux $(q)$ based on the inner surface area $\left(A_{S}\right)$ of the test section is calculated as:

$$
\begin{aligned}
& q=\frac{Q}{A_{s}}=\frac{300 \times 10^{3} \mathrm{~W}}{\pi\left(8 \times 10^{-3} \mathrm{~m}\right)(2 \mathrm{~m})} \\
& q=5.97 \times 10^{6} \frac{\mathrm{W}}{\mathrm{m}^{2}}
\end{aligned}
$$

Utilizing the determined heat flux and fluid heat transfer coefficient at a bulk temperature of $600^{\circ} \mathrm{C}$ from Figure 4.12 , the test-section wall temperature can be evaluated by the following equation [37]:

$$
q=h\left(T_{w}-T_{b}\right)
$$

In this equation, $T_{w}$ represents the test-section wall temperature and $T_{b}$ represents the fluid bulk temperature. Inserting the known parameters into the equation and evaluating the test-section wall temperature results in: 


$$
\begin{aligned}
& T_{w}=\frac{5.97 \times 10^{6} \frac{W}{m^{2}}}{11.9 \times 10^{3} \frac{W}{m^{2}{ }^{\circ} \mathrm{C}}}+600{ }^{\circ} \mathrm{C} \\
& T_{w}=1102{ }^{\circ} \mathrm{C}
\end{aligned}
$$

This wall temperature is extremely high. Based on ASME Section II, Part D, none of the previously researched materials is allowed to be used at such a high temperature. Furthermore, a wall thickness calculated to withstand the internal fluid design pressure of up to $28.35 \mathrm{MPa}$ at this temperature will be very large. This will result in a lower electrical resistance through the test section and consequently, the nominal power of the power supply will not be applied to the test section. Therefore, a compromise must be struck among the test-section heat flux, maximum fluid bulk temperature, required wall thickness for the maximum power input and the required wall thickness to withstand the fluid internal pressure.

As determined above, the wall temperature of the test section will be higher than the fluid bulk temperature. The amount of the temperature difference between the fluid bulk temperature and the test-section wall temperature will depend on the heat flux and the fluid heat transfer coefficient. Thus, to arrive at an optimal wall thickness, the maximum test-section wall temperature must be specified. The wall temperature of the test section must be monitored at all times during operation to ensure that the specified maximum wall temperature is not exceeded. 
To select the maximum test-section wall temperature, it is necessary to refer to the allowable stress for the test-section material as a function of temperature. Figure 4.13 illustrates the allowable stress for solution annealed Inconel 625 seamless tube/pipe and its dependence on temperature, as per ASME Section II, Part D. As depicted in the figure, the strength of the material drops quickly at temperatures above $650^{\circ} \mathrm{C}$, and at $800^{\circ} \mathrm{C}$ the allowable stress for Inconel 625 is reduced to $30.3 \mathrm{MPa}$.

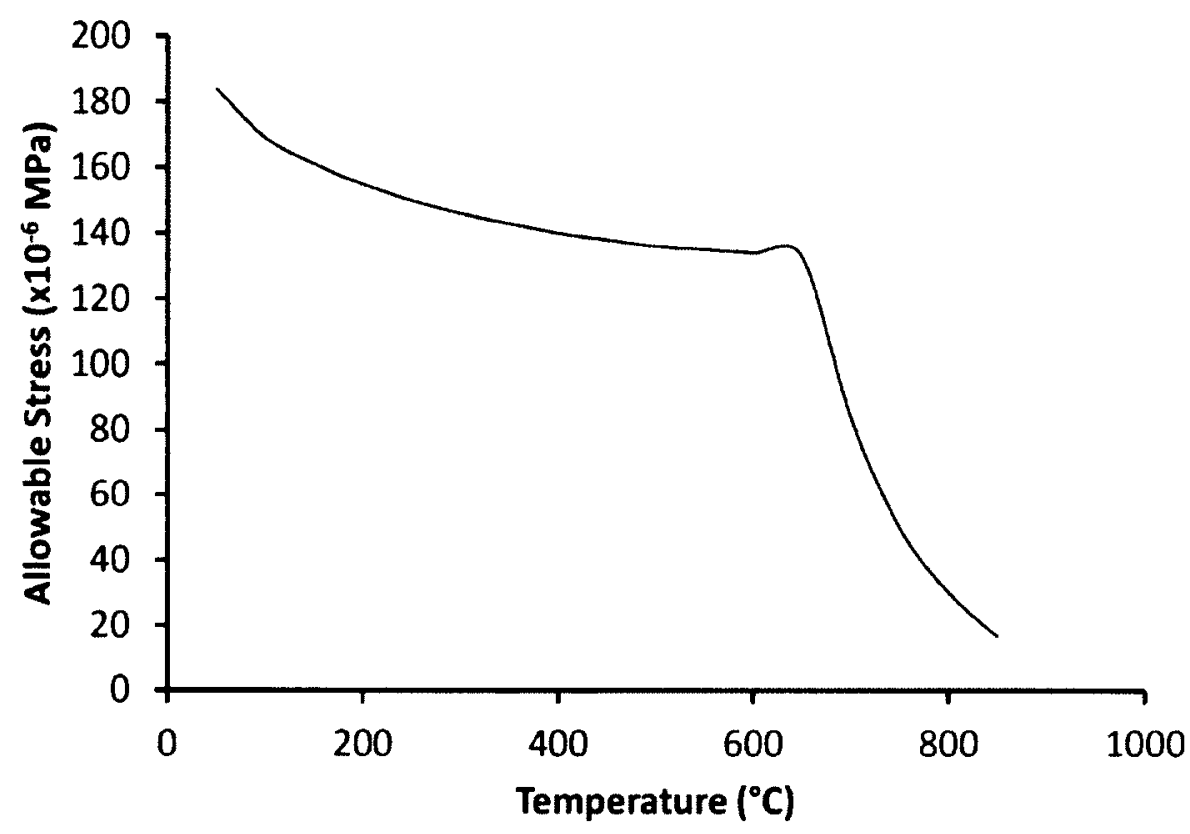

Figure 4.13: Allowable stresses for solution annealed Inconel 625 seamless tube/pipe as a function of temperature [10]

The required wall thickness of the test section under internal pressure is calculated as per Mandatory Appendix 1 of the ASME VIII, Div.1. Based on the ASME Code, the thickness of the test section under internal pressure must not be less than that calculated by the Equations (3.27), reproduced here as Equations (4.5): 
For $P>0.385 S_{f} E: \quad t=R\left(Z^{1 / 2}-1\right)$

$$
Z=\frac{S_{f} E+P}{S_{f} E-P}
$$

In these equations, $P$ is the design pressure, $R$ is the internal radius of the test section, $S_{f}$ is the maximum allowable stress at the design temperature from ASME Section II Part D, $E$ is the weld joint efficiency (unity for seamless tube/pipe), and $t$ is the minimum required wall thickness of the test section at the design temperature and pressure.

Using a design pressure of $28.35 \mathrm{MPa}$, the required wall thickness for various wall temperatures is calculated and the results are presented in Figure 4.14. As shown in the figure, the required wall thickness increases exponentially as the wall temperature is increased due to a similar exponential drop in the allowable stress for the test-section material within the specified temperature range.

At the test-section wall temperature of $800^{\circ} \mathrm{C}$, the required wall thickness is about $14 \mathrm{~mm}$. This wall thickness results in a large cross-sectional area, thereby drastically reducing the electrical resistance of the test section for Joule heating purposes. On the other hand, the required wall thickness for a test-section wall temperature of $650^{\circ} \mathrm{C}$ is approximately $1 \mathrm{~mm}$, which is smaller than the value calculated for $t_{e_{-}}$tubular. The wall thickness that is equivalent to $t_{e_{-} \text {tubular }}$ occurs at a temperature of about $680^{\circ} \mathrm{C}$. However, this temperature is only $80^{\circ} \mathrm{C}$ higher than the maximum fluid bulk 
temperature of $600{ }^{\circ} \mathrm{C}$. This low temperature difference between the fluid bulk temperature and the test-section wall temperature imposes a heat input limit based on Equation (4.4).

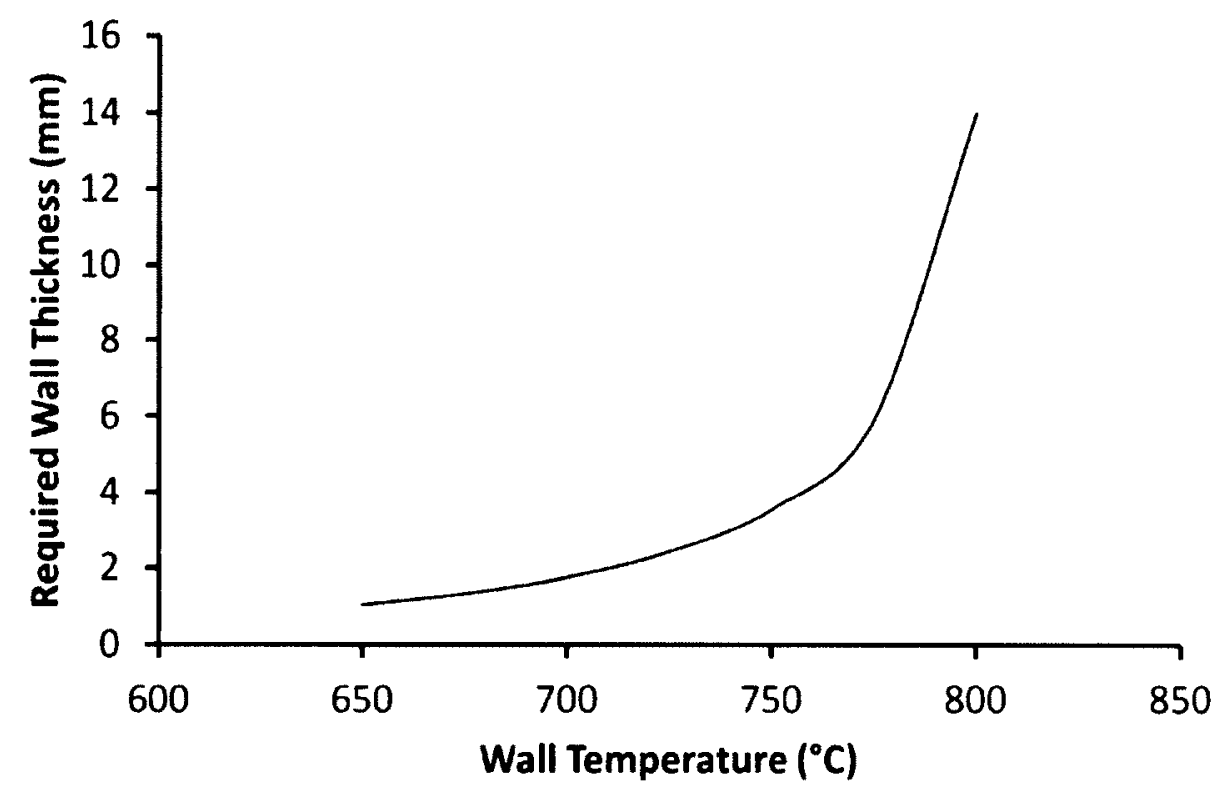

Figure 4.14: Required wall thickness as a function of wall temperature

Based on the surveyed test sections, the test-section wall temperature is generally limited to $150-200{ }^{\circ} \mathrm{C}$ above the maximum fluid bulk temperature. As discussed previously, limiting the test-section wall temperature to $800{ }^{\circ} \mathrm{C}\left(200{ }^{\circ} \mathrm{C}\right.$ above the maximum fluid bulk temperature) results in a relatively thick wall. Therefore, the maximum test-section wall temperature is selected to be $725^{\circ} \mathrm{C}$. This wall temperature results in a test-section wall thickness $(t)$ of $2.5 \mathrm{~mm}$.

Upon further evaluation of the selected inner diameter, it is determined that the resulting pressure drop is too high and it exceeds the capabilities of the purchased SCW 
loop pump. A number of progressively larger inner diameter values are evaluated against pressure drop, estimated heat transfer coefficient and the required wall thickness to withstand the internal pressure in an iterative manner based on the foregoing procedure. It is determined that a $12.5 \mathrm{~mm}$ inner diameter value results in the right balance among all the parameters listed above. To withstand the maximum operating pressure of $27 \mathrm{MPa}$ at a maximum test-section wall temperature of approximately $723^{\circ} \mathrm{C}$, a $3.5 \mathrm{~mm}$ thick tube wall is required.

\subsubsection{Specifications of the Tubular Test Section}

The selected test-section design has an ID of $12.5 \mathrm{~mm}$ and a wall thickness equal to $3.5 \mathrm{~mm}$. The heated length of the test section is $2000 \mathrm{~mm}$. The selected wall thickness is larger than the one required for the application of the nominal power rating of the power supply. Therefore, it is necessary to re-evaluate the capabilities of the test section for the selected wall thickness and maximum wall temperature, and to determine whether the power input to the test section is limited by the available amperage from the power supply or the selected maximum wall temperature of the test section.

Using Equation (4.3), the cross-sectional wall area of the test section is determined to be approximately $1.76 \times 10^{-4} \mathrm{~m}^{2}$. Substituting this value for the cross-sectional area in Equation (4.2) and using the values for the average resistivity and heated length of the test section, the electrical resistance of the test section is evaluated to be $15.3 \mathrm{~m} \Omega$. 
Using Joule's Law from Equation (4.1), the power dissipated on the test section when a current of 2000 A flows through its cross-section is calculated to be approximately $61.2 \mathrm{~kW}$. This power input results in a heat flux of $779 \mathrm{~kW} / \mathrm{m}^{2}$ based on the inner surface are of the test section.

The estimated power input to the test section based on the specified maximum testsection wall temperature can be determined by using Equation (4.4). In order to maintain the test-section wall temperature at $723{ }^{\circ} \mathrm{C}$ when the fluid bulk temperature and heat transfer coefficient are $600^{\circ} \mathrm{C}$ and $5.3 \times 10^{3} \mathrm{~W} / \mathrm{m}^{2} \mathrm{~K}$, respectively, the maximum heat flux should be maintained at $660 \mathrm{~kW} / \mathrm{m}^{2}$. Based on the inner surface area of the test section $\left(A_{S}=7.85 \times 10^{-2} \mathrm{~m}^{2}\right)$, the resulting power input is approximately $51.5 \mathrm{~kW}$.

The heat flux and consequently heat input to the test section is limited by the maximum allowable test-section wall temperature when the fluid bulk temperature is $600^{\circ} \mathrm{C}$. It equals $660 \mathrm{~kW} / \mathrm{m}^{2}$ at a fluid mass flux of $1050 \mathrm{~kg} / \mathrm{m}^{2} \mathrm{~s}$ and fluid bulk temperature of $600^{\circ} \mathrm{C}$

\subsubsection{Design of the Tubular Test Section}

The test section consists of a $19.5 \mathrm{~mm}$ outer diameter, $3.5 \mathrm{~mm}$ wall thickness Inconel 625 tube welded to two Grayloc ${ }^{\mathrm{TM}}$ reducing hubs made of Inconel 625 . The overall length of the test section between the faces of the two hubs is $2169.5 \mathrm{~mm}$. Two copper bus bars $2000 \mathrm{~mm}$ apart are attached to the Inconel tube. The copper bus bars 
are $20 \mathrm{~mm}$ wide and $15 \mathrm{~mm}$ thick. They are secured in place with the help of nuts and bolts. The bolts have a $6.4 \mathrm{~mm}(1 / 4 \mathrm{in})$ diameter and are $50 \mathrm{~mm}(2 \mathrm{in})$ in length.

The test section tube and Grayloc ${ }^{\top M}$ reducing hubs are joined together with the help of full penetration butt welds. This type of weld joint results in high strength and weld integrity.

For purposes of temperature measurement, type $\mathrm{N}$ thermocouples can be directly spot welded or securely clamped onto the test section tube at $100 \mathrm{~mm}$ axial intervals similar to Yamagata's test section [4]. At each $100 \mathrm{~mm}$ interval, up to four type $\mathrm{N}$ thermocouples can be spot welded or clamped at four angular positions of $0^{\circ}, 90^{\circ}, 180^{\circ}$ and $270^{\circ}$. Therefore, a maximum of 76 type $\mathrm{N}$ thermocouples $(0.5 \mathrm{~mm}$ sheath diameter $)$ are required for this test section.

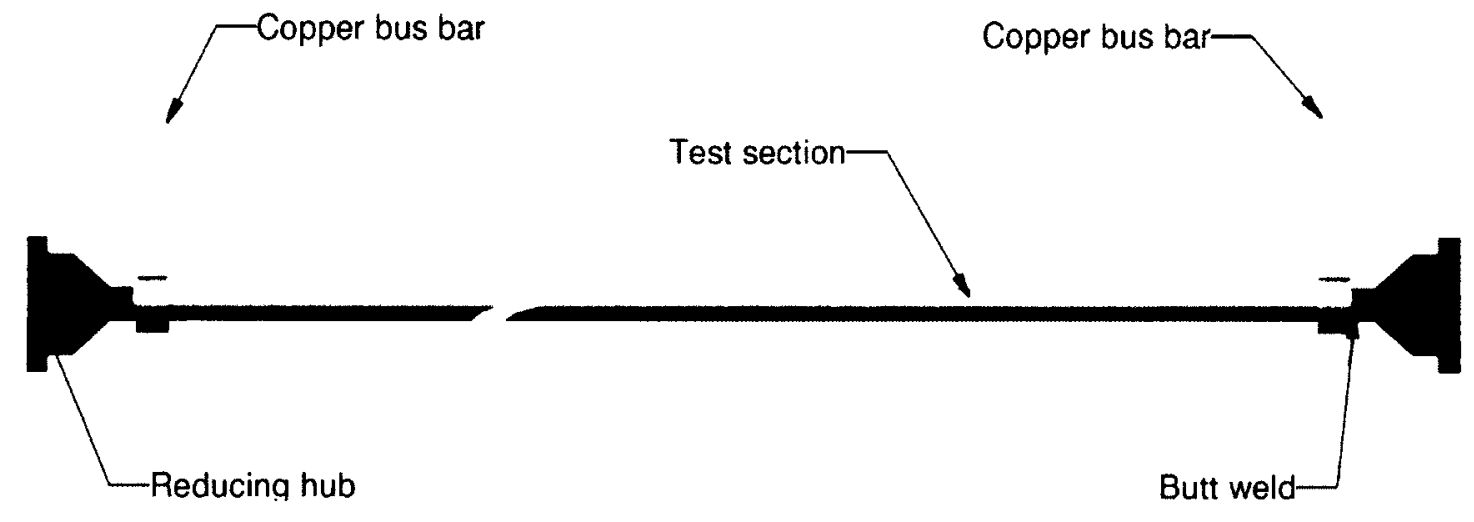

Figure 4.15: Tubular test section overview 


\subsubsection{Annular Test Section}

The annular test section constitutes the internally heated design. The inner rod, which is used as the heating element, is required to be hollow and internally accessible for temperature measurements. As such, the final required wall thickness will be a compromise between the wall thickness required to withstand the fluid pressure at the maximum predicted test-section wall temperature and the required wall thickness to apply the nominal power rating of the power supply to the test section. To determine an optimal wall thickness, the heated length of the test section, and the inner or outer diameter of the test section must be specified.

Unlike the tubular test section, the length of the annular test section is not restricted by the Grayloc ${ }^{\top M}$ connectors and the maximum full length between the inlet and outlet (2380 $\mathrm{mm}$ ) can be used as the heated length. However, to provide for a flow stabilization length as per Recommendation 4 stated in Section 4.3, a test-section length of $2000 \mathrm{~mm}$ is selected. The flow stabilization length of approximately $380 \mathrm{~mm}$ is over 47 diameters (based on the hydraulic diameter as evaluated below), which is well within the recommended 20-50 diameter range. In the case of the annular test-section design, the wall thickness is evaluated based on the outer diameter of the inner rod. Based on the surveyed test sections and closeness to the CANDU-SCWR reactor fuel pin, an outer diameter of $10 \mathrm{~mm}$ is selected. To comply with Recommendation 1 and the proposed hydraulic diameter (Table 4.1), the inner diameter of the outer shell is selected as $18 \mathrm{~mm}$. This results in a hydraulic diameter of $8 \mathrm{~mm}$. 


\subsubsection{Wall Thickness Sizing for Nominal Power Input}

The requirements for the sizing of the test section based on the power supply nominal power input are similar to those for the tubular test section. To apply the nominal power rating of the power supply $(300 \mathrm{~kW})$ to the test section, the electrical resistance of the test section must match the internal electrical resistance of the power supply.

The internal electrical resistance of the power supply is evaluated in Section 4.5.1.1 and it is found to be $0.075 \Omega$.

The cross-sectional area $\left(A_{C}\right)$ with an equivalent resistance as the internal resistance of the power supply is calculated using Equation (4.2) by substituting an average resistivity ( $\rho$ ) value of $134.5 \times 10^{-8} \Omega \cdot \mathrm{m}$ for Inconel 625 and a test section length equal to $2000 \mathrm{~mm}$, and it is evaluated to be $35.9 \times 10^{-6} \mathrm{~m}^{2}$.

Using a modified version of Equation (4.3), the required wall thickness ( $t_{e_{-} \text {annular }}$ ) to apply the nominal power of the power supply to the heated length of the test section, with a particular outer diameter $(D)$ of the inner rod is given by Equation (4.7). Inserting the numerical equivalents of the outer diameter and the cross-sectional area into the equation, the required wall thickness is determined to be:

$$
t_{e_{-} \text {annular }}=\frac{D-\sqrt{D^{2}-\frac{4 A_{C}}{\pi}}}{2}
$$




$$
t_{e_{\_} \text {annular }}=1.31 \mathrm{~mm}
$$

\subsubsection{Wall Thickness Sizing for External Pressure}

After determining the required wall thickness for nominal heating, this thickness value must be compared with the required wall thickness to withstand the external pressure exerted by the fluid on the inner rod. To determine the required wall thickness for external pressure, the maximum test-section wall temperature must be evaluated.

The maximum test-section wall temperature is dependent on the heat flux input to the test section and the fluid mass flux, which in turn determines the fluid heat transfer coefficient. The heat flux is determined from the power input to the test section and the outer surface area of the heated inner rod. Similar to the tubular test section, the heat transfer coefficient of supercritical working fluid in the annular test section can be predicted with reasonable accuracy using the Dittus-Boetler correlation [5]. It is predicted that the minimum fluid heat transfer coefficient occurs at the minimum mass flow rate of $0.126 \mathrm{~kg} / \mathrm{s}$. Figure 4.16 shows the heat transfer coefficient $(h)$ of SCW as a function of the fluid bulk temperature of the annular test section.

Based on the heat transfer values shown in Figure 4.16 and a preliminary input power of $300 \mathrm{~kW}$, it can be shown that as seen with the tubular test section, the maximum annular test-section wall temperature occurs at the maximum fluid bulk temperature of $600{ }^{\circ} \mathrm{C}$. Unlike the tubular test section, where the wall thickness was optimized only for 
the current carrying capacity and the required structural strength of the test section to withstand the internal pressure, the design of the annular test section imposes a third limitation based on the allowable internal diameter of the inner heater rod.

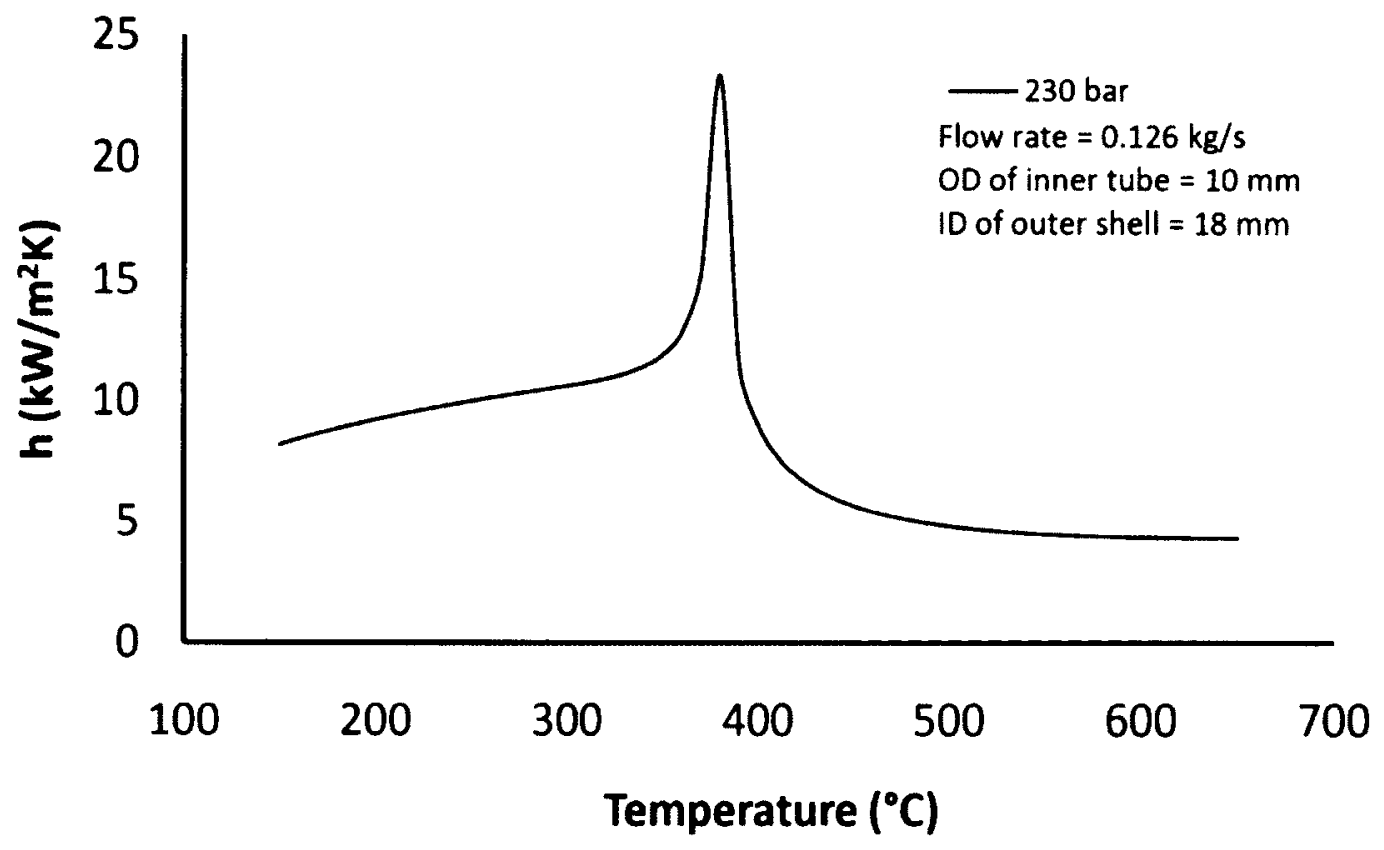

Figure 4.16: Predicted heat transfer coefficient of SCW as a function of fluid bulk temperature in the annular test section

The inner heater rod is hollow to allow temperature measurements at the inner surface of the rod. The temperature measurement probe requires a certain minimum space which affects the minimum inner diameter of the heater rod. It was determined to allow an inner diameter of $5 \mathrm{~mm}$ for the temperature measuring mechanism. Hence, based on the $10 \mathrm{~mm}$ outer diameter, a wall thickness of $2.5 \mathrm{~mm}$ is permitted for the inner heater rod. Therefore, the maximum pressure and temperature combination that can be withstood by this wall thickness value should be evaluated. 
Unlike the design of the test section for internal pressure, there is no one formula, which can be used to determine the required wall thickness to withstand the imposed external pressure. Determination of the wall thickness for external pressure requires an iterative procedure, which is dependent on the length, the use, size, and spacing of stiffening rings among other factors such as the magnitude of the pressure and the concurrent temperature. The procedure is outlined in ASME Section VIII, Div. 1 (UG$28(c)(2))[42]$. In the current design, a wall thickness is already given based on the required internal diameter for the temperature measurement probe and the outside diameter of the heater rod. Therefore, it is checked to determine if the given wall thickness can withstand the exerted external pressure of the supercritical working fluid.

The maximum allowable pressure (the lesser of $P_{a 1}$ or $P_{a 2}$ ) that can be accommodated for a given wall thickness is calculated by the following equations [42]:

$$
\begin{aligned}
& P_{a 1}=\left(\frac{2.167}{D / t}-0.0833\right) B \\
& P_{a 2}=\frac{2 S}{D / t}\left(1-\frac{1}{D / t}\right)
\end{aligned}
$$

In these equations, $D$ is the outside diameter of the tube/shell, $t$ represents the wall thickness, $B$ is a factor determined from applicable material chart in ASME Section II, Part D Subpart 3 and $S$ is the allowable stress value determined according to the rules of $U G-28(c)(2)$ 
Performing the calculations, it is determined that a $2.5 \mathrm{~mm}$ thick tube with a $10 \mathrm{~mm}$ outside diameter can withstand a maximum external pressure of $28.13 \mathrm{MPa}$ at $780^{\circ} \mathrm{C}$.

\subsubsection{Wall Thickness Sizing of the Outer Shell for Internal Pressure}

The sizing of the annular test-section outer shell for internal pressure is carried out exactly in the same manner as the tubular test section. To ensure that the outer shell can withstand high temperatures due to possible radiation heat transfer from the inner heater rod and the possibility of using the outer shell as a tubular test section in future experiments, a design temperature of $690^{\circ} \mathrm{C}$ is selected. The design pressure remains the same as for the external pressure, i.e. $28.35 \mathrm{MPa}$. Applying Equation (4.5) with the numerical equivalents of various factors and solving for the wall thickness results in $3.3 \mathrm{~mm}$. For the test-section design, a wall thickness of $3.5 \mathrm{~mm}$ is selected resulting in an outer diameter of $25 \mathrm{~mm}$.

\subsubsection{Discussion on the Annular Test Section}

It is determined that the given wall thickness allows a maximum wall temperature of $780^{\circ} \mathrm{C}$ at a maximum pressure of $28.13 \mathrm{MPa}$. The resulting allowable maximum pressure is close to the design pressure of $28.35 \mathrm{MPa}$ and is therefore an acceptable value. However, the maximum allowable test-section temperature will affect the maximum power input due to the low convective heat transfer coefficient of SCW at the high end of the bulk temperature spectrum. Using Equation (4.4), the maximum heat flux input to the test section can be evaluated for bulk and wall temperatures of $600{ }^{\circ} \mathrm{C}$ and $780^{\circ} \mathrm{C}$, 
respectively, and fluid heat transfer coefficient of $4.36 \mathrm{~kW} / \mathrm{m}^{2} \mathrm{~K}$ (taken from Figure 4.16 at fluid bulk temperature of $600^{\circ} \mathrm{C}$ ).

$$
\begin{aligned}
& q=4.36 \times 10^{3} \frac{W}{m^{2} K}(780-600) K \\
& q=784 \times 10^{3} \frac{W}{m^{2}}
\end{aligned}
$$

The maximum power input based on the outer surface area of the heater rod is calculated to be approximately $50 \mathrm{~kW}$. This power input value can be increased by reducing the hydraulic diameter of the annulus thereby increasing the heat transfer coefficient of the SCW. For this very reason, annuli test sections generally have a gap of 0.3-1.65 $\mathrm{mm}$ [3]. However, reducing the hydraulic diameter to the values suggested above would result in substantial deviation from the CANDU fuel bundle hydraulic diameter of approximately $8 \mathrm{~mm}$. Additionally, attempts to reduce the hydraulic diameter of the current annular test-section design resulted in very large pressure drops in the test section, which cannot be compensated with the available pump head.

\subsubsection{Specifications of the Annular Test Section}

The inner heater rod of the annular test-section design has inner and outer diameters of $5 \mathrm{~mm}$ and $10 \mathrm{~mm}$, respectively, with a total heated length of approximately $2000 \mathrm{~mm}$. The outer shell has an inner diameter of $18 \mathrm{~mm}$ and an outer diameter of $25 \mathrm{~mm}$. Since the $2.5 \mathrm{~mm}$ wall thickness of the inner heater rod is different from the wall thickness 
required for the nominal power supply power input to the test section, it is necessary to re-evaluate the capabilities of the test section for the selected wall thickness and maximum wall temperature, and to determine whether the power input to the test section is limited by the available amperage from the power supply or the selected maximum wall temperature of the test section.

Based on the given inner and outer diameters of the heater rod, its wall cross-sectional area is determined to be approximately $5.9 \times 10^{-5} \mathrm{~m}^{2}$. Substituting this value for the cross-sectional area in Equation (4.2) and using the values for the average resistivity and heated length of the test section, the electrical resistance of the test section is evaluated to be $45.7 \mathrm{~m} \Omega$. Using Joule's Law from Equation (4.1), the power dissipated in the test section when a current of 2000 A flows through its cross-section is calculated to be approximately $183 \mathrm{~kW}$. This power input results in a heat flux of $2.91 \mathrm{MW} / \mathrm{m}^{2}$ based on the outer surface area of the heater rod.

The estimated power input to the test section based on the specified maximum testsection wall temperature is determined previously and it is found to be $50 \mathrm{~kW}$. The corresponding heat flux based on the outer surface area of the heater rod is $784 \mathrm{~kW} / \mathrm{m}^{2}$.

Therefore, the heat flux and consequently the heat input to the test section are limited by the maximum allowable wall temperature of $780^{\circ} \mathrm{C}$. The heat flux equals $784 \mathrm{~kW} / \mathrm{m}^{2}$ at a fluid mass flux of $716.2 \mathrm{~kg} / \mathrm{m}^{2} \mathrm{~s}$ and maximum fluid bulk temperature of $600^{\circ} \mathrm{C}$. 


\subsubsection{Design of the Annular Test Section}

The annular test-section is designed to interface with the inlet and outlet ports provided by the SCW and R-134a loops. The interfacing is achieved similar to the tubular test section with the help of reducing Grayloc ${ }^{\top M}$ connectors. The distance between the two Grayloc $^{\mathrm{TM}}$ hub faces is $2169.5 \mathrm{~mm}$, and $2000 \mathrm{~mm}$ is the proposed heated length of the annular test section. Figure 4.17 shows an overview of the annular test section.

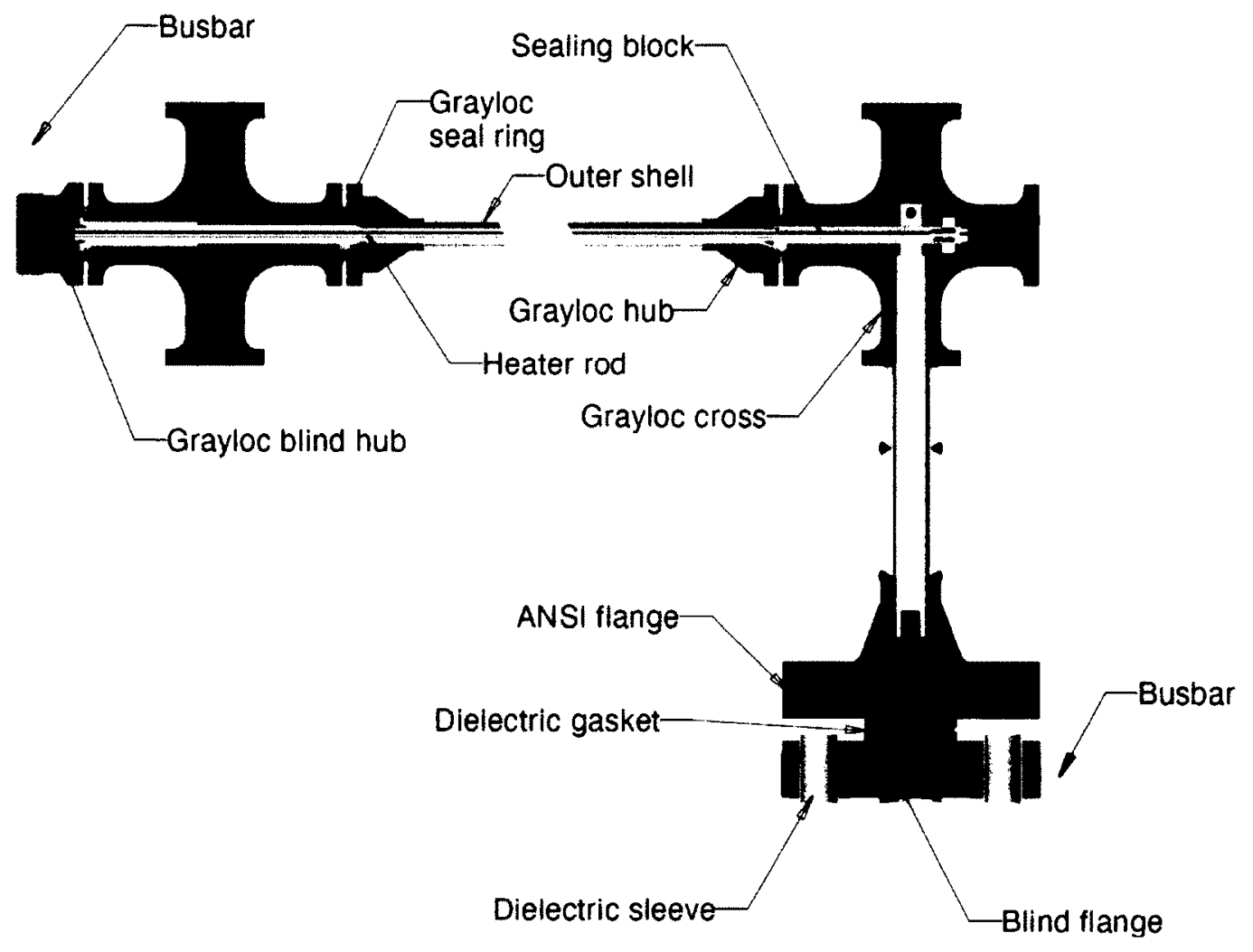

Figure 4.17: Annular test-section overview

The transmission of power to the heater rod takes place over a dielectrically isolated blind flange. The blind flange is isolated from the mating flange with the help of Pikotek $^{\text {TM }}$ dielectric isolating kit, which comes with dielectric sleeves for isolation of nuts 
and bolts. Bus bars connected to the blind flange carry the current to the sealing block. From the sealing block, electric current flows through the heater rod, at the end of which a Grayloc ${ }^{\top m}$ blind hub is socket welded. A copper bus bar attached to the blind hub completes the electric circuit.

This type of test-section arrangement allows access to the interior of the heater rod only from one end for temperature measurement purposes. The sealing block on the opposite end closes off the heater rod during operation. The sealing block consists of a compression packing type pressure seal (Figure 4.18). A washer pushes the graphite packing against the throat and the nut screw thereby achieving a leak-proof seal. The nut screw is intended for use with the temperature measurement probe. The connection between the sealing block and the heater rod is achieved with the help of socket welding. The design of the compression packing sealing assembly is based on a similar design given in [5].

The bus bar attached to the sealing block allows for thermal expansion of the heater rod in the axial direction. The proposed bus bar material for the interior of the test section is copper due to its excellent current carrying capacity and tribological characteristics.

The dielectrically isolated blind flange assembly is located further away from the test section to avoid high temperatures due to the low temperature rating of the isolating gasket. The Pikotek ${ }^{\mathrm{Tm}}$ isolating gasket is rated only up to $200{ }^{\circ} \mathrm{C}$ for a Class 2500 flange [23]. 


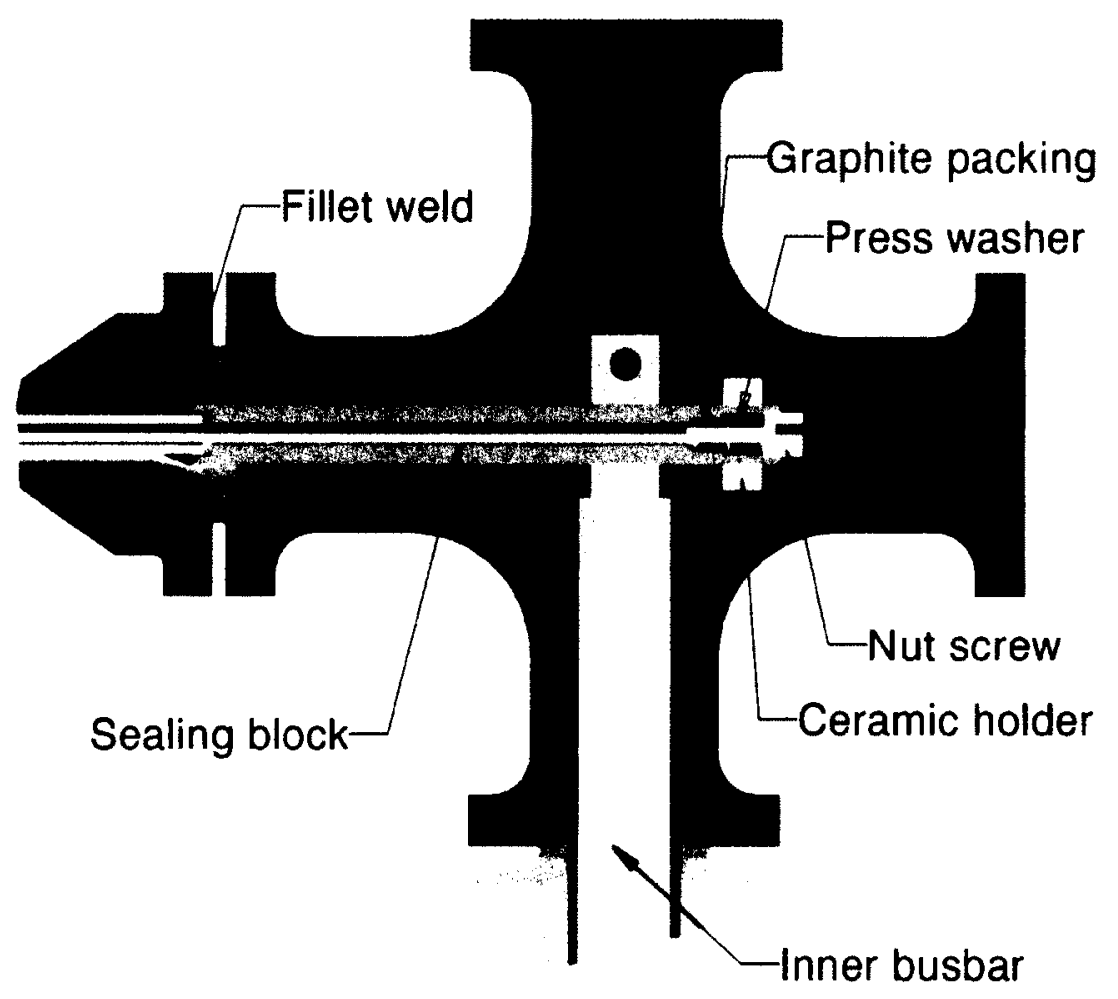

Figure 4.18: Sealing block assembly

\subsubsection{Bundle Test Section}

Similar to the annular test section, the bundle test section is an internally-heated design. Inner rods, which are used as heating elements, are required to be hollow and internally accessible for the temperature measurement sensors and their positioning apparatus. As such, the final required wall thickness will be a compromise between the wall thickness required to withstand the fluid pressure at the maximum predicted testsection wall temperature and the required wall thickness to apply the nominal power rating of the power supply to the test section. To determine an optimal wall thickness, the heated length of the test section, and the inner or outer diameter of the heater rod must be specified. 
As with the annular test section, the heated length of the bundle test section is selected to be $2000 \mathrm{~mm}$ to provide for some flow stabilization as per Recommendation 4 stated in Section 4.3. Similar to the annular test section, the wall thickness of the bundle heater rods is determined based on the outer diameter of the heater rods. Through an extensive iterative process, the outer diameter of the bundle heater rods is selected as $7.4 \mathrm{~mm}$. The inner diameter of the outer shell is chosen to be the same as the inner diameter of the rest of the piping on the SCW loop (i.e. $27.94 \mathrm{~mm}$ ) to allow the use of the "substitute" test section as the outer shell of the bundle test section.

The "substitute" test section is a pipe segment between the inlet and outlet ports of the SCW loop and it was initially designed to close off the loop in situations where no test section is connected to the loop. Subsequently, its purpose was re-evaluated and it was decided to use it as the outer shell of the bundle test section.

\subsubsection{Wall Thickness Sizing for Nominal Power Input}

From the previous analyses performed for the tubular and annular test sections, it is found that the driving factor for determining the optimal wall thickness is the maximum test-section wall temperature. The steps for determining the required wall thickness for nominal power input is a little varied for the bundle test-section design compared to the standard procedure used for the tubular and annular designs due to the seven-rod combination in effect creating a circuit with seven resistors in parallel. 
Based on the foregoing discussion on the equivalent seven-resistor analogy, it can be concluded that the required wall thickness for the nominal power input will be much less compared to the one for the maximum wall temperature. Therefore, the wall thickness is determined based on the maximum wall temperature and subsequently, the possible power input based on the determined wall thickness is calculated.

\subsubsection{Wall Thickness Sizing for External Pressure}

As discussed previously, the required wall thickness for external pressure is dependent on the maximum test-section wall temperature. Similar to the annular design, the maximum test-section wall temperature is predicted to occur at the maximum fluid bulk temperature of $600^{\circ} \mathrm{C}$, where the fluid heat transfer coefficient has its minimum value. The heat transfer coefficient is also directly proportional to the mass flow rate of the supercritical working fluid in the test section and as a result the lowest heat transfer coefficient value is predicted to occur at the lower end of the experimental flow rate range, i.e. $0.126 \mathrm{~kg} / \mathrm{s}$. The predicted heat transfer coefficient $(h)$ for the $7.4 \mathrm{~mm}$ bundle design is shown in Figure 4.19.

Similar to the annular test section, the bundle test section wall thickness must be optimized based on the required internal diameter for accommodating the temperature measurement probe, the current carrying capacity and the required structural strength to withstand the imposed external pressure. The required inner diameter for the temperature measurement probe is $5 \mathrm{~mm}$. This allows for a maximum wall thickness of 
$1.2 \mathrm{~mm}$ based on the $7.4 \mathrm{~mm}$ outside diameter for the heater rods. From the results of Equations (4.8) and (4.9), it is determined that this wall thickness-outer diameter combination can withstand a maximum external pressure of $38 \mathrm{MPa}$ at a maximum temperature of $650^{\circ} \mathrm{C}$, for the selected inconel 625 grade. The maximum allowable pressure is well above the design pressure of $28.35 \mathrm{MPa}$.

Similar to previous analyses, the maximum allowable heat flux based on the maximum heater rods wall temperature and the minimum concurrent heat transfer coefficient (Figure 4.19 ) at $600{ }^{\circ} \mathrm{C}$ bulk temperature is evaluated to be $151 \mathrm{~kW} / \mathrm{m}^{2}$. This results in a total power input of $50 \mathrm{~kW}$ based on the maximum heater rods wall temperature. The maximum possible power input based on the electrical resistance of the seven-rod bundle test section and the available amperage is determined to be $64.1 \mathrm{~kW}$. In this case, the maximum heat flux is not limited by the available amperage, but rather by the maximum test-section wall temperature. 


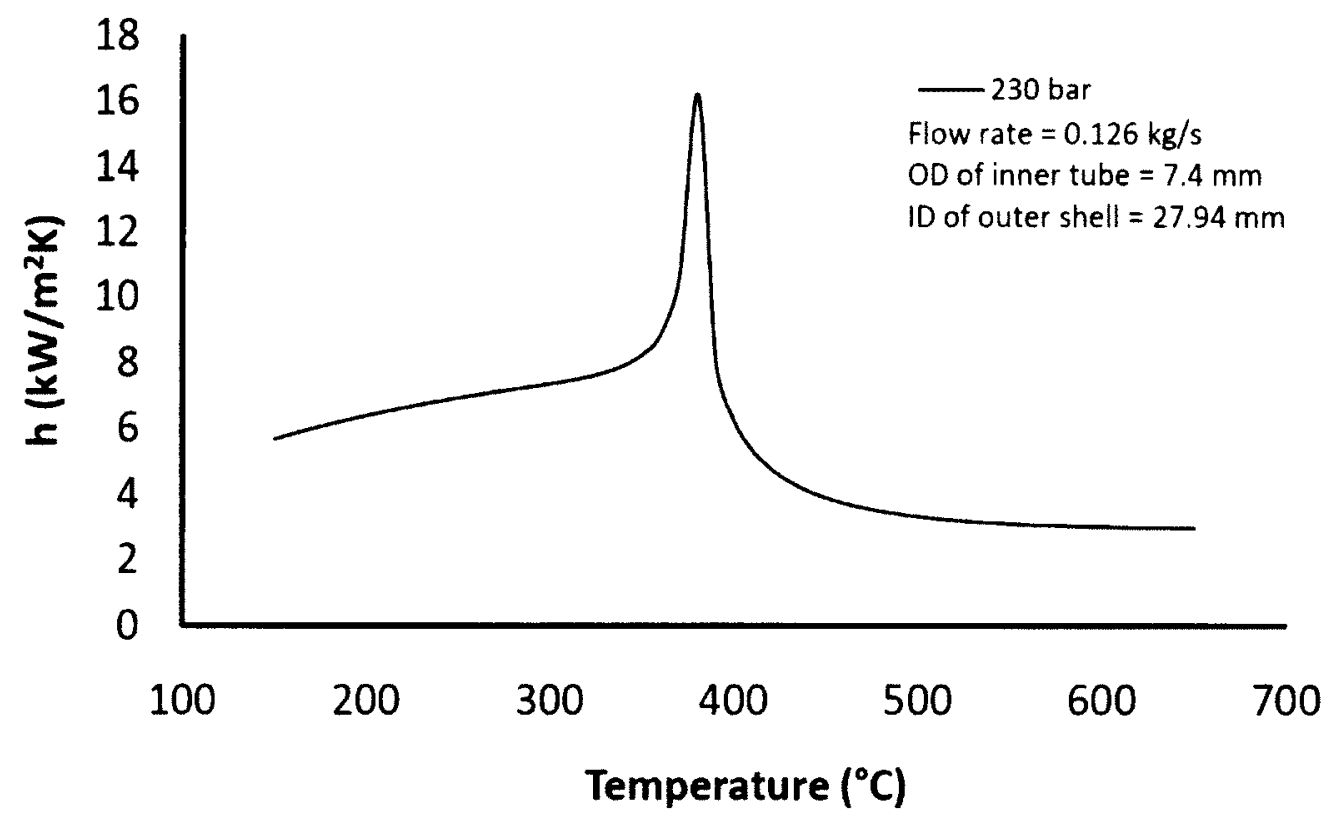

Figure 4.19: Predicted heat transfer coefficient of SCW as a function of fluid bulk temperature in the $7.4 \mathrm{~mm}$ bundle test section

\subsubsection{Wall Thickness Sizing of the Outer Shell for Internal Pressure}

The sizing of the outer shell can be performed in the same manner as the one for the annular test-section outer shell. Since the surface temperature of the heater rods in the bundle test section is not expected to be higher than $650^{\circ} \mathrm{C}$, the design temperature for sizing of the outer shell is selected as $625^{\circ} \mathrm{C}$, the same as the design temperature for the rest of the SCW loop piping. The design pressure remains the same as that for the external pressure in case of the bundle and annular designs and the internal pressure in case of the tubular test section, i.e. 28.35 MPa. Using Equation (4.5), the required wall thickness to withstand the internal design pressure at a temperature of $625{ }^{\circ} \mathrm{C}$ is determined to be $8.2 \mathrm{~mm}$. The wall thickness of the outer shell is the same as the wall 
thickness for the rest of the piping on the SCW loop, i.e. schedule XXS, which is equivalent to $10.2 \mathrm{~mm}$.

\subsubsection{Discussion on the Bundle Test Section}

In the initial stages of the test-section sizing and materials procurement for the test section, the tolerances on the wall thickness of the inner heater rods were discussed with the supplier. It was claimed that tolerances of up to $0.5 \%$ were readily achievable on the tube dimensions. Therefore, to be consistent with the material selection for the rest of the test sections, Inconel 625 Grade 2 was selected for the bundle heater rods. This grade of Inconel 625 can be used at temperatures of up to $871{ }^{\circ} \mathrm{C}$ and as such allows for the use of the bundle test section at relatively high heater rod wall temperatures. However, when it was the time to order the tubing material for the testsection fabrication, the supplier confirmed that the best tolerance they could achieve on the tube wall thickness was $\pm 10 \%$. This tolerance value has signification implications on the pressure rating of the bundle test-section heater rods. At $-10 \%$ tolerance on the wall thickness, the pressure rating of the heater rods drops well below the maximum operating pressure of $27 \mathrm{MPa}$ at $650^{\circ} \mathrm{C}$. Therefore, the Inconel 625 grade was changed to Grade 1, which has relatively higher allowable stress values compared to Grade 2 , but its use is limited to a maximum temperature of $650^{\circ} \mathrm{C}[10]$. From the re-evaluation of the wall thickness based on the new material grade, it is determined that a wall thickness of $1.2 \mathrm{~mm}$ can withstand pressures well above the recommended design pressure of $28.35 \mathrm{MPa}$ at a maximum test-section wall temperature of $650^{\circ} \mathrm{C}$. 


\subsubsection{Specifications of the Bundle Test Section}

The bundle test section incorporates a seven-rod heater rod assembly. The heater rods have a heated length of approximately $2000 \mathrm{~mm}$ with an outer diameter of $7.4 \mathrm{~mm}$. The proposed wall thickness of $1.2 \mathrm{~mm}$ can withstand an imposed external pressure of $38 \mathrm{MPa}$ at a maximum design temperature of $650^{\circ} \mathrm{C}$. The maximum wall temperature of the heater rods allows a maximum heat flux of $151 \mathrm{~kW} / \mathrm{m}^{2}$ based on the minimum predicted heat transfer coefficient, resulting in a total heat input of $49.3 \mathrm{~kW}$. The corresponding mass flux is $221 \mathrm{~kg} / \mathrm{m}^{2} \mathrm{~s}$. The heat flux, based on the available amperage and the electrical resistance of the seven-rod assembly, is close to that achievable at the most severe experimental condition (i.e. $600^{\circ} \mathrm{C}$ fluid bulk temperature and $650^{\circ} \mathrm{C}$ heater rod wall temperature). It is determined to be $197 \mathrm{~kW} / \mathrm{m}^{2}$. The outer shell has a thickness of $10.2 \mathrm{~mm}$ with an inner diameter of $27.94 \mathrm{~mm}$. It is rated for a design pressure of 28.35 MPa and design temperature of $625^{\circ} \mathrm{C}$.

\subsubsection{Design of the Bundle Test Section}

The design of the seven-rod bundle test section is an extension of the annular testsection design. It is interfaced with the loop using Grayloc ${ }^{\text {TM }}$ hubs. Similar to the other test sections, the distance between the faces of the Grayloc hubs is $2169.5 \mathrm{~mm}$ and $2000 \mathrm{~mm}$ is the approximate heated length of the bundle test section. Figure 4.20 shows an overview of the bundle test-section design. 


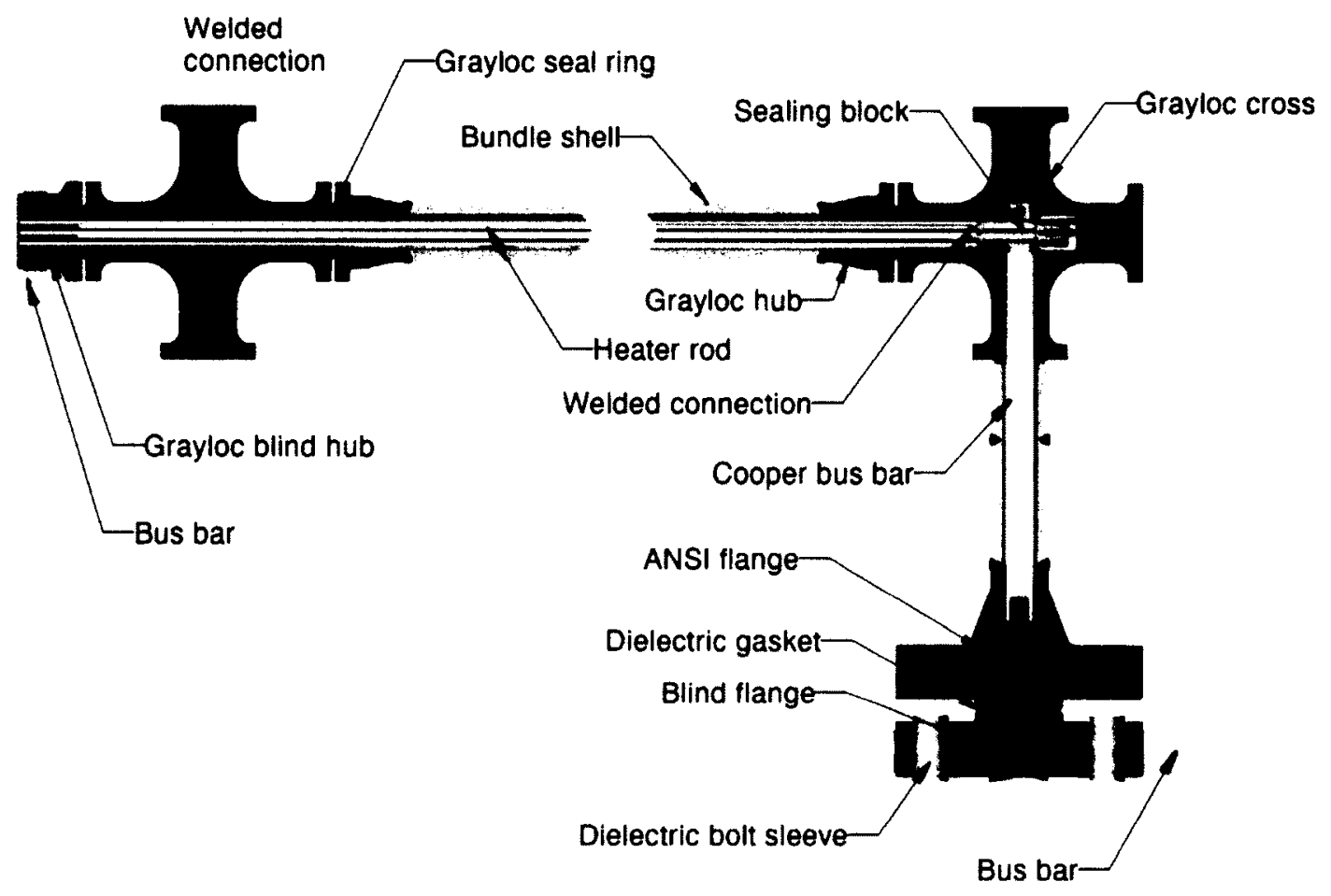

Figure 4.20: Seven-rod bundle test-section overview

Transmission of electrical current to the heater rods takes place in the same manner as for the annular test section. Pikotek ${ }^{\mathrm{T}}$ dielectric isolating kit is used to isolate the blind flange that is connected to the bus bar from the mating flange. Electric current from the blind flange to the heater rods is directed through an internal bus bar and the sealing blocks. The heater rods are connected to the Grayloc ${ }^{\mathrm{TM}}$ blind hub via fillet welded connections. A copper bus bar connected to the blind hub completes the electric circuit.

Similar to the annular test section, the bundle test section allows access to the interior of the heater rods only from one end during operation. The ends of the heater rods located inside the pressurized boundary are sealed using a compression packing method (Figure 4.21). 


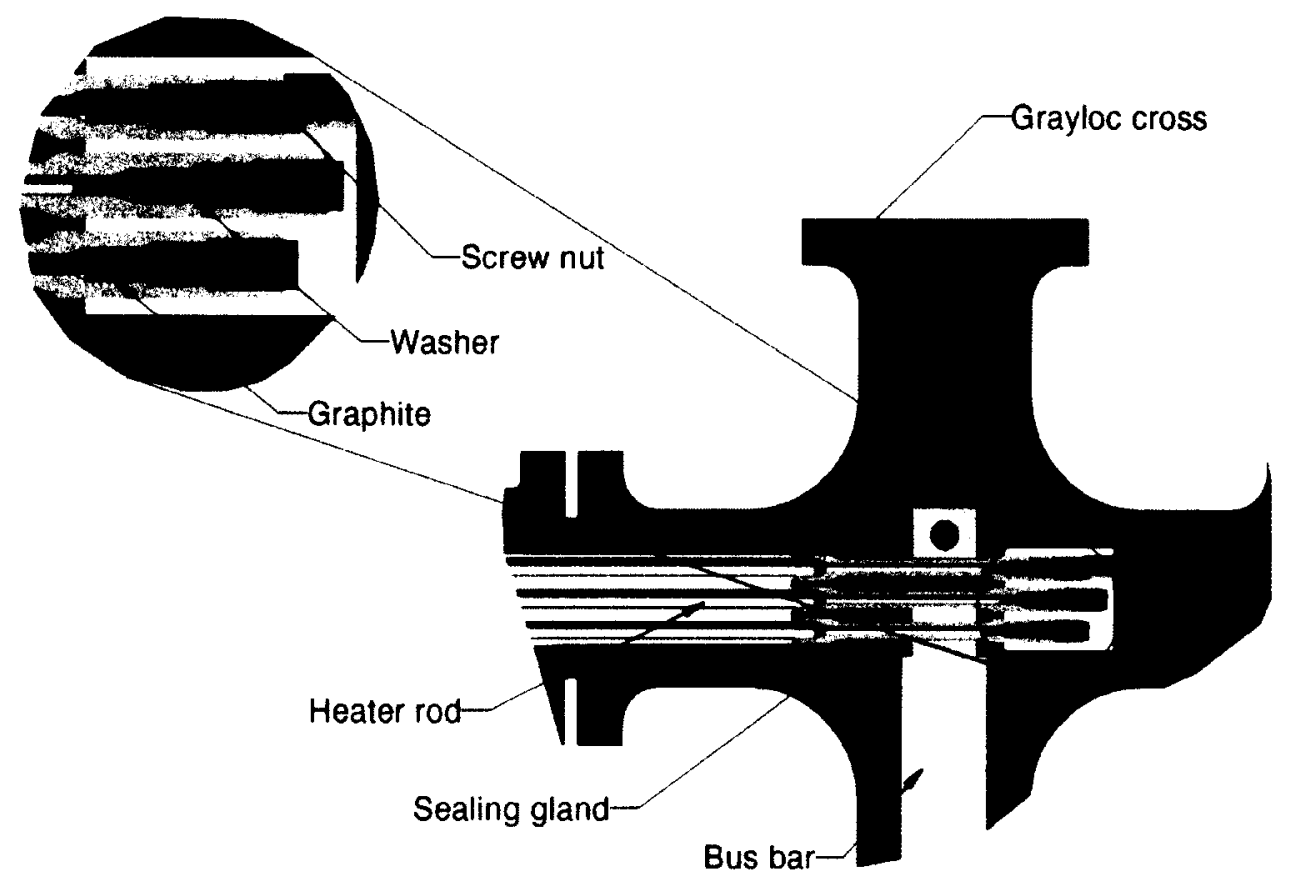

Figure 4.21: Sealing block assembly for bundle test section

Each heater rod is individually connected to a dedicated sealing block. This arrangement is devised to accommodate welding of the sealing blocks to the heater rods. The sealing blocks are welded to the heater rods through full penetration butt welds. The sealing is affected by tightening the nut which in turn pushes the washer onto the graphite packing. The graphite packing is compressed against the throat of the seal gland and the nut screw creating a seal. The design of the compression packing sealing assembly is based on a similar design given in [5].

The copper bus bar attached to the sealing block allows for thermal expansion of the heater rods in the axial direction. To prevent overheating of the dielectric gasket (rated up to $200{ }^{\circ} \mathrm{C}$ for Class 2500 flange), the dielectric isolating assembly is located away from the test section. 


\subsection{Design of the Pre-Heater for the SCW Loop}

A pre-heater is typically used to regulate the fluid temperature at the test section inlet. In the current design, a pre-heater is required for more than just the regulation of the fluid inlet temperature. The loop is designed for a maximum SCW bulk temperature of $600^{\circ} \mathrm{C}$ and a maximum power input of $300 \mathrm{~kW}$. However, from the preceding discussions on the test-section designs, it is found that not all of the $300 \mathrm{~kW}$ available power can be imparted to the fluid in the test section. In certain instances, the maximum power input is limited by the maximum test-section wall temperature, whereas in others, the limiting factors are the electrical resistance of the test section and the available amperage. The power input is limited to a maximum of approximately $50 \mathrm{~kW}$ for the test sections based on the maximum test-section wall temperature. Therefore, the remaining available power should be imparted to the fluid upstream of the test section. It is important to point out that similar to the test sections, the maximum power input in the pre-heater is limited by the maximum allowable piping wall temperature.

It is decided to use piping segments upstream of the test section as pre-heaters (Figure 4.22). Locations 1 and 2 can be utilized when the flow direction is vertically upwards and all of the four locations can be utilized for vertically downwards and horizontal flow directions. 


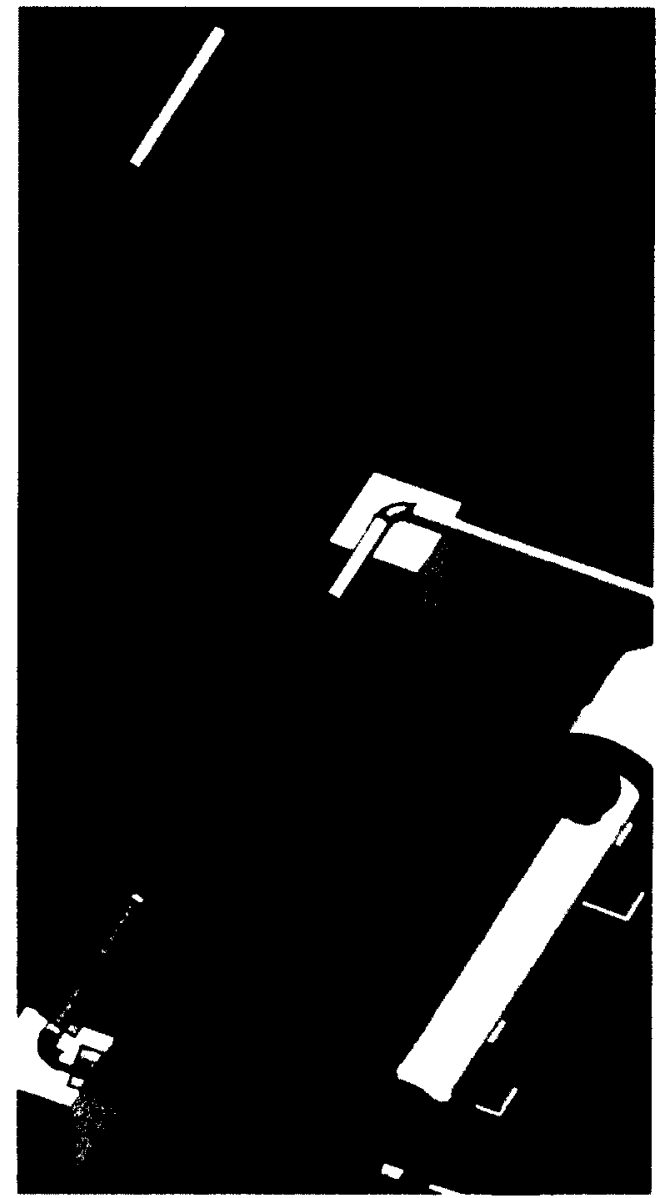

(a)

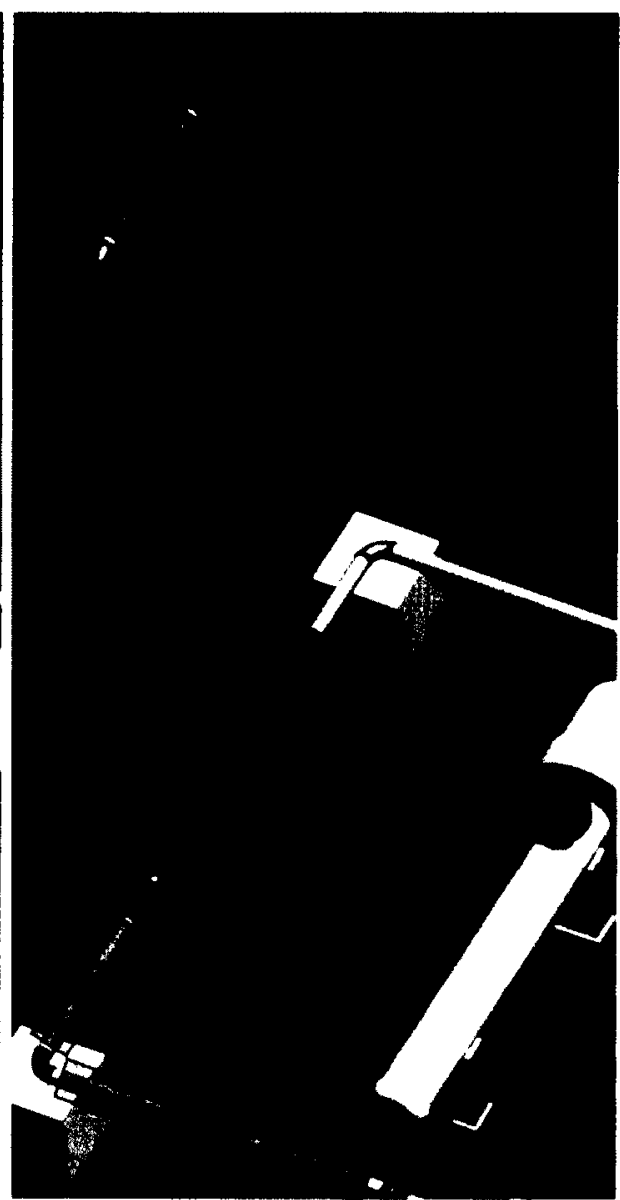

(b)

Figure 4.22: Pre-heater locations

The piping of the SCW loop is designed for a maximum temperature of $625^{\circ} \mathrm{C}$. As such, heat transfer calculations are performed to determine what maximum heat fluxes and consequently, maximum power inputs can be achieved without exceeding the design temperature limit of $625^{\circ} \mathrm{C}$. The calculations are similar to the ones performed for the tubular test section.

The results of design calculations indicate that up to $170 \mathrm{~kW}$ of power can be imparted to the water in pipe segments 1 and 2, over a total pipe length of approximately 
$2500 \mathrm{~mm}$. This limits the fluid bulk temperature at the outlet of the test section to a maximum of approximately $450^{\circ} \mathrm{C}$, for the vertically upward flow direction.

For horizontal and vertically downward flow directions, all four pipe segments can be used as pre-heaters, resulting in a total pipe length of $5500 \mathrm{~mm}$. Thermal analysis has determined that a maximum of $220 \mathrm{~kW}$ of power can be imparted to the fluid. This limits the fluid bulk temperature at the test-section outlet to a maximum of $550^{\circ} \mathrm{C}$ and $520^{\circ} \mathrm{C}$ for the tubular and bundle test sections, respectively. No such limitation is imposed on the bulk outlet temperature of the annular test section. Therefore, the preheaters are sized for a maximum power input of $170 \mathrm{~kW}$ for the combination of pipe segments 1 and 2, and $50 \mathrm{~kW}$ for the combination of pipe segments 3 and 4 .

\subsubsection{Pre-heater Heating Element}

The pre-heater heating element is required to withstand the high temperatures, possess a reasonably constant resistivity to avoid hot spots due to variable heat flux, and be of a design that allows straightforward installation on the piping segments. Based on these criteria, an Inconel tube/pipe of the required dimensions can be used as the pre-heater heating element. For homogeneity of design, Inconel 625 is selected as the pre-heater heating element.

\subsubsection{Sizing of Pre-Heater}

Pre-heaters are sized based on the required power and the available surface area. The available surface area is that of the piping segments based on their outside diameter, 
over which the pre-heaters are installed. For segments 1 and 2, a total surface area of $0.38 \mathrm{~m}^{2}$ (based on $48.26 \mathrm{~mm}$ outer diameter and $2500 \mathrm{~mm}$ length) is available. Equation (4.1) is used to determine the required electrical resistance of the pre-heater heating element. For a maximum current of $2000 \mathrm{~A}$ and power input of $170 \mathrm{~kW}$, the electrical resistance of the heating element is determined to be $42.5 \mathrm{~m} \Omega$. Since the heating element tube is installed on the piping segments, it is selected to have similar inner diameter as the outer diameter of the pipe segment. Hence, the selected heating element tube is of $48 \mathrm{~mm}$ inner diameter.

Using the calculated electrical resistance and Equation (4.2), the required cross-sectional area is calculated. And finally, using Equation (4.3), the pre-heater heating element thickness is evaluated. The results are as follows:

- Cross-sectional area: $79.1 \mathrm{~mm}^{2}$

- Wall thickness: $0.52 \mathrm{~mm}$

In a similar manner, using a heat input value of $50 \mathrm{~kW}$, inner diameter of $48 \mathrm{~mm}$, total length of $3000 \mathrm{~mm}$, the specifics of the pre-heater element for the piping segments 3 and 4 are evaluated as:

- Electrical resistance: $12.5 \mathrm{~m} \Omega$

- Cross-sectional area: $322.8 \mathrm{~mm}^{2}$

- Wall thickness: $2.0 \mathrm{~mm}$ 


\subsubsection{Design and Installation of Pre-Heater Heating Elements}

The heating elements are installed as two halves on the piping segments as shown in Figure 4.23. A $0.25 \mathrm{~mm}$ mica insulation sleeve is installed on the piping segment used as the pre-heater under the heating element. The mica insulation serves as dielectric insulation between the heating elements and the piping segments. The two halves of the heating element are clamped together by bolted clamps that simultaneously serve as the power bus bars to the heating elements. To avoid heat loss, the heating elements are overlaid with an optimal thickness of thermal insulation, as is the case with the rest of the test loop components.

To monitor the wall temperature of the piping segments and to ensure that the maximum metal design temperature is not exceeded, thermocouples are strategically located in contact with the piping segment walls under the mica insulation.

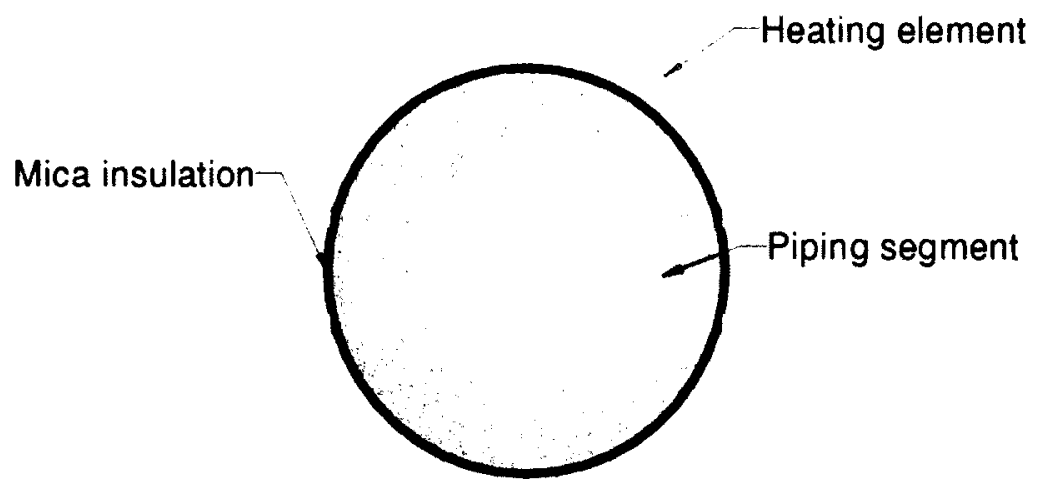

Figure 4.23: Pre-heater heating element installation 


\section{Chapter 5. Carleton University R-134a Loop}

A thermalhydraulic test loop with working fluid $\mathrm{R}-134 \mathrm{a}$ is designed to investigate the heat transfer and thermohydraulic properties of R-134a under near-critical and supercritical conditions. The experimental data thus obtained will be in part used to identify correlations between the heat transfer properties of supercritical R-134a and SCW.

The use of supercritical R-134a as a modeling substitute for SCW is driven by its lower critical pressure and temperature. The critical point of R-134a occurs at $101.1^{\circ} \mathrm{C}$ and 4.06 MPa, whereas the critical point of water occurs at $373.9^{\circ} \mathrm{C}$ and $22.06 \mathrm{MPa}$ [3][13]. The lower critical pressure and temperature of $\mathrm{R}-134$ a provides a simpler design with shorter development and commissioning times, a safer testing environment and reduces the cost of the experimental facility.

\subsection{R-134a Loop Design Requirements}

The Carleton R-134a loop is designed to be compatible with the testing conditions summarized in Table 5.1, and accommodate the same test section designs as the Carleton SCW loop, which are schematically illustrated in Figure 4.1.

Steady fluid motion in the loop is realized with a pump, all fluid heating is realized in the test section, and the working fluid discharging from the test section is passed through a heat exchanger to reduce its temperature before reaching components on the loop that 
have temperature restrictions. The charging of the loop and pressure control during operation is realized via an accumulator.

Table 5.1: Operating parameters of the supercritical R-134a loop

\begin{tabular}{|c|c|c|c|}
\hline \multirow{4}{*}{ 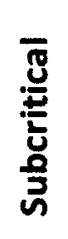 } & Pressure & \multicolumn{2}{|c|}{$1.7-4 \mathrm{MPa}$} \\
\hline & \multirow{2}{*}{ Temperature } & Inlet & Outlet \\
\hline & & $40-80^{\circ} \mathrm{C}$ & $60-100^{\circ} \mathrm{C}$ \\
\hline & Mass flux & \multicolumn{2}{|c|}{$500-6000 \mathrm{~kg} / \mathrm{m}^{2} \mathrm{~s}$} \\
\hline \multirow{4}{*}{ 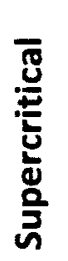 } & Pressure & \multicolumn{2}{|c|}{$4.4-6 \mathrm{MPa}$} \\
\hline & \multirow{2}{*}{ Temperature } & Inlet & Outlet \\
\hline & & $60-100^{\circ} \mathrm{C}$ & $102-140^{\circ} \mathrm{C}$ \\
\hline & Mass flux & \multicolumn{2}{|c|}{$500-4000 \mathrm{~kg} / \mathrm{m}^{2} \mathrm{~s}$} \\
\hline
\end{tabular}

The R-134a loop should be able to withstand the maximum pressure of the fluid ( $6 \mathrm{MPa}$ ) under the elevated temperature conditions of the experiments. In order to accommodate a number of loop components with restricted temperature capability, reduce the cost of the $\mathrm{R}-134 \mathrm{a}$ loop components, simplify the loop design and meet the experimental requirements listed in Table 5.1, the temperature of the fluid should be reduced from its maximum value at the test-section outlet $\left(140^{\circ} \mathrm{C}\right)$ over a portion of the loop. The reduction in the temperature of the fluid is achieved using a heat exchanger.

The loop must have provisions for accurate measurement of R-134a mass flow rate. To provide steady fluid flow through the loop by compensating for the frictional pressure drop, a pump capable of working at the loop operating pressure and temperature is required. 


\subsection{Survey of Similar Test Facilities}

The R-134a loop design presented herein has been developed on the basis of the SCW loop discussed previously. Test facilities that exist elsewhere for the study of supercritical thermalhydraulic phenomena with fluids of similar critical conditions as R-134a have also influenced the design decisions. What follows is a survey of such test facilities.

\subsubsection{KAERI Supercritical R-134a Loop}

The supercritical R-134a loop at Korea Atomic Energy Research Institute (KAERI) is a closed thermalhydraulic experimental loop [61]. Figure 5.1 shows a schematic of the loop. The mass flux for this facility ranges from 600 to $2000 \mathrm{~kg} / \mathrm{m}^{2} \mathrm{~s}$. The loop has a maximum system pressure of $4.5 \mathrm{MPa}$ and a maximum operating temperature of $150^{\circ} \mathrm{C}$. The test-section heated length is $2000 \mathrm{~mm}$ and it is heated uniformly by direct Joule heating. The DC power applied to the test section is measured by means of voltage and current readings. The temperature measurement for the study of heat transfer is carried out by silver-soldering $0.5 \mathrm{~mm}$ sheathed type $K$ thermocouples on the testsection wall. R-134a circulated with two non-seal canned type pumps is heated by two pre-heaters before reaching the test section. Once the $\mathrm{R}-134 \mathrm{a}$ leaves the test section, its temperature is lowered by passing it through a condenser and then through a cooler before returning it to the pump. A mass flow meter located upstream of the test section measures the flow rate of the fluid. The amount of flow to the test section is controlled 
by a throttling valve located upstream of the test section. Pressurization of the loop is achieved by two gas-loaded accumulators. The accumulators are located downstream of the pumps to minimize any pulsations generated by the pumps.

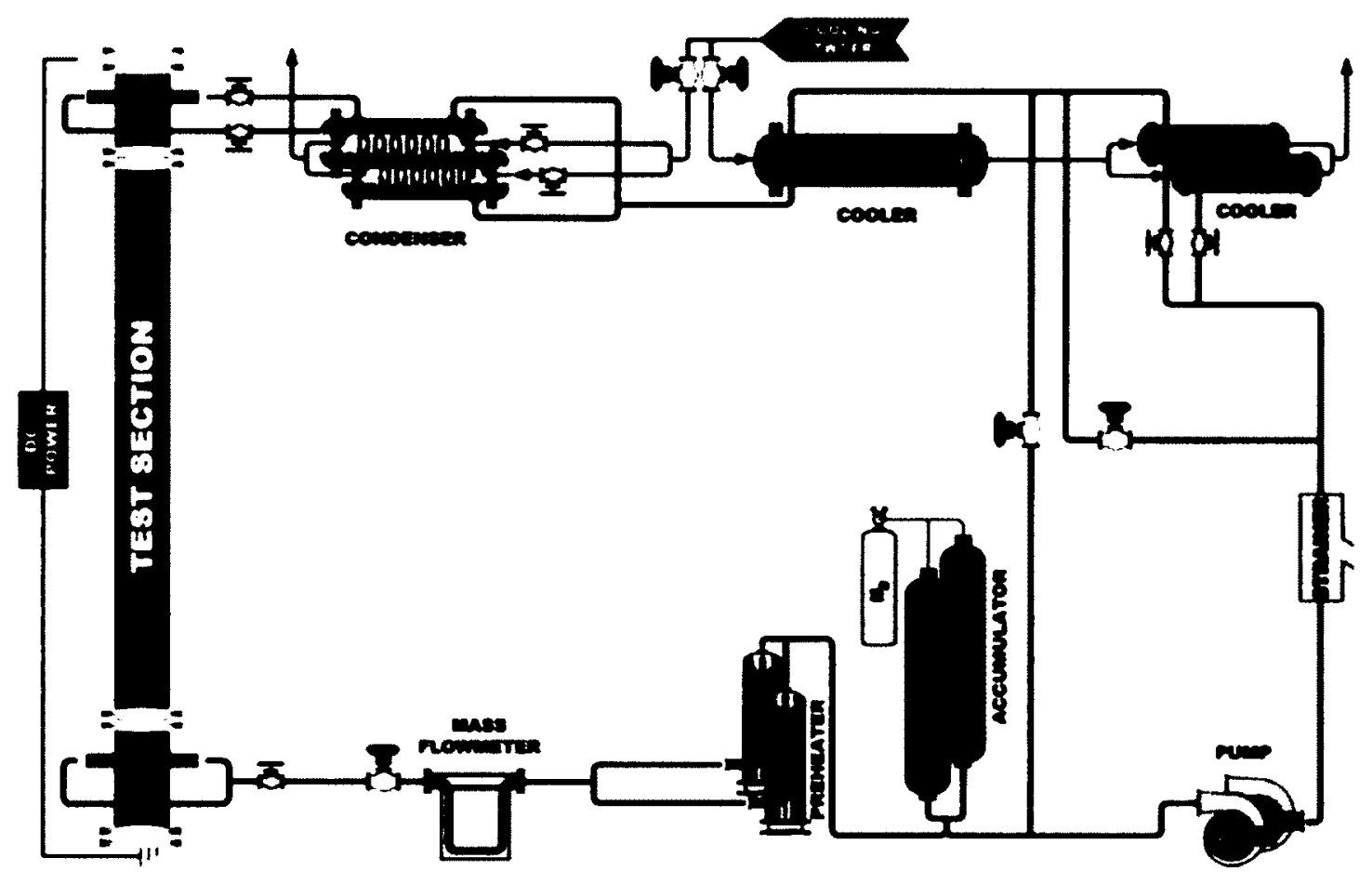

Figure 5.1: Schematic diagram of KAERI supercritical R-134a loop [61]

\subsubsection{SPHINX Supercritical $\mathrm{CO}_{2}$ Loop}

SPHINX is a supercritical $\mathrm{CO}_{2}$ loop designed for performing heat transfer experiments with various test-section geometries [62]. The schematic of the facility is shown in Figure 5.2. The facility is located at the Korean Atomic Energy Research Institute. It is designed for pressures up to $8.12 \mathrm{MPa}$ and temperatures up to $100^{\circ} \mathrm{C}$ (critical pressure and temperature for $\mathrm{CO}_{2}$ are $7.38 \mathrm{MPa}$ and $30.98^{\circ} \mathrm{C}$, respectively). Mass fluxes ranging from 400 to $1200 \mathrm{~kg} / \mathrm{m}^{2} \mathrm{~s}$ are achievable on the loop. The facility is designed to 
accommodate a $2.65 \mathrm{~m}$ long Inconel test section. Type $\mathrm{K}$ thermocouples are soldered on the test-section surface for heat transfer study purposes. To minimize flow fluctuations, a gear-type circulation pump is used on the SPHINX facility. Liquid-like $\mathrm{CO}_{2}$ is circulated by the pump and passed through an electric pre-heater to control the fluid temperature at the inlet of the test section. The fluid then passes through a Coriolis-type flow meter before reaching the test section. At the test section, heat is added by direct Joule heating with the help of a DC power supply. The power supply can provide heat fluxes up to $90 \mathrm{~kW} / \mathrm{m}^{2}$. After exiting the test section, the fluid goes through a spiral-type cooler, where its temperature is lowered to the required pump inlet temperature. Additionally, an auxiliary chiller system is provided to feed chilled coolant to the cooler. Pressurization of the loop is achieved by charging $\mathrm{CO}_{2}$ gas from main tanks utilizing an air-driven boosting compressor. An accumulator filled with gaseous nitrogen, installed downstream of the pumps perform the precise regulation of the pressure in the SPHINX facility. Valves installed on the main loop perform a number of functions, such as bypass flow control, isolation of a specific test section and pressure relief. 


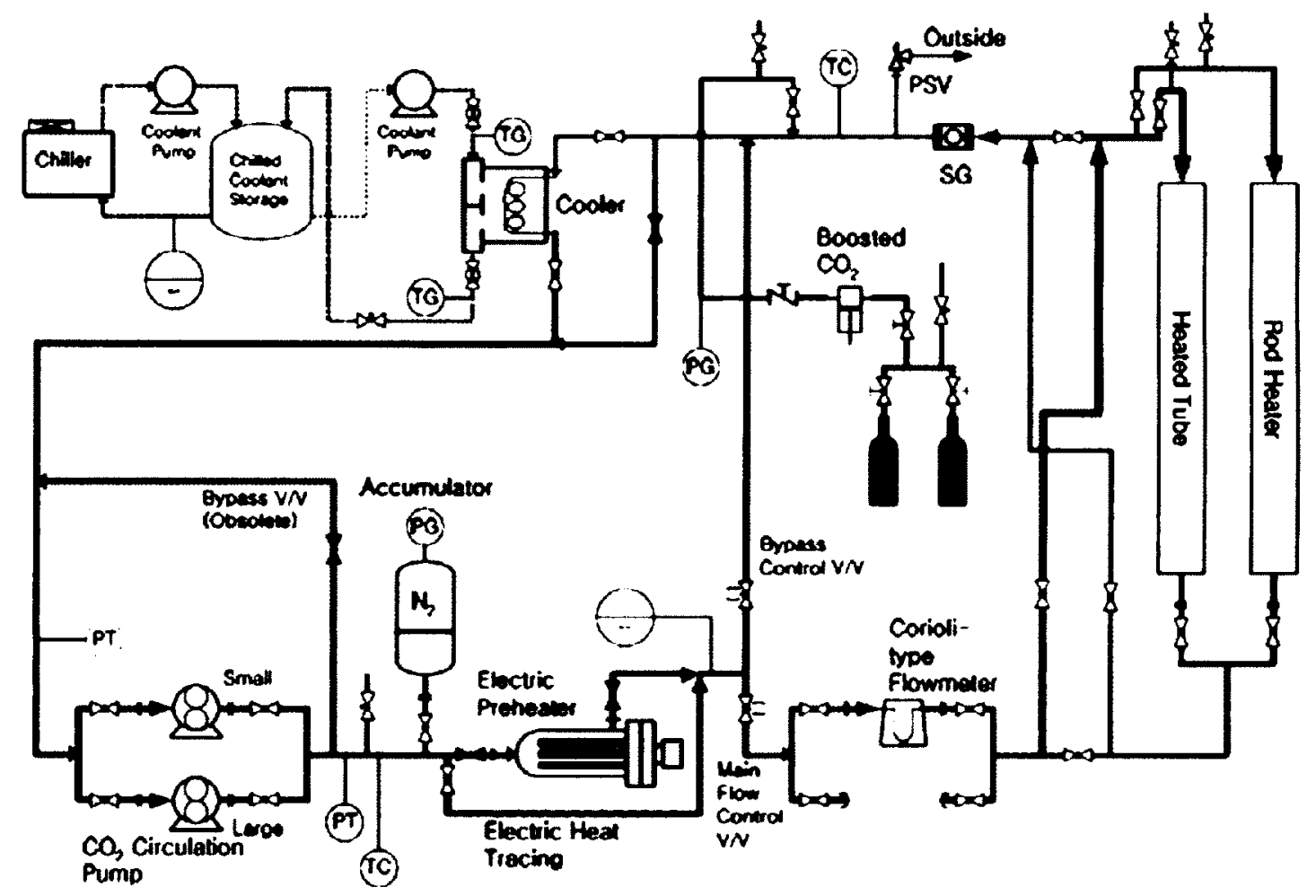

Figure 5.2: Schematic diagram of SPHINX test facility [62]

\subsection{Carleton R-134a Thermalhydraulic Loop}

Following the same design philosophy as for the Carleton SCW loop and based on the information gathered from the surveyed supercritical heat transfer facilities with similar critical thermal states, a supercritical R-134a loop meeting the previously outlined experimental requirements is designed. The following sections discuss the design of the Carleton R-134a thermalhydraulic loop and its components.

\subsubsection{Design Overview}

The R-134a loop is a forced-flow experimental facility designed for the study of heat transfer properties of R-134a under subcritical and supercritical conditions. The R-134a 
loop is to be located in the same test facility as the SCW loop, on Carleton University's campus. The loop is designed to operate with pressures as high as $6 \mathrm{MPa}$ and temperatures up to $140^{\circ} \mathrm{C}$.

Figure 5.3 shows the layout and major components of the R-134a loop, and the piping and instrumentation diagram is depicted in Figure 5.4. The design of the R-134a loop is performed based on the same methodology employed in the design of the SCW loop with comparable overall dimensions. It is approximately $1.5 \mathrm{~m}$ wide, $4 \mathrm{~m}$ long and $2.5 \mathrm{~m}$ high when the test section is in the vertical position. The test section can be readily reoriented to the horizontal position, in which case the loop has dimensions of $1.5 \mathrm{~m}$ in width and $6.5 \mathrm{~m}$ in length.

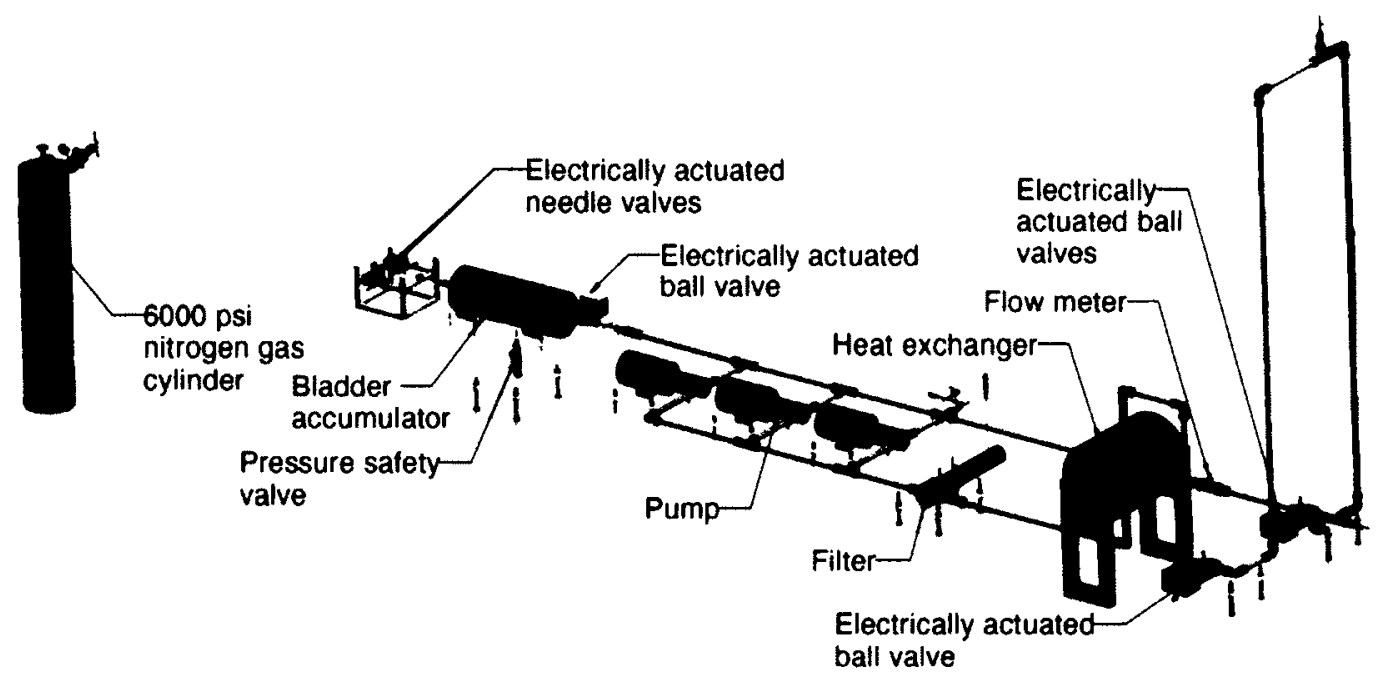

Figure 5.3: Layout and major components of the Carleton R-134a loop 


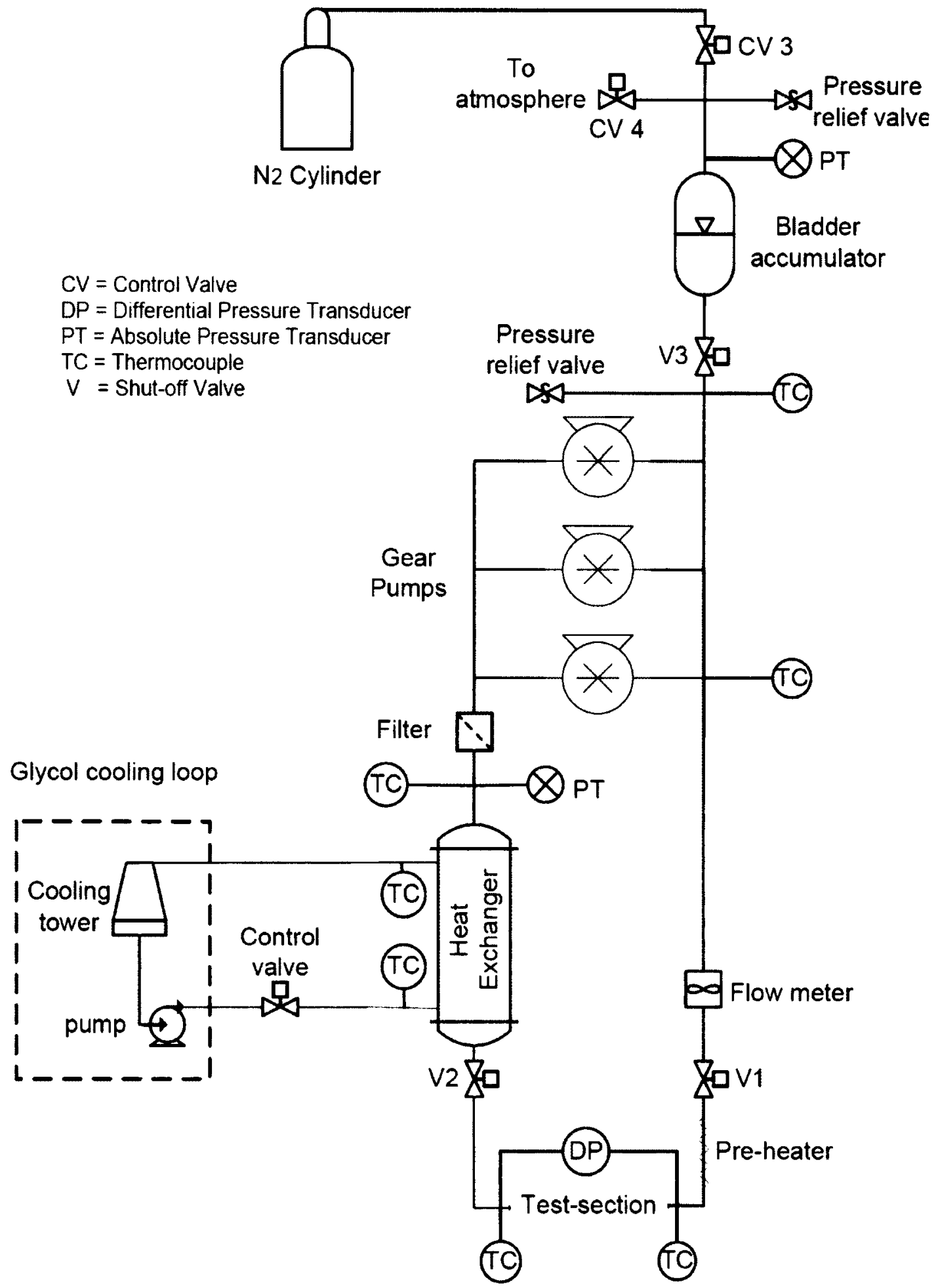

Figure 5.4: Piping and instrumentation of the Carleton R-134a loop 
The R-134a loop tubing is of $31.75 \mathrm{~mm}(1-1 / 4 \mathrm{in})$ outside diameter with a wall thickness of $2.8 \mathrm{~mm}$ (0.109 in). The tubing is made of Type 316 stainless steel of seamless construction. Tube and component connections are made with compression-type and NPT threaded tube fittings.

Similar to the SCW loop, the test-section leg of the R-134a loop is designed such that different test sections can be easily interfaced with the loop using the provided inlet/outlet connections. Heat is imparted to $\mathrm{R}-134 \mathrm{a}$ in the test section through Joule heating of the heater rod(s) or the pressure containing tube itself.

Three gear pumps generate flow rates in the range of 0.021 to $2.1 \mathrm{~kg} / \mathrm{s}$. The pumps can operate at a maximum pressure of $10.3 \mathrm{MPa}$ at $121{ }^{\circ} \mathrm{C}$. Since the pumps are connected in parallel and each pump is driven by its own dedicated variable frequency drive (VFD), the flow of the R-134a through the test section can be finely regulated. Additionally, the remotely-actuated ball valve located upstream of the test-section leg and intended for shut-off purposes can be used to regulate the flow through the test section.

The flow of R-134a is monitored by a turbine-type flow meter with a flow range of $1.1 \mathrm{~m}^{3} / \mathrm{hr}$ to $11.4 \mathrm{~m}^{3} / \mathrm{hr}$ (5 to $50 \mathrm{GPM}$ ). The flow meter is rated for a maximum pressure of $34.5 \mathrm{MPa}(5000 \mathrm{psi})$ and can be used at temperatures up to $177^{\circ} \mathrm{C}$.

A heat exchanger after the test section lowers the temperature of R-134a in order to meet the temperature rating requirements of the pump and achieve the desired testsection inlet temperature. The heat exchanger is designed to lower the R-134a 
temperature to a minimum of $40^{\circ} \mathrm{C}$ for subcritical experiments. The heat exchanger is sized to match the maximum Joule heating capability of $300 \mathrm{~kW}$. It is designed to operate at a maximum pressure of $6.2 \mathrm{MPa}$ at a maximum temperature of $149^{\circ} \mathrm{C}$.

Pressurization of the R-134a loop is achieved in a similar manner as the SCW loop with the help of a high-pressure accumulator. The accumulator is connected to an auxiliary high-pressure nitrogen cylinder and the pressure in the loop is regulated by allowing nitrogen gas to flow into the accumulator or by venting off excessive gas to the atmosphere. The accumulator also helps cushion the pressure oscillations created by the pumps. Two electrically-actuated control valves, CV 3 and CV 4 as shown in Figure 5.4 are used to assist in the pressure regulation.

Before the fluid returns to the pumps, it is passed through an in-line filter in order to protect the gear pumps from corrosion and/or erosion particulate that maybe dislodged from the tubing, in particular the test section where direct Joule heating of the tubes is carried out. The filter has a 5 micron stainless steel mesh.

The loop is instrumented with static pressure taps connected to absolute and differential pressure transducers, and with thermocouples. These sensors are used for both health monitoring and for studying the heat transfer and flow development processes in the test section. The flow rate is measured with a flow meter located upstream of the test-section inlet. 
The following sections discuss the design of the R-134a loop and its components in detail.

\subsubsection{Sizing and Selection of the Carleton R-134a Tubing Components}

The tubing components on the R-134a loop are designed based on the rules stipulated by ASME B31.1 Power Piping Code [8] and the final assembly is certified by TSSA. The components are selected and sized in a number of steps. The first step is to select a material suitable for use with R-134a at the expected operating conditions of the loop. Then, the size of the straight tubing segments under internal pressure is determined and a standard tube size meeting or exceeding the determined size is selected. The tube size forms the basis on which other tubing components, such as fittings are selected.

The following subsections describe this process in detail.

\subsubsection{Materials Selection}

The R-134a loop will contain the pressurized working fluid at high pressures up to $6 \mathrm{MPa}$ and temperatures as high as $140^{\circ} \mathrm{C}$. Therefore, it is important that the material has very good high temperature strength. The strength of the material at elevated temperatures plays a crucial role in the bulk size of the loop. It determines the thickness of the pressure retaining tube wall and any other pressure boundary components. Since the pressurized fluid flowing through a portion of the loop is near-critical/supercritical $\mathrm{R}-134 \mathrm{a}$, the corrosion resistance of the material in contact with the working fluid is also a significant factor. 
The materials used for the SCW loop (i.e., stainless steel 316, Inconel 625 and Hastelloy C-276) are also considered for use on the R-134a loop. Any of the materials mentioned can be used on the R-134a loop because the maximum expected operating temperature $\left(140^{\circ} \mathrm{C}\right)$ of the $\mathrm{R}-134$ a loop is relatively low compared to that of the SCW loop. However, the most common and the least expensive of the materials is stainless steel Type 316. It possesses the required strength at the operating temperatures of the loop and it has excellent corrosion resistance, which is necessary for durability of the material in the presence of supercritical $R-134 a$.

\subsubsection{Pressure Sizing of Tubes}

The sizing of tubes is carried out in three steps. First, an inner diameter is selected; then, a wall thickness is calculated based on the selected inner diameter, and the design pressure and design temperature of the fluid that needs to be contained. Finally, once these dimensions are determined, they are compared with the standard tube sizes and the next-larger tube size meeting the calculated wall thickness requirement is selected.

\subsection{Initial Selection of the Inner Diameter}

The sizing of piping in an earlier design iteration on the Carleton R-134a loop performed by other student members of the research group was based on the maximum recommended pressure drop of $180 \mathrm{kPa}$ (26 psi) in $30 \mathrm{~m}$ (100 ft) of piping as suggested by Dickenson's Pumping Manual [63]. This method resulted in a pipe inside diameter of $20.32 \mathrm{~mm}(0.8 \mathrm{in})$ for the experimental flow conditions. A pipe size of NPS 1 was 
selected and the maximum total pressure drop in the loop was estimated at $560 \mathrm{kPa}$ (80 psi) based on this pipe size. Subsequently, this pressure drop information was used to specify the required pump head for the R-134a loop.

\subsection{Re-evaluation of the Selected Inner Diameter}

The initially selected inner diameter is re-evaluated to determine if it can be reduced. In doing so, it is important to take the available pump head into consideration. Additionally, the pump is specifically designed for operation with a liquid working fluid. Therefore, the pressure drop should be limited to the liquid saturation point for any given experimental condition in addition to the available pump head.

An extensive pressure drop evaluation is carried out for various experimental conditions and different tube sizes. It is determined that for any tube inner diameter smaller than $25.4 \mathrm{~mm}(1 \mathrm{in}) \mathrm{ID}$, the pressure drop either surpassed the available pump head or the fluid crossed the liquid saturation line into the liquid-vapour mixture region as a result of the frictional pressure drop.

The calculations show that the maximum pressure drop occurs through the test section and in the tube connecting the test section to the heat exchanger since the fluid has the minimum density in this region for any given experimental condition. As an alternative, it is possible to reduce the inside diameter in the rest of the loop while increasing the inside diameter in the section connecting the test section to the heat exchanger. This 
will minimize the overall pressure drop in the loop; however, it will complicate the design by requiring the components and fittings to be of two different sizes.

Therefore, a tube inner diameter of $25.4 \mathrm{~mm}(1 \mathrm{in})$ established in an earlier design iteration has been confirmed to provide the best tradeoff between the level of frictional pressure drop in the loop, suitable inflow conditions for the pumps and cost/simplicity of the design.

\subsection{Determination of the Wall Thickness}

In order to calculate the required tube wall thickness, it is necessary to establish the design pressure and design temperature for the tube. It is common to select a design pressure $10 \%$ higher than the operating pressure of the system, whereas there is no stipulated requirement for the design temperature. Therefore, a design pressure of $7 \mathrm{MPa}$, which is more than $10 \%$ higher than the operating pressure of the system and a temperature of $200{ }^{\circ} \mathrm{C}$, which is 60 degrees higher than the expected maximum operating temperature are selected.

The required wall thickness of the tubing can be calculated by either Equation (3.3) or (3.4) reproduced here as Equation (5.1) and (5.2), depending on whether the tubing inner diameter or outer diameter is used.

$$
t=\frac{P D_{0}}{2(S E+P y)}
$$




$$
t=\frac{P D_{i}}{2(S E+P y-P)}
$$

Substituting the corresponding values into Equation (5.2) yields:

$$
\begin{aligned}
& t=\frac{7.0 \times 10^{6} \mathrm{~Pa} \cdot 25.4 \times 10^{-3} \mathrm{~m}}{2\left(99.2 \times 10^{6}+7.0 \times 10^{6} \cdot 0.4-7.0 \times 10^{6}\right) \mathrm{Pa}} \\
& t=0.94 \times 10^{-3} \mathrm{~m}=0.94 \mathrm{~mm}
\end{aligned}
$$

Therefore, the required wall thickness suitable for the design conditions set out earlier is $0.94 \mathrm{~mm}$.

\subsection{Tube Sizing Conclusion}

The final tube wall thickness selection must provide adequately for containing the pressurized fluid at the design temperature and pressure, dead weight of the tubing and in some instances the components, thermally induced stresses and pressure excursions due to factors such as possible water hammer. Comparing the calculated wall thickness and internal diameter with standard tube sizes, a tube with an OD of $31.75 \mathrm{~mm}$ (1.25 in) and a wall thickness of $2.8 \mathrm{~mm}(0.109 \mathrm{in})$ is selected. This selection results in a tube ID of $26.2 \mathrm{~mm}$. This is very close to the previously selected inner diameter of $25.4 \mathrm{~mm}$.

The selected wall thickness is approximately two times larger than the one calculated according to the ASME formula. This specific selection is driven by the recommendations given in Swagelok $k^{T M}$ tubing catalogue [64]. Swagelok ${ }^{\text {TM }}$ recommends 
tubes with thicker walls for gases for use with Swagelok ${ }^{\mathrm{TM}}$ compression type fittings. As will be discussed in the following section, compression type fittings are selected for connecting the tubing and the components.

\subsubsection{Selection of Tube Fittings}

Fittings are used in a piping system to modify the flow direction, bring two or more pipes/tubes together, alter the tube diameter or terminate a tubing line. The most commonly used types of fittings are elbows, tees, reducers and unions. Tube fittings are generally categorized based on the method of joining, as socket-welding, screwed, compression-type, etc. Compression-type fittings are by far the most widely used type of fittings for tubing applications.

Compression joining is a form of mechanical joining other than welding, soldering or joining by flanges. The most commonly used method of compression joining in tubing systems is swaging [65]. Swage fittings are typically made of a body, a ferrule and a nut (Figure 5.5). As the nut threads into the body, it compresses the ferrule on the surface slightly deforming the tube. The ferrule bites into the surface of the tube providing a fixed point to tighten the joint. 

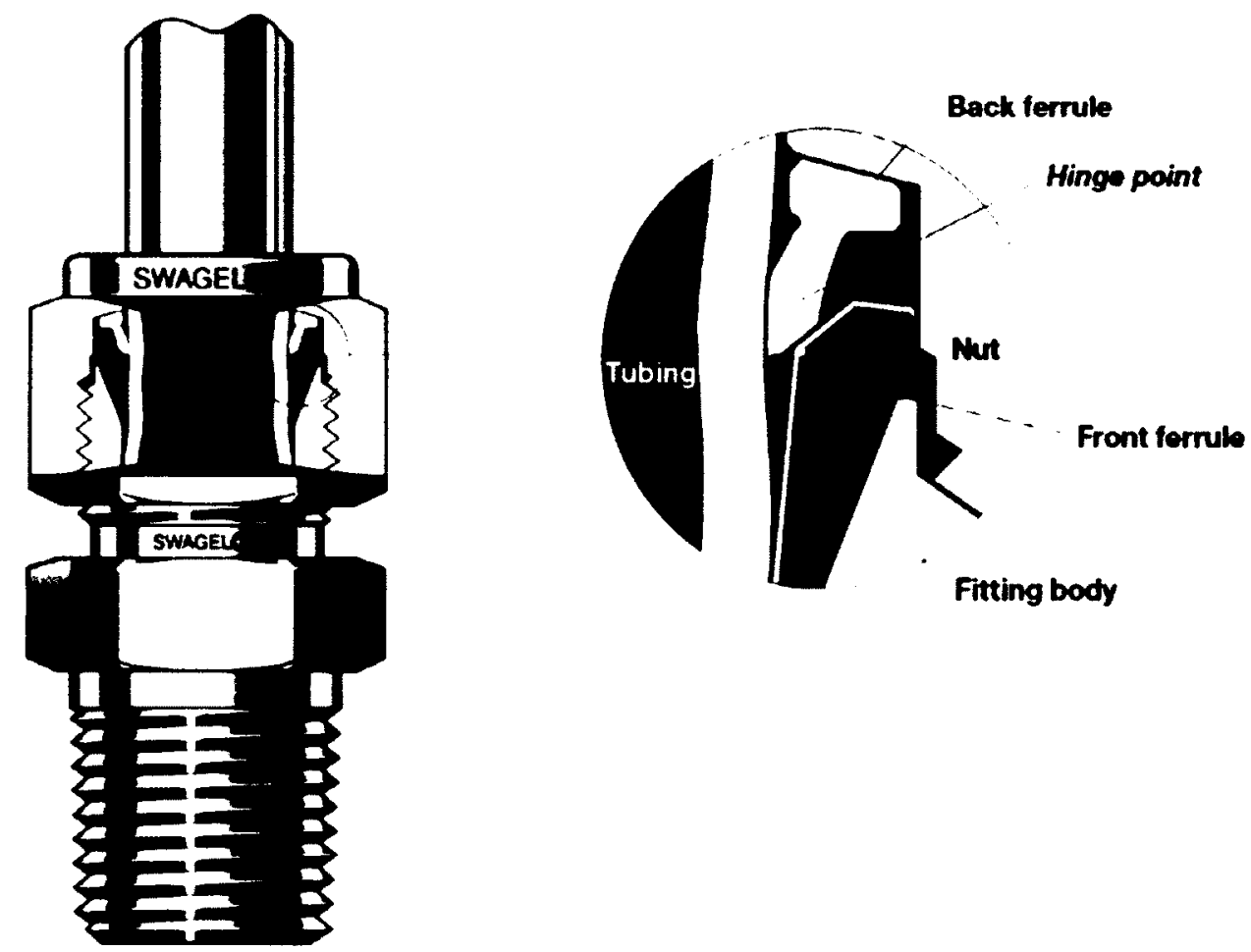

Figure 5.5: Anatomy of a swage fitting [66]

Swage fittings are available in a wide range of materials, heat treatment and coatings.

They come in standard sizes ranging from $1.5 \mathrm{~mm}(1 / 16 \mathrm{in})$ to $50 \mathrm{~mm}(2 \mathrm{in})$ OD [66]. Swage fittings are typically rated to the working pressure of the corresponding tubing. For fittings with both tube fitting and pipe thread ends, pressure ratings are determined by the end connection with the lower pressure rating.

For the R-134a loop assembly, swage fittings manufactured by Swagelok ${ }^{\mathrm{TM}}$ and made of stainless steel Type 316 are selected. A number of different sizes, from $1.5 \mathrm{~mm}$ (1/16 in) to $50 \mathrm{~mm}(1-1 / 4 \mathrm{in})$ OD, are utilized on the R-134a loop. 


\subsubsection{Pump}

A pump is required to circulate the R-134a fluid in the Carleton R-134a loop compensating for the flow induced pressure losses. The pump must be capable of operating at the prevalent experimental conditions encountered during the operation of the R-134a loop. The following subsections outline the procedure followed in the selection of a suitable pump.

Initial sizing of the pump, based on the operating point of the Carleton R-134a loop that corresponds to the maximum flow rate and hence pressure drop, was carried out by Chukwudi Azih, a graduate-student member of the research group. The sizing calculations suggested a rotary positive displacement pump to be most suitable for this application. Therefore, three gear pumps capable of operating at high pressures and temperatures required for experiments in supercritical R-134a with flow rates in the range of 0.021 to $2.1 \mathrm{~kg} / \mathrm{s}$ are selected. The pump is manufactured by Micropump ${ }^{\mathrm{TM}}$ (GN Series). The pressure retaining parts are made of stainless steel 316 and the pumps can operate at a maximum pressure of $10.3 \mathrm{MPa}$ at $121^{\circ} \mathrm{C}$. Since the pumps are connected in parallel and each pump is driven by its own dedicated variable frequency drive (VFD), the flow of the R-134a through the test section can be finely regulated. Additionally, the remotely-actuated ball valve located upstream of the test-section leg and intended for shut-off purposes can be used to regulate the flow through the test section. As recommended by the manufacturer, each pump is to be driven directly by a 2 HP1340 RPM 2 pole induction motor. 


\subsubsection{Flow Control and Measurement}

The flow of R-134a is controlled by regulating the speed of the gear pumps. Each gear pump is equipped with its dedicated variable-frequency drive, which allows independent control of the pumps. This arrangement should make precise control of fluid flow into the test section possible. However, should the need arise, two remotelyactuated shut-off valves located upstream and downstream of the test section may be used for supplementary flow control. The shut-off valves must be capable of operating at up to $6 \mathrm{MPa}$ and temperatures up to $140^{\circ} \mathrm{C}$. Valves are commonly manufactured with a soft polymeric seat. Caution is in order to ensure that the seat material is compatible with R-134a fluid at elevated temperatures.

Accurate measurement of $\mathrm{R}-134 \mathrm{a}$ flow rate in the test section is critical for the quality of the experimental data to be measured in the test section. The flow rate sensor must be capable of operating at pressures up to $6 \mathrm{MPa}$ and elevated temperatures as high as $100^{\circ} \mathrm{C}$. The flow sensor must be compatible with the required flow rate ranges $\left(0.08 \mathrm{~m}^{3} / \mathrm{hr}-7.7 \mathrm{~m}^{3} / \mathrm{hr}\right.$ or $\left.0.34 \mathrm{GPM}-34 \mathrm{GPM}\right)$.

\subsubsection{Shut-off Valve Selection}

As the name implies, shut-off valves are used to stop flow or isolate a portion of the system from the rest of the piping system. The main design requirement of shut-off valves is to offer minimum flow resistance in the fully open position and to achieve a 
leak-tight barrier when fully closed [11]. A number of valve designs, such globe, angle, plug, ball and butterfly satisfy the outlined requirement.

As discussed previously, the shut-off valves are installed upstream and downstream of the test section to isolate the test section from the rest of the loop when required. Hence, it is necessary that the shut-off valve possesses excellent shut-off characteristics when fully closed. Additionally, the valve should also pose negligible restriction to the flow of R-134a when positioned in the fully open direction. By considering the characteristics of the above mentioned valves, it is concluded that a ball valve serves this requirement very well. Ball valves shut off and open only with a quarter turn and they also offer very low pressure drops. They are readily available with seating materials compatible with the operating conditions of the R-134a loop.

Two reduced-port ball valves, made of stainless steel 316 with a pressure rating of 7.2 $\mathrm{MPa}$ at $150{ }^{\circ} \mathrm{C}$ are procured by Yi-Li Jin, another graduate-student member of the research group. The ball valves utilize R-134a compatible PTFE-filled graphite seat. The valves are supplied by Armour Valve Ltd. (model 84-66NG-TE) equipped with NEMA4X encased 120 VAC electric actuators.

\subsubsection{Flow Sensor Selection}

A similar selection procedure as for the SCW loop is carried out to decide on a suitable flow sensor for the R-134a loop. Considering the merits and disadvantages of different types of flow meters, a turbine flow meter with 1 in nominal pipe size manufactured by 
Blancett (model 1100) is selected. The flow meter has an extended range of 5-50 GPM and is equipped with a magnetic pick-off sensor rated to $177^{\circ} \mathrm{C}$. The interfacing of the flow meter with the rest of the R-134a loop is achieved by 1 in NPT threaded Swagelok ${ }^{\text {TM }}$ fittings. The required upstream straightening tube length is determined by Equation (3.5) and it is found that a $1600 \mathrm{~mm}$ long tube (63 diameters) is sufficient based on the empirical correlation.

\subsubsection{Temperature Measurement and Control}

The fluid temperature at the test-section outlet can be as high as $140^{\circ} \mathrm{C}$. To meet the temperature ratings of the pumps and several other components on the loop, the temperature of R-134a must be lowered downstream of the test section. Similar to the SCW loop, the lowering of the fluid temperature is achieved with the help of a heat exchanger. Additionally, the heat exchanger is required to lower the temperature of the fluid to the desired test-section inlet temperature to steadily impart heat to the working fluid in the test section thus allowing measurement of this energy transfer process. Design requirements for the heat exchanger are that it must be capable of operating at temperatures and pressures of $150{ }^{\circ} \mathrm{C}$ and $6 \mathrm{MPa}$, respectively. Lowering the fluid temperature to $40-90{ }^{\circ} \mathrm{C}$ from various test-section outlet temperatures, ranging from $60-140{ }^{\circ} \mathrm{C}$, and realizing this over the flow rate range of $0.08 \mathrm{~m}^{3} / \mathrm{hr}$ to $7.7 \mathrm{~m}^{3} / \mathrm{hr}$, requires the heat exchanger to be sized for $300 \mathrm{~kW}$ maximum heat exchange capability. 
Measurement of temperature along the R-134a loop is essential for health monitoring and for the study of the heat transfer process in the test section. It is necessary that the temperature sensing devices are capable of accurate temperature measurement throughout the required temperature range. It is also necessary that the temperature sensors are capable of withstanding the operating environments of the locations where they are used.

\subsubsection{Heat Exchanger Selection}

Same heat exchanger types as for the SCW loop are also considered for the R-134a loop. It is concluded that a variety of heat exchanger designs meet the operational requirements of the current application. The selection and sizing of the heat exchanger for the R-134a loop was carried out in an earlier design iteration on the Carleton R-134a loop, as documented in [67]. According to this earlier design report, a plate-and-shell heat exchanger, which is a variant of the plate-type heat exchanger, was selected. The heat exchanger was sized for a heat duty of $300 \mathrm{~kW}$ with a hot fluid inlet temperature of $140^{\circ} \mathrm{C}$. The heat exchanger was sized to lower the R-134a temperature from a maximum of $140^{\circ} \mathrm{C}$ to a minimum of $50^{\circ} \mathrm{C}$. The coolant inlet and outlet temperatures used in sizing the heat exchanger were $26^{\circ} \mathrm{C}$ and $31^{\circ} \mathrm{C}$, respectively.

The plate-and-shell heat exchanger is manufactured by GEA Heat Exchangers. It is rated for a maximum heat exchange capacity of $300 \mathrm{~kW}$ with the glycol/water cooling tower via a $9.33 \mathrm{~m}^{2}$ heat transfer area. The high-pressure side of the heat exchanger is made 
of stainless steel 316 rated for operation at $6.2 \mathrm{MPa}$ and $149^{\circ} \mathrm{C}$. The heat exchanger is interfaced with the upstream and downstream loop tubing via welded Swagelok ${ }^{\text {TM }}$ fittings.

\subsubsection{Thermocouple Selection}

Following the same selection process as for the SCW loop, $1.5 \mathrm{~mm}(1 / 16 \mathrm{in})$ stainless steel sheathed thermocouples are selected for use on the R-134a loop. Type E and type $K$ thermocouples are selected as the preferred thermocouple types based on the previous discussion in Section 3.3.5.2.

To monitor the health of the loop against unexpected temperature excursions, thermocouples are soldered or tightly clamped on the tubing surface at a number of locations around the loop. For the study of heat transfer, fluid bulk temperatures are measured by inserting thermocouples into the fluid flow via Swagelok ${ }^{\top M}$ fittings at the inlet and outlet of the test section. As discussed earlier, fluid flow rate is also an important parameter in the heat transfer study; to measure the fluid temperature at a location close to the turbine flow meter, a thermocouple is inserted into the fluid flow through a Swagelok ${ }^{\mathrm{m}}$ fitting.

\subsubsection{Pressure Control and Measurement}

The pressure control and measurement requirements are the same as the ones for the SCW loop. Similar to the SCW loop, the pressure control system must accommodate the expanding fluid volume contained in the loop while maintaining a constant pressure as 
heat is imparted to the fluid in the test section. It is also necessary to accurately measure the pressure in the R-134a loop for the purposes of heat transfer studies and operating-condition/health monitoring. The absolute pressure of the R-134a in the loop is required to determine the properties of $\mathrm{R}-134 \mathrm{a}$ in conjunction with temperature and to ensure that the pressure in the R-134a loop does not exceed its maximum allowable limit. On the other hand, the pressure drop along the test section is required for studying the heat transfer and flow development in the test section.

\subsubsection{Pressurization and Control Method Selection}

Based on the same reasons outlined in the selection of a suitable pressurization and pressure control system for SCW loop in Section 3.3.6.1.5, an accumulator and gas cylinder assembly is chosen for the pressurization and pressure control of the R-134a loop. The same accumulator and gas cylinder assembly as used for the SCW loop is reproduced here as Figure 5.6.

A 41.3 MPa (6000 psi) type $\mathrm{K}$ nitrogen gas cylinder is connected to a high-pressure bladder-type accumulator. Similar to the SCW loop, two electrically-actuated needle valves $C V 3$ and $C V 4$ allow the real-time regulation of the pressure in the R-134a loop.

The assembly, selection and types of needle valves, and connecting tubing are the same as the ones for the SCW loop. The reader is referred to Section 3.3.6.2 for a detailed description. 


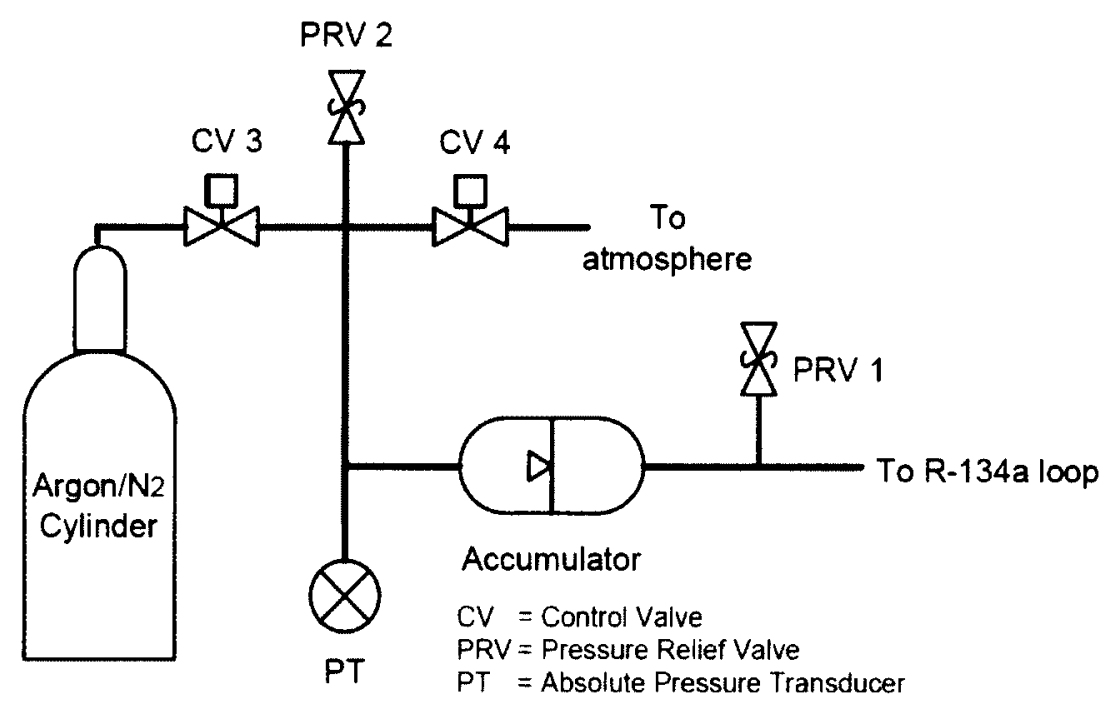

Figure 5.6: Accumulator and gas cylinder assembly

\subsubsection{Pressure Relief Valve}

Two 1/2 in ASME certified Apollo ${ }^{\mathrm{TM}}$ pressure relief (safety) valves are installed to protect the R-134a loop against overpressurization. The pressure relief valves are interfaced with the rest of the system via $1 / 2$ in male NPT threads. The valves have a certified flow capacity of $24.3 \mathrm{~m}^{3} / \mathrm{hr}(107$ USGPM) and are made of stainless steel 316.

\subsubsection{Pressure Sensor Selection}

Following the same selection logic as outlined in Section 3.3.6.3 for the SCW loop, two $1 / 4$ in Swagelok ${ }^{\top M} S$ Model industrial absolute pressure transducers are installed at the locations indicated in Figure 5.6. The absolute pressure transducers have a measurement range of $0-10.34 \mathrm{MPa}(0-1500 \mathrm{psi})$ and a maximum operating range of $100^{\circ} \mathrm{C}$. The pressure readings are converted to $0-10 \mathrm{Vdc}$ output signals. 
For differential pressure measurement, a Rosemount 3051CD differential pressure transducer (same as the one for the SCW loop) is used. This transducer is rated for a maximum line pressure of $31 \mathrm{MPa}$ with a pressure range of -250 to $+250 \mathrm{kPa}$. The operating temperature of the $\mathrm{D} / \mathrm{P}$ transducer is limited to $85^{\circ} \mathrm{C}$. The $\mathrm{D} / \mathrm{P}$ transducer transmits the differential pressure readings via 1-5Vdc HART communications protocol.

\subsubsection{Pressure Transducer Installation}

It is intended to install two absolute pressure transducers, one on the accumulator to monitor its pressure and a second one on the loop to directly monitor the pressure of the loop, as indicated in Figure 5.4. The differential pressure transducer will be installed on the test section to detect the test-section pressure drop (Figure 5.4). The temperature of the accumulator will be kept at the same level as the room temperature and therefore, the pressure transducer can be directly installed on the accumulator. However, the temperature at the location of the second absolute pressure transducer is expected to be as high as $90^{\circ} \mathrm{C}$ and for the $\mathrm{D} / \mathrm{P}$ transducer, the fluid temperature will reach $140^{\circ} \mathrm{C}$. As described in the preceding section, the operating temperature of the selected transducers is limited to maximum $85^{\circ} \mathrm{C}$. To accommodate the pressure transducers, similar to the SCW loop (Figure 3.29), a remote seal and impulse tube combination is used.

For the absolute pressure transducer located on the loop, the impulse tube is used to lower the temperature of the fluid before reaching the transducer. The impulse tube is 
of $6.4 \mathrm{~mm}(1 / 4 \mathrm{in})$ OD stainless steel Type 316 tubing with a wall thickness of $1.2 \mathrm{~mm}$ (0.049 in). The impulse tube is connected to the loop and the pressure transducer via $1 / 4$ in Swagelok ${ }^{\top M}$ fittings.

\subsubsection{Flow Conditioning}

Similar to the SCW loop, a filter is required to separate and collect particulate contamination from the working fluid in the R-134a loop. The filter requirements for the R-134a loop are not as stringent as the ones for the SCW loop. The R-134a loop operates at relatively low pressure and temperature of $7 \mathrm{MPa}$ and $150^{\circ} \mathrm{C}$. However, the maximum flow rate in the R-134a loop is four times higher than in the SCW loop. Like on the SCW loop, the filter is located after the heat exchanger and upstream of the pump and as such the filter must be able to accommodate large flow variations depending on the experiments being performed. Due to the relatively lower operating pressures and temperatures in R-134a loop, NPT threaded connections are used on the filter. The recommended filter element medium is a stainless steel wire mesh similar to the one for the SCW loop. The operation manual for the gear pump, used to circulate the fluid in the R-134a loop, recommends a 5 micron filtration [68].

Considering these requirements, a 5 micron stainless steel mesh United Filtration ${ }^{\mathrm{TM}}$ Teetype filter is installed upstream of the gear pumps. The filter is made of stainless steel 316 rated to $34.5 \mathrm{MPa}$ at $205^{\circ} \mathrm{C}$. The interfacing of the filter with the $\mathrm{R}-134 \mathrm{a}$ loop piping is achieved with the help of 1 " NPT threaded connections. 


\subsection{Design of the Pre-Heater for the R-134a Loop}

The pre-heater requirements for the R-134a loop are not as demanding as the ones for the SCW loop. In case of the R-134a loop, the pre-heater is just used to fine tune the temperature of the fluid at the inlet of the test section. To achieve this, a flexible heater of the type shown in Figure 5.7 is wrapped around the tube segment upstream of the test section. The exact location of the pre-heater is shown in Figure 5.4. The pre-heater can impart a maximum of $3.97 \mathrm{~kW}$ (@ 230V) of heating power to the fluid.

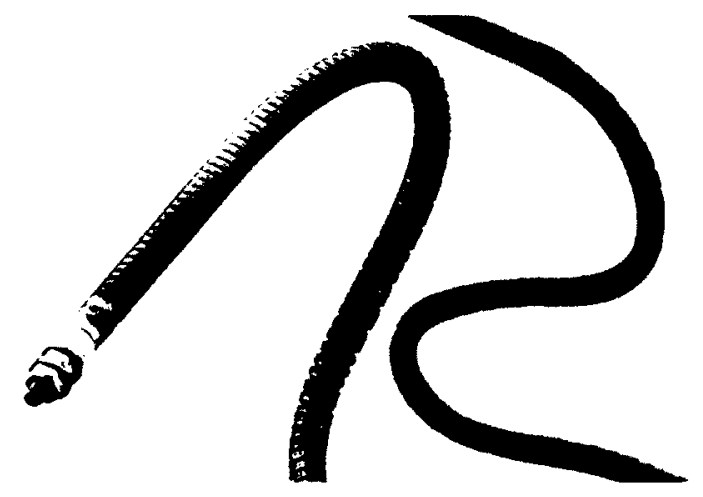

Figure 5.7: Flexible tubular heater [60] 


\section{Chapter 6. Corrosion Issues and Mitigation}

\subsection{Corrosion under SCW Conditions}

Water properties in the supercritical phase are significantly different from those of liquid water under atmospheric conditions. Depending on pressure and temperature, the density of SCW can vary from less than $0.1 \mathrm{~g} / \mathrm{cm}^{3}$ to values similar to that of water below the critical point [69]. The corrosive behaviour of SCW over this range of densities varies widely depending upon the values of properties such as ion product, dielectric constant and the presence of dissolved oxygen.

The ionic product and density of water versus temperature are shown in Figure 6.1. Based on the figure, low-density SCW behaves like a non-polar solvent with low solvency for ionic compounds. Therefore, chemical reactions occurring in low-density SCW are more of radical nature, whereas high-density SCW favours ionic reactions [70].

There are a number of factors that influence the corrosion properties of SCW. These factors include behaviour of ions in SCW and their effect on the oxide film, temperature, $\mathrm{pH}$-value, solubility of gases and presence of anions [70]. In general, the exact influence of these factors depends on the temperature and pressure of the SCW, and the interaction of these factors with the metal. 


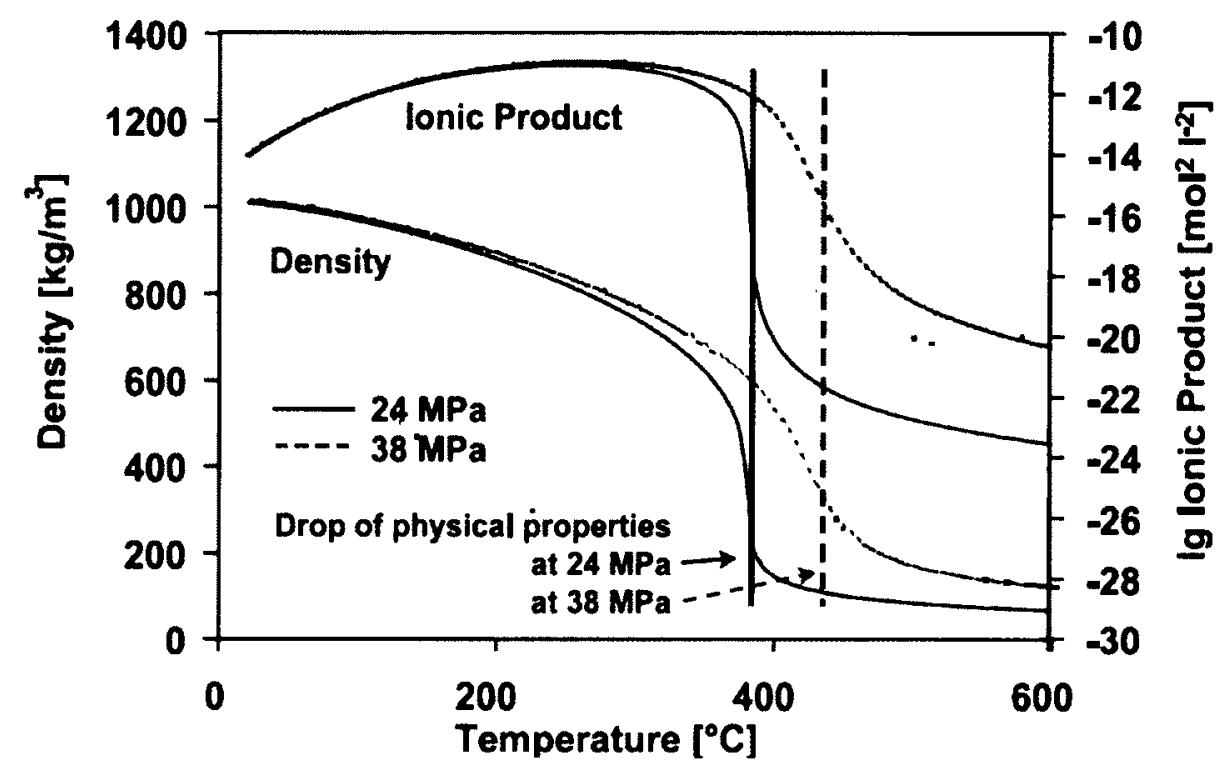

Figure 6.1: Physical properties of water at different temperatures and pressures [70]

The following sections discuss the factors relevant to the SCW loop and chemical treatment strategies of SCW to reduce or increase their effects depending on whether the influence is positive or negative.

\subsubsection{Parameters Influencing SCW Corrosion}

\subsubsection{Ionic Reactions and Oxide Film Stability}

As can be seen in Figure 6.1, the solvent characteristics of SCW change from highly polar at high densities to nearly non-polar at low densities. High polarity favours the solubility of ionic compounds, such as salts. And contrary to the behaviour of water at ambient conditions, also non-polar gases and organic compounds might be completely soluble in low-density (i.e., high-temperature) SCW [70]. 
Low-density SCW suppresses ionic reactions and favours radical reactions instead, especially at high temperatures. Generally, the high temperatures drastically accelerate all chemical reactions [70].

Aqueous corrosion processes are generally ionic in nature. The rate-determining reaction commonly is the dissolution of a protective surface salt, mostly an oxide film [70]. As mentioned above, in high-density SCW, where ionic reactions are favoured, the dissolution of this protective oxide layer is accelerated.

\subsubsection{Temperature}

High temperatures generally increase corrosion rates in water [70]. However, this simplistic temperature dependence of corrosion is valid only if the other properties of the solution remain unchanged. It has been observed that the corrosion rate of materials is lower by orders of magnitude at very high SCW temperatures of $500^{\circ} \mathrm{C}$ compared with corrosion at subcritical $300^{\circ} \mathrm{C}[70]$. This behavior can be traced to the $\mathrm{pH}$ of water at various temperatures and pressures, as discussed below.

\subsubsection{3. $\mathrm{pH}$-Value}

The $\mathrm{pH}$-value is generally based on the equilibrium reaction of the self-dissociation of water into hydrogen (hydroxonium) and hydroxide ions [70]:

$$
\mathrm{H}_{2} \mathrm{O} \leftrightarrow \mathrm{H}^{+}+\mathrm{OH}^{-}
$$


This reaction is endothermic in nature and hence, the rate of dissociation increases with increasing temperature [70]. For example, referring to Figure 6.1, at a pressure of $24 \mathrm{MPa}$, the dissociation reaction reaches a maximum at about $300^{\circ} \mathrm{C}$. At these temperatures, the concentration of both $\mathrm{H}^{+}$and $\mathrm{OH}^{-}$ions are about three times higher than the values at ambient water. Therefore, the water can be considered to be both acidic and alkaline [70]. At higher temperatures with constant pressure, the selfdissociation drastically drops down above a certain temperature and the water takes on more of a non-polar character.

The $\mathrm{pH}$-value is one of the factors, which has the most influence on corrosion in SCW [70]. High or low pH-values lead to the chemical dissolution of the protective oxide layer.

\subsubsection{Water Treatment Strategies to Minimize SCW Corrosion}

High-temperature and SCW are mostly used in power station cycles and, in order to reduce the detrimental effects of corrosion under these conditions, a number of conventional water treatment strategies are employed to minimize corrosion.

One of the earliest water treatments was the phosphate treatment for use in subcritical circulation boilers [70]. In such boiler systems, steam is continuously removed from the boiler, which leads to a rise in the concentration of phosphate salts in the remaining aqueous phase. This has lead to high corrosion rates as the concentrated phosphate solutions were able to dissolve the protective iron oxides of the stainless steels leading 
to a rapid oxidation and dissolution of the underlying alloy [70]. This treatment strategy is not applicable to SCW due to the low solubility of phosphates in SCW.

To overcome the precipitation problem and find a strategy applicable to $\mathrm{SCW}$, a so called all-volatile treatment was introduced [70]. The treatment involves addition of ammonia or hydrazine to form an alkaline solution under low oxygen concentrations. The alkaline solution increases the $\mathrm{pH}$ of water to levels where the iron oxide protective film is stable, however, the reducing environment leads to incomplete formation of the protective iron oxide $\left(\mathrm{Fe}_{2} \mathrm{O}_{3}\right)$ film [70]. As a result Ni-base alloys and stainless steels show elevated corrosion rates under these conditions.

In order to support the formation of the protective iron oxide layer, the solution is made oxidizing by addition of oxygen in the amounts of $100 \mathrm{ppb}$ to the alkaline solution [70]. However, under SCW conditions, ammonia is oxidized in the presence of oxygen to nitrogen gas and $\mathrm{N}_{2} \mathrm{O}[70]$. Therefore, in order to keep corrosion rates low, oxygen and ammonia levels need to be replenished on a regular basis. An alternative treatment is the addition of small amounts of $\mathrm{NaOH}$ or $\mathrm{KOH}$ instead of ammonia $\left(\mathrm{NH}_{3}\right)$ to stabilize the $\mathrm{pH}$ of water at around $9.5[70]$. $\mathrm{NaOH}$ or $\mathrm{KOH}$ cannot be oxidized under $\mathrm{SCW}$ conditions and has therefore been used successfully to reduce corrosion under SCW conditions to acceptable rates. 


\subsubsection{Corrosion Rate of Stainless Steel Type 316 under SCW Conditions}

A number of experiments have been performed to determine the corrosion behaviour of stainless steels under SCW conditions. Horvath et al. [71] investigated the corrosion of stainless steel Type 316 among other materials, whereas Was et al. [69] compiled SCW corrosion data for a number of materials, including stainless steel Type $316 \mathrm{~L}$ and Type 316, under various conditions.

Figure 6.2 shows the oxide layer thickness for stainless steel Type 316 when exposed to SCW at a pressure of $25 \mathrm{MPa}$ and a temperature of $500^{\circ} \mathrm{C}$. The data for stainless steel Type 316 shows some scatter and is not a monotonously increasing curve as for the other materials noted on the figure.

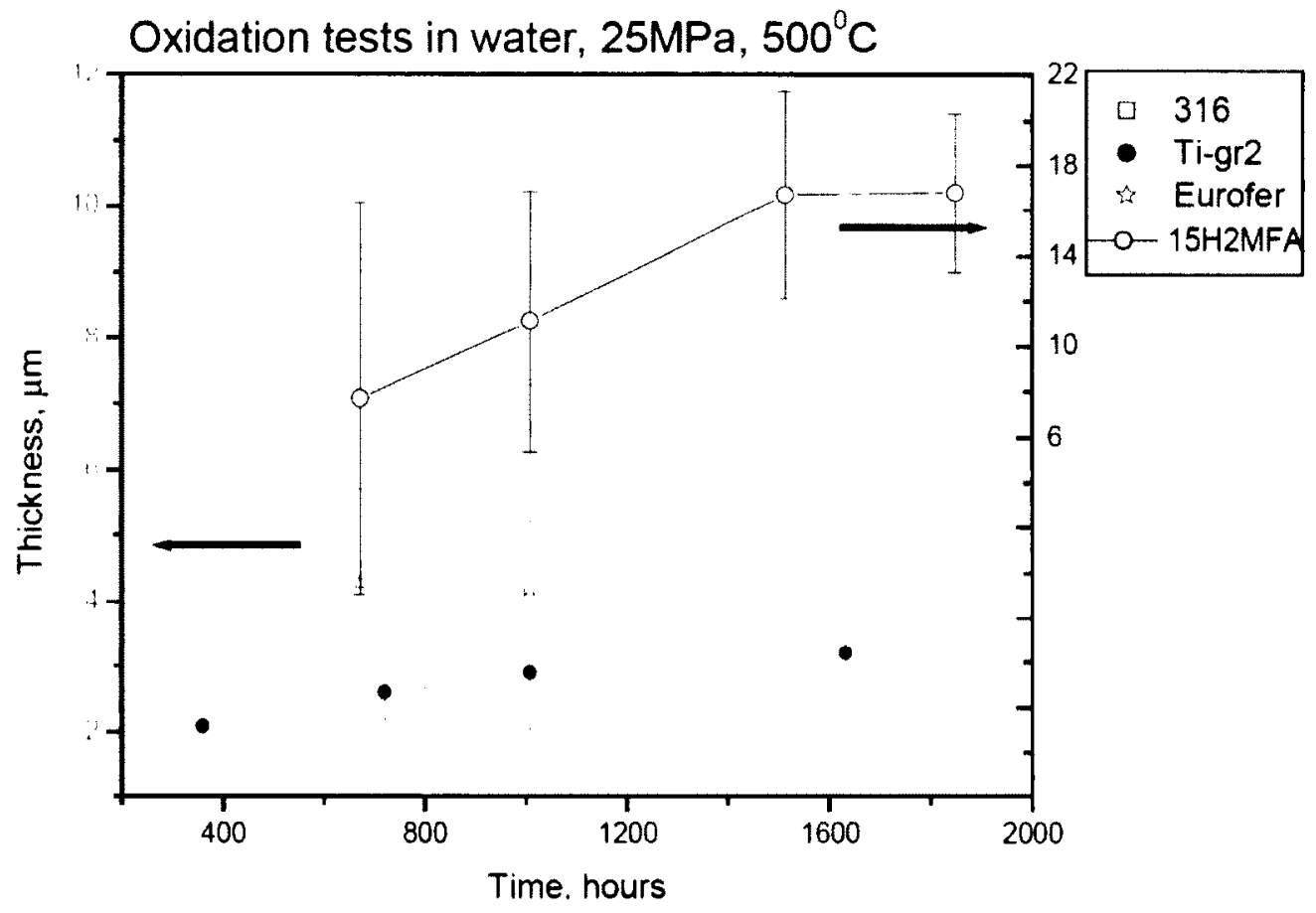

Figure 6.2: Oxide layer thickness versus time for a number of materials [71] 
On average, the oxide layer thickness of stainless steel Type 316 grew to about $3 \mu \mathrm{m}$ when exposed to SCW for approximately 1600 hours. This indicates a rather low rate of corrosion under these conditions, however, higher corrosion rates at temperatures above $500^{\circ} \mathrm{C}$ have been reported [69][71].

The data compiled by Was et al. compares the corrosion of stainless steel Type 316 at 500 and $600{ }^{\circ} \mathrm{C}$ in low oxygen SCW. Based on the data, weight gain due to corrosion at $600{ }^{\circ} \mathrm{C}$ is by two orders of magnitude higher than the weight gain at $500{ }^{\circ} \mathrm{C}$. Figure 6.3 illustrates the weight gain trend for stainless steel Type 316 along with austenitic steels D9 and $800 \mathrm{H}$ when exposed to de-aerated SCW at $600^{\circ} \mathrm{C}$.

Similarly, the effect of dissolved oxygen on the corrosion rate of stainless steel Type 316 is depicted in Figure 6.4. It is found that the rate of corrosion increases as the content of dissolved oxygen in SCW is increased. The rate of corrosion for $2000 \mathrm{ppb}$ dissolved oxygen is slightly higher than the rate of corrosion at $25 \mathrm{ppb}$ dissolved oxygen at the same temperature. 


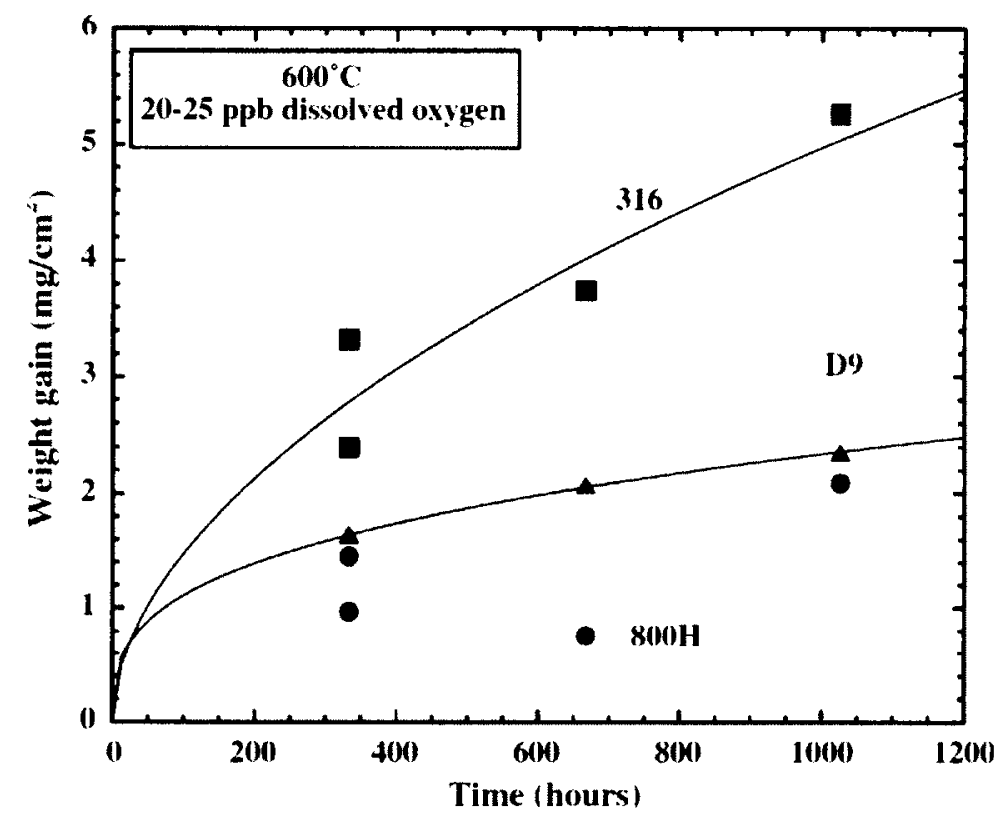

Figure 6.3: Weight gain versus time for Type 316 when exposed to SCW at $600{ }^{\circ} \mathrm{C}$ [69]

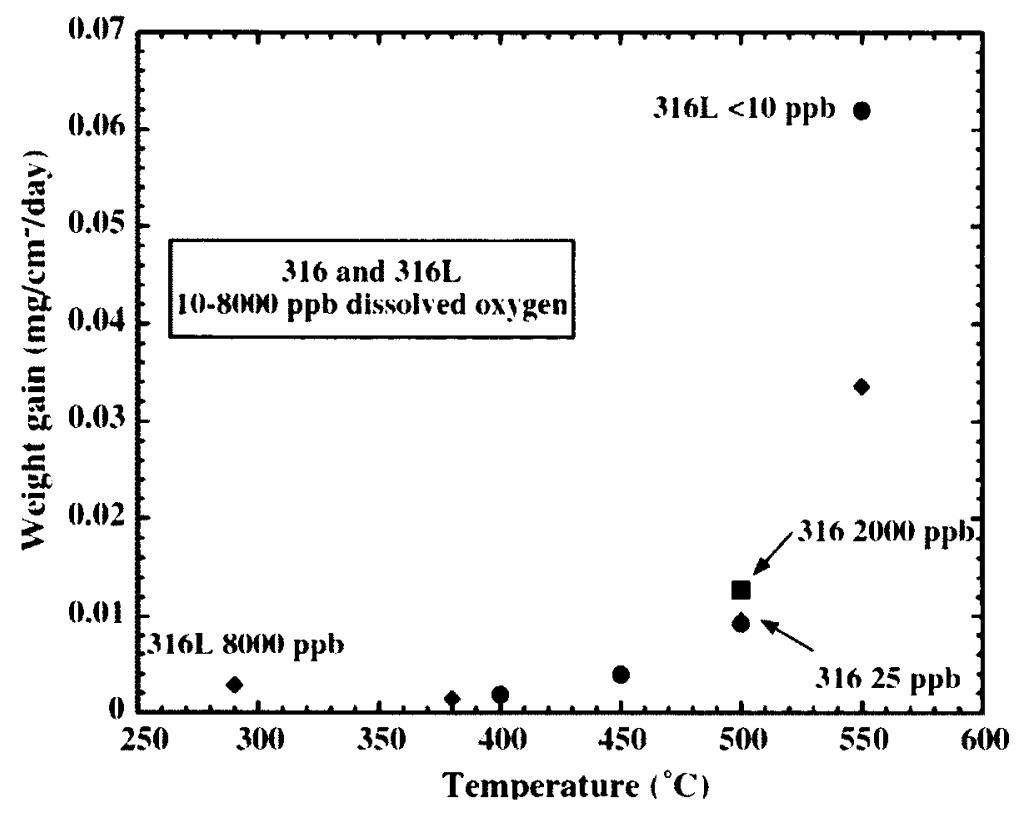

Figure 6.4: Weight gain rate versus temperature for Type 316 at various dissolved oxygen concentrations [69] 


\subsubsection{Corrosion of SCW Loop}

Based on the foregoing discussion of corrosion under SCW conditions and the corrosion of stainless steel Type 316 under such conditions, the following observations can be made:

- Rate of corrosion at locations where the fluid temperature is in the subcritical range will be higher compared to the locations where the fluid will be in the supercritical state.

- According to the data on corrosion of stainless steel Type 316 when exposed to $600^{\circ} \mathrm{C} \mathrm{SCW}$ (Figure 6.3), which is the maximum temperature of the SCW loop, the estimated corrosion rate of Type 316 is $0.05 \mathrm{~mm} /$ year when converting from weight gain.

- This estimated corrosion rate suggests that the corrosion allowance provided for the SCW loop piping may be sufficient for the expected life-time of the loop.

- To reduce corrosion, it is recommended to use de-ionized and de-aerated water.

- It is also recommended to vacuum pump the loop before filling it up with deionized and de-aerated water.

- A further step to reduce corrosion in low temperature locations would be to treat the water with $\mathrm{NaOH}$ or $\mathrm{KOH}$ and increase its $\mathrm{pH}$ to about 9.5 . 


\section{Chapter 7. Conclusions and Recommendations}

A SCW loop and an R-134a loop capable of operating at supercritical conditions of their corresponding fluids were designed. Also designed were three test-section geometries (i.e. tubular, annular and bundle) to accommodate various experimental requirements in support of supercritical fluids forced-convection heat transfer studies. Through this design exercise, the following conclusions were drawn. Recommendations for future work also discussed in this chapter following the conclusions.

\subsection{Conclusions}

\subsubsection{SCW and R-134a Loops}

The SCW loop was designed to carry out experiments with SCW as the working fluid at pressures and temperatures as high as $28 \mathrm{MPa}$ and $600^{\circ} \mathrm{C}$, respectively; whereas the $\mathrm{R}-134 \mathrm{a}$ loop was designed for operating conditions up to $6 \mathrm{MPa}$ and $140^{\circ} \mathrm{C}$. Based on the applicable ASME code stress analyses, it was found that stainless steel $316 / 316 \mathrm{H}$ pipes of nominal sizes NPS 1.5 with a wall thickness of schedule XXS and NPS $3 / 4$ with a wall thickness of schedule 160 for the SCW loop, and tubing of $31.75 \mathrm{~mm}(1.25 \mathrm{in})$ OD with a wall thickness of $2.8 \mathrm{~mm}(0.109 \mathrm{in})$ for the R-134a loop provide the required wall thicknesses to withstand the operating conditions of their respective applications.

When no specific requirement for the flow velocity in the piping exists, using industry accepted flow velocities is an effective way of determining the internal diameter of the 
piping. The internal diameters of the selected pipe and tube sizes were determined based on the industry accepted flow velocities, and therefore they result in reasonable flow velocities and hence pressure drops.

Based the survey of similar test loops, the arrangement of various components on the SCW loop and R-134a loop were determined. It was found that a suitable location for a heat exchanger is immediately downstream of the test section and upstream of the pump. This location lowers the temperature to which the rest of the components on the test loop will be subjected and also increases the efficiency of the pump.

Reviewing various types of heat exchangers and their applications, it was determined that due to the high pressures and temperatures encountered in the SCW loop, a double-pipe or a shell-and-tube heat exchanger would be the most suitable type for use on the SCW loop. This conclusion was validated by the selection of a shell-and-tube heat exchanger by Advanced Industrial Components, Inc. (AIC), the company contracted to manufacture the heat exchanger for the SCW loop. On the other hand, the operating pressures and temperatures of the $\mathrm{R}-134$ a loop are relatively low and hence a shell-andplate type heat exchanger has been selected by the heat exchanger manufacturer, GEA Heat Exchangers.

The centrifugal pump on the SCW loop has a minimum flow rate, which is higher than the maximum flow rate required for the experimental purposes. It was determined that the most suitable way to control the flow rate through the test section is to use a bypass 
line with control valves installed on the bypass line and the main line feeding the test section. This arrangement allows for diversion of excess flow through the bypass line in a controlled fashion while providing the option to directly regulate the flow rate through the test section. The flow circulation in the R-134a loop is provided by three gear pumps connected in parallel. As such, fine regulation of the flow rate is possible by running any pump combination since each pump is equipped with its own dedicated variablefrequency drive.

\subsubsection{Test Sections}

Three different test-section geometries (i.e. tubular, annular and seven-rod bundle) were designed to meet the experimental requirements. All of the three test sections have a heated length of $2000 \mathrm{~mm}$ and are made of Inconel 625 . The tubular test section was designed to have an inner diameter of $12.5 \mathrm{~mm}$ and can achieve heat and mass fluxes of up to $660 \mathrm{~kW} / \mathrm{m}^{2}$ and $1050 \mathrm{~kg} / \mathrm{m}^{2} \mathrm{~s}$, respectively, at the maximum allowable test-section wall temperature of $723^{\circ} \mathrm{C}$. The annular test-section heater rod has an outer diameter of $10 \mathrm{~mm}$ and can be used with wall temperatures as high as $780^{\circ} \mathrm{C}$. At this wall temperature, heat and mass fluxes of up to $784 \mathrm{~kW} / \mathrm{m}^{2}$ and $716.2 \mathrm{~kg} / \mathrm{m}^{2} \mathrm{~s}$, respectively, are achievable. The same parameters for the bundle test section as for the annular test section are $7.4 \mathrm{~mm} O D, 151 \mathrm{~kW} / \mathrm{m}^{2}, 221 \mathrm{~kg} / \mathrm{m}^{2} \mathrm{~s}$ and a maximum allowable wall temperature of $650^{\circ} \mathrm{C}$. 
The test sections were designed to have a hydraulic diameter close to that of the CANDU $^{\mathrm{Tm}}$ fuel bundle, i.e. $8 \mathrm{~mm}$. This ensures that the experimental data can be extrapolated to the behavior of the fluid in the actual fuel bundle.

The wall thicknesses of the heated parts of the test sections were determined based on the applicable ASME code while attempting to match the electrical resistance of the heated parts to the internal resistance of the power supply. This was to ensure that the maximum available power from the power supply is applied to the test sections. However, calculations showed that the required wall thickness to withstand the imposed pressures was much larger and hence the overriding factor.

Method of power transmission to the heated parts of the test sections depends on the test-section geometry. Power transmission to the tubular test section is achieved by simply clamping the bus bars to the test section. For the annular and bundle test sections, it was determined that the most suitable method of power transmission to the heater rod(s) is via a dielectrically isolated blind flange.

The annular and bundle test sections were designed to allow access for a temperature probe to measure the wall temperature of the heater rod(s). This required that one end of the heat rod(s) be exposed to atmospheric pressure while the opposite end was subjected to the operating pressure of the test section. To seal off the opposite end, a compression packing type sealing method was employed. 
The test sections were designed to use the same size Grayloc $^{\text {TM }}$ connectors as the interfaces on the test loops. This allows for easy interchangeability of the test sections.

\subsubsection{ASME Codes}

To ensure a high level of safety and simplify the TSSA certification, the test loops and the test sections were designed to applicable ASME codes. Based on the operation of the test loops resembling power generating stations, they were designed to ASME Power Piping Code B31.1. The test sections, on the other hand, can be considered as unfired pressure vessels as defined in the ASME Boiler and Pressure Vessel Code, Section VIII-Division 1. Therefore, the test sections were designed to this Code.

\subsubsection{Materials and Materials Costs}

Based on the operating conditions of the test loops, in particular those of the SCW loop, a material with very good high temperature strength and good corrosion resistance is required. Stainless steel Types 316 and $316 \mathrm{H}$ were selected as the materials of construction for the test loops. R-134a loop is constructed entirely of stainless steel Type 316, whereas the SCW loop uses both Types 316 and 316H. Type 316H is used at the locations where the expected temperature is higher than $538^{\circ} \mathrm{C}$.

A number of factors, such as the high temperature strength, corrosion resistance, electrical resistivity and thermal conductivity were considered in the selection of a suitable material for the test sections. Also of importance in the selection process were the recognition of the material by ASME Boiler and Pressure Vessel Code and the cost of 
the material. Considering all of these factors, Inconel 625 was selected as the material of construction for the test sections. It was found that of all the researched nickel-based superalloys, Inconel 625 was the least expensive.

\subsubsection{Grayloc ${ }^{\mathrm{m}}$ Connectors}

As discussed in one of the sections above, standard ASME/ANSI flanges are not rated for the maximum operating conditions of the SCW loop. Therefore, a proprietary connector design, called Grayloc ${ }^{\mathrm{rm}}$ is used at the locations where standard flanges cannot be used. Grayloc ${ }^{\text {im }}$ connectors are very versatile and rated for operating pressures and temperatures well above those of the SCW loop. Particularly, Grayloc ${ }^{\mathrm{rm}}$ blind hubs are of significant advantage in the current project. The blind hub can be drilled, tapped and modified as required to accommodate instrumentation feedthroughs. In the case of the annular and bundle test sections, blind hubs are drilled to allow access for the temperature measurement traverse probe. However, all of these advantages come at a cost. Grayloc ${ }^{\mathrm{TM}}$ connectors are relatively expensive.

\subsubsection{Swagelok ${ }^{\mathrm{IM}}$ Fittings}

Swagelok ${ }^{\top M}$ fittings can be used at very high pressures with small diameter tubing. As the tube diameter is increased, the pressure rating of Swagelok ${ }^{\mathrm{TM}}$ fittings decreases. They are used on the R-134a loop to accomplish all of the connections. However, on the SCW loop, they can only be used for instrumentation purposes where $1 / 4$ in tubing is used. 


\subsubsection{Corrosion}

Based on the available literature on the general corrosion of stainless steel Type 316 under SCW conditions, the corrosion rate is calculated to be relatively low. It is expected that the corrosion rate will be higher at the locations where the material is exposed to the lower subcritical temperatures compared to the higher supercritical temperatures. In general, Inconel 625 has a lot better corrosion resistance in the presence of SCW.

\subsubsection{Experimental Capabilities}

The SCW loop offers higher temperature and pressure capabilities compared to most of the surveyed test loops. Similarly, the test sections can be used at much higher wall temperatures of up to $780^{\circ} \mathrm{C}$ (for the annular test section) compared to the surveyed test sections. These capabilities allow performing experiments with SCW as the fluid in the pressure-temperature range for which the existing data in the literature is scarce. Furthermore, these higher experimental capabilities are in line with the requirement to perform experiments in the operating range of the proposed CANDU-SCWR.

The test loops were designed to allow for easy reconfiguration of the test section orientation relative to the gravitational direction. This allows performing experiments with flow in three fundamental directions, i.e. vertically upward, vertically downward and horizontal. Additionally, flow in any inclined angle between the horizontal and vertical directions can be readily accomplished by orienting the test section at the desired angle. 


\subsection{Recommendations}

\subsubsection{Test-Section Power Regulation}

As mentioned in the facility description, the DC power supply does not possess fine power regulation capability. To better control the test-section power, it is recommended to connect an electronic DC load in parallel to the test section. Two different electronic DC loads, one manufactured by QuadTech ${ }^{\mathrm{M}}$ and the other manufactured by Sorensen ${ }^{\mathrm{TM}}$ were researched for this purpose. The electronic DC load by Sorensen is recommended. This electronic DC load allows real-time fine-tuning of power on the test section.

\subsubsection{Test-Section Dielectric Gasket}

As shown in the design of the annular and bundle test sections, the blind flange that connects to the internal bus bar is offset from the test section to prevent excessive heating of the dielectric gasket when used on the SCW loop. Numerical simulations have shown that the offset distance used in the design is sufficient to keep the temperature of the dielectric gasket below $200{ }^{\circ} \mathrm{C}$. However, the blind flange assembly should be continuously monitored during experiments on the SCW loop so that the temperature limit of the dielectric gasket is not exceeded and cooling, in the form of a fan, should be provided if required. 


\subsubsection{Filter/Strainer Dielectric Gasket}

As discussed before, a dielectric gasket is installed between the filter and heat exchanger to avoid inadvertent heating of the rest of the SCW loop when passing current through the tubular test section. To keep the high-temperature water from contacting the dielectric gasket, a thin PTFE sleeve is inserted in the bore of the flange assembly and this particular flange assembly should not be insulated. The temperature of this particular flange assembly should be monitored to keep the temperature of the dielectric gasket below $200{ }^{\circ} \mathrm{C}$. Cooling, in the form of a fan, should be provided if required.

\subsubsection{Grayloc ${ }^{\text {tM }}$ Dielectric Connector}

Similar to the SCW loop, it is also necessary to dielectrically break the continuous connection of the R-134a loop tubing. In this case, it is accomplished by using a dielectric Grayloc ${ }^{\mathrm{m}}$ connector installed just upstream of the test-section inlet. The

dielectric Grayloc ${ }^{\mathrm{m}}$ connector is rated for a maximum temperature of $121{ }^{\circ} \mathrm{C}$. The temperature of this specific joint is not expected to exceed $90{ }^{\circ} \mathrm{C}$, nevertheless it should be monitored against unexpected temperature excursions and cooling, in the form of a fan, should be provided if required.

\subsubsection{SCW Loop Pre-Heater}

Maximum power input to the $\mathrm{SCW}$ is possible if the pre-heater is connected in series to the test section. This requires that the power input to the pre-heater is adjustable. The 
power input to the pre-heater can be adjusted manually or remotely. The remote method is recommended as this allows the online adjustment of the pre-heater power. A high-power switch can be used to achieve this.

\subsubsection{Corrosion Control and Inspection}

To reduce the rate of corrosion, particularly in the SCW loop, the chemistry of the water should be controlled by increasing its $\mathrm{pH}$ value, as discussed previously. It is also recommended that the water be tested regularly for corrosion products to obtain an estimate of the severity of corrosion in the loop. Finally, an inspection program should be put in place to monitor the rate of corrosion in areas of interest, such as the elbows, using a non-destructive examination method. A common non-destructive examination method for corrosion monitoring is using ultrasonic wall thickness measuring devices. 


\section{References}

[1] Baindur S. Materials challenges for the supercritical water-cooled reactor. Proceedings of the $28^{\text {th }}$ Annual Conference of the Canadian Nuclear Society; 2007 June 3-6, St. John, New Brunswick. Toronto: Canadian Nuclear Society; 2007.

[2] Chow CK et. al. A fuel channel design for CANDU-SCWR. Proceedings of the 14th International Conference on Nuclear Engineering; 2006 July 17-20, Miami, Florida, USA. New York: American Society of Mechanical Engineers; 2006.

[3] Pioro IL, Duffey RB. Heat transfer and hydraulic resistance at supercritical pressures in power-engineering applications. ASME Press, New York, NY; 2007.

[4] Yamagat $K$ et. al. Forced convective heat transfer to supercritical water flowing in tubes. Int. Journal of Heat and Mass Transfer 1972; 15: 2575-2593.

[5] Licht $J$ et al. Heat transfer phenomena in supercritical water nuclear reactors. Nuclear Engineering Education Research. Final technical report; No.: DE-FG-0704ID 14602. Wisconsin, Madison; August 2007.

[6] Laurien E et al. Flow and heat transfer of a heated rod with a wrapped wire inside a channel. $4^{\text {th }}$ International Symposium on Supercritical Water-Cooled Reactors; 2009 March 8-11, Heidelberg, Germany.

[7] Yin F et al. An investigation on heat transfer to supercritical water in inclined upward smooth tubes. Heat Transfer Engineering 2008; 27: No.: 9: 44-52.

[8] Power Piping. ASME B31.1-2007. ASME Code for Pressure Piping, B31. ASME; 2007.

[9] Process Piping. ASME B31.3-2006. ASME Code for Pressure Piping, B31. ASME; 2006.

[10] Materials Properties (Metric). Section II, Part D. 2007 ASME Boiler and Pressure Vessel Code. ASME; 2007. 
[11] Nayyar ML. Piping Handbook. $7^{\text {th }}$ ed. MCGraw-Hill, USA; 2000.

[12] Recommended Practice for Design and Installation of Offshore Production Platform Piping Systems. API recommended practice 14E. $5^{\text {th }}$ ed. API; October 1991.

[13] NIST Standard Reference Data. Thermophysical properties of fluid systems. Viewed Online; July 2010. http://webbook.nist.gov/chemistry/fluid/

[14] White FM. Fluid Mechanics. $4^{\text {th }}$ ed. McGraw-Hill, Canada; 1998.

[15] Stainless Steel Pipes-Dimensions and Weights. ASME B36.19. ASME; 2000.

[16] Parisher RA, Rhea RA. Pipe Drafting and Design. Gulf Professional Publishing, USA; 2002.

[17] Standard Specification for Wrought Austenitic Stainless Steel Piping Fittings. ASTM A 403/A 403 M-02. ASTM; 2002.

[18] Factory-Made Wrought Buttwelding Fittings. ASME B16.9-2003. ASTM; 2004.

[19] Huitt WM. Engineering Practice, Piping design, Part 1 - Flanges. Chemical Engineering; March 2007.

[20] Pipe flanges and flanged fittings. ASME B16.5. ASME; 2003.

[21] Flitney R. Seals and Sealing Handbook. $5^{\text {th }}$ ed. Elsevier Ltd.; 2007.

[22] Shigley JE et. al. Standard Handbook of Machine Design. $3^{\text {rd }}$ ed. McGraw-Hill, USA; 2004.

[23] VCS Flange Gasket. Pikotek. Viewed Online; March 2010. http://www.pikotek.com

[24] Grayloc Product Catalogue. An Oceaneering International Company. Viewed Online; May 2010. http://www.grayloc.com 
[25] Valves - Flanged, Threaded, and Welding End. ASME B16.34-2004. ASME; 2005.

[26] Liptak BG. Instrument Engineers' Handbook: Process Measurement and Analysis; Vol. 1. CRC Press LLC, Florida; 2003.

[27] Measurement of Liquid Hydrocarbons by Turbine Meter Systems. API 2534. $1^{\text {st }}$ ed. American Petroleum Institute, Washington, D.C.; 1970.

[28] Kakac S, Liu H. Heat Exchangers - Selection, Rating and Thermal Design. CRC Press LLC, Florida; 1998.

[29] Shah RK, Sekulic DP. Fundamentals of Heat Exchanger Design. John Wiley \& Sons, Inc., Hoboken, New Jersey; 2003.

[30] Kuppan T. Heat Exchanger Design Handbook. Marcel Dekker, Inc., New York, NY; 2000.

[31] Heatric Division of Meggitt (UK) Limited. Compact heat transfer solutions. Viewed Online; March 2010. http://www.heatric.com/index.html

[32] Genivar. V-SIM Building, Thermal hydraulic testing laboratory. Ottawa, June 2009. File No.: OT09-030-00-70.

[33] Monnery WD, et al. Viscosity: A Critical Review of Practical Predictive and Correlative Methods. The Canadian Journal of Chemical Engineering 1995; 73: 340.

[34] Saksena MP, Harminder MP. Thermal Conductivity of Binary Liquid Mixtures. Chemical Physics Letters 1974; 25: No.: 3: 445-448.

[35] Ng K, Rosenberg A. Heat Capacity of Poly (Ethylene Glycol)-Water Mixtures. Thermochimica Acta 1990; 169: 339-346.

[36] Dittus FW, Boetler LMK. Heat Transfer in Automobile Radiators of the Tubular Type. Univ. Calif. Publ. Eng. 1930; 2: No.: 13: 443-461.

[37] Ozisik MN. Heat Transfer-A basic approach. McGraw-Hill, Inc., New York; 1985. 
[38] Dow Propylene Glycol, Industrial Grade: Technical Data Sheet. Dow. Viewed Online; December 2009. http://www.dow.com/propyleneglycol/prod/pgi.htm

[39] Thermophysical Properties of Brines. M. Conde Engineering, Zurich; 2002. Viewed Online; December 2009. www.mrc-eng.com/Downloads/Brine\%20Properties.pdf

[40] Utamura $\mathrm{M}$ et al. A generalized mean temperature difference method for thermal design of heat exchangers. Int. Journal of Nuclear Energy Science and Technology 2008; 4: No. 1: 11-31.

[41] Cheng $X$, Schulenberg T. Heat transfer at supercritical pressures-Literature review and application to an HPLWR. Karlsruhe, Germany: Forschungszentrum Karlsruhe $\mathrm{GmbH}$; 2007. Report No.: FZKA 6609.

[42] Rules for construction of pressure vessels. Section VIII, Division 1. 2007 ASME Boiler and Pressure Vessel Code. ASME; 2007.

[43] Welded and Seamless Wrought Steel Pipe. ASME B36.10M-2000. ASME; March 2001.

[44] Omega Temperature Measurement Handbook. OMEGA ENGINEERING, Inc., USA; 2010.

[45] Webster JG. Measurement, Instrumentation and Sensors Handbook. CRC Press LLC, Florida; 1999.

[46] Conoflow High Pressure Regulator-HP800. ITT Conoflow. Viewed Online; July 2010. http://www.conoflow.com/pdf/products/hp800.pdf

[47] Pressure regulators. Swagelok Company. Viewed Online; August 2010. http://www.swagelok.com

[48] Back Pressure Regulators. Circle Seal Controls, Inc. Viewed Online; August 2010. http://www.circle-seal.com 
[49] Warring RH. Hydraulic Handbook. $8^{\text {th }}$ ed. Trade \& Technical Press Ltd., Surrey, England; 1983.

[50] Kurlovits J, Svindenkov F. Hydraulic Accumulator for Constant Pressure Operation. Engineer's Digest 1946; 3: No.: 10: 516-516.

[51] Gard MF, Rabinovich SM. Thermal Pressure Control: Regulation of High-pressure Gas by Exploitation of Temperature Sensitivity. IEEE Transactions on Control Systems Technology 1994; 2: No.: 2: 151-154.

[52] Totten GE, ed. Handbook of Hydraulic Fluid Technology. Marcel Dekker, New York; 2000.

[53] Tubol Accumulator Catalogue. Tubol Accumulator, Inc. Viewed Online; August 2010. http://www.tubol.com

[54] Information provided by Praxair Ottawa; December 2010.

[55] Rosemount DP Level Transmitters and Remote Seals. Emerson Process Management. Viewed Online; June 2010. http://www.rosemount.com

[56] Norman Filters. Filter Training. Viewed Online; August 2010. http://www.normanfilters.com/training/training1.html

[57] Special Metals, Inc. Inconel Alloy N06230. Viewed Online; December 2010. http://www.specialmetals.com/documents/Inconel\%20alloy\%20N06230.pdf

[58] Ward S. Electrical Engineering. Global Media. Chandni Chowk, Delhi; 2007.

[59] Theraja BL, Theraja AK. A textbook of electrical technology: Vol. 1 Basic electrical engineering. Chand \& Co Ltd., India; 2006.

[60] HotSet. Hotflex Flexible tubular heater. Viewed Online; April 2011. http://www.hotset-orldwide.com/us/products/hotflex 
[61] Kang KH et al. An experimental study on the pressure transient heat transfer up to supercritical pressures. 4th International Symposium on Supercritical WaterCooled Reactors. Heidelberg, Germany. March 8-11, 2009.

[62] Bae YY et al. Heat transfer experiments in a wire-inserted tube at supercritical conditions. $4^{\text {th }}$ International Symposium on Supercritical Water-Cooled Reactors. Heidelberg, Germany. March 8-11, 2009.

[63] Dickenson C. Pumping Manual. 8th ed. Trade \& Technical Press Ltd., Surrey, England; 1988.

[64] Tubing Data. Swagelok Company. Viewed Online; August 2010. http://www.swagelok.com

[65] Antaki GA. Piping and Pipeline Engineering: Design, Construction, Maintenance, Integrity and Repair. Marcel Dekker, Inc., New York, NY; 2003.

[66] Gaugeable Tube Fittings and Adapter Fittings. Swagelok Company. Viewed Online; March 2010. http://www.swagelok.com

[67] Azih C et al. R-134a Thermalhydraulics Loop: Detailed Design. Report No.: CUM\&A-2009-12. Department of Mechanical and Aerospace Engineering, Carleton University, Ottawa; 2009.

[68] Micropump Installation, Operation and Warranty Information. Micropump, Inc.; March 2006.

[69] Was GS et al. Corrosion and stress corrosion cracking in supercritical water. Journal of Nuclear Materials 2007; 371: 176-201.

[70] Kritzer P. Corrosion in high-temperature and supercritical water and aqueous solutions: a review. Journal of Supercritical Fluids 2004; 29: 1-29.

[71] Horvath $A$ et al. Study of corrosion in supercritical water. $4^{\text {th }}$ International Symposium on Supercritical Water-Cooled Reactors; 2009 March 8-11, Heidelberg, Germany. 
APPENDIX A: Supercritical Fluid Heat Transfer Facility 
The Carleton University supercritical fluid test facility is a high-temperature highpressure facility for performing forced-convection heat transfer experiments with fluids at supercritical conditions. It is located in the VSIM building on the Carleton University campus. The test facility will house two supercritical fluid-flow loops, namely a SCW loop and a supercritical R-134a loop. Figure A-1 depicts the locations of various equipment and the loops in the facility.

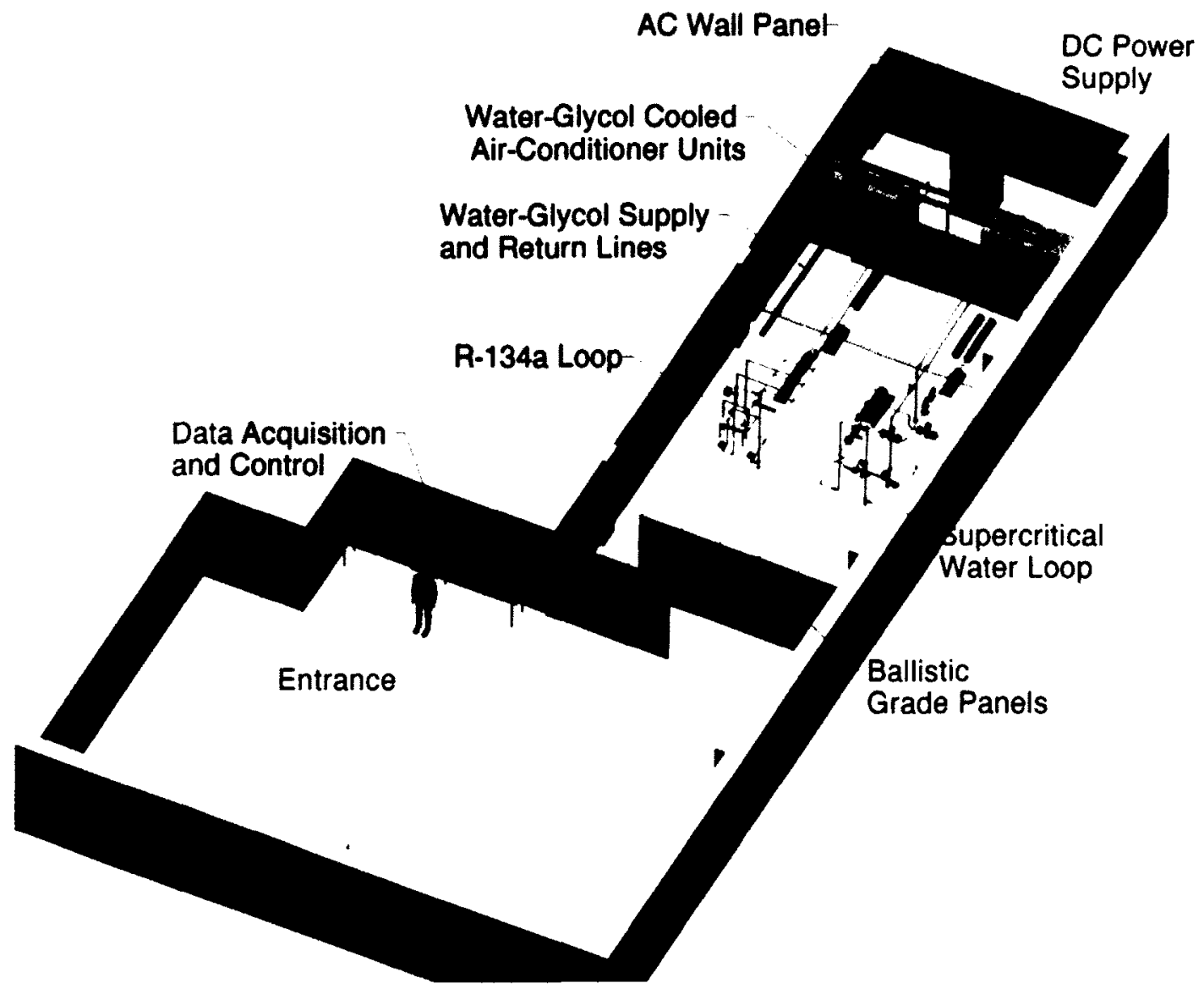

Figure A-1: Layout of supercritical flow test facility 


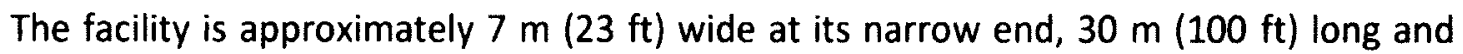
$2.9 \mathrm{~m}(9.7 \mathrm{ft})$ high. Although limited in the vertical direction, the facility can be used for experiments involving very long horizontally oriented test sections.

$500 \mathrm{~kW}$ of 3-phase AC electrical power at $600 \mathrm{~V}$ is delivered to the test facility, a portion of which is then transformed to DC power $(0-150 \mathrm{~V}, 0-2000 \mathrm{~A})$ for use in resistive heating of the working fluids in the test loops. A Magnavolt Model DTLG 600-150/2000 transformer provides the power conversion with an efficiency of $94 \%$ and a maximum ripple factor of $7 \%$, and allows for control of the output power through adjustable voltage and current with $\pm 1 \%$ stability and $\pm 1 \%$ regulation capability. The $A C$ power not utilized by the transformer unit is sufficient to power the pump motors of the two loops and two air-conditioning units each rated at about $25 \mathrm{~kW}$ cooling capacity. The airconditioning units are conservatively sized to offset the stray heat transfer from the loops, the transformer and other auxiliary equipment in the facility.

The $500 \mathrm{~kW}$ electric power entering the facility is removed from the facility in the form of heat and released to the atmosphere through a forced-draft counter-flow wet/dry cooling tower. A $168.3 \mathrm{~mm}$ outer diameter (NPS 6) pipe supplies water/glycol coolant at a temperature of $29^{\circ} \mathrm{C}\left(85^{\circ} \mathrm{F}\right)$ to the experimental facility. The coolant that is circulated at a constant rate of 470 GPM is used to accomplish the rejection of heat from the supercritical fluid loops by exchange of heat energy through the loops' heat exchangers. The main coolant pipe line is provided with a multitude of connection ports for 
interfacing with the heat exchangers and the water/glycol-cooled air-conditioning units. The cooling tower adapts to the thermal load through adjustment of the air-fan speed and introduction of a water spray when needed.

The test loops are located some distance away from the above-described electric-power and air-conditioning infrastructure to take advantage of the highest floor-to-ceiling distance available in the laboratory. The laboratory space occupied by the two test loops and the supporting infrastructure is separated from the remainder of the laboratory by ballistic-grade composite panels for added protection of personnel during operation of the facility. The control of the cooling tower system, the electric power supply, and the test loops is realized remotely from a location in the laboratory that is not in direct line of sight of the test loops. Signals acquired from various sensors on the test loops are also transmitted to this location via a wiring harness.

The supercritical fluid loops and the accompanying equipment are instrumented in such a way that all relevant parameters such as temperature, pressure, flow rate, and voltage and current for resistive heating can be measured. The measured data are recorded by a state-of-the-art data acquisition system. 
APPENDIX B: Material Descriptions 


\section{Stainless Steel Type 316 [1]}

Type 316 (UNS S31600) is a chromium-nickel-molybdenum stainless steel with high heat-resistant properties. When exposed to many types of chemical corrodents, as well as marine atmosphere, Type 316 shows better corrosion resistance in comparison to other chromium-nickel steels. It also has higher tensile, creep and stress-to-rupture strengths than other stainless steels.

Type 316 is susceptible to intergranular corrosion after welding and therefore it must be annealed to dissolve the intergranular carbides and then water quenched after welding. It is less susceptible to pinhole and pitting type corrosion when exposed to hot and cold acidic environments compared to other grades of stainless steel.

Table B-1: Chemical composition of stainless steel Type 316

\begin{tabular}{lc}
\hline Element & Composition, max \% \\
\hline Carbon & 0.080 \\
Manganese & 2.0 \\
Phosphorus & 0.045 \\
Sulphur & 0.030 \\
Silicon & 1.0 \\
Chromium & $16-18$ \\
Nickel & $10-14$ \\
Molybdenum & $2.0-3.0$ \\
\hline
\end{tabular}

This type of stainless steel has a vast area of usage. It is used for chemical storage and transportation tanks, food processing equipment, digesters and evaporators for the paper industry, nuclear fuel cladding, heat exchanger components and oil refining equipment.

Type 316 shows very good ductility in annealed state and can easily be roll formed, deep drawn, bent and upset. Since it work hardens, it is necessary to restore ductility by annealing for further cold working. Annealing is also recommended for rigorously cold worked parts to remove stress. 
Table B-2: Thermal conductivity of stainless steel Type 316

\begin{tabular}{cc}
\hline Temperature $\left[{ }^{\circ} \mathrm{C}\right]$ & Thermal Conductivity $[\mathrm{W} / \mathrm{mK}]$ \\
\hline 100 & 16.3 \\
500 & 21.5 \\
\hline
\end{tabular}

Table B-3: Tensile properties of stainless steel Type 316 at elevated temperatures

\begin{tabular}{ccccc}
\hline $\begin{array}{c}\text { Temperature } \\
{\left[{ }^{\circ} \mathrm{C}\right]}\end{array}$ & $\begin{array}{c}\text { Tensile strength } \\
{[\mathrm{MPa}]}\end{array}$ & $\begin{array}{c}\text { Yield strength } \\
{[\mathrm{MPa}]}\end{array}$ & $\begin{array}{c}\text { Elongation, } \\
\%\end{array}$ & $\begin{array}{c}\text { Reduction in } \\
\text { area, \% }\end{array}$ \\
\hline $\mathbf{2 0 5}$ & 560 & 240 & 51 & 76 \\
$\mathbf{3 1 5}$ & 540 & 215 & 48 & 72 \\
$\mathbf{4 2 5}$ & 525 & 195 & 47 & 66 \\
540 & 485 & 165 & 44 & 60 \\
650 & 395 & 145 & 40 & 53 \\
760 & 240 & 125 & 37 & 46 \\
870 & 165 & 110 & 39 & 44 \\
\hline
\end{tabular}

Table B-4: Selected physical properties for stainless steel Type 316

\begin{tabular}{lc}
\hline Melting range & $1370-1400^{\circ} \mathrm{C}$ \\
Density & $8.0 \mathrm{~g} / \mathrm{cm}^{3}$ \\
Specific heat at $0-100^{\circ} \mathrm{C}$ & $500 \mathrm{~J} / \mathrm{kgK}$ \\
Electrical resistivity at $20^{\circ} \mathrm{C}$ & $740 \mathrm{n} \Omega \mathrm{m}$ \\
\hline
\end{tabular}

As with most stainless steels, Type 316 can be welded by common fusion and resistance welding methods. It is fairly machinable and requires rigid setups and sharp tools. The finish quality of the machined products can be improved by using Type 316 in a moderately cold worked condition rather than in an annealed condition. It is also recommended that Type 316 be machined with heavy feeds and adequate supply of coolant. 


\section{Stainless Steel Type 316H [2]}

Stainless steel Type $316 \mathrm{H}$ is a higher carbon variant of Type 316 making the steel more suitable for use in applications where elevated temperatures are present.

Table B-5: Chemical composition of stainless steel Type 316H

\begin{tabular}{lc}
\hline Element & Composition, max \% \\
\hline Carbon & $0.04-0.10$ \\
Manganese & 2.0 \\
Phosphorus & 0.045 \\
Sulphur & 0.030 \\
Silicon & 0.75 \\
Chromium & $16-18$ \\
Nickel & $10-14$ \\
Molybdenum & $2.0-3.0$ \\
\hline
\end{tabular}

The increased carbon content (minimum 0.04\%) and large grain size (6 or coarser) delivers a greater tensile and yield strength. The austenitic structure of the material also gives this grade excellent toughness, which is sustained even down to cryogenic temperatures. The higher carbon content and coarse grain size increases the elevated temperature rupture and creep strengths of Type $316 \mathrm{H}$.

Most other properties of Type $316 \mathrm{H}$, such as corrosion resistance, ductility, machinability and weldability, remain similar to those of stainless steel Type 316.

Type $316 \mathrm{H}$ finds use in similar applications as Type 316. It is used in the petrochemical, gas and chemical industry, pressure vessels, industrial boilers and heat exchangers.

\section{Inconel Alloy $625[3]$}

Inconel 625 (UNS N06625) is a nickel-base alloy with excellent resistance to corrosion and oxidation. The matrix of the alloy is stiffened by adding molybdenum and columbium to the nickel-chromium base. Inconel 625 is a nonmagnetic alloy with 
exceptional fatigue strength. It has excellent stress-rupture properties up to $650^{\circ} \mathrm{C}$ and great strength and toughness at high temperatures of up to $1100^{\circ} \mathrm{C}$. For service at temperatures below $650^{\circ} \mathrm{C}$, hot-finished, cold-finished and mill-annealed conditions are recommended and for service above $650^{\circ} \mathrm{C}$, either mill-annealed or solution annealed states may be used. The alloy retains its ductility and toughness at very low temperatures and its tensile strength can be further improved by cold working.

Inconel 625 is resistant to chlorine ion stress corrosion cracking and oxidation in a broad spectrum of corrosive environments. Compared to some other Inconel alloys, e.g. Inconel 600, inconel 625 has superior corrosion resistance properties.

Table B-6: Chemical composition of Inconel 625

\begin{tabular}{lclc}
\hline Element & $\begin{array}{c}\text { Composition, } \\
\max \%\end{array}$ & Element & $\begin{array}{c}\text { Composition, } \\
\max \%\end{array}$ \\
\hline Carbon & 0.10 & Iron & 5.0 \\
Manganese & 0.50 & Sulphur & 0.015 \\
Titanium & 0.40 & Silicon & 0.50 \\
Cobalt & 1.00 & Chromium & $20.0-23.0$ \\
Molybdenum & $8.0-10.0$ & Columbium (+Ta) & $3.15-4.15$ \\
Aluminum & 0.40 & Nickel & Remainder \\
\hline
\end{tabular}

The alloy can readily be worked by common process, but it does show resistance to deformation even at hot-forming temperatures. Hot forming is done at close to $1200^{\circ} \mathrm{C}$ and forging is performed at a lower temperature of $1000^{\circ} \mathrm{C}$. Below $1000^{\circ} \mathrm{C}$, the alloy is stiff and forging at lower temperatures than above may cause hammer splits.

Inconel 625 needs to be machined at low cutting speeds with ample cutting fluid. A sulphur base cutting fluid is recommended for machining Alloy 625 .

Alloy 625 has excellent welding properties and it does not require any post-weld heat treatment to maintain its high corrosion resistance. It is readily welded by gas-shielded welding methods and brazing tests have also shown excellent results. 
Table B-7: Normal room temperature mechanical properties for Inconel 625

\begin{tabular}{rcccc}
\hline $\begin{array}{c}\text { Form and } \\
\text { Condition }\end{array}$ & $\begin{array}{c}\text { Tensile strength } \\
{[\mathrm{MPa}]}\end{array}$ & $\begin{array}{c}\text { Yield strength } \\
{[\mathrm{MPa}]}\end{array}$ & $\begin{array}{c}\text { Elongation, } \\
\% \text { in 50 } \mathbf{m m}\end{array}$ & $\begin{array}{c}\text { Reduction in } \\
\text { area, \% }\end{array}$ \\
\hline $\begin{array}{r}\text { Rod, Bar, Plate } \\
\text { As-rolled }\end{array}$ & $827-1100$ & $410-760$ & $30-60$ & $40-60$ \\
$\begin{array}{r}\text { Annealed } \\
\text { Sheet and } \\
\text { Strip }\end{array}$ & $827-1040$ & $410-660$ & $30-60$ & $40-60$ \\
$\begin{array}{r}\text { Annealed } \\
\text { Tube and Pipe } \\
\text { Cold Drawn } \\
\text { Annealed } \\
\text { Solution }\end{array}$ & $827-965$ & $410-520$ & $30-55$ & - \\
Annealed & $627-965$ & $410-520$ & $30-55$ & - \\
\hline
\end{tabular}

Table B-8: Selected physical properties for Inconel 625

\begin{tabular}{rl}
\hline $\begin{array}{l}\text { Specific gravity } \\
\text { Density }\end{array}$ & 8.44 \\
Specific heat & $8.44 \mathrm{~g} / \mathrm{cm}^{3}$ \\
Thermal conductivity & $410 \mathrm{~J} / \mathrm{kgK}$ \\
at $21^{\circ} \mathrm{C}$ & \\
at $315^{\circ} \mathrm{C}$ & $9.8 \mathrm{~W} / \mathrm{mK}$ \\
at $870^{\circ} \mathrm{C}$ & $12 \mathrm{~W} / \mathrm{mK}$ \\
Electrical resistivity & $23 \mathrm{~W} / \mathrm{mK}$ \\
Modulus of elasticity & $1.29 \mu \Omega \mathrm{m}$ \\
in tension & \\
in torsion & $205 \mathrm{GPa}$ \\
Poisson's ratio & $79 \mathrm{GPa}$ \\
\hline
\end{tabular}

Due to its excellent high temperature properties, Alloy 625 is used in jet engine components, aerospace equipment, chemical processing construction, seawater equipment, etc. 


\section{Hastelloy C-276 [1]}

Alloy $\mathrm{C}-276$ is a high temperature alloy with excellent corrosion resistance and good fabricability properties. Alloy $C-276$ is an improved version of Alloy $C$, which is one of the most universally corrosion-resistant alloys available.

Table B-9: Chemical composition of Hastelloy C-276

\begin{tabular}{lclc}
\hline Element & $\begin{array}{c}\text { Composition, } \\
\text { max } \%\end{array}$ & Element & $\begin{array}{c}\text { Composition, } \\
\text { max \% }\end{array}$ \\
\hline Molybdenum & $15.00-17.00$ & Vanadium & 0.35 \\
Chromium & $14.50-16.50$ & Sulphur & 0.03 \\
Iron & $4.00-7.00$ & Silicon & 0.05 \\
Tungsten & $3.00-4.50$ & Phosphorus & 0.03 \\
Cobalt & 2.50 & Carbon & 0.02 \\
Manganese & 1.00 & Nickel & Remainder \\
\hline
\end{tabular}

Alloy $\mathrm{C}-276$ is heat treated by raising its temperature to $1150^{\circ} \mathrm{C}$ and rapidly cooling it by air or water quenching it. It has greater machinability compared to Hastelloy $C$ and can be readily machined by conventional methods. Tungsten carbide tipped tools are recommended. The alloy work hardens and therefore the tools need to be engaged in the cut at all times.

C-276 is readily workable by forging, hot-upsetting, impact extruding, deep drawing, spinning, press forming and punching. Although it has a tendency to work harden, it can still be cold worked. The alloy can be welded by all common welding procedures. However, caution must be taken regarding the method of welding and the intended use of the fabricated part.

The Alloy is used in chemical and petrochemical process equipment such as reaction vessels, heat exchangers, piping, pump parts and high temperature applications in aircrafts. 
Table B-10: Selected physical properties for Hastelloy C-276

\begin{tabular}{ll}
\hline $\begin{array}{l}\text { Specific gravity } \\
\text { Density }\end{array}$ & 8.90 \\
$\begin{array}{l}\text { Specific heat } \\
\text { Thermal conductivity }\end{array}$ & $8.90 \mathrm{~g} / \mathrm{cm}^{3}$ \\
$\quad$ at $-170^{\circ} \mathrm{C}$ & $427 \mathrm{~J} / \mathrm{kgK}$ \\
$\quad$ at $-18^{\circ} \mathrm{C}$ & \\
at $38^{\circ} \mathrm{C}$ & $7.2 \mathrm{~W} / \mathrm{mK}$ \\
at $538^{\circ} \mathrm{C}$ & $9.4 \mathrm{~W} / \mathrm{mK}$ \\
at $760^{\circ} \mathrm{C}$ & $10.2 \mathrm{~W} / \mathrm{mK}$ \\
at $1100^{\circ} \mathrm{C}$ & $19 \mathrm{~W} / \mathrm{mK}$ \\
Electrical resistivity & $23 \mathrm{~W} / \mathrm{mK}$ \\
Modulus of elasticity (dynamic) & $28 \mathrm{~W} / \mathrm{mK}$ \\
$\quad$ at Room temperature & $1.295 \mu \Omega \mathrm{m}$ \\
at $538^{\circ} \mathrm{C}$ & \\
Coefficient of thermal expansion & $205 \mathrm{GPa}$ \\
$25-93^{\circ} \mathrm{C}$ & $176 \mathrm{GPa}$ \\
$25-538^{\circ} \mathrm{C}$ & \\
$25-930^{\circ} \mathrm{C}$ & $11.2 \times 10^{-6} 1 /{ }^{\circ} \mathrm{C}$ \\
\end{tabular}

\section{Inconel Alloy $617[4]$}

Inconel 617 (UNS N06617) is a solid-solution strengthened, nickel-chromium-cobaltmolybdenum alloy. This material possesses an exceptional combination of hightemperature strength and oxidation resistance. The nickel-chromium base is strengthened by the solid-solution of cobalt and molybdenum. This imparts high mechanical strength to Inconel 617, which is maintained at elevated temperatures over $980^{\circ} \mathrm{C}$. The material exhibits exceptional low cycle fatigue and high-temperature creep properties. It is generally used in the solution-annealed condition, for the best creeprupture strength.

The high nickel and chromium contents impart excellent resistance to a variety of both reducing and oxidizing media while aluminum, in conjunction with chromium, provides 
high-temperature oxidation resistance. The alloy exhibits excellent resistance to aqueous corrosion in many wet environments.

Table B-11: Chemical composition of Inconel 617

\begin{tabular}{lclc}
\hline Element & $\begin{array}{c}\text { Composition, } \\
\text { max \% }\end{array}$ & Element & $\begin{array}{c}\text { Composition, } \\
\text { max \% }\end{array}$ \\
\hline Carbon & 0.15 & Iron & 3.0 \\
Manganese & 1.0 & Sulphur & 0.015 \\
Titanium & 0.60 & Silicon & 1.0 \\
Cobalt & 15.0 & Chromium & $20.0-24.0$ \\
Molybdenum & $8.0-10.0$ & Copper (+Boron) & $0.50(+0.006)$ \\
Aluminum & $0.80-1.50$ & Nickel & Remainder \\
\hline
\end{tabular}

Inconel 617 demonstrates similar hot-forming characteristics to those of Inconel 625. The alloy can be lightly worked at temperatures down to $925^{\circ} \mathrm{C}$, but for heavy forming or forging average temperatures of 1010 to $1205^{\circ} \mathrm{C}$ are required. In general, Inconel 617 has good hot formability, but due to its inherent strength at elevated temperatures, it requires high forces. The alloy can be readily cold worked using conventional procedures, but due to its high work-hardening rate frequent intermediate anneals should be used.

Table B-12: Typical room temperature mechanical properties of Inconel 617

\begin{tabular}{ccccc}
\hline $\begin{array}{c}\text { Form and } \\
\text { Condition }\end{array}$ & $\begin{array}{c}\text { Tensile strength } \\
\text { [MPa] }\end{array}$ & $\begin{array}{c}\text { Yield strength } \\
\text { [MPa] }\end{array}$ & $\begin{array}{c}\text { Elongation, } \\
\% \text { in 50mm }\end{array}$ & $\begin{array}{c}\text { Reduction in } \\
\text { area, \% }\end{array}$ \\
\hline $\begin{array}{c}\text { Plate } \\
\text { Hot-rolled }\end{array}$ & 734 & 322 & 62 & 56 \\
Bar $\begin{array}{c}\text { Hot-rolled } \\
\quad\end{array}$ & 769 & 318 & 56 & 50 \\
$\begin{array}{c}\text { Sheet or Strip } \\
\text { Cold-rolled }\end{array}$ & 755 & 351 & - & 58 \\
$\begin{array}{c}\text { Tube and Pipe } \\
\text { Cold Drawn }\end{array}$ & 758 & 351 & 56 & - \\
\hline
\end{tabular}


Table B-13: Selected physical properties for Inconel 617

\begin{tabular}{|c|c|}
\hline Specific gravity & 8.36 \\
\hline Density & $8.36 \mathrm{~g} / \mathrm{cm}^{3}$ \\
\hline \multicolumn{2}{|l|}{ Specific heat } \\
\hline at $26^{\circ} \mathrm{C}$ & $419 \mathrm{~J} / \mathrm{kgK}$ \\
\hline \multicolumn{2}{|l|}{ Thermal conductivity } \\
\hline at $20^{\circ} \mathrm{C}$ & $13.4 \mathrm{~W} / \mathrm{mK}$ \\
\hline \multicolumn{2}{|l|}{ Electrical resistivity } \\
\hline at $26^{\circ} \mathrm{C}$ & $1.29 \mu \Omega \mathrm{m}$ \\
\hline \multicolumn{2}{|l|}{ Modulus of elasticity } \\
\hline in tension & $211 \mathrm{GPa}$ \\
\hline in torsion & $81 \mathrm{GPa}$ \\
\hline Poisson's ratio & 0.30 \\
\hline
\end{tabular}

Machining of alloy 617 should be performed with sharp tools and positive rake angles to minimize work hardening of the material. Sufficient cutting feed and depth of cut must be used to prevent the surface of the work piece from burnishing.

Any of the conventional welding procedures, such as gas-tungsten-arc, gas-metal-arc or shielded metal-arc can be used on alloy 617 with excellent results. Welding of Inconel 617 is generally carried out with the filler metal of the same composition as the base metal resulting in a weld that is comparable to the wrought alloy in strength and corrosion resistance.

Due to its high strength and oxidation resistance at elevated temperatures, Inconel 617 finds usage in combustion cans, and other high-temperature components, such as ducting and transition liners of gas turbines. Because of its excellent high-temperature corrosion resistance, the alloy is used in the production of nitric acid and for reduction boats in the refining of molybdenum.

\section{Inconel Alloy N06230 [5]}

Inconel N06230 (UNS N06230) is a carbide-strengthened nickel-chromium-tungstenmolybdenum alloy. The alloy offers exceptional strength, stability and resistance to 
corrosion at very high temperatures. Inconel N06230 derives its strength from the solidsolution of tungsten and molybdenum in conjunction with its high carbon content. The alloy's high carbon content leads to secondary carbide particles, which significantly contribute to the materials strength. The alloy exhibits excellent strength at temperatures above $982^{\circ} \mathrm{C}$ and it is generally used in the solution-annealed condition at these high temperatures for optimum creep-rupture properties.

Table B-14: Chemical composition of alloy N06230

\begin{tabular}{lclc}
\hline Element & $\begin{array}{c}\text { Composition, } \\
\max \%\end{array}$ & Element & $\begin{array}{c}\text { Composition, } \\
\text { max \% }\end{array}$ \\
\hline Carbon & $0.05-0.15$ & Iron & 3.0 \\
Manganese & 1.0 & Sulphur & 0.015 \\
Phosphorus & 0.030 & Silicon & $0.25-0.75$ \\
Cobalt & 5.0 & Chromium & $20.0-24.0$ \\
Molybdenum & $1.0-3.0$ & Tungsten & $13.0-15.0$ \\
Aluminum & $0.20-0.50$ & Boron & 0.015 \\
Lanthanum & $0.005-0.050$ & Nickel & Remainder \\
\hline
\end{tabular}

Table B-15: Room temperature tensile properties of Inconel N06230

\begin{tabular}{lccc}
\hline $\begin{array}{c}\text { Form and } \\
\text { Condition }\end{array}$ & $\begin{array}{c}\text { Tensile strength } \\
\text { [MPa] }\end{array}$ & $\begin{array}{c}\text { Yield strength } \\
\text { [MPa] }\end{array}$ & $\begin{array}{c}\text { Elongation, } \\
\text { \% in 50mm }\end{array}$ \\
\hline Plate & & & \\
Hot-rolled & 807 & 380 & 44 \\
Annealed & 841 & 427 & 48 \\
\hline
\end{tabular}

The nickel-chromium base provides resistance to a variety of corrosion mechanisms at elevated temperatures. Its corrosion resistance is further improved by the addition of the rare earth metal lanthanum. Inconel N06230 has excellent corrosion resistance to nitric acid and carburization. The oxidation resistance of the alloy at temperatures above $1093^{\circ} \mathrm{C}$ is unmatched by any other conventional, high strength alloy. 
Inconel N06230 can be worked by standard procedures for high strength nickel alloys, but the alloy's work hardening rate may affect certain operations. Hot forming is generally carried out at temperatures close to 1010 to $1230^{\circ} \mathrm{C}$. Although the alloy is readily cold formed by conventional procedures, frequent intermediate annealing at temperatures of 1066 to $1149^{\circ} \mathrm{C}$ is necessary due to its high rate of work hardening.

Table B-16: Selected physical properties of Inconel N06230

\begin{tabular}{|c|c|}
\hline Specific gravity & 8.91 \\
\hline Density & $8.91 \mathrm{~g} / \mathrm{cm}^{3}$ \\
\hline \multicolumn{2}{|c|}{ Coefficient of thermal expansion } \\
\hline at 21 to $315^{\circ} \mathrm{C}$ & $419 \mathrm{~J} / \mathrm{kgK}$ \\
\hline Melting range & $1360-1410$ \\
\hline \multicolumn{2}{|l|}{ Electrical resistivity } \\
\hline at $21^{\circ} \mathrm{C}$ & $1.26 \mu \Omega m$ \\
\hline \multicolumn{2}{|l|}{ Modulus of elasticity } \\
\hline in tension & $212 \mathrm{GPa}$ \\
\hline in torsion & $79 \mathrm{GPa}$ \\
\hline Poisson's ratio & 0.34 \\
\hline
\end{tabular}

Inconel N06230 has similar machining properties to those of Inconel 617. Due to characteristic work hardening of the alloy, sharp cutting tools with positive rake angles should be employed. Sufficient cutting feed and depth of cut must be used to prevent the surface of the work piece from burnishing.

Inconel N06230 has good weldability properties. Any of the conventional welding procedures, such as gas-tungsten-arc with Inconel filler metal 617, gas-metal-arc with Inconel filler metal 617 or shielded metal-arc with Inconel welding electrode 117 can be used on alloy N06230. For best results in welding dissimilar metals, Inconel filler metal 617 or Inconel welding electrode 117 should be used.

Due to its combined high-temperature strength and creep properties, and its corrosion resistance, the alloy is used for service at temperatures above $980^{\circ} \mathrm{C}$. Its uses include equipment and components for land-based gas turbines, thermal and petrochemical processing, and ore and metal refining. 


\section{References}

[1] ASM Alloy Centre Online. ASM Materials Information. ASM International; 2005.

[2] Masteel UK Ltd. Type 316H Stainless Steel. Viewed Online; March 2010. http://www.masteel.co.uk/type-316h-stainless-steel.htm

[3] Special Metals, Inc. Inconel Alloy 625. Viewed Online; December 2010. http://www.specialmetals.com/documents/Inconel\%20allov\%20625.pdf

[4] Special Metals, Inc. Inconel Alloy 617. Viewed Online; December 2010. http://www.specialmetals.com/documents/Inconel\%20alloy\%20617.pdf

[5] Special Metals, Inc. Inconel Alloy N06230. Viewed Online; December 2010. http://www.specialmetals.com/documents/Inconel\%20alloy\%20N06230.pdf 


\section{APPENDIX C: HEX Quotes}


Heat Exchanger Specification Sheet

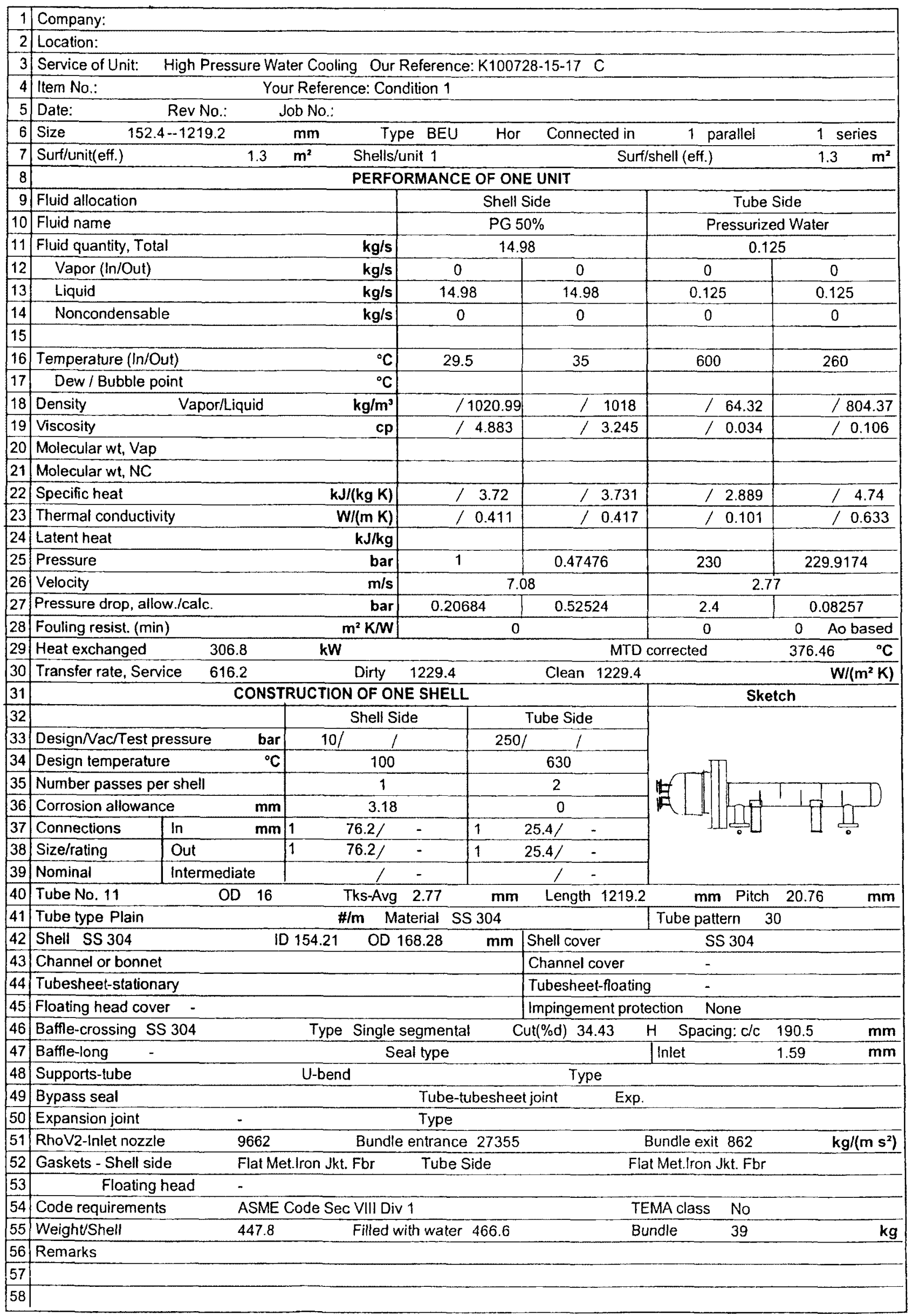


R. W. HOI I A N D, I N C.

EXCHANGER SPECIFICATION SHEET

(S.I. UNITS)

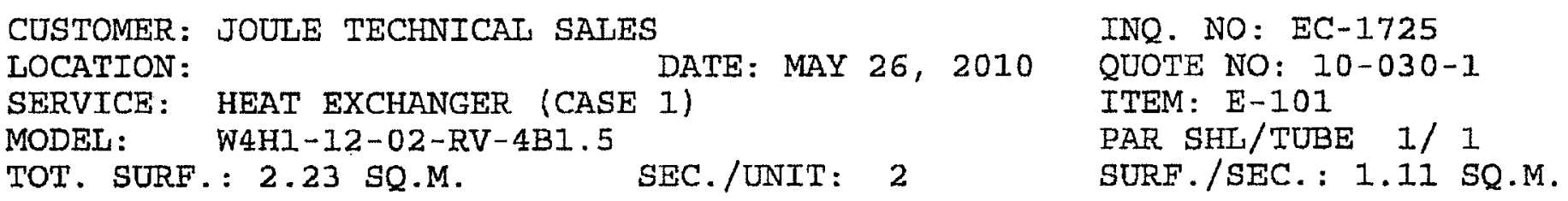

PERFORMANCE OF ONE UNIT

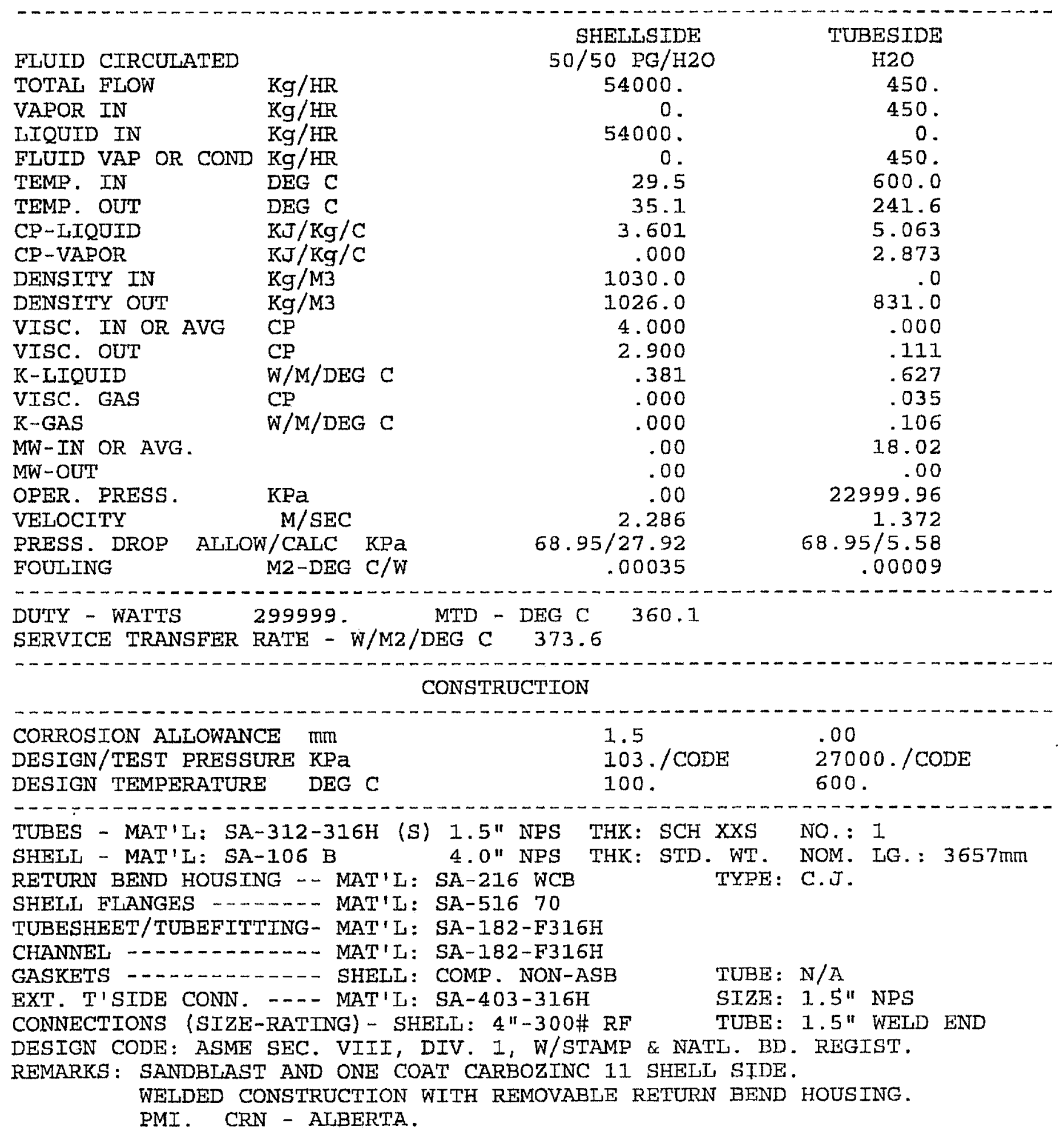


APPENDIX D: Sizing Calculations 


\section{Sizing of SCW Loop Piping}

Maximum operating $\quad P=28.35 \mathrm{MPa}$

conditions:

$$
\begin{aligned}
& T=625^{\circ} \mathrm{C} \\
& \dot{m}_{f l u x}=3000 \frac{\mathrm{kg}}{\mathrm{m}^{2} \mathrm{~s}}
\end{aligned}
$$

\section{Inner Diameter}

Determined at a temperature of $260^{\circ} \mathrm{C}$ and $23 \mathrm{MPa}$ :

$$
\begin{aligned}
& A_{C}=3.46 \times 10^{-4} \mathrm{~m}^{2} \quad \begin{array}{l}
\text { (initial estimate for the } \\
\text { bundle test section) }
\end{array} \\
& \dot{m}=\frac{\dot{m}_{\text {flux }}}{A_{C}}=1.038 \frac{\mathrm{kg}}{\mathrm{s}} \\
& D_{i}=\sqrt{\frac{4 \dot{m}}{\pi \rho V}}=\sqrt{\frac{4 \times 1.038 \frac{\mathrm{kg}}{\mathrm{s}}}{3.14 \times 805 \frac{\mathrm{kg}}{\mathrm{m}^{3}} \times 2.5 \frac{\mathrm{m}}{\mathrm{s}}}} \\
& D_{i}=25.6 \mathrm{~mm}
\end{aligned}
$$

(initial estimate for the

Wall Thickness as per ASME B31.1-2007

\section{General loop piping}

$$
\begin{array}{lll}
\text { Design Data: } & D_{i}=27.94 \mathrm{~mm} & P=28.35 \mathrm{MPa} \\
D_{o}=48.26 \mathrm{~mm} & T=625^{\circ} \mathrm{C} \\
t_{a}=10.16 \mathrm{~mm} & S=65.5 \mathrm{MPa} \text { (Table A-3 in [1]) } \\
\delta=1.27 \mathrm{~mm}\left(12.5 \% \text { of } t_{a}\right) & \mathrm{SA3} 12 / 316 \mathrm{H}, \mathrm{NPS} 1.5 \text { Sch XXS } \\
& E=1 \text { (Seamless) } & y=0.7 \text { (Table 104.1.2(A) in [1]) }
\end{array}
$$


Calculation:

$$
\begin{aligned}
& t=\frac{P D_{i}}{2(S E+P y-P)} \quad \text { Paragraph 104.1.2 in [1] } \\
& t=\frac{\left(28.35 \times 10^{6} P a\right)\left(27.94 \times 10^{-3} \mathrm{~m}\right)}{2(65.5+28.35 \times 0.7-28.35) \times 10^{6} P a} \\
& t=7 \mathrm{~mm} \\
& t_{a}>t+\delta \quad \text { (It is therefore acceptable.) }
\end{aligned}
$$

\section{Piping upstream and downstream of the flow meter}

$$
\begin{array}{lll}
\text { Design Data: } & D_{i}=15.6 \mathrm{~mm} & P=28.35 \mathrm{MPa} \\
D_{o}=26.6 \mathrm{~mm} & T=625^{\circ} \mathrm{C} \\
t_{a}=5.5 \mathrm{~mm} & S=65.5 \mathrm{MPa} \text { (Table A-3 in [1]) } \\
\delta=0.7 \mathrm{~mm}\left(12.5 \% \text { of } t_{a}\right) & \text { SA312/316, NPS } 3 / 4 \text { Sch } 160 \\
& E=1 \text { (Seamless) } & y=0.7 \quad \text { (Table 104.1.2(A) in [1]) }
\end{array}
$$

Calculation:

$$
\begin{aligned}
& t=\frac{P D_{i}}{2(S E+P y-P)} \quad \text { Paragraph 104.1.2 in [1] } \\
& t=\frac{\left(28.35 \times 10^{6} P a\right)\left(15.6 \times 10^{-3} \mathrm{~m}\right)}{2(65.5+28.35 \times 0.7-28.35) \times 10^{6} P a} \\
& t=3.9 \mathrm{~mm} \\
& t_{a}>t+\delta \quad \text { (It is therefore acceptable.) }
\end{aligned}
$$


Flow Meter Upstream Straightening Length

As per API 2534

Calculation:

$$
\begin{aligned}
& L=(0.35 D)\left(\frac{K_{s}}{f}\right) \\
& L=(0.35 D)\left(\frac{4.25}{0.022}\right) \\
& L=68 D
\end{aligned}
$$

\section{SCW Loop Heat Exchanger Sizing}

\section{Wall Thickness per ASME Section VIII, Div.1}

\section{Double-Pipe Heat Exchanger}

Design Data:

$$
\begin{array}{ll}
R=\frac{27.94 \mathrm{~mm}}{2}=13.97 \mathrm{~mm} & \begin{array}{l}
P=28.35 \mathrm{MPa} \\
D_{o}=48.26 \mathrm{~mm}
\end{array} \\
t_{a}=10.16 \mathrm{~mm} & S_{f}=65.5 \mathrm{MPa} \text { (Table 1A in [2]) } \\
\delta=1.27 \mathrm{~mm}\left(12.5 \% \text { of } t_{a}\right) & \mathrm{SA} 312 / 316 \mathrm{H}, \mathrm{NPS} 1.5 \mathrm{Sch} \mathrm{XXS} \\
E=1 \text { (Seamless) } &
\end{array}
$$

Calculation:

$$
\begin{aligned}
& t=R\left(Z^{1 / 2}-1\right) \quad \text { (Appendix } 1 \text { in }[3] \text { for } \mathrm{P}>0.385 \mathrm{~S}_{\mathrm{f}} \mathrm{E} \text { ) } \\
& R=\frac{S_{f} E+P}{S_{f} E-P}=\frac{65.5+28.35}{65.5-28.35}=2.53 \\
& t=(13.97 \mathrm{~mm})\left(2.53^{\frac{1}{2}}-1\right)=8.23 \mathrm{~mm} \\
& t_{a}>t+\delta \quad \text { (It is therefore acceptable.) }
\end{aligned}
$$




\section{Hairpin Heat Exchanger}

Design Data:

$$
\begin{array}{ll}
R=\frac{11.02 \mathrm{~mm}}{2}=5.51 \mathrm{~mm} & P=28.35 \mathrm{MPa} \\
D_{o}=26.67 \mathrm{~mm} & T=625^{\circ} \mathrm{C} \\
t_{a}=7.82 \mathrm{~mm} & \left.S_{f}=65.5 \mathrm{MPa} \text { (Table } 1 \mathrm{~A} \text { in }[2]\right) \\
\delta=0.98 \mathrm{~mm}\left(12.5 \% \text { of } t_{a}\right) & \text { SA312/316H, NPS 3/4 Sch XXS } \\
E=1 \text { (Seamless) } &
\end{array}
$$

Calculation:

$$
\begin{aligned}
& t=R\left(Z^{1 / 2}-1\right) \quad \text { (Appendix } 1 \text { in [3] for } \mathrm{P}>0.385 \mathrm{~S}_{\mathrm{f}} \mathrm{E} \text { ) } \\
& R=\frac{S_{f} E+P}{S_{f} E-P}=\frac{65.5+28.35}{65.5-28.35}=2.53 \\
& t=(5.51 \mathrm{~mm})\left(2.53^{\frac{1}{2}}-1\right)=3.25 \mathrm{~mm} \\
& t_{a}>t+\delta \quad \text { (It is therefore acceptable.) }
\end{aligned}
$$

\section{D/P Transducer Impulse Tube Sizing}

Wall Thickness as per ASME B31.1-2007

Design Data:

$$
\begin{array}{ll}
D_{i}=4 \mathrm{~mm} & P=28.35 \mathrm{MPa} \\
D_{o}=6.4 \mathrm{~mm} & T=625^{\circ} \mathrm{C} \\
t_{a}=1.2 \mathrm{~mm} & S=65.5 \mathrm{MPa} \text { (Table A-3 in [1]) } \\
\delta=0.12 \mathrm{~mm}\left(10 \% \text { of } t_{a}\right) & \mathrm{SA} 213 / 316,1 / 4 \mathrm{in} \times 0.049 \mathrm{in} \text { Tube } \\
E=1 \text { (Seamless) } & y=0.7 \text { (Table 104.1.2(A) in [1]) }
\end{array}
$$


Calculation:

$$
\begin{aligned}
& t=\frac{P D_{i}}{2(S E+P y-P)} \quad \text { Paragraph 104.1.2 in [1] } \\
& t=\frac{\left(28.35 \times 10^{6} P a\right)\left(4 \times 10^{-3} \mathrm{~m}\right)}{2(65.5+28.35 \times 0.7-28.35) \times 10^{6} P a} \\
& t=0.995 \mathrm{~mm} \\
& t_{a}>t+\delta \quad \text { (It is therefore acceptable.) }
\end{aligned}
$$

\section{Test-Section Sizing as per ASME Section VIII, Div.1}

\section{Tubular Test Section}

\section{Enthalpy Balance}

Enthalpy balance is used to determine the maximum achievable flow rates based on the available power. As noted in Table 4.1, the fluid enters the test section at $260^{\circ} \mathrm{C}$ and exists at either $380^{\circ} \mathrm{C}$ or $600^{\circ} \mathrm{C}$, while the pressure varies between 23 and $27 \mathrm{MPa}$. These conditions result in two extreme operating conditions. In one case, the inlet and outlet temperatures are relatively low and the flow rate is a maximum, whereas in the second case, the outlet temperature is a maximum and the flow rate is a minimum. The maximum flow rate occurs at inlet and outlet temperatures of $260^{\circ} \mathrm{C}$ and $380^{\circ} \mathrm{C}$, respectively, and a pressure of $27 \mathrm{MPa}$. The determination of the minimum flow rate is given as an example below.

Sample calculation $\quad T_{i}=260^{\circ} \mathrm{C}$ at $23 \mathrm{MPa}$ :

$$
\begin{aligned}
& T_{o}=600^{\circ} \mathrm{C} \\
& h_{i}=1133.6 \frac{\mathrm{kJ}}{\mathrm{kg}} \\
& \begin{array}{l}
P=300 \mathrm{~kW} \quad \text { (maximum available } \quad h_{o}=3509.1 \frac{\mathrm{kJ}}{\mathrm{kg}} \\
\text { power) }
\end{array}
\end{aligned}
$$




$$
\begin{aligned}
& Q=\dot{m}\left(h_{o}-h_{i}\right) \\
& 300 \times 10^{3} \mathrm{~W}=\dot{m}\left(3509.1 \frac{\mathrm{kJ}}{\mathrm{kg}}-1133.6 \frac{\mathrm{kJ}}{\mathrm{kg}}\right) \\
& \dot{m}=0.126 \frac{\mathrm{kg}}{\mathrm{s}}
\end{aligned}
$$

\section{Heat Transfer Coefficient}

Due to the strong dependence of the heat transfer coefficient of SCW on temperature, its values vary greatly along the length of the test section. For the determination of the test-section wall thickness, the minimum heat transfer coefficient expected is of importance. The minimum heat transfer coefficient occurs at the minimum flow rate and it is calculated as follows:

Sample heat transfer coefficient calculation at $260^{\circ} \mathrm{C}$ and $23 \mathrm{MPa}$ :

$$
\begin{array}{ll}
d_{i}=12.5 \mathrm{~mm} & c_{p}=4.74 \frac{\mathrm{kJ}}{\mathrm{kg} \mathrm{K}} \\
\dot{m}=0.126 \frac{\mathrm{kg}}{\mathrm{s}} & \mu=0.107 \mathrm{mPas} \\
\rho=805 \frac{\mathrm{kg}}{\mathrm{m}^{3}} & k=0.633 \frac{\mathrm{W}}{\mathrm{mK}}
\end{array}
$$

$$
\begin{aligned}
& R e=\frac{4 \dot{m}}{\mu \pi d_{i}} \\
& R e=\frac{4\left(0.126 \frac{\mathrm{kg}}{\mathrm{s}}\right)}{\left(0.107 \times 10^{-3} \mathrm{Pas}\right)(3.14)\left(12.5 \times 10^{-3} \mathrm{~m}\right)} \\
& \operatorname{Re}=1.2 \times 10^{5}
\end{aligned}
$$


Prandtl number can be calculated as follows:

$$
\operatorname{Pr}=\frac{\mu \cdot C_{p}}{k}
$$

$$
\operatorname{Pr}=\frac{\left(0.107 \times 10^{-3} \mathrm{Pas}\right)\left(4.74 \frac{\mathrm{kJ}}{\mathrm{kgK}}\right)}{0.633 \frac{\mathrm{W}}{\mathrm{mK}}}
$$

$$
\operatorname{Pr}=0.799
$$

Nusselt number equals:

$$
\begin{aligned}
& N u=0.023 \cdot R e^{0.8} \cdot \operatorname{Pr}^{0.4} \\
& N u=0.023\left(1.2 \times 10^{5}\right)^{0.8}(0.799)^{0.4} \\
& N u=249.2
\end{aligned}
$$

Therefore,

$$
\begin{aligned}
& h=\frac{N u \cdot k}{D} \\
& h=\frac{(249.2)\left(0.633 \frac{\mathrm{W}}{\mathrm{mK}}\right)}{12.5 \times 10^{-3} \mathrm{~m}} \\
& h=12.34 \frac{\mathrm{kW}}{\mathrm{m}^{2} \mathrm{~K}}
\end{aligned}
$$

In a similar manner, the heat transfer coefficient for other relevant temperatures and test sections are calculated and listed in the table below.

Table D-1: Heat transfer coefficient at $23 \mathrm{MPa}$ and $0.126 \mathrm{~kg} / \mathrm{s}$ for tubular test section

\begin{tabular}{|c|c|c|c|c|c|c|c|}
\hline $\begin{array}{c}\mathbf{T} \\
{\left[{ }^{\circ} \mathrm{C}\right]}\end{array}$ & $\begin{array}{c}\mathrm{Cp} \\
{[\mathbf{K J} / \mathrm{kgK}]}\end{array}$ & $\operatorname{Pr}$ & $\begin{array}{c}\mu \\
{[\mathrm{Pa} . \mathrm{s}]}\end{array}$ & $\begin{array}{c}\mathbf{K} \\
{[\mathbf{W} / \mathrm{mK}]}\end{array}$ & $\operatorname{Re}$ & $\mathbf{N u}$ & $\begin{array}{c}\boldsymbol{\rho} \\
{\left[\mathbf{k g}^{\prime} / \mathbf{m}^{3}\right]}\end{array}$ \\
\hline 260 & 4.7403 & 0.799 & $1.07 \mathrm{E}-04$ & 0.6332 & $1.203 \mathrm{E}+05$ & 249.2 & 804.98 \\
\hline 270 & 4.834 & 0.798 & $1.03 \mathrm{E}-04$ & 0.6212 & $1.252 \mathrm{E}+05$ & 257.2 & 790.17 \\
\hline 280 & 4.9441 & 0.802 & $9.86 \mathrm{E}-05$ & 0.6079 & $1.302 \mathrm{E}+05$ & 265.9 & 774.47 \\
\hline 290 & 5.0757 & 0.811 & $9.47 \mathrm{E}-05$ & 0.5931 & $1.355 \mathrm{E}+05$ & 275.3 & 757.74 \\
\hline
\end{tabular}




\begin{tabular}{|c|c|c|c|c|c|c|c|}
\hline 300 & 5.2359 & 0.826 & 9.10E-05 & 0.5768 & $1.410 E+05$ & 285.9 & 739.79 \\
\hline 310 & 5.4357 & 0.849 & $8.74 \mathrm{E}-05$ & 0.5590 & $1.469 \mathrm{E}+05$ & 297.9 & 720.37 \\
\hline 320 & 5.6931 & 0.882 & 8.37E-05 & 0.5398 & $1.534 \mathrm{E}+05$ & 312.0 & 699.1 \\
\hline 330 & 6.0393 & 0.929 & $7.99 \mathrm{E}-05$ & 0.5193 & $1.607 E+05$ & 328.8 & 675.43 \\
\hline 340 & 6.5358 & 0.997 & $7.59 \mathrm{E}-05$ & 0.4976 & $1.691 E+05$ & 349.8 & 648.47 \\
\hline 350 & 7.3265 & 1.104 & $7.15 \mathrm{E}-05$ & 0.4744 & $1.795 E+05$ & 378.3 & 616.57 \\
\hline 360 & 8.8718 & 1.312 & $6.63 \mathrm{E}-05$ & 0.4485 & $1.935 \mathrm{E}+05$ & 423.1 & 576.02 \\
\hline 370 & 13.816 & 1.959 & 5.91E-05 & 0.4165 & $2.173 E+05$ & 523.6 & 513.97 \\
\hline 380 & 41.948 & 4.964 & 3.07E-05 & 0.2595 & $4.180 E+05$ & 1168.0 & 208.68 \\
\hline 390 & 13.458 & 2.341 & 2.79E-05 & 0.1605 & $4.598 E+05$ & 1006.0 & 153.75 \\
\hline 400 & 9.2097 & 1.877 & $2.74 \mathrm{E}-05$ & 0.1347 & $4.676 E+05$ & 954.3 & 133.73 \\
\hline 410 & 7.3264 & 1.656 & 2.74E-05 & 0.1213 & $4.681 E+05$ & 919.9 & 121.45 \\
\hline 420 & 6.231 & 1.520 & $2.76 \mathrm{E}-05$ & 0.1130 & $4.656 E+05$ & 892.7 & 112.7 \\
\hline 430 & 5.506 & 1.425 & $2.78 \mathrm{E}-05$ & 0.1074 & $4.616 E+05$ & 869.5 & 105.96 \\
\hline 440 & 4.9883 & 1.353 & $2.81 \mathrm{E}-05$ & 0.1036 & $4.567 E+05$ & 849.0 & 100.51 \\
\hline 450 & 4.5996 & 1.297 & 2.84E-05 & 0.1008 & $4.515 E+05$ & 830.5 & 95.955 \\
\hline 460 & 4.2973 & 1.251 & $2.88 \mathrm{E}-05$ & 0.0989 & $4.460 E+05$ & 813.5 & 92.058 \\
\hline 470 & 4.0558 & 1.212 & $2.91 \mathrm{E}-05$ & 0.0975 & $4.404 E+05$ & 797.8 & 88.661 \\
\hline 480 & 3.8589 & 1.180 & $2.95 \mathrm{E}-05$ & 0.0966 & $4.348 E+05$ & 783.2 & 85.657 \\
\hline 490 & 3.6958 & 1.151 & $2.99 \mathrm{E}-05$ & 0.0960 & $4.292 \mathrm{E}+05$ & 769.4 & 82.969 \\
\hline 500 & 3.5589 & 1.126 & 3.03E-05 & 0.0957 & 4.237E+05 & 756.5 & 80.54 \\
\hline 510 & 3.4427 & 1.104 & 3.07E-05 & 0.0957 & $4.183 E+05$ & 744.3 & 78.328 \\
\hline 520 & 3.3431 & 1.084 & $3.11 \mathrm{E}-05$ & 0.0959 & $4.130 E+05$ & 732.7 & 76.298 \\
\hline 530 & 3.2571 & 1.066 & 3.15E-05 & 0.0962 & $4.078 E+05$ & 721.7 & 74.425 \\
\hline 540 & 3.1823 & 1.049 & 3.19E-05 & 0.0967 & $4.027 E+05$ & 711.1 & 72.687 \\
\hline 550 & 3.117 & 1.034 & 3.23E-05 & 0.0973 & $3.977 E+05$ & 701.1 & 71.068 \\
\hline 560 & 3.0596 & 1.021 & 3.27E-05 & 0.0979 & $3.929 E+05$ & 691.5 & 69.552 \\
\hline 570 & 3.0089 & 1.008 & $3.31 \mathrm{E}-05$ & 0.0987 & $3.882 E+05$ & 682.3 & 68.129 \\
\hline 580 & 2.964 & 0.996 & 3.35E-05 & 0.0995 & $3.836 E+05$ & 673.5 & 66.788 \\
\hline 590 & 2.9242 & 0.986 & $3.39 \mathrm{E}-05$ & 0.1004 & $3.791 E+05$ & 665.0 & 65.521 \\
\hline 600 & 2.8886 & 0.976 & 3.43E-05 & 0.1014 & 3.747E+05 & 656.9 & 64.321 \\
\hline
\end{tabular}

Wall Thickness under Internal Pressure

Design Data:

$$
\begin{array}{ll}
R=\frac{12.5 \mathrm{~mm}}{2}=6.25 \mathrm{~mm} & P=27 \mathrm{MPa} \\
L=2000 \mathrm{~mm} & T=723^{\circ} \mathrm{C}
\end{array}
$$




$$
\begin{array}{ll}
t_{a}=3.5 \mathrm{~mm} & S_{f}=65.5 \mathrm{MPa} \text { (Table 1B in [2]) } \\
E=1 \text { (Seamless) } & \text { SB444/IN625 Gr. } 2
\end{array}
$$

Calculation:

$$
\begin{aligned}
& t=R\left(Z^{1 / 2}-1\right) \quad \text { (Appendix } 1 \text { in }[3] \text { for } P>0.385 S_{\mathrm{f}} \mathrm{E} \text { ) } \\
& R=\frac{S_{f} E+P}{S_{f} E-P}=\frac{65.5+27}{65.5-27}=2.4 \\
& t=(6.25 \mathrm{~mm})\left(2.4^{\frac{1}{2}}-1\right)=3.4 \mathrm{~mm} \\
& t_{a}>t
\end{aligned}
$$

\section{Achievable Heat Flux and Power Input}

Heat flux calculation:

$$
\begin{aligned}
& q=h\left(T_{w}-T_{b}\right) \\
& q=\left(5.3 \times 10^{3} \frac{\mathrm{W}}{\mathrm{m}^{2} \mathrm{~K}}\right)\left(723^{\circ} \mathrm{C}-600^{\circ} \mathrm{C}\right) \\
& q=660 \frac{\mathrm{kW}}{\mathrm{m}^{2}}
\end{aligned}
$$

Power input

calculation:

$$
\begin{aligned}
& A_{S}=\pi d_{i} L=(3.14)(0.0125 \mathrm{~m})(2 \mathrm{~m}) \\
& A_{S}=7.8 \times 10^{-2} \mathrm{~m}^{2} \\
& Q=q A_{S}=\left(660 \frac{\mathrm{kW}}{\mathrm{m}^{2}}\right)\left(7.8 \times 10^{-2} \mathrm{~m}^{2}\right) \\
& Q=51.5 \mathrm{~kW}
\end{aligned}
$$

\section{Pressure Drop}

The pressure drop in the test section is estimated for the most extreme condition resulting in maximum pressure drop based on the assumption that the fluid enters the test section at $500^{\circ} \mathrm{C}$ and exits at $600^{\circ} \mathrm{C}$. 
Friction factor calculation:

$$
\begin{aligned}
& \frac{1}{f^{\frac{1}{2}}}=-1.8 \log \left[\frac{6.9}{R e}+\left(\frac{\varepsilon / d}{3.7}\right)^{1.11}\right] \quad \text { [5] } \\
& \varepsilon=0.003 \mathrm{~mm} \quad \text { (for stainless steel pipe from [5]) } \\
& R e \approx 4 \times 10^{5} \quad \text { (from Table D-1 above) } \\
& \frac{1}{f^{\frac{1}{2}}}=-1.8 \log \left[\frac{6.9}{400000}+\left(\frac{\frac{0.003}{12.5}}{3.7}\right)^{1.11}\right] \\
& f=0.02
\end{aligned}
$$

Pressure drop calculation:

$$
\begin{aligned}
& \rho=71 \frac{\mathrm{kg}}{\mathrm{m}^{3}} \quad \text { (estimated from Table D-1 above) } \\
& \Delta p_{f}=\frac{8}{\rho}\left(\frac{\dot{m}}{\pi}\right)^{2} f \frac{L}{d^{5}} \\
& \Delta p_{f}=\left(\frac{8}{71 \frac{\mathrm{kg}}{\mathrm{m}^{3}}}\right)\left(\frac{0.126 \frac{\mathrm{kg}}{\mathrm{s}}}{\pi}\right)^{2}(0.02)\left[\frac{2 \mathrm{~m}}{(0.0125 \mathrm{~m})^{5}}\right] \\
& \Delta p_{f} \approx 24 \mathrm{kPa}
\end{aligned}
$$

In a similar manner, the pressure drop in the rest of the loop piping and piping components was estimated and the pressure drop in the test section was adjusted by changing its diameter to ensure that the overall pressure drop in the loop is equal to or less than the available pump head.

\section{Annular Test Section}

\section{Enthalpy Balance}

Enthalpy balance is the same as for the tubular test section. 


\section{Heat Transfer Coefficient}

The procedure for the calculation of the heat transfer coefficient values of the annular test section is carried out similar to the one for the cold side of the heat exchanger, as outlined in Section 3.3.5.1.3. The values are listed in the table below.

Table D-2: Heat transfer coefficient at $23 \mathrm{MPa}$ and $0.126 \mathrm{~kg} / \mathrm{s}$ for annular test section

\begin{tabular}{|c|c|c|c|c|c|c|c|}
\hline $\begin{array}{c}\mathrm{T} \\
{\left[{ }^{\circ} \mathrm{C}\right]}\end{array}$ & $\begin{array}{c}\mathrm{Cp} \\
{[\mathrm{kJ} / \mathrm{kgK}]}\end{array}$ & Pr & $\underset{[\mathrm{Pa} . \mathrm{s}]}{\mu}$ & $\begin{array}{c}K \\
{[W / m k]}\end{array}$ & Re & $\mathrm{Nu}$ & $\stackrel{\rho}{\left[\mathrm{kg} / \mathrm{m}^{3}\right]}$ \\
\hline 260 & 4.7403 & 0.799 & $1.07 E-04$ & 0.6332 & $5.369 E+04$ & 127.8 & 804.98 \\
\hline 270 & 4.834 & 0.798 & $1.03 \mathrm{E}-04$ & 0.6212 & $5.588 \mathrm{E}+04$ & 131.9 & 790.17 \\
\hline 280 & 4.9441 & 0.802 & $9.86 \mathrm{E}-05$ & 0.6079 & $5.813 E+04$ & 136.4 & 774.47 \\
\hline 290 & 5.0757 & 0.811 & $9.47 E-05$ & 0.5931 & $6.048 E+04$ & 141.4 & 757.74 \\
\hline 300 & 5.2359 & 0.826 & 9.10E-05 & 0.5768 & $6.295 E+04$ & 147.1 & 739.79 \\
\hline 310 & 5.4357 & 0.849 & $8.74 E-05$ & 0.5590 & $6.559 E+04$ & 153.8 & 720.37 \\
\hline 320 & 5.6931 & 0.882 & $8.37 E-05$ & 0.5398 & $6.849 E+04$ & 161.6 & 699.1 \\
\hline 330 & 6.0393 & 0.929 & 7.99E-05 & 0.5193 & $7.173 E+04$ & 171.2 & 675.43 \\
\hline 340 & 6.5358 & 0.997 & $7.59 \mathrm{E}-05$ & 0.4976 & $7.550 \mathrm{E}+04$ & 183.5 & 648.47 \\
\hline 350 & 7.3265 & 1.104 & $7.15 \mathrm{E}-05$ & 0.4744 & $8.013 E+04$ & 200.4 & 616.57 \\
\hline 360 & 8.8718 & 1.312 & $6.63 \mathrm{E}-05$ & 0.4485 & $8.637 E+04$ & 228.0 & 576.02 \\
\hline 370 & 13.816 & 1.959 & $5.91 E-05$ & 0.4165 & $9.702 E+04$ & 293.8 & 513.97 \\
\hline 380 & 41.948 & 4.964 & 3.07E-05 & 0.2595 & $1.866 E+05$ & 719.2 & 208.68 \\
\hline 390 & 13.458 & 2.341 & $2.79 \mathrm{E}-05$ & 0.1605 & $2.053 E+05$ & 574.5 & 153.75 \\
\hline 400 & 9.2097 & 1.877 & $2.74 \mathrm{E}-05$ & 0.1347 & $2.088 \mathrm{E}+05$ & 533.2 & 133.73 \\
\hline 410 & 7.3264 & 1.656 & $2.74 E-05$ & 0.1213 & $2.090 E+05$ & 507.5 & 121.45 \\
\hline 420 & 6.231 & 1.520 & $2.76 \mathrm{E}-05$ & 0.1130 & $2.079 E+05$ & 488.3 & 112.7 \\
\hline 430 & 5.506 & 1.425 & $2.78 \mathrm{E}-05$ & 0.1074 & $2.061 E+05$ & 472.5 & 105.96 \\
\hline 440 & 4.9883 & 1.353 & 2.81E-05 & 0.1036 & $2.039 E+05$ & 459.0 & 100.51 \\
\hline 450 & 4.5996 & 1.297 & $2.84 \mathrm{E}-05$ & 0.1008 & $2.015 E+05$ & 447.1 & 95.955 \\
\hline 460 & 4.2973 & 1.251 & $2.88 \mathrm{E}-05$ & 0.0989 & $1.991 E+05$ & 436.4 & 92.058 \\
\hline 470 & 4.0558 & 1.212 & $2.91 \mathrm{E}-05$ & 0.0975 & $1.966 \mathrm{E}+05$ & 426.6 & 88.661 \\
\hline 480 & 3.8589 & 1.180 & $2.95 \mathrm{E}-05$ & 0.0966 & $1.941 E+05$ & 417.7 & 85.657 \\
\hline 490 & 3.6958 & 1.151 & $2.99 \mathrm{E}-05$ & 0.0960 & $1.916 \mathrm{E}+05$ & 409.3 & 82.969 \\
\hline 500 & 3.5589 & 1.126 & 3.03E-05 & 0.0957 & $1.891 E+05$ & 401.6 & 80.54 \\
\hline 510 & 3.4427 & 1.104 & $3.07 E-05$ & 0.0957 & $1.867 E+05$ & 394.3 & 78.328 \\
\hline 520 & 3.3431 & 1.084 & 3.11E-05 & 0.0959 & $1.844 E+05$ & 387.4 & 76.298 \\
\hline 530 & 3.2571 & 1.066 & $3.15 \mathrm{E}-05$ & 0.0962 & $1.820 E+05$ & 381.0 & 74.425 \\
\hline 540 & 3.1823 & 1.049 & $3.19 E-05$ & 0.0967 & $1.798 E+05$ & 374.8 & 72.687 \\
\hline
\end{tabular}




\begin{tabular}{|l|c|c|c|c|c|c|c|}
\hline 550 & 3.117 & 1.034 & $3.23 \mathrm{E}-05$ & 0.0973 & $1.776 \mathrm{E}+05$ & 369.0 & 71.068 \\
\hline 560 & 3.0596 & 1.021 & $3.27 \mathrm{E}-05$ & 0.0979 & $1.754 \mathrm{E}+05$ & 363.5 & 69.552 \\
\hline 570 & 3.0089 & 1.008 & $3.31 \mathrm{E}-05$ & 0.0987 & $1.733 \mathrm{E}+05$ & 358.2 & 68.129 \\
\hline 580 & 2.964 & 0.996 & $3.35 \mathrm{E}-05$ & 0.0995 & $1.712 \mathrm{E}+05$ & 353.2 & 66.788 \\
\hline 590 & 2.9242 & 0.986 & $3.39 \mathrm{E}-05$ & 0.1004 & $1.692 \mathrm{E}+05$ & 348.4 & 65.521 \\
\hline 600 & 2.8886 & 0.976 & $3.43 \mathrm{E}-05$ & 0.1014 & $1.673 \mathrm{E}+05$ & 343.8 & 64.321 \\
\hline
\end{tabular}

\section{Wall Thickness of Inner Rod/Heater under External Pressure}

The required wall thickness to withstand external pressure is calculated in an iterative process. In the case of the annular test section, the dimensions of the inner rod subjected to external pressure are preselected. Using the following method, the external pressure that the inner rod can withstand at a specific temperature is calculated.

$\begin{array}{rlrl}\text { Design Data: } & d_{i}=5 \mathrm{~mm} & L=2000 \mathrm{~mm} \\ d_{o}=10 \mathrm{~mm} & \text { SB444/IN625 Gr. 2 } \\ t_{a}=2.5 \mathrm{~mm} & \end{array}$
Determination of A: $\frac{L}{d_{o}}=\frac{2000}{10}=200>50$$$
\frac{d_{o}}{t_{a}}=\frac{10}{2.5}=4
$$$$
A=0.07 \text { (from Chart } \mathrm{G} \text { in [2]) }
$$
Therefore, on Chart $G$ in [2] use $\mathrm{L} / \mathrm{Do}=50[3]$.

From Figure NFN-22 in [2], a B factor curve for a specific temperature is selected and the pressure rating of the inner rod is determined. If the resulting pressure rating is lower than the maximum operating pressure of $27 \mathrm{MPa}$, the $\mathrm{B}$ factor curve for a lower temperature is considered as a second iteration. On the other hand, if the pressure rating is substantially higher than the one calculated using the equations given below (also given in Section 4.5.2.2), the B factor curve for a higher temperature is considered. Following is a sample calculation for the pressure rating that has been selected for the SCW loop annular test section. 
Determination of $\mathrm{B}$ and $\mathrm{S}$ at $780^{\circ} \mathrm{C}$ :

$$
B=65.3 \mathrm{MPa}
$$

From Fig. FNF-22 in [2]

$$
S=2 S_{f}=2(37.5 \mathrm{MPa})=75 \mathrm{MPa} \quad \text { From Table 1B in [2] }
$$

Calculation:

$$
\begin{aligned}
& P_{a 1}=\left(\frac{2.167}{D / t}-0.0833\right) B \\
& P_{a 1}=\left(\frac{2.167}{10 / 2.5}-0.0833\right)(65.3 \mathrm{MPa}) \\
& P_{a 1}=29.94 \mathrm{MPa} \\
& P_{a 1}>27 \mathrm{MPa}
\end{aligned}
$$

Calculation:

$$
\begin{aligned}
& P_{a 2}=\frac{2 S}{D / t}\left(1-\frac{1}{D / t}\right) \\
& P_{a 2}=\frac{2(75 \mathrm{MPa})}{10 / 2.5}\left(1-\frac{1}{10 / 2.5}\right) \\
& P_{a 2}=28.13 \mathrm{MPa} \\
& P_{a 2}>27 \mathrm{MPa}
\end{aligned}
$$

\section{Thickness of Outer Shell under Internal Pressure}

$$
\text { Design Data: } \quad \begin{aligned}
R & =\frac{18 \mathrm{~mm}}{2}=9 \mathrm{~mm} \\
t_{a} & =3.5 \mathrm{~mm} \\
E & =1 \text { (Seamless) }
\end{aligned}
$$$$
\begin{aligned}
& P=28.35 \mathrm{MPa} \\
& T=690^{\circ} \mathrm{C} \\
& S_{f}=92.6 \mathrm{MPa} \quad \text { (Table 1B in [2]) }
\end{aligned}
$$$$
\text { SB444/IN625 Gr. } 2
$$ 


$$
\begin{aligned}
& \text { Calculation: } \quad \begin{aligned}
t & \left.=R\left(Z^{1 / 2}-1\right) \quad \text { (Appendix } 1 \text { in [3] for } \mathrm{P}>0.385 S_{\mathrm{f}} \mathrm{E}\right) \\
R & =\frac{S_{f} E+P}{S_{f} E-P}=\frac{92.6+28.35}{92.6-28.35}=1.9 \\
t & =(9 \mathrm{~mm})\left(1.9^{\frac{1}{2}}-1\right)=3.3 \mathrm{~mm} \\
t_{a} & >t
\end{aligned}
\end{aligned}
$$

However, the criterion $\left(P>0.385 \mathrm{~S}_{\mathrm{F}} \mathrm{E}\right)$ for using the above formula is not satisfied. The Code stipulates the use of formulae for a shell to calculate the required wall thickness. Therefore, the wall thickness is recalculated as follows:

Calculation:

$$
\begin{aligned}
& t=\frac{P R}{S_{f} E-0.6 P} \quad \text { Paragraph UG 27(c) in [3] } \\
& t=\frac{P R}{S_{f} E-0.6 P}=\frac{(28.35)(9 \mathrm{~mm})}{92.6-(0.6)(28.35)}=3.4 \\
& t_{a}>t
\end{aligned}
$$

\section{Thickness of Blind Hub}

The blind hub of the annular test section, where the heater rod mates with it has a $10 \mathrm{~mm}$ hole. Therefore, it is calculated to determine if the thickness of the blind hub meets the code requirements after the hole has been drilled. Since the diameter of the hole does not exceed one-half the diameter of the blind flange, the required blind hub thickness to withstand the exerted pressure is calculated according to UG-39(d)(1).

$$
\begin{array}{rlrl}
\text { Design Data: } & D=27.94 \mathrm{~mm} & P=28.35 \mathrm{MPa} \\
t_{a}=39.7 \mathrm{~mm} \text { (taken from [6] } & T=650^{\circ} \mathrm{C} \\
C=0.50 \text { (based on UG-39(d)(1)) } & S_{f}=89.0 \mathrm{MPa} \quad \text { (Table 1B in [2]) } \\
E & =1 \text { (no welds) } & \text { SB564/IN625 }
\end{array}
$$


Calculation:

$$
\begin{aligned}
& t=D \sqrt{\frac{C P}{S_{f} E}} \\
& t=(27.94 \mathrm{~mm}) \sqrt{\frac{(0.50)(28.35 \mathrm{MPa})}{(89.0 \mathrm{MPa})(1)}} \\
& t=11.15 \mathrm{~mm} \\
& t_{a}>t
\end{aligned}
$$

\section{Fillet Weld Size}

Fillet welds are used to connect the sealing gland to the heater rod and the heater rod to the blind hub. According to the requirements of the Code, the force exerted on the one fillet weld must equal the product of the weld area based on minimum weld leg, the allowable stress value of the material being welded and a joint efficiency of 0.55 .

$$
\begin{array}{lll}
\text { Design Data: } & d_{o}=10 \mathrm{~mm} & P=28.35 \mathrm{MPa} \\
d_{i}=5 \mathrm{~mm} & T=650^{\circ} \mathrm{C} \\
t=2.5 \mathrm{~mm} & S_{f}=89.0 \mathrm{MPa} \quad \text { (Table 1B in [2]) } \\
E & =0.55 \text { (for fillet weld) } & \text { SB564/IN625 }
\end{array}
$$

Calculations: $\quad A_{w}=\pi d_{o} w_{L} \quad$ Area of fillet weld

$$
\begin{aligned}
& F=(28.35 \mathrm{MPa})\left(\frac{\pi}{4} 0.01^{2} \mathrm{~m}^{2}\right) \quad \text { Load acting on the fillet weld } \\
& F=2.23 \mathrm{kN}
\end{aligned}
$$

Therefore, $\quad 0.55 A_{w} S_{f}=2.23 k N$

$$
\begin{aligned}
w_{L} & =\frac{2.23 k N}{(0.55)(89.0 \mathrm{MPa})\left(d_{o} \pi\right)} \\
w_{L} & =1.5 \mathrm{~mm}
\end{aligned}
$$




\section{Bundle Test Section}

\section{Enthalpy Balance}

Enthalpy balance is the same as for the tubular test section.

\section{Heat Transfer Coefficient}

The procedure for the calculation of the heat transfer coefficient values of the bundle test section is carried out similar to the one for the cold side of the heat exchanger, as outlined in Section 3.3.5.1.3. The values are listed in the table below.

Table D-3: Heat transfer coefficient at $23 \mathrm{MPa}$ and $0.126 \mathrm{~kg} / \mathrm{s}$ for bundle test section

\begin{tabular}{|c|c|c|c|c|c|c|c|}
\hline $\begin{array}{c}\mathrm{T} \\
{\left[{ }^{\circ} \mathrm{C}\right]}\end{array}$ & $\begin{array}{c}C p \\
{[k J / k g K]}\end{array}$ & Pr & $\underset{[\mathrm{Pa} .5]}{\mu}$ & $\begin{array}{c}K \\
{[W / m K]}\end{array}$ & $\operatorname{Re}$ & $\mathrm{Nu}$ & $\underset{\left[\mathrm{kg} / \mathrm{m}^{3}\right.}{\rho}$ \\
\hline 260 & 4.7403 & 0.799 & $1.07 \mathrm{E}-04$ & 0.6332 & $1.885 E+04$ & 55.3 & 804.98 \\
\hline 270 & 4.834 & 0.798 & $1.03 \mathrm{E}-04$ & 0.6212 & $1.962 E+04$ & 57.1 & 790.17 \\
\hline 280 & 4.9441 & 0.802 & $9.86 \mathrm{E}-05$ & 0.6079 & $2.041 E+04$ & 59.1 & 774.47 \\
\hline 290 & 5.0757 & 0.811 & $9.47 \mathrm{E}-05$ & 0.5931 & $2.124 E+04$ & 61.2 & 757.74 \\
\hline 300 & 5.2359 & 0.826 & $9.10 \mathrm{E}-05$ & 0.5768 & $2.210 \mathrm{E}+04$ & 63.7 & 739.79 \\
\hline 310 & 5.4357 & 0.849 & $8.74 E-05$ & 0.5590 & $2.303 E+04$ & 66.6 & 720.37 \\
\hline 320 & 5.6931 & 0.882 & 8.37E-05 & 0.5398 & $2.405 E+04$ & 70.0 & 699.1 \\
\hline 330 & 6.0393 & 0.929 & $7.99 \mathrm{E}-05$ & 0.5193 & $2.519 \mathrm{E}+04$ & 74.1 & 675.43 \\
\hline 340 & 6.5358 & 0.997 & $7.59 \mathrm{E}-05$ & 0.4976 & $2.651 E+04$ & 79.4 & 648.47 \\
\hline 350 & 7.3265 & 1.104 & 7.15E-05 & 0.4744 & $2.814 E+04$ & 86.8 & 616.57 \\
\hline 360 & 8.8718 & 1.312 & 6.63E-05 & 0.4485 & $3.033 E+04$ & 98.7 & 576.02 \\
\hline 370 & 13.816 & 1.959 & $5.91 \mathrm{E}-05$ & 0.4165 & $3.407 E+04$ & 127.2 & 513.97 \\
\hline 380 & 41.948 & 4.964 & $3.07 E-05$ & 0.2595 & $6.553 E+04$ & 311.3 & 208.68 \\
\hline 390 & 13.458 & 2.341 & $2.79 \mathrm{E}-05$ & 0.1605 & $7.208 E+04$ & 248.7 & 153.75 \\
\hline 400 & 9.2097 & 1.877 & $2.74 \mathrm{E}-05$ & 0.1347 & $7.330 E+04$ & 230.8 & 133.73 \\
\hline 410 & 7.3264 & 1.656 & $2.74 E-05$ & 0.1213 & $7.338 \mathrm{E}+04$ & 219.7 & 121.45 \\
\hline 420 & 6.231 & 1.520 & $2.76 \mathrm{E}-05$ & 0.1130 & $7.299 E+04$ & 211.4 & 112.7 \\
\hline 430 & 5.506 & 1.425 & $2.78 \mathrm{E}-05$ & 0.1074 & $7.235 E+04$ & 204.6 & 105.96 \\
\hline 440 & 4.9883 & 1.353 & $2.81 E-05$ & 0.1036 & $7.160 E+04$ & 198.7 & 100.51 \\
\hline 450 & 4.5996 & 1.297 & $2.84 \mathrm{E}-05$ & 0.1008 & $7.077 \mathrm{E}+04$ & 193.6 & 95.955 \\
\hline 460 & 4.2973 & 1.251 & $2.88 \mathrm{E}-05$ & 0.0989 & $6.991 E+04$ & 188.9 & 92.058 \\
\hline 470 & 4.0558 & 1.212 & $2.91 E-05$ & 0.0975 & $6.903 E+04$ & 184.7 & 88.661 \\
\hline 480 & 3.8589 & 1.180 & $2.95 E-05$ & 0.0966 & $6.815 E+04$ & 180.8 & 85.657 \\
\hline
\end{tabular}




\begin{tabular}{|l|l|l|l|l|l|l|l|}
\hline 490 & 3.6958 & 1.151 & $2.99 \mathrm{E}-05$ & 0.0960 & $6.728 \mathrm{E}+04$ & 177.2 & 82.969 \\
\hline 500 & 3.5589 & 1.126 & $3.03 \mathrm{E}-05$ & 0.0957 & $6.642 \mathrm{E}+04$ & 173.8 & 80.54 \\
\hline 510 & 3.4427 & 1.104 & $3.07 \mathrm{E}-05$ & 0.0957 & $6.557 \mathrm{E}+04$ & 170.7 & 78.328 \\
\hline 520 & 3.3431 & 1.084 & $3.11 \mathrm{E}-05$ & 0.0959 & $6.473 \mathrm{E}+04$ & 167.7 & 76.298 \\
\hline 530 & 3.2571 & 1.066 & $3.15 \mathrm{E}-05$ & 0.0962 & $6.392 \mathrm{E}+04$ & 164.9 & 74.425 \\
\hline 540 & 3.1823 & 1.049 & $3.19 \mathrm{E}-05$ & 0.0967 & $6.312 \mathrm{E}+04$ & 162.3 & 72.687 \\
\hline 550 & 3.117 & 1.034 & $3.23 \mathrm{E}-05$ & 0.0973 & $6.235 \mathrm{E}+04$ & 159.7 & 71.068 \\
\hline 560 & 3.0596 & 1.021 & $3.27 \mathrm{E}-05$ & 0.0979 & $6.159 \mathrm{E}+04$ & 157.3 & 69.552 \\
\hline 570 & 3.0089 & 1.008 & $3.31 \mathrm{E}-05$ & 0.0987 & $6.085 \mathrm{E}+04$ & 155.1 & 68.129 \\
\hline 580 & 2.964 & 0.996 & $3.35 \mathrm{E}-05$ & 0.0995 & $6.013 \mathrm{E}+04$ & 152.9 & 66.788 \\
\hline 590 & 2.9242 & 0.986 & $3.39 \mathrm{E}-05$ & 0.1004 & $5.942 \mathrm{E}+04$ & 150.8 & 65.521 \\
\hline 600 & 2.8886 & 0.976 & $3.43 \mathrm{E}-05$ & 0.1014 & $5.874 \mathrm{E}+04$ & 148.8 & 64.321 \\
\hline
\end{tabular}

\section{Wall Thickness of Inner Rod/Heater under External Pressure}

The required wall thickness to withstand external pressure is calculated in an iterative process. In the case of the bundle test section, a number of wall thickness and outer diameter variations were checked for pressure-temperature rating and achievable heat flux. In a similar manner, as for the annular test section, the following calculations show the pressure rating of the heater rods.

Design Data:

$$
\begin{array}{lll}
d_{i}=5.24 \mathrm{~mm} & \begin{array}{l}
\text { (increased from } 5 \mathrm{~mm} \text { due } \\
\text { to reduced wall thickness) }
\end{array} & L=2000 \mathrm{~mm} \\
d_{o}=7.4 \mathrm{~mm} & \text { SB444/IN625 Gr. } 1 \\
\left.t_{a}=1.08 \mathrm{~mm} \quad \text { (reduced by } 10 \%\right) & \\
\delta=0.12 \mathrm{~mm} \quad(10 \% \text { of } 1.2 \mathrm{~mm}) &
\end{array}
$$

Determination of A: $\quad \frac{L}{d_{o}}=\frac{2000}{7.4}=270>50$

Therefore, on Chart $G$ in [2] use $\mathrm{L} / \mathrm{Do}=50$ [3].

$$
\begin{aligned}
& \frac{d_{o}}{t_{a}}=\frac{7.4}{1.08}=6.8 \\
& A=0.03 \quad \text { (from Chart } \mathrm{G} \text { in [2]) }
\end{aligned}
$$


From Figure NFN-17 in [2], a B factor curve for a specific temperature is selected and the pressure rating of the inner rod is determined. If the resulting pressure rating is lower than the maximum operating pressure of $27 \mathrm{MPa}$, the $\mathrm{B}$ factor curve for a lower temperature is considered as a second iteration. On the other hand, if the pressure rating is substantially higher than the one calculated using the equations given below (also given in Section 4.5.2.2), the B factor curve for a higher temperature is considered. Following is a sample calculation for the pressure rating that has been selected for the SCW loop bundle test section.

Determination of $\mathrm{B} \quad B=141 \mathrm{MPa}$

From Fig. FNF-17 in [2] and $\mathrm{S}$ at $650^{\circ} \mathrm{C}$ :

$$
S=2 S_{f}=2(89.0 \mathrm{MPa})=178 \mathrm{MPa} \quad \text { From Table 1B in [2] }
$$

Calculation:

$$
\begin{aligned}
& P_{a 1}=\left(\frac{2.167}{D / t}-0.0833\right) B \\
& P_{a 1}=\left(\frac{2.167}{7.4 / 1.08}-0.0833\right)(141 \mathrm{MPa}) \\
& P_{a 1}=32.8 \mathrm{MPa} \\
& P_{a 1}>27 \mathrm{MPa}
\end{aligned}
$$

Calculation:

$$
\begin{aligned}
& P_{a 2}=\frac{2 S}{D / t}\left(1-\frac{1}{D / t}\right) \\
& P_{a 2}=\frac{2(178 \mathrm{MPa})}{7.4 / 1.08}\left(1-\frac{1}{7.4 / 1.08}\right) \\
& P_{a 2}=44.37 \mathrm{MPa} \\
& P_{a 2}>27 \mathrm{MPa}
\end{aligned}
$$




\section{Thickness of Outer Shell under Internal Pressure}

The outer shell is the same as the rest of the piping on the loop, i.e. NPS 1.5, Sch XXS $\mathrm{SA} 312 / 316 \mathrm{H}$. It was shown in the thermal sizing calculation of the heat exchanger in this appendix that this pipe can withstand an internal pressure of $28.35 \mathrm{MPa}$ at $625^{\circ} \mathrm{C}$ when evaluated according to ASME Section VIII, Div.1.

\section{Thickness of Blind Hub}

The blind hub of the bundle test section, where the heater rods mate with it has a number of $10 \mathrm{~mm}$ holes. Therefore, it is calculated to determine if the thickness of the blind hub meets the code requirements after the holes have been drilled. Due to the arrangement of the holes and their dimensions, the Code rules do not apply in this instance. The Code refers to $\mathrm{U}-2(\mathrm{~g})$ in such an instance, which means that calculations outside the scope of the Code and preferably numerical simulations are required. Nonetheless, to estimate the required blind hub thickness, instead of seven individual holes, one large hole encompassing all the seven holes located at the centre of the blind hub is considered. Since the diameter of such a hole is larger than one-half diameter of the blind hub, the calculations are carried out as per Mandatory Appendix 14 of ASME Section VIII, Div.1. The method is rather lengthy and involves a large number of variables. The reader is referred to ASME Section VIII, Div.1 for the explanation of various variables and their significance.

$$
\begin{aligned}
& \text { Design Data: } \quad A=48.26 \mathrm{~mm} \quad h_{s}=0 \\
& B_{n}=24.2 \mathrm{~mm} \text { (size of hole) } \quad P=28.35 \mathrm{MPa} \\
& B_{s}=27.94 \mathrm{~mm} \quad T=650^{\circ} \mathrm{C} \\
& g_{o s} \approx 15 \mathrm{~mm} \quad S_{f}=89.0 \mathrm{MPa} \text { (Table 1B in [2]) } \\
& g_{1 s} \approx 15 \mathrm{~mm} \quad \text { SB564/IN625 } \\
& t=39.7 \mathrm{~mm} \\
& \text { Calculation: } \quad g r_{s}=\frac{g_{1 s}}{g_{o s}}=1 \\
& h_{0 s}=\sqrt{B_{s} g_{o s}}=20.47 \mathrm{~mm}
\end{aligned}
$$




$$
\begin{aligned}
& h r_{s}=\frac{h_{s}}{h_{o s}}=0 \\
& F_{s}=0.909 \\
& V_{s}=0.550 \\
& f_{s}=1
\end{aligned}
$$

$F, V$ and $f$ are default values from Table 2 7.1 in [3].
Calculation of $\mathrm{K}$ and associated factors:

$$
K=\frac{A}{B_{n}}=1.99
$$

$$
\begin{aligned}
& T=\frac{K^{2}(1+8.55 \log K)-1}{\left(1.05+1.99 K^{2}\right)(K-1)}=1.47 \\
& U=\frac{K^{2}(1+8.55 \log K)-1}{1.36\left(K^{2}-1\right)(K-1)}=3.28 \\
& Y=\frac{1}{K-1}\left(0.67+5.72 \frac{K^{2} \log K}{K^{2}-1}\right)=2.99 \\
& Z=\frac{K^{2}+1}{K^{2}-1}=1.68 \\
& Z_{1}=\frac{2 K^{2}}{K^{2}-1}=2.68
\end{aligned}
$$

Calculation of loads and moments:

$$
H=0.785 B_{s}^{2} P=17.4 k N
$$

$$
\begin{aligned}
& H_{D}=0.785 B_{n}^{2} P=13.0 \mathrm{kN} \\
& H_{T}=H-H_{D}=4.4 \mathrm{kN} \\
& R=\frac{B_{s}-B_{n}}{2}=1.87 \mathrm{~mm} \\
& h_{D}=R=1.87 \mathrm{~mm} \\
& h_{T}=\frac{R}{2}=0.94 \mathrm{~mm}
\end{aligned}
$$


Calculation of loads $M_{D}=H_{D} h_{D}=24.31 \mathrm{Nm}$

and moments

continued:

$$
M_{T}=H_{T} h_{T}=4.14 \mathrm{Nm}
$$

$$
M_{0}=M_{D}+M_{T}=28.45 \mathrm{Nm}
$$

Calculation of stresses:

$$
S_{T}=\frac{Y M_{0}}{t^{2} B_{n}}=2.24 M P a
$$

Calculation of $(E \Theta)^{*}$ :

$$
(E \theta)^{*}=\left(\frac{B_{n}}{t}\right) S_{T}=1.37 \mathrm{MPa}
$$

Calculation of $\mathrm{M}_{\mathrm{H}}: \quad B_{1 s}=B_{S}+g_{o s}=42.94 \mathrm{~mm}$

$$
M_{H}=\frac{(E \theta)^{*}}{\frac{1.74 h_{o s} V_{s}}{g_{o s}^{3} B_{1 s}}+\frac{(E \theta)^{*}}{M_{0}}\left(1+\frac{F_{s} t}{h_{o s}}\right)}=5.1 \mathrm{Nm}
$$

Calculation of $X_{1}$ :

$$
X_{1}=\frac{M_{0}-M_{H}\left(1+\frac{F_{s} t}{h_{o s}}\right)}{M_{0}}=0.5
$$

Calculation of longitudinal hub stress in the shell:

$$
S_{H S}=\frac{1.10 h_{o s} f_{s}}{\left(\frac{g_{1 s}}{g_{o s}}\right)^{2} B_{s} V_{s}} X_{1}(E \theta)^{*}=1.0 \mathrm{MPa}
$$

Calculation of radial stress at the outside diameter of $S_{R S}=\frac{1.19 M_{H}\left(1+\frac{F_{s} t}{h_{o S}}\right)}{B_{s} t^{2}}+\frac{0.64 F_{s} M_{H}}{B_{s} h_{o s} t}=0.74 \mathrm{MPa}$ shell: 
Calculation of tangential stress at the outside

$$
S_{T S}=\frac{X_{1}(E \theta)^{*} t}{B_{S}}-\frac{0.57 M_{H}\left(1+\frac{F_{s} t}{h_{o S}}\right)}{B_{S} t^{2}}+\frac{0.64 F_{s} Z M_{H}}{B_{S} h_{o s} t}
$$

diameter of shell:

$$
S_{T S}=1.0 \mathrm{MPa}
$$

Calculation of tangential stress at

$$
S_{T o}=X_{1} S_{T}+\frac{0.64 F_{s} Z_{1} M_{H}}{B_{S} h_{o s} t}=1.5 \mathrm{MPa}
$$

diameter of hole:

Comparison with $\mathrm{S}_{\mathrm{f}}$

$$
S_{H S}=1.0 \mathrm{MPa} \leq 1.5 S_{f}=133.5 \mathrm{MPa}
$$
to determine if the stresses meet Code

$$
S_{R S}=0.74 \mathrm{MPa} \leq S_{f}=89.0 \mathrm{MPa}
$$
requirements:

$$
\begin{aligned}
& S_{T S}=1.0 \mathrm{MPa} \leq S_{f}=89.0 \mathrm{MPa} \\
& \frac{S_{H S}+S_{R S}}{2}=0.87 \mathrm{MPa} \leq S_{f}=89.0 \mathrm{MPa} \\
& \frac{S_{H S}+S_{T S}}{2}=1.0 \mathrm{MPa} \leq S_{f}=89.0 \mathrm{MPa} \\
& S_{T O}=1.5 \mathrm{MPa} \leq S_{f}=89.0 \mathrm{MPa}
\end{aligned}
$$
All the stresses are less than the allowable stress. Therefore, it meets the Code. However, an FEA of the actual seven holes along with the heater rods must carried out.

\section{Fillet Weld Size}

Fillet welds are used to connect the sealing glands to the heater rods and the heater rods to the blind hub. According to the requirements of the Code, the force exerted on the one fillet weld must equal the product of the weld area based on minimum weld leg, the allowable stress value of the material being welded and a joint efficiency of 0.55 .

$$
\begin{aligned}
& \text { Design Data: } \quad d_{o}=7.4 \mathrm{~mm} \quad P=28.35 \mathrm{MPa} \\
& d_{i}=5 \mathrm{~mm} \quad T=650^{\circ} \mathrm{C} \\
& t=1.2 \mathrm{~mm} \quad S_{f}=89.0 \mathrm{MPa} \text { (Table 1B in [2]) }
\end{aligned}
$$




$$
E=0.55 \text { (for fillet weld) }
$$

Calculations: $\quad A_{w}=\pi d_{i} w_{L}$ $F=(28.35 M P a)\left(\frac{\pi}{4} 0.0074^{2} m^{2}\right)$ $F=1.23 k N$

Therefore,

$$
\begin{aligned}
& 0.55 A_{w} S_{f}=1.23 \mathrm{kN} \\
& w_{L}=\frac{1.23 \mathrm{kN}}{(0.55)(89.0 \mathrm{MPa})\left(d_{i} \pi\right)} \\
& w_{L}=1.5 \mathrm{~mm}
\end{aligned}
$$

SB564/IN625

Area of fillet weld

Load acting on the fillet weld

An FEA simulation should be performed to verify whether a weld leg equal to the wall thickness of the heater rod tube would be enough to withstand the exerted forces.

\section{Sizing of R-134a Loop Piping/Tubing}

$$
\begin{aligned}
& \text { Design Data: } \quad D_{i}=26.92 \mathrm{~mm} \quad P=7.0 \mathrm{MPa} \\
& D_{o}=31.75 \mathrm{~mm} \quad T=200^{\circ} \mathrm{C} \\
& t_{a}=2.41 \mathrm{~mm} \quad S=99.2 \mathrm{MPa} \text { (Table A-3 in [1]) } \\
& \delta=0.24 \mathrm{~mm}\left(10 \% \text { of } t_{a}\right) \quad \mathrm{SA} 213 / 316,1.25 " \mathrm{OD} \times 0.109 " \text { Thk } \\
& E=1 \text { (Seamless) } \quad y=0.4 \text { (Table 104.1.2(A) in [1]) } \\
& t=\frac{P D_{i}}{2(S E+P y-P)} \quad \text { Paragraph 104.1.2 in [1] } \\
& t=\frac{\left(7.0 \times 10^{6} P a\right)\left(26.92 \times 10^{-3} \mathrm{~m}\right)}{2(99.2+7.0 \times 0.4-7.0) \times 10^{6} \mathrm{~Pa}} \\
& t=0.94 \mathrm{~mm} \\
& t_{a}>t+\delta \text { (It is therefore acceptable.) }
\end{aligned}
$$




\section{References}

[1] Power Piping. ASME B31.1-2007. ASME Code for Pressure Piping, B31. ASME; 2007.

[2] Materials Properties (Metric). Section II, Part D. 2007 ASME Boiler and Pressure Vessel Code. ASME; 2007.

[3] Rules for construction of pressure vessels. Section VIII, Division 1. 2007 ASME Boiler and Pressure Vessel Code. ASME; 2007.

[4] NIST Standard Reference Data. Thermophysical properties of fluid systems. Viewed Online; July 2010. http://webbook.nist.gov/chemistry/fluid/

[5] White FM. Fluid Mechanics. $4^{\text {th }}$ ed. McGraw-Hill, Canada; 1998.

[6] Grayloc Product Catalogue. An Oceaneering International Company. Viewed Online; May 2010. http://www.grayloc.com 
APPENDIX E: FEA Simulation Results 


\section{Structural Analysis of SCW Loop}

In order to determine the stresses caused due to thermal expansion/contraction and bending moments, an FEA analysis of the SCW loop using the in-house code VrSuite ${ }^{\mathrm{TM}}$ was carried out by Rubicel G. Alena, a member of the design team, the results of which are recorded in [1]. The resulting displacement stress range is compared with the allowable stress range, $S_{A}$, given by the following equation [2]:

$$
S_{A}=f\left(1.25 S_{c}+0.25 S_{h}\right)
$$

Design data: $\quad S_{c}=138 \mathrm{MPa} \quad$ (from Table A-1 in [2] for SA312/316H)

$$
\begin{array}{ll}
S_{h}=123.2 \mathrm{MPa} & \text { (from Table A-1 in [2] for SA312/316H) } \\
f=1.0 & \text { (due to the small number of cycles expected) }
\end{array}
$$

$$
\text { Calculation: } \quad \begin{aligned}
S_{A} & =(1.0)[(1.25)(138 \mathrm{MPa})+(0.25)(123.2 \mathrm{MPa})] \\
S_{A} & =203.3 \mathrm{MPa}
\end{aligned}
$$

Figures E-1 and E-2 show the results of FEA analysis for two of the several simulated test scenarios. In one scenario, displacement stresses as high as $200 \mathrm{MPa}$ are found to exist in the piping segment between the pump and bypass Tee. Comparing this maximum displacement stress with the allowable displacement stress, it is concluded that the stresses caused mainly by thermal expansion of the loop piping, fall within the acceptable limits stipulated by ASME B31.1. Reference [1] can be consulted for more information regarding the FEA simulations. 


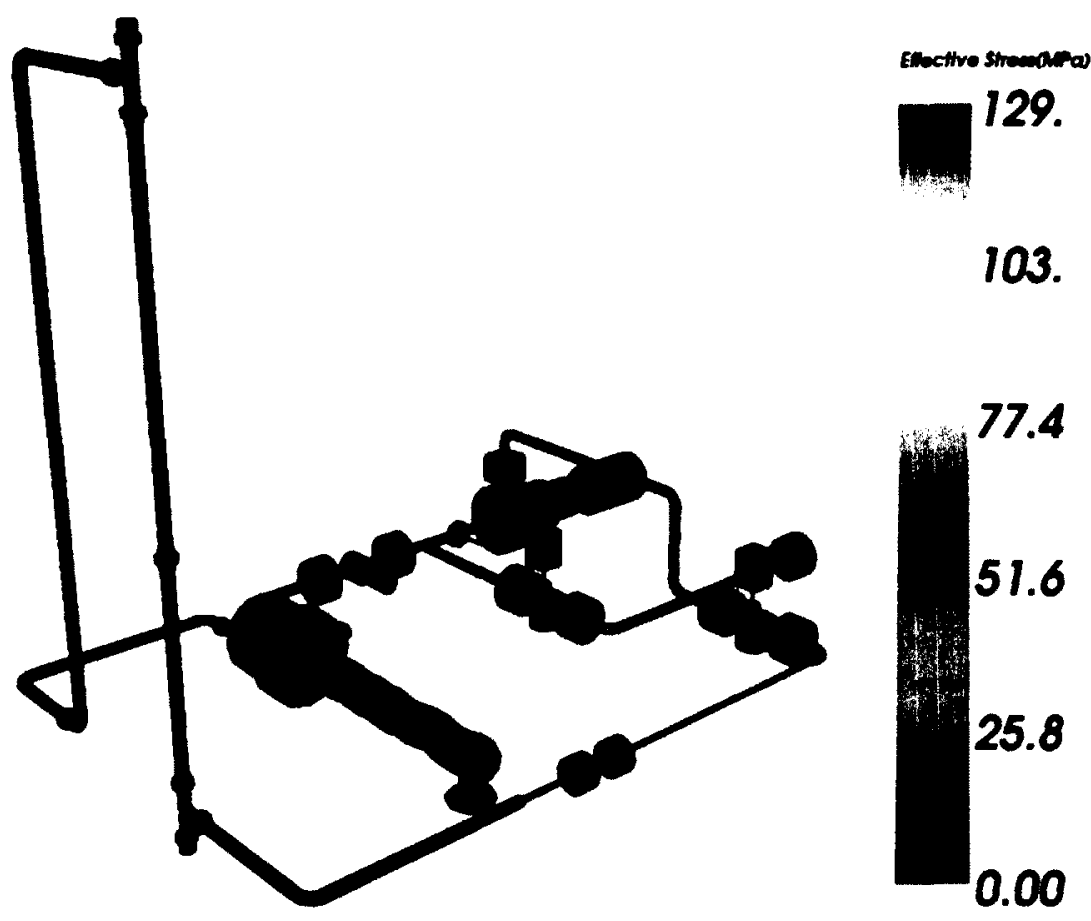

Figure E-1: Stress distribution due to a combination of internal pressure and thermal stresses [1]

a)
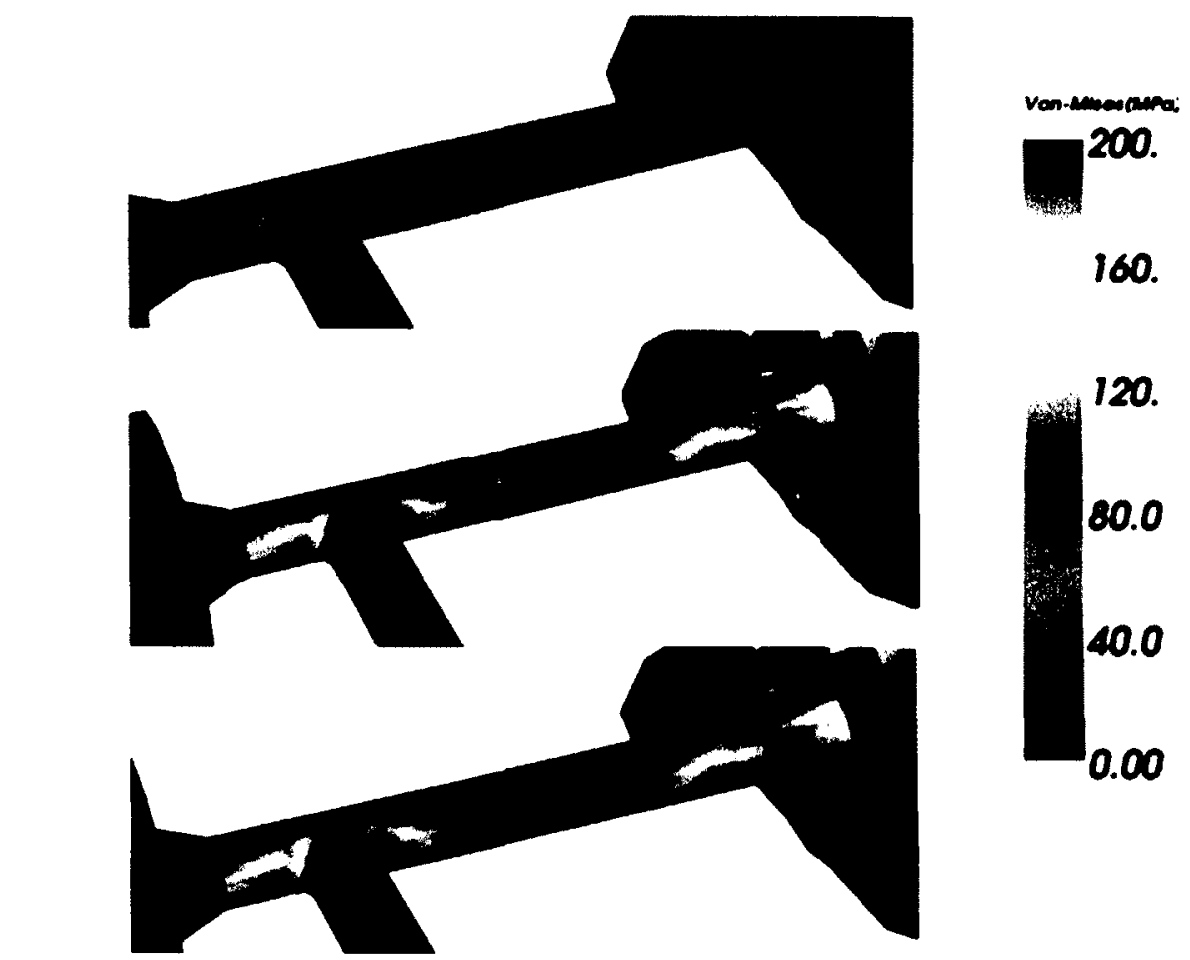

160.

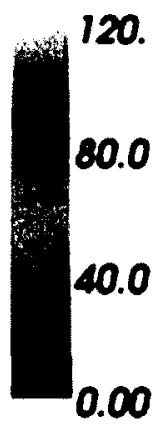

c)

0.00

Figure E-2: Stress distribution due to a) pressure only, b) temperature only, and c) combined pressure and temperature [1] 


\section{Thermal Analysis of the Impulse Tube}

The impulse tube is used to lower the temperature of the fluid from $600^{\circ} \mathrm{C}$ to $320^{\circ} \mathrm{C}$, at which point the capillary tubing, as discussed in Section 3.3.6.3.2, is installed. An FEA analysis using Ansys Multiphysics ${ }^{\mathrm{TM}}$ was carried out to ensure that the selected length of $500 \mathrm{~mm}$ for the impulse tube is sufficient to reduce the temperature of the fluid from $600^{\circ} \mathrm{C}$ to at least $320^{\circ} \mathrm{C}$.

The FEA analysis involved the following assumptions:

a) The fluid/water is stagnant and hence only conduction is considered.

b) Coefficient of thermal conductivity for the tube: 14.6 to $23.9 \mathrm{~W} / \mathrm{mK}$ for 50 to $700^{\circ} \mathrm{C}$, respectively [3].

c) Coefficient of thermal conductivity for fluid: 0.6 to $0.1 \mathrm{~W} / \mathrm{mK}$ for 50 to $700^{\circ} \mathrm{C}$, respectively [4].

d) Natural convective heat transfer coefficient for air: $2 \mathrm{~W} / \mathrm{m}^{2} \mathrm{~K}[5]$.

e) Ambient temperature: $30^{\circ} \mathrm{C}$.

Figure E-3 shows the results of the simulation. It can be observed that the temperature of the fluid is reduced from a maximum of $600^{\circ} \mathrm{C}$ to approximately $202^{\circ} \mathrm{C}$ over a length of $500 \mathrm{~mm}$ for the conditions specified above. Therefore, it can be concluded that the $500 \mathrm{~mm}$ length of the impulse tube is sufficient to reduce the temperature of the fluid equal to or below the one required for the capillary tubing installation.

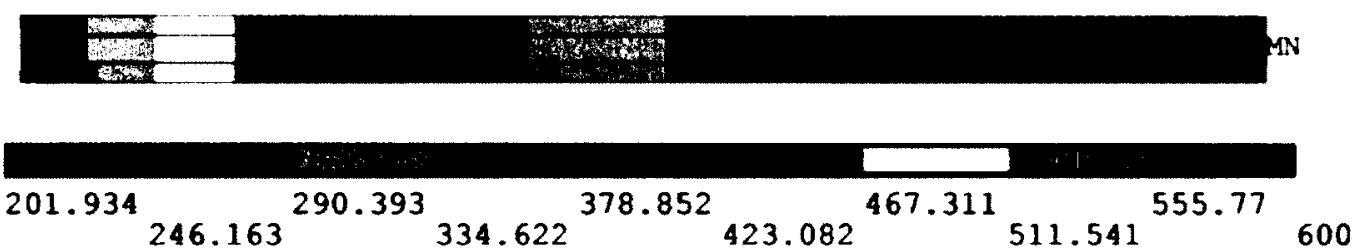

Figure E-3: Temperature distribution in the impulse tube 


\section{Thermal Analysis of the Dielectric Gasket}

The dielectric gasket is used to minimize the electric current flowing through the heater $\operatorname{rod}(s)$ from leaking through the rest of the loop and it needs to be maintained equal to or below $200^{\circ} \mathrm{C}$. To ensure that this requirement is met, a thermal simulation of the dielectric gasket assembly is carried out with the following simulation conditions:

a) The fluid/water is stagnant and hence only conduction is considered.

b) Coefficient of thermal conductivity for SS $316 \mathrm{H}$ : 14.6 to $23.9 \mathrm{~W} / \mathrm{mK}$ for 50 to $700^{\circ} \mathrm{C}$, respectively [3].

c) Coefficient of thermal conductivity for fluid: 0.6 to $0.1 \mathrm{~W} / \mathrm{mK}$ for 50 to $700^{\circ} \mathrm{C}$, respectively [4].

d) Coefficient of thermal conductivity for copper bus bar: 400 to $360 \mathrm{~W} / \mathrm{mK}$ for 50 to $700^{\circ} \mathrm{C}$, respectively [6].

e) Natural convective heat transfer coefficient for air: $2 \mathrm{~W} / \mathrm{m}^{2} \mathrm{~K}[5]$.

f) Ambient temperature: $30^{\circ} \mathrm{C}$.

Based on the simulation results (Figure E-4), it can be concluded that the temperature at the location of the gasket is close to its maximum allowable temperature.

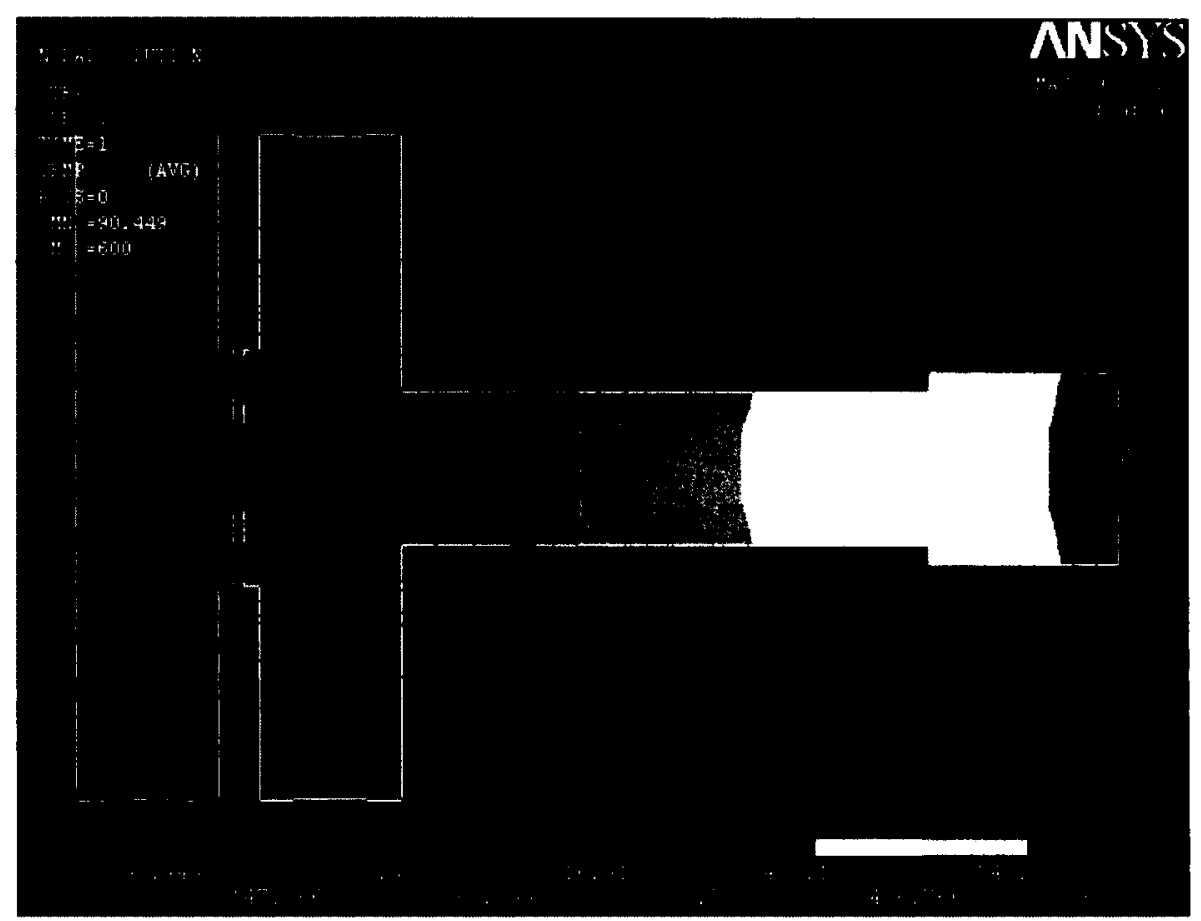

Figure E-4: Temperature distribution in the dielectric gasket assembly 


\section{References}

[1] Alena RG. Carleton supercritical water loop: design-driven structural analysis. Master's thesis. Carleton University; 2010.

[2] Power Piping. ASME B31.1-2007. ASME Code for Pressure Piping, B31. ASME; 2007.

[3] Materials Properties (Metric). Section II, Part D. 2007 ASME Boiler and Pressure Vessel Code. ASME; 2007.

[4] NIST Standard Reference Data. Thermophysical properties of fluid systems. Viewed Online; July 2010. http://webbook.nist.gov/chemistry/fluid/

[5] Kakac S, Liu H. Heat Exchangers - Selection, Rating and Thermal Design. CRC Press LLC, Florida; 1998.

[6] Incropera FP, Dewitt DP. Fundamentals of heat and mass transfer. $6^{\text {th }}$ Edition. John Wiley \& Sons, Inc., Hoboken, New Jersey; 2007. 
APPENDIX F: Engineering Drawings 
R-134a Loop 
$\mathrm{CV}=$ Control valve

$P R V=$ Pressure relief valve

PSV = Pressure safety val

$=$ Shut-off valve

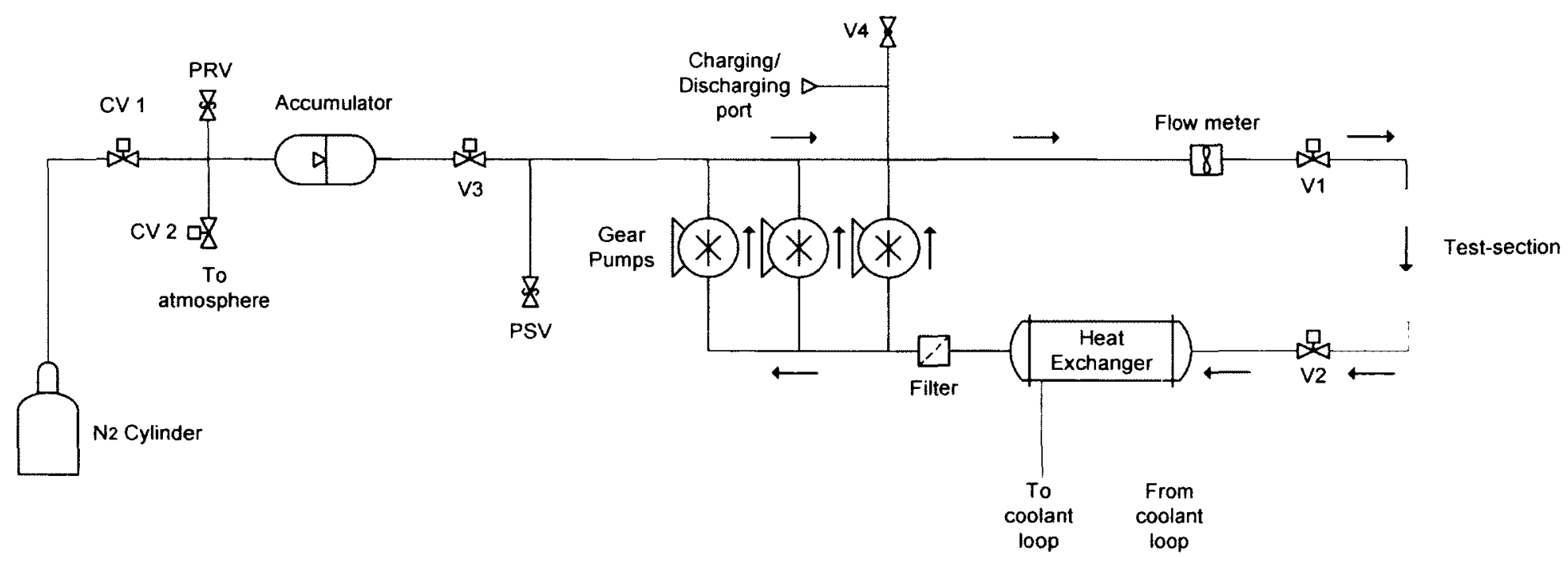

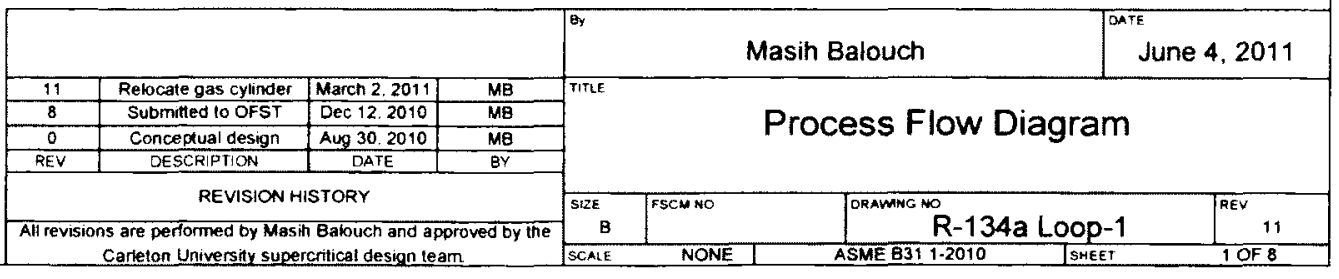




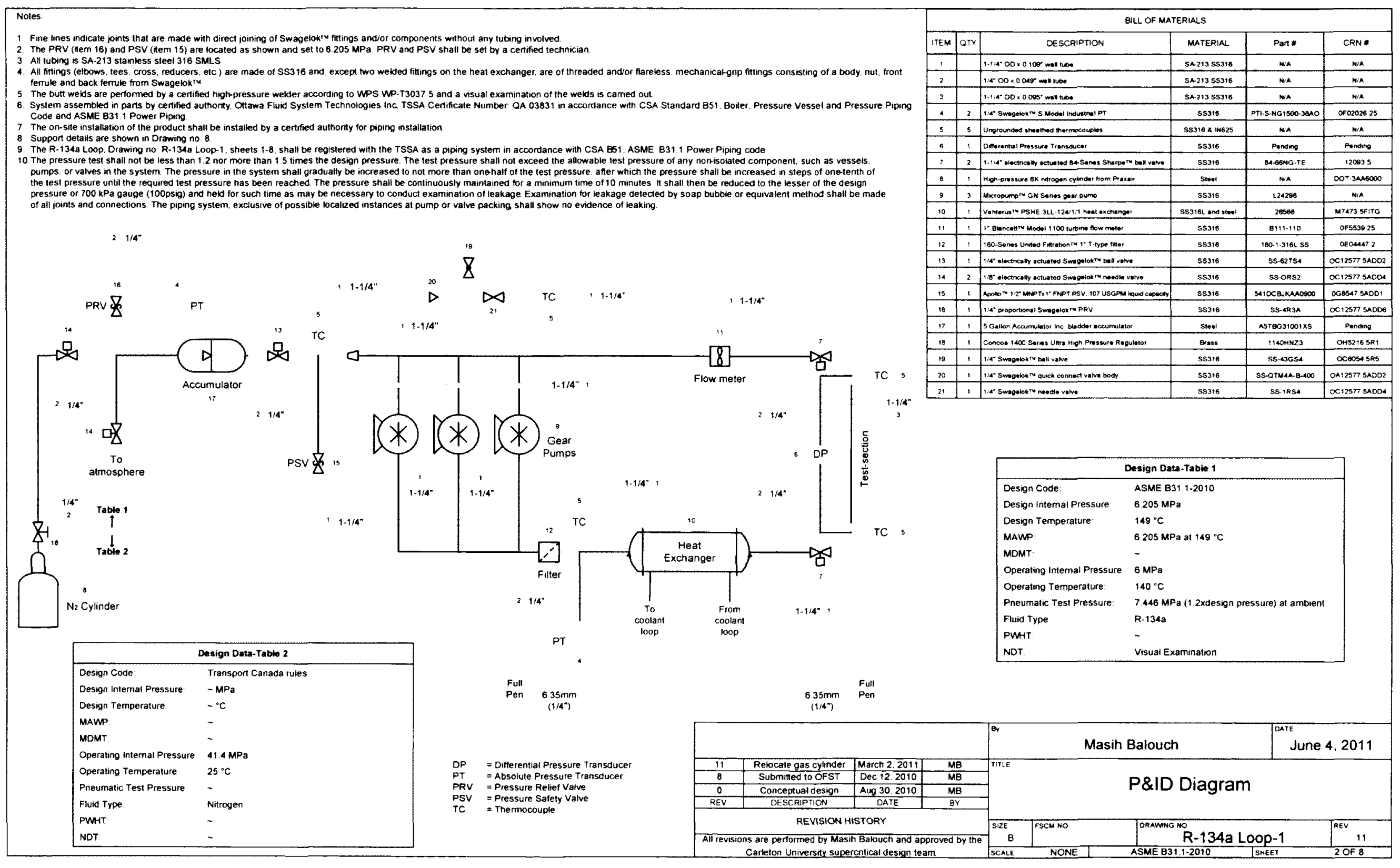




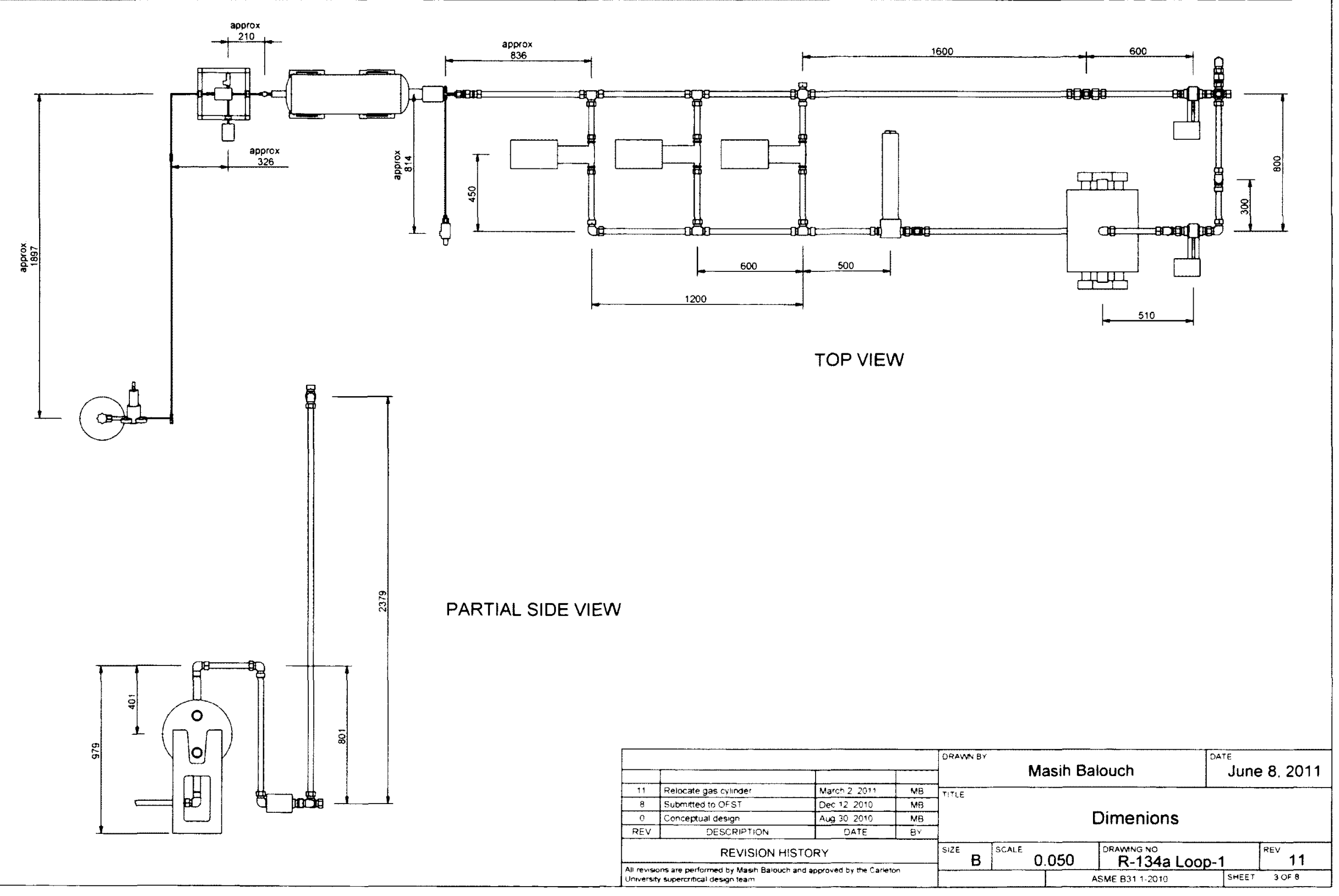




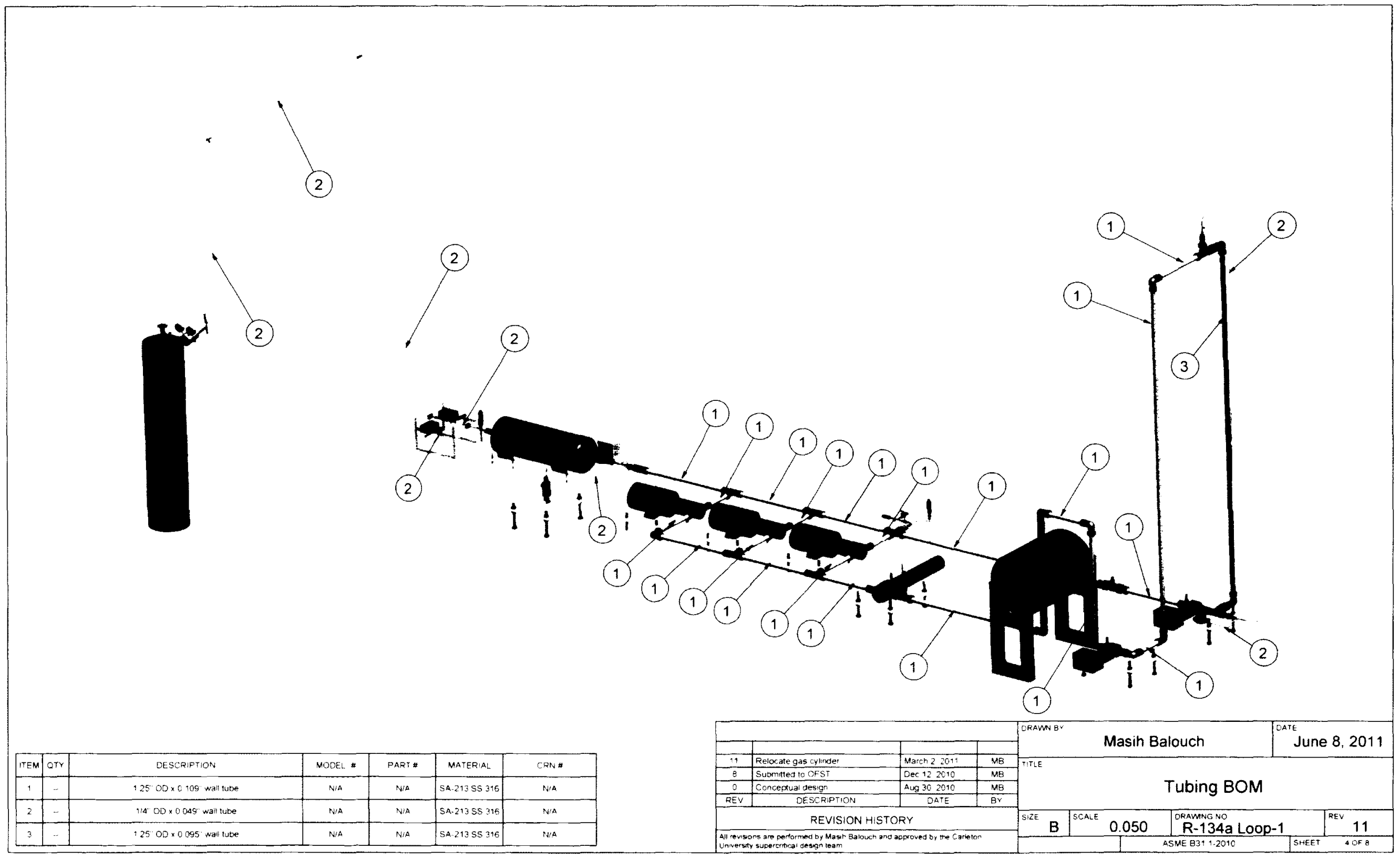




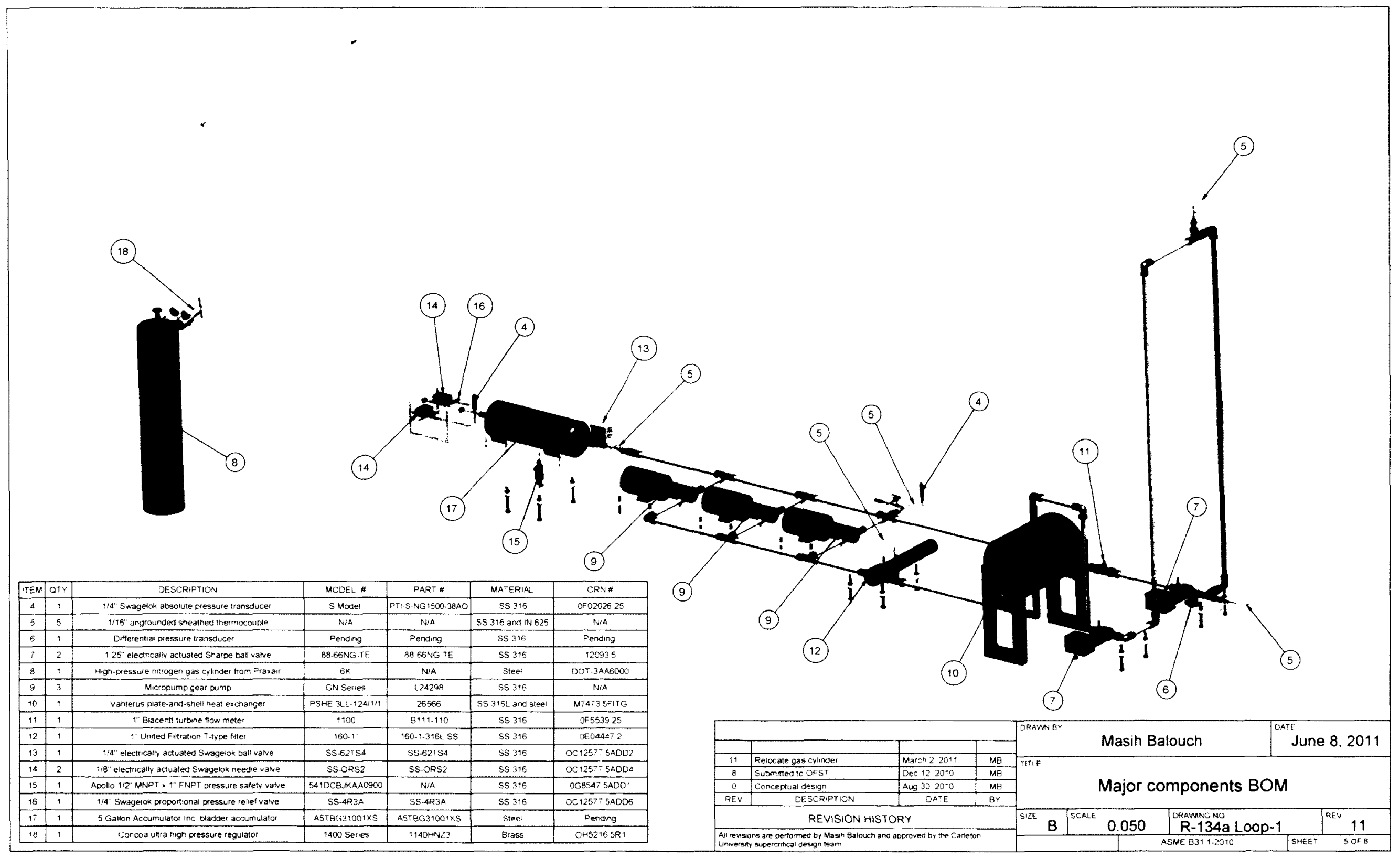




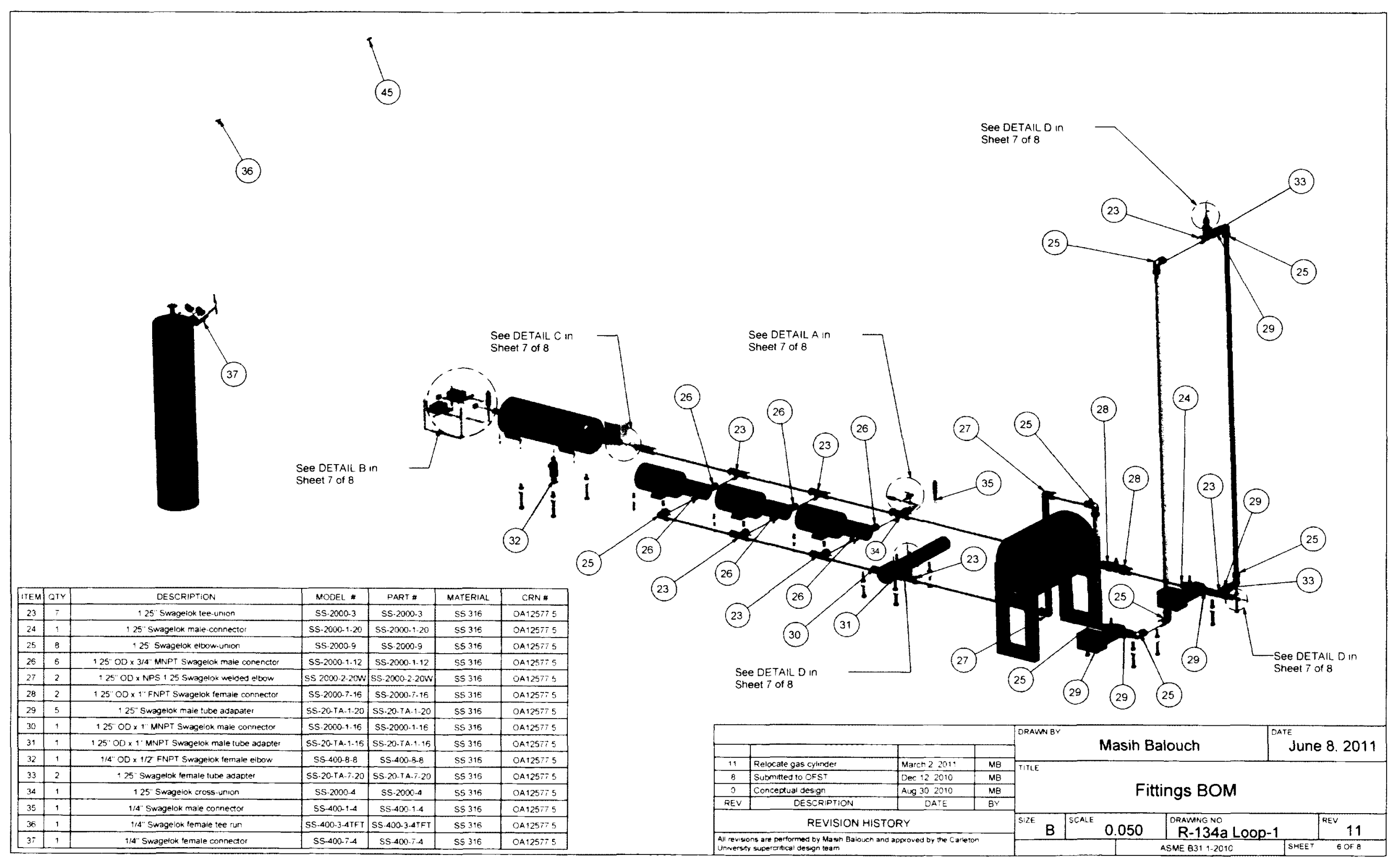




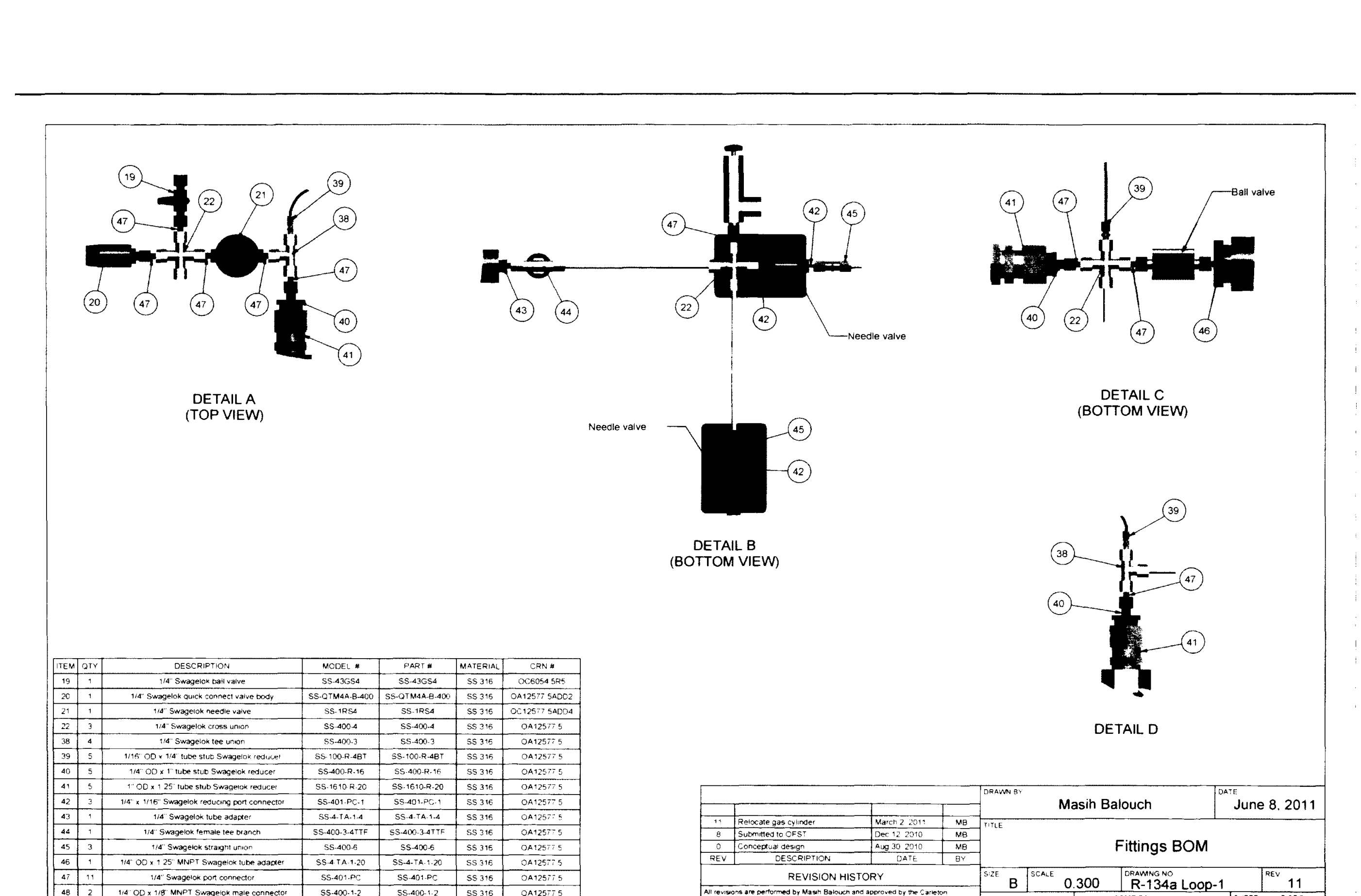




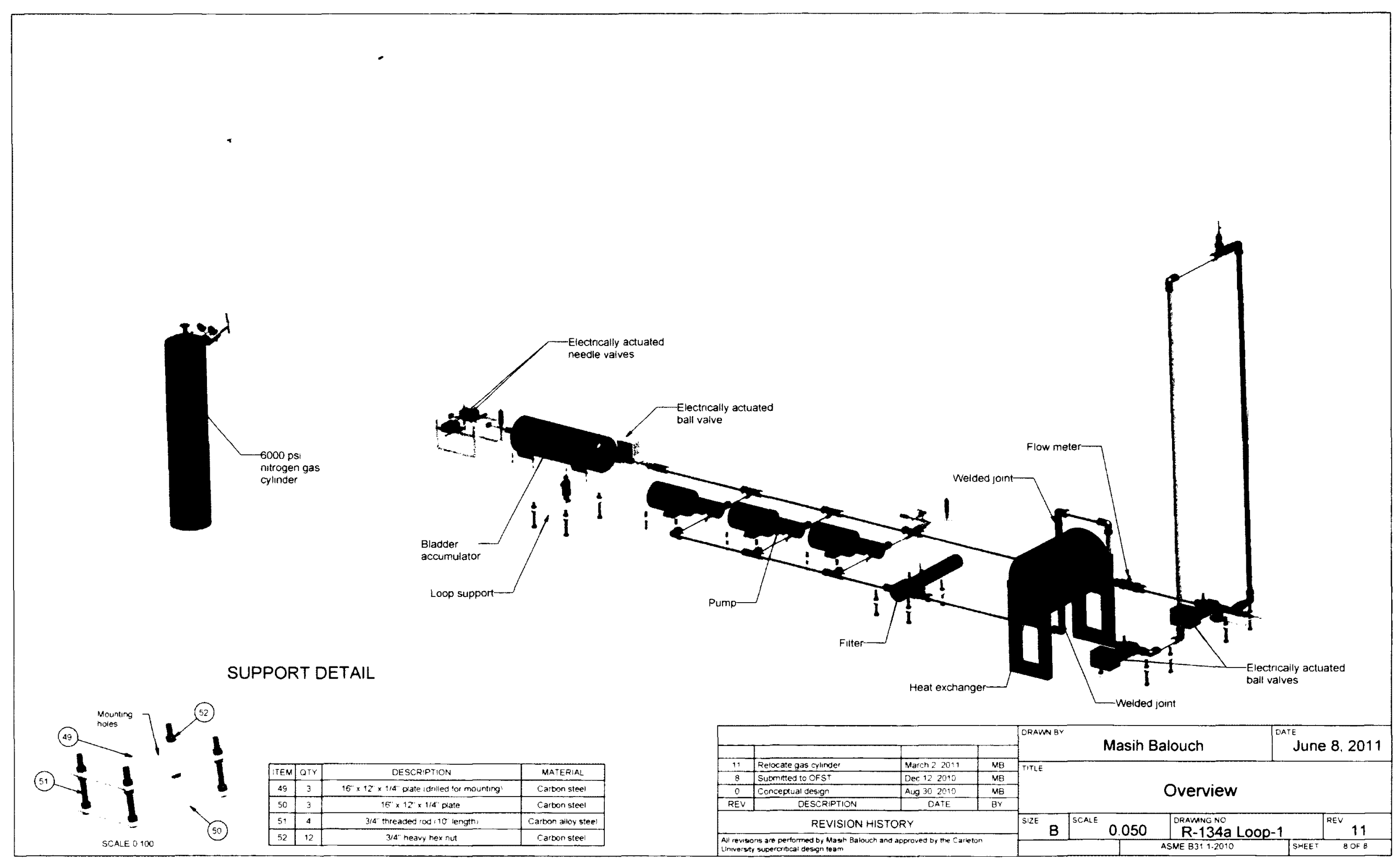


SCW Loop 

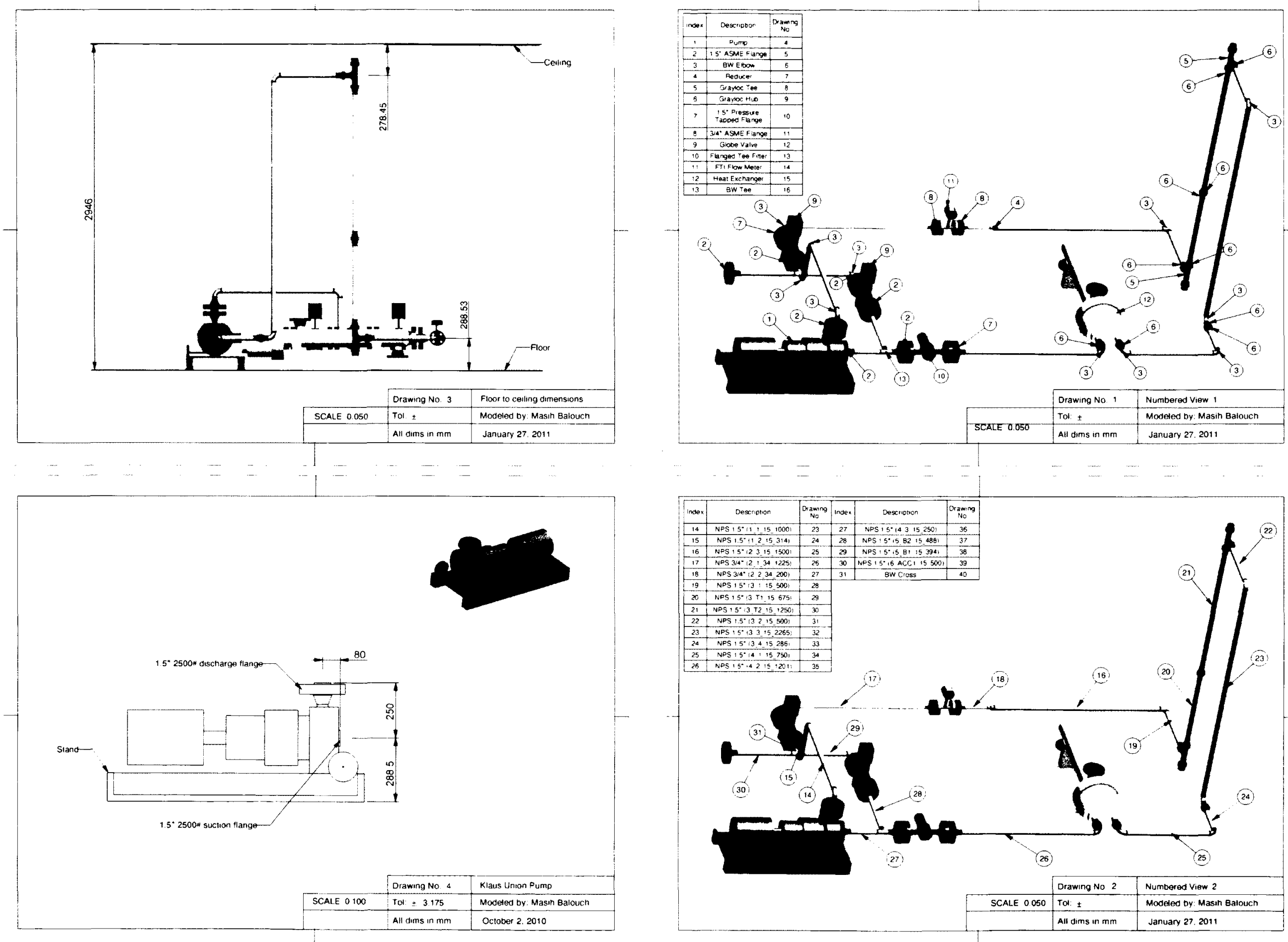

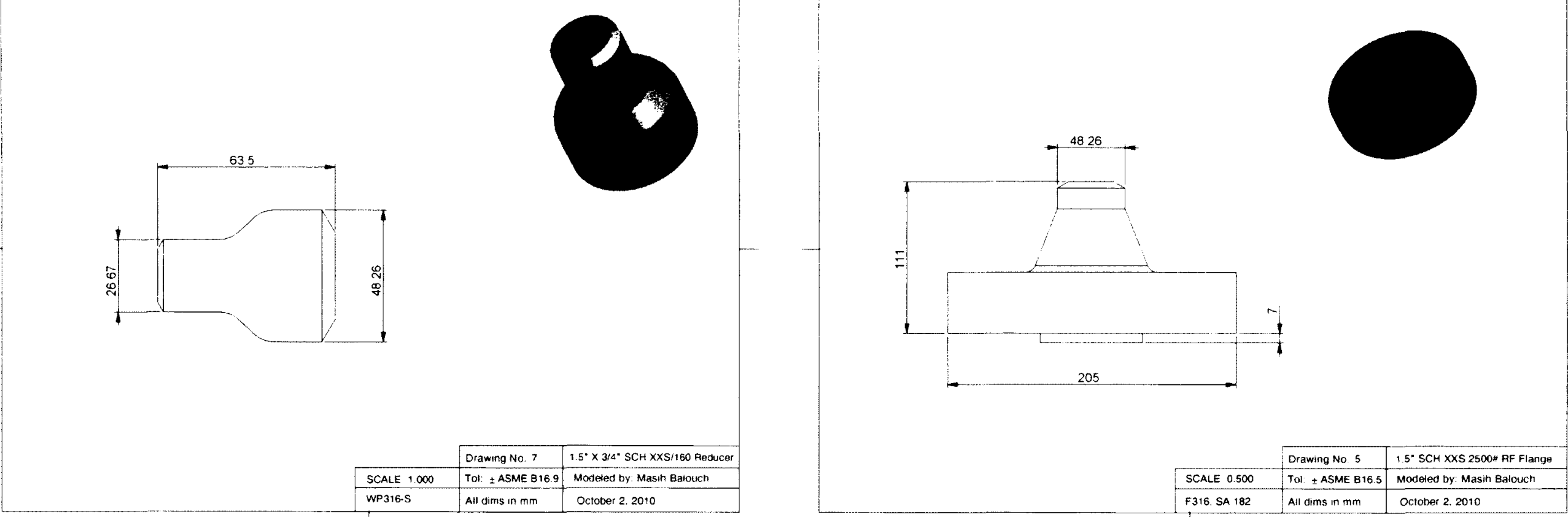

\begin{tabular}{l|l|l|l} 
& All dims in mm & October 2.20 \\
\hline
\end{tabular}

\begin{tabular}{l|l}
\hline All dims in mm & Octoter 2. 2010
\end{tabular}
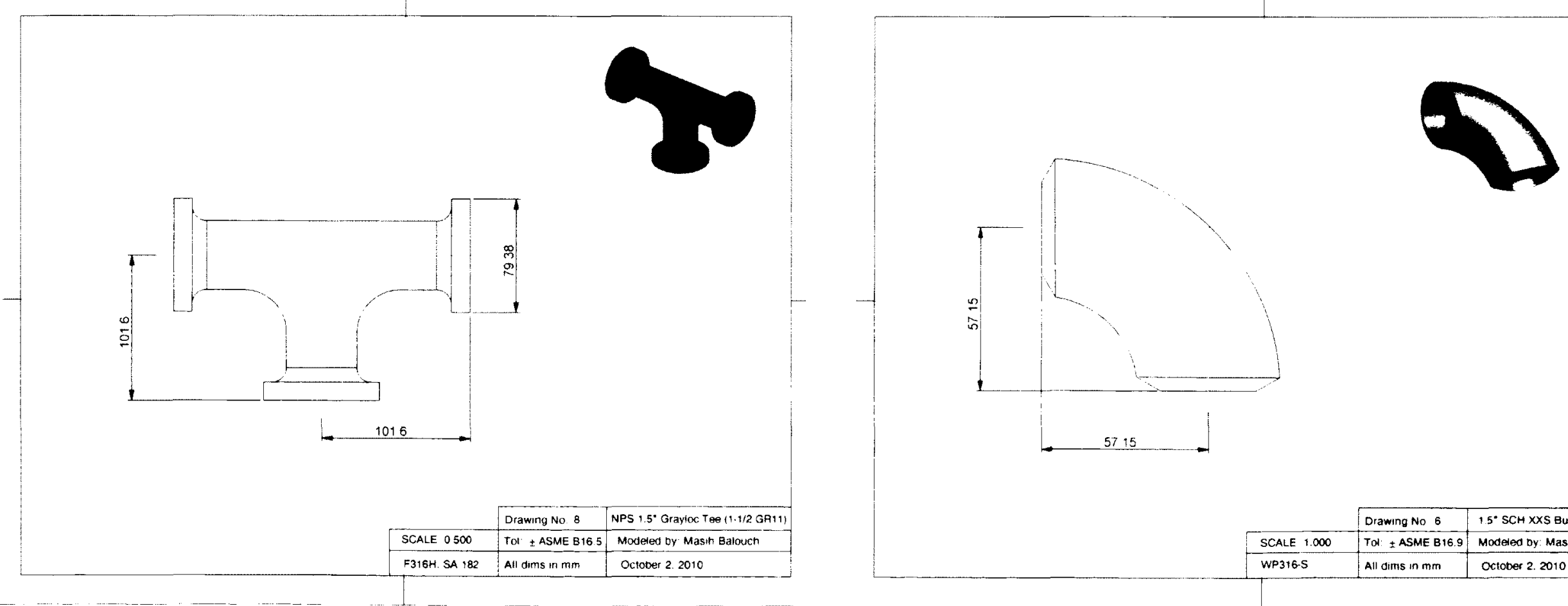

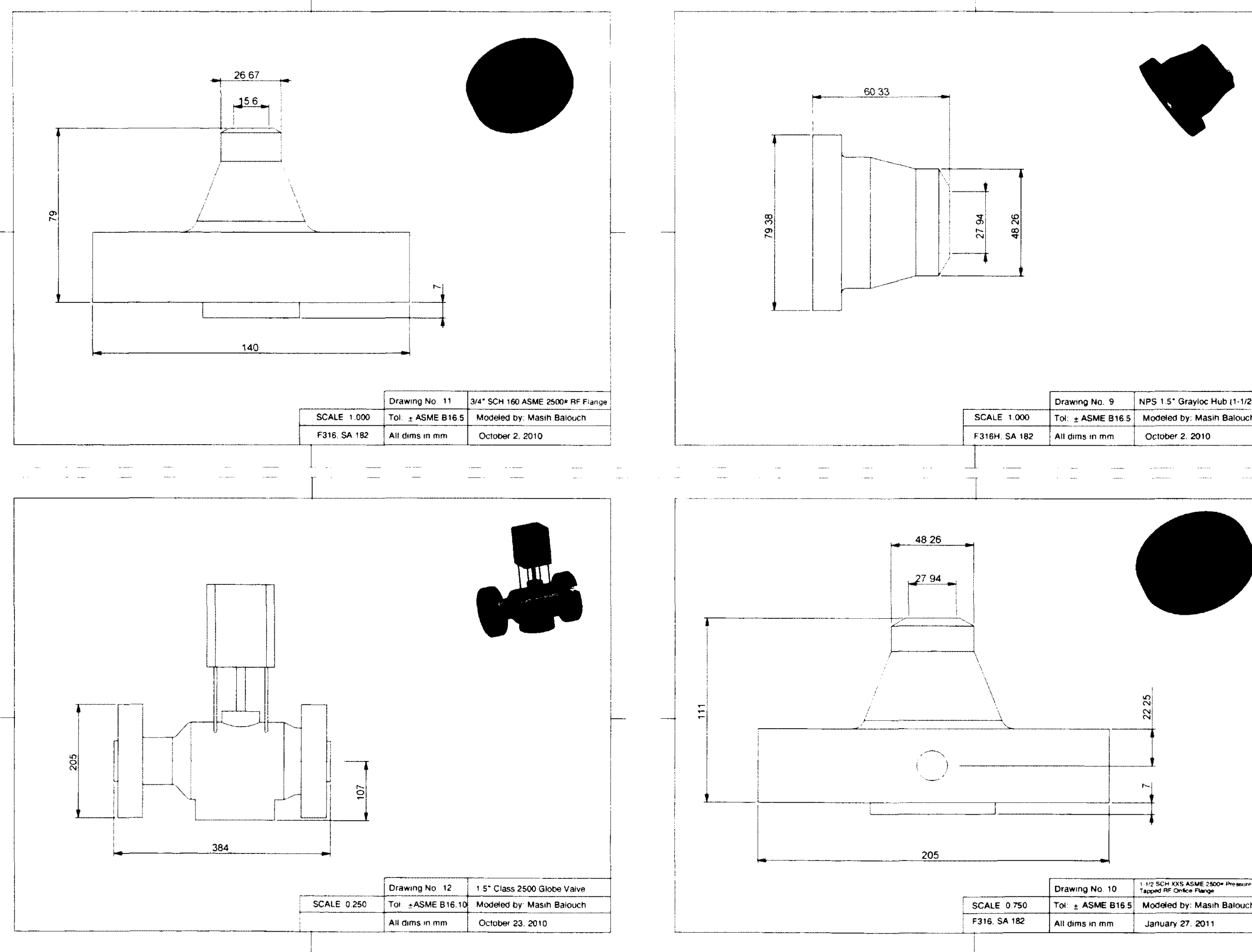

Drawing No. 9 NPS 1.5* Grayloc Hub (1-1/2GR +1) \begin{tabular}{|l|l|l|l|l|l|l}
\hline SCALE 1.000 & TOl: \pm ASME B16.5 & Modeled by: Masin Balouch \\
\hline
\end{tabular} \begin{tabular}{|l|l|l}
\hline F316H. SA 182 & All dims in mm & Octobet 2.2010 \\
\hline
\end{tabular}

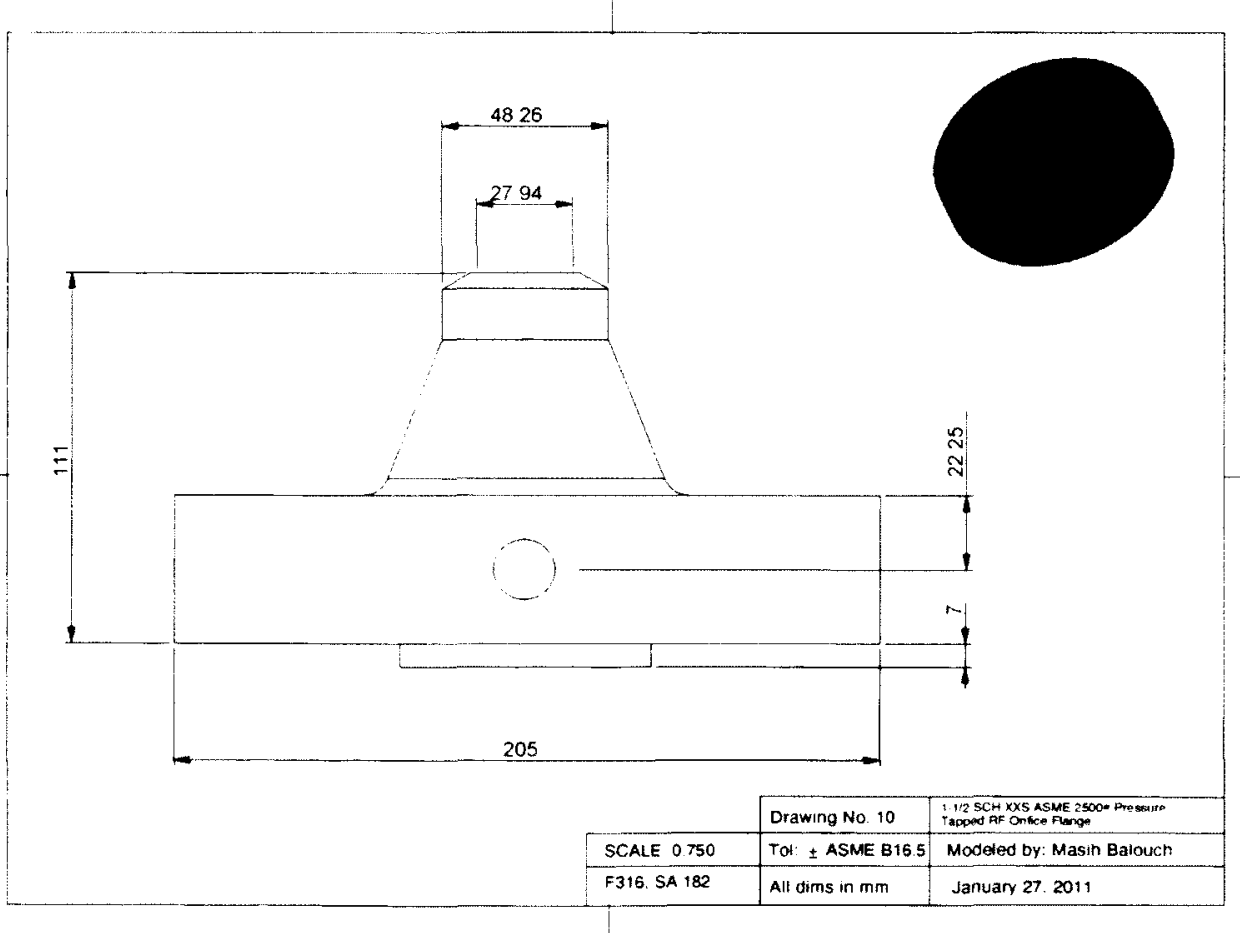



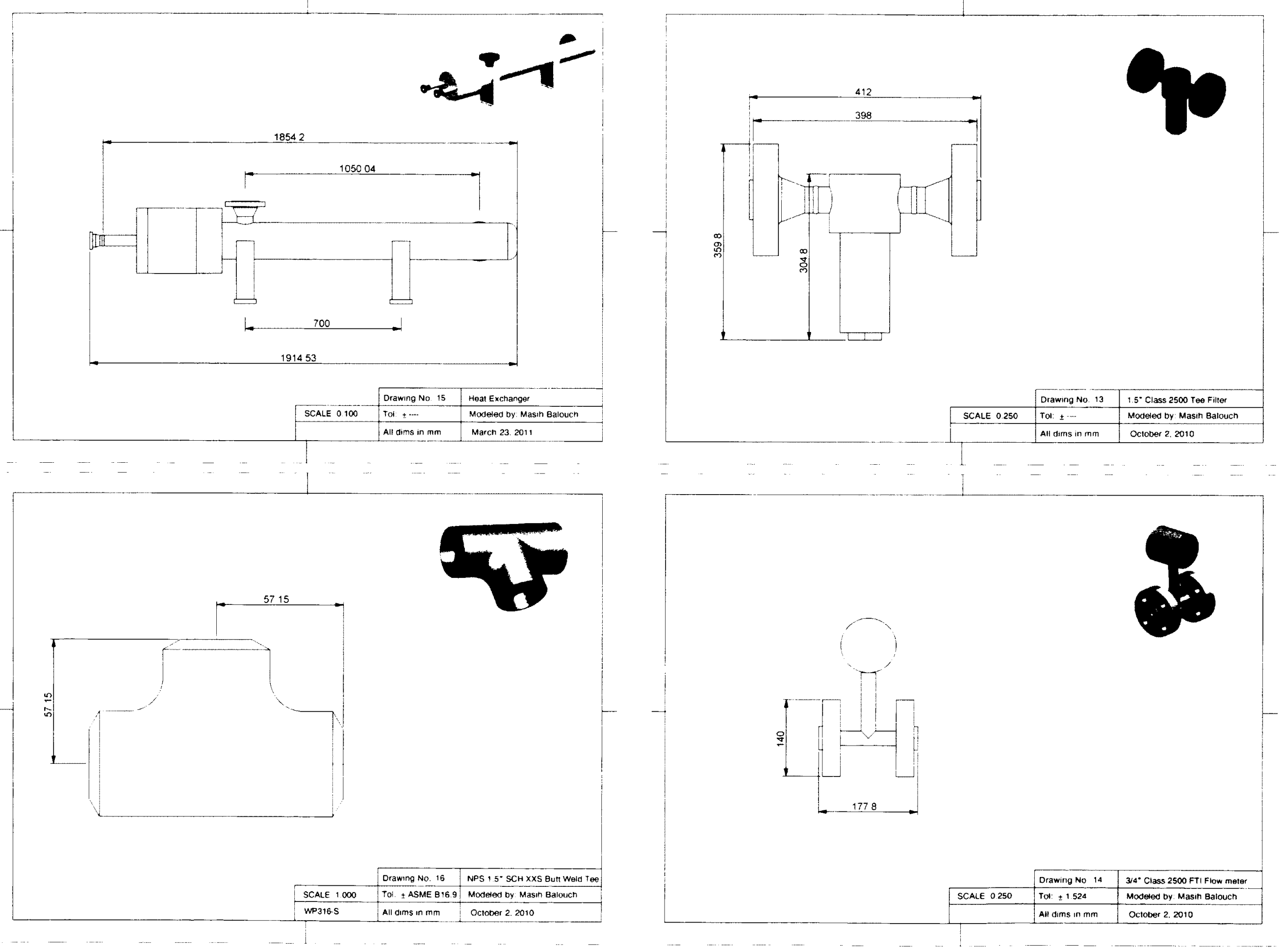


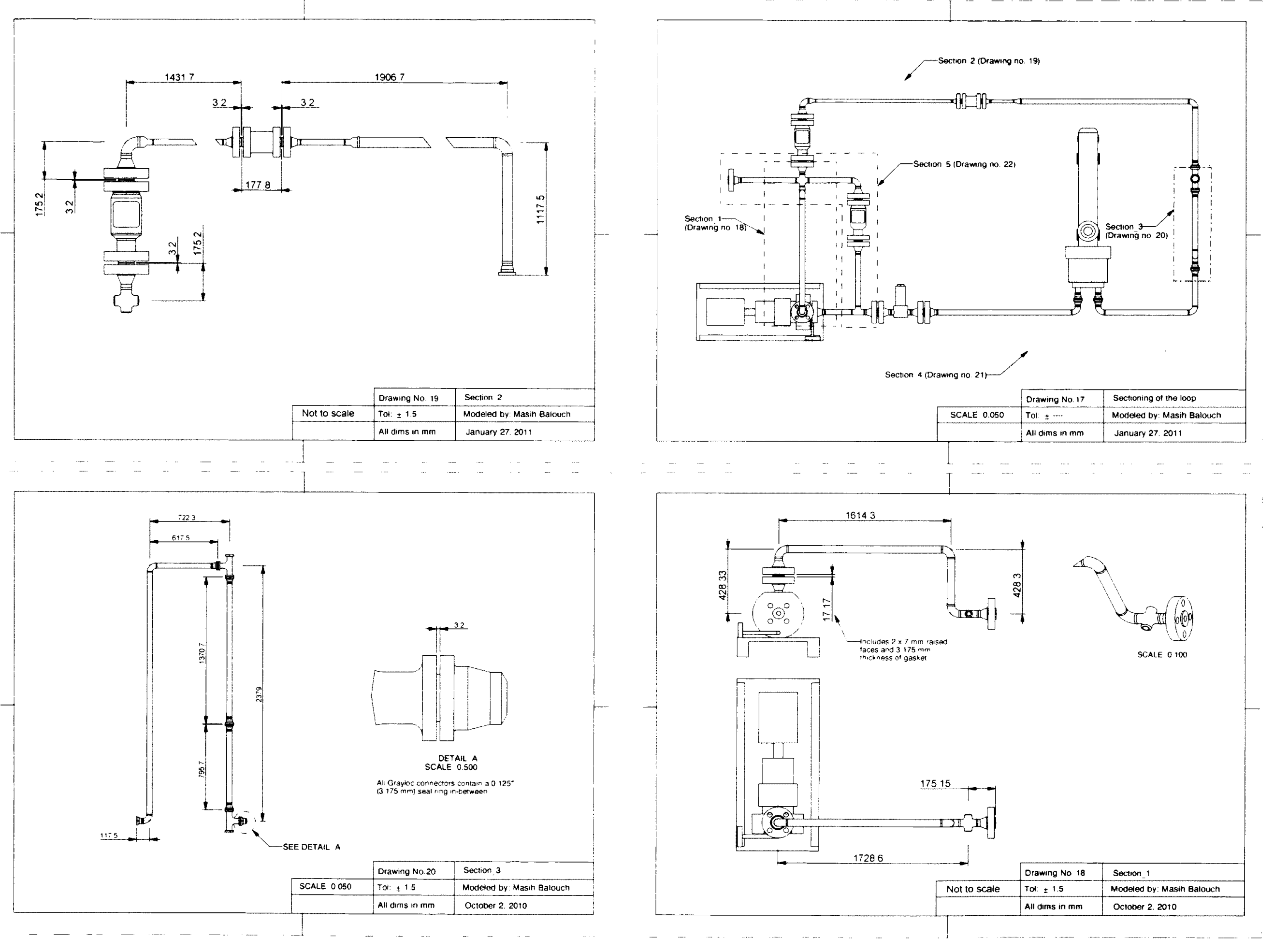



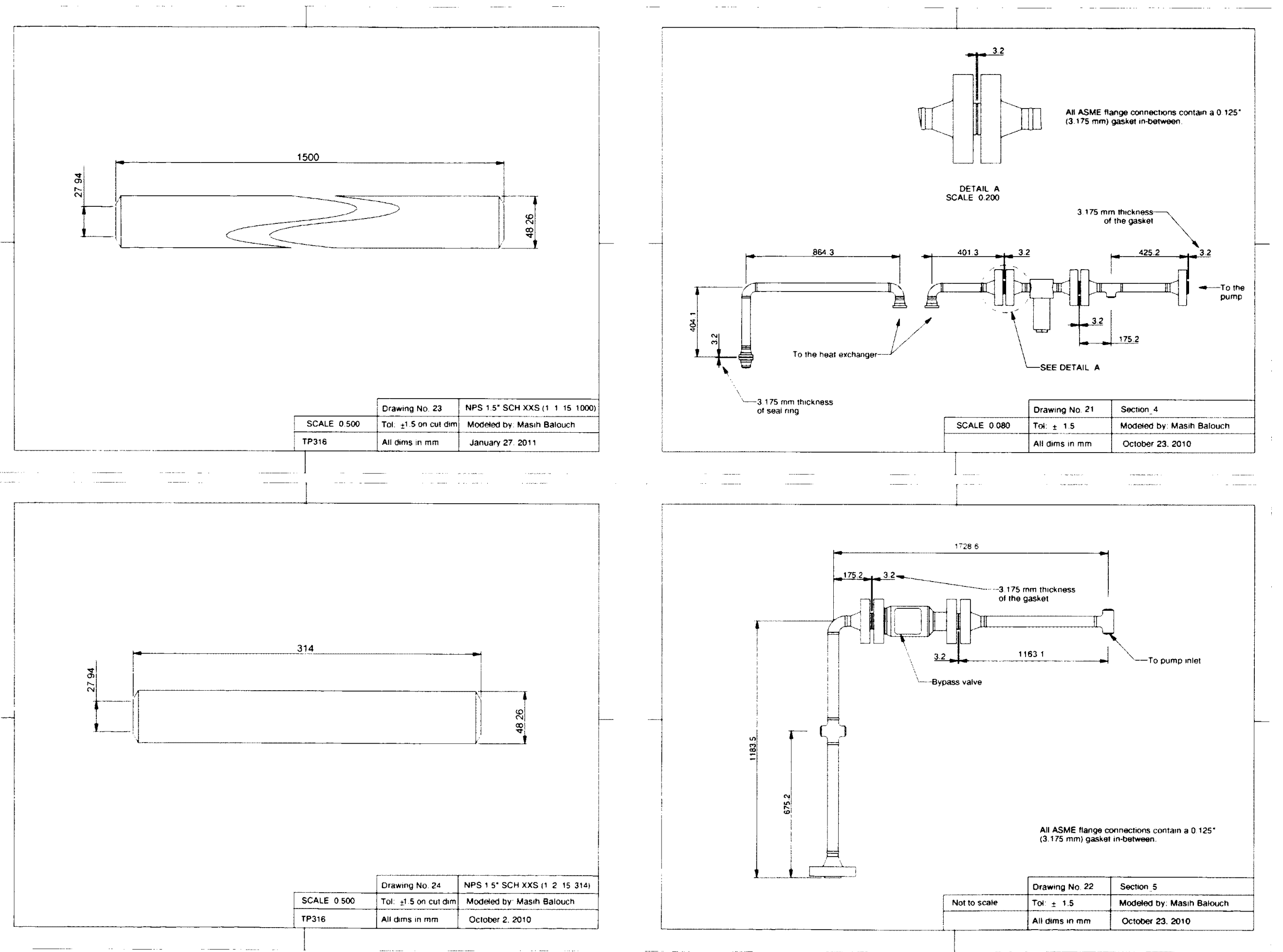


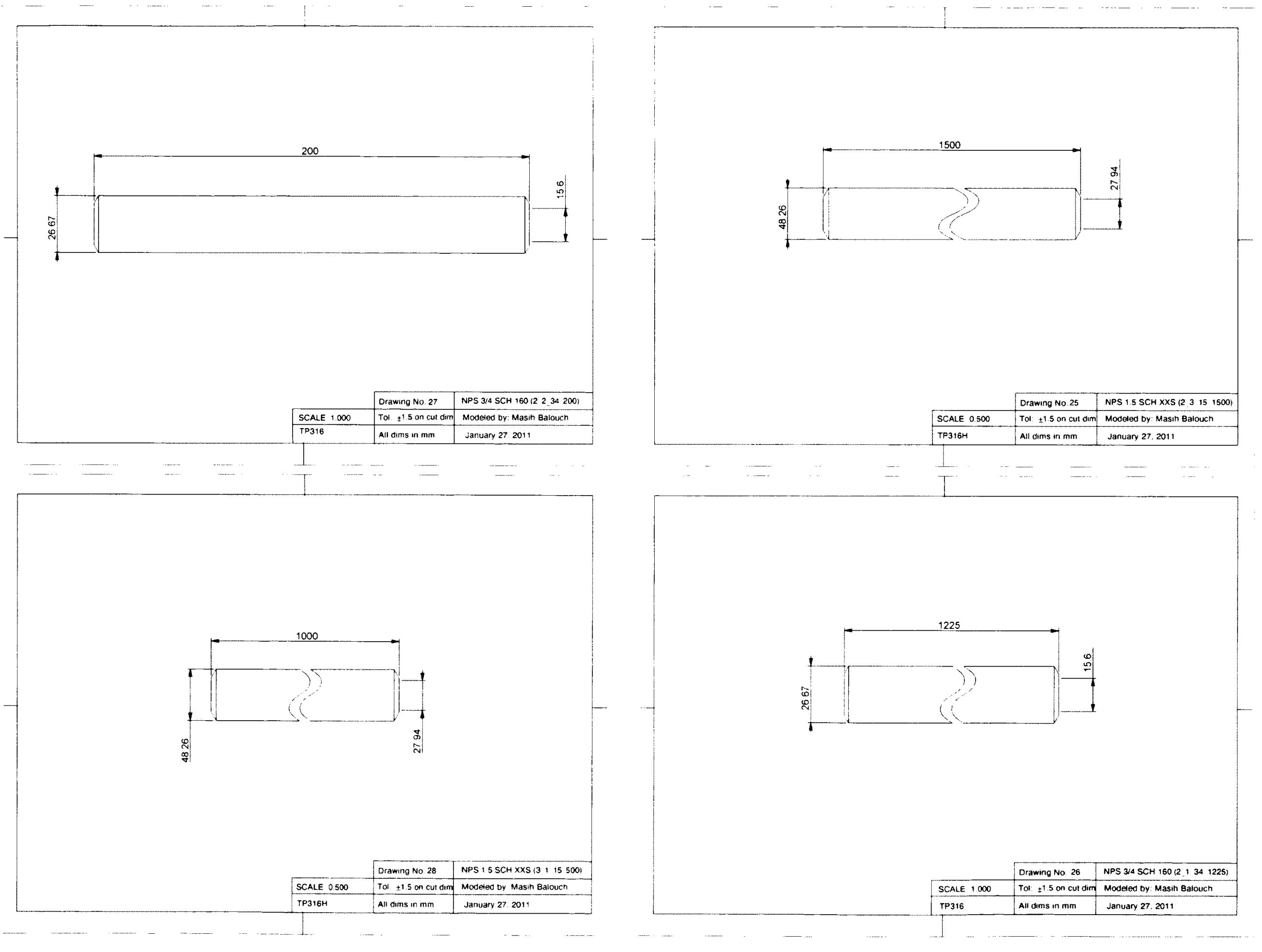



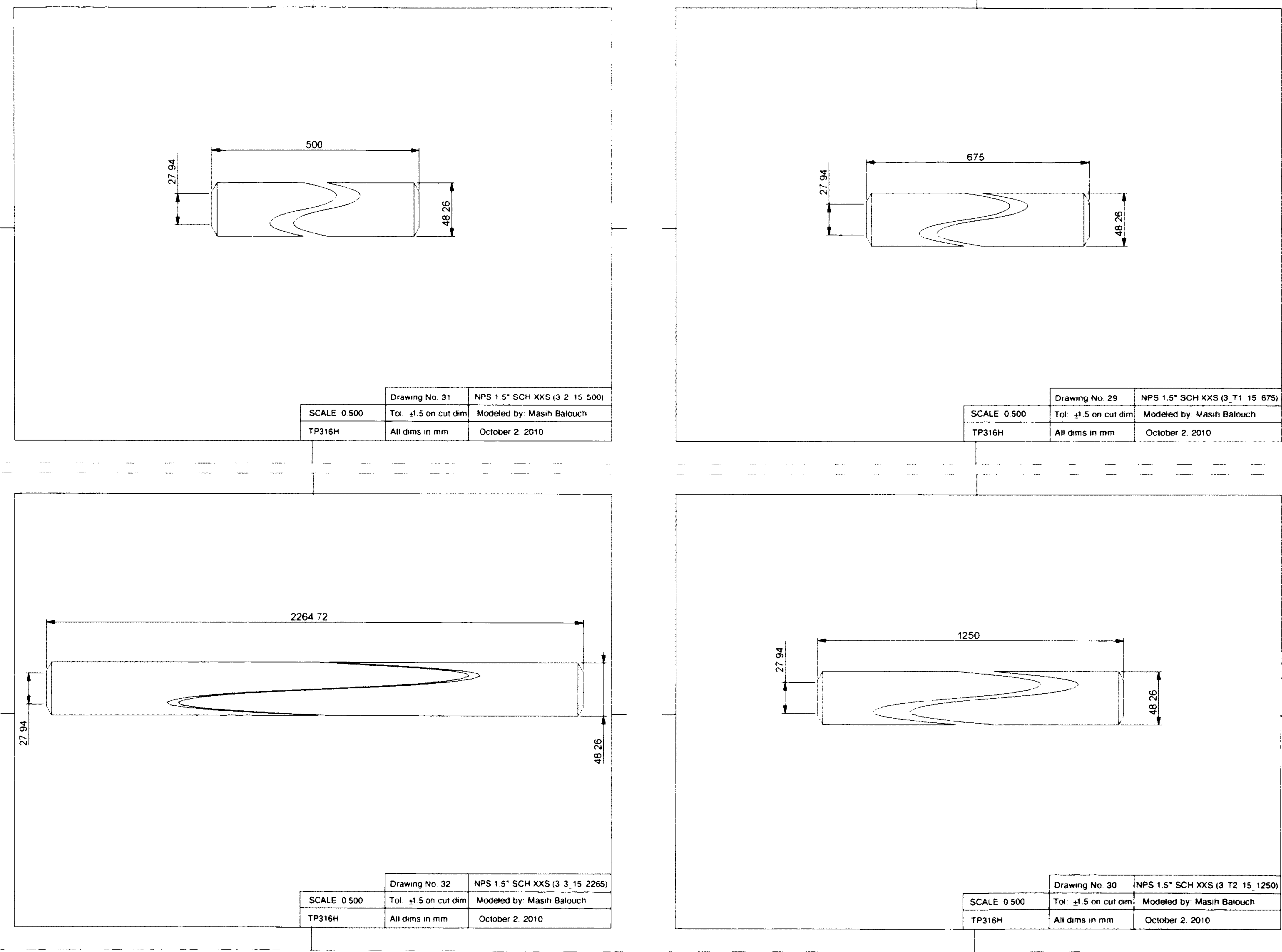

TP316

\begin{tabular}{|l|l} 
All dims in $\mathrm{mm}$ & Oclober 2. 2010
\end{tabular}

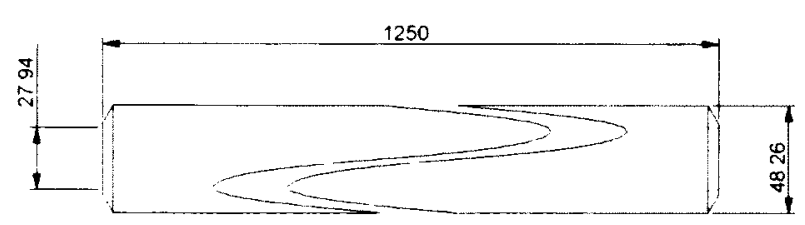

Drawing No. 30 NPS $1.5^{\circ}$ SCH XXS 13 T2 15.1250 Tot: $\mathbf{t}^{1.5}$ on cut dirn Modeted by Masin Balouch All dims in mm October 2. 2010 

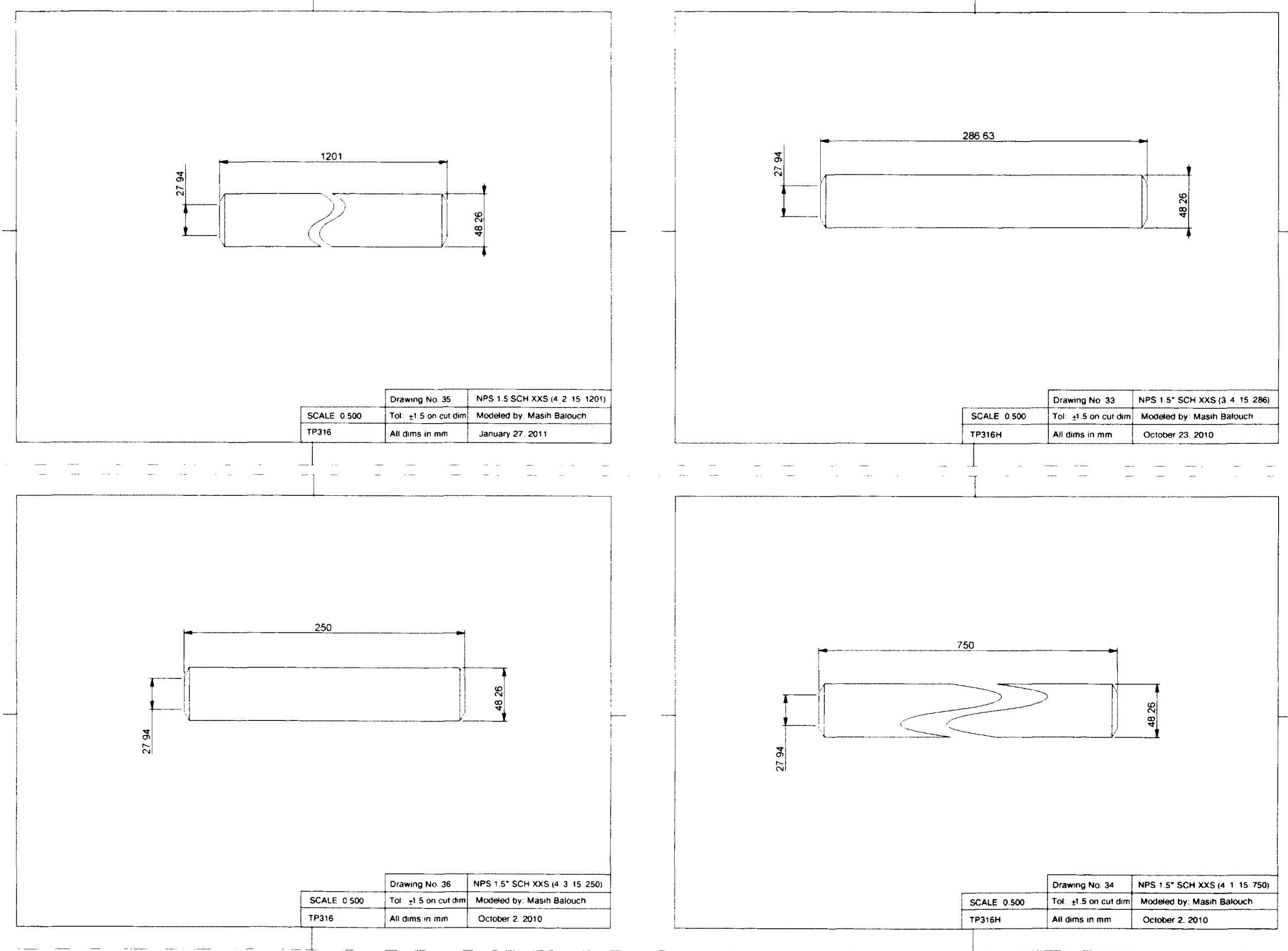

TP316

\begin{tabular}{|l|l}
\hline All dims in mm & October 23. 2010
\end{tabular}

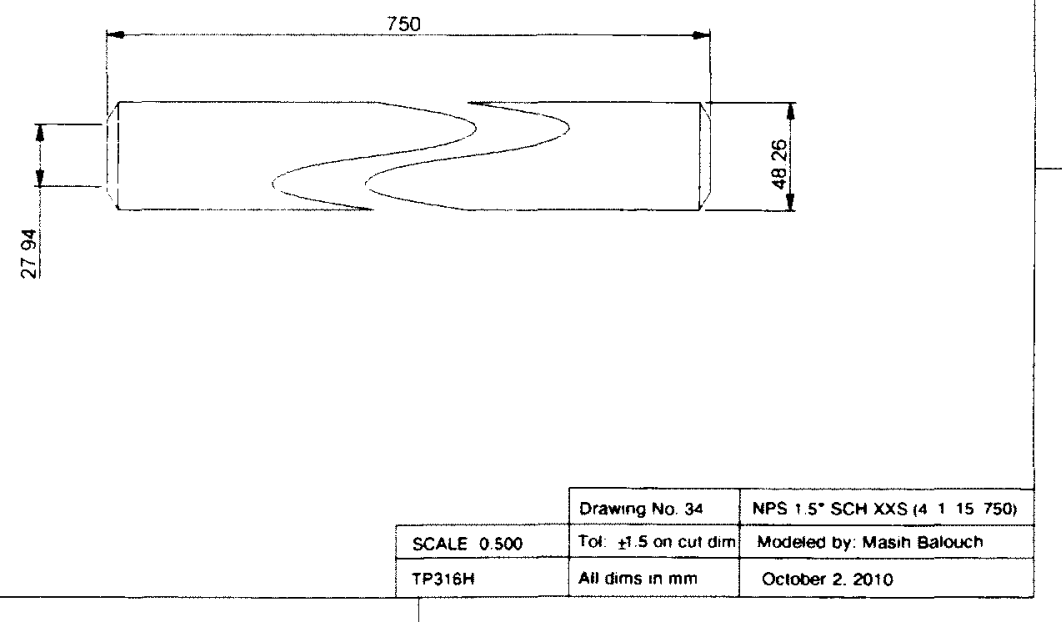



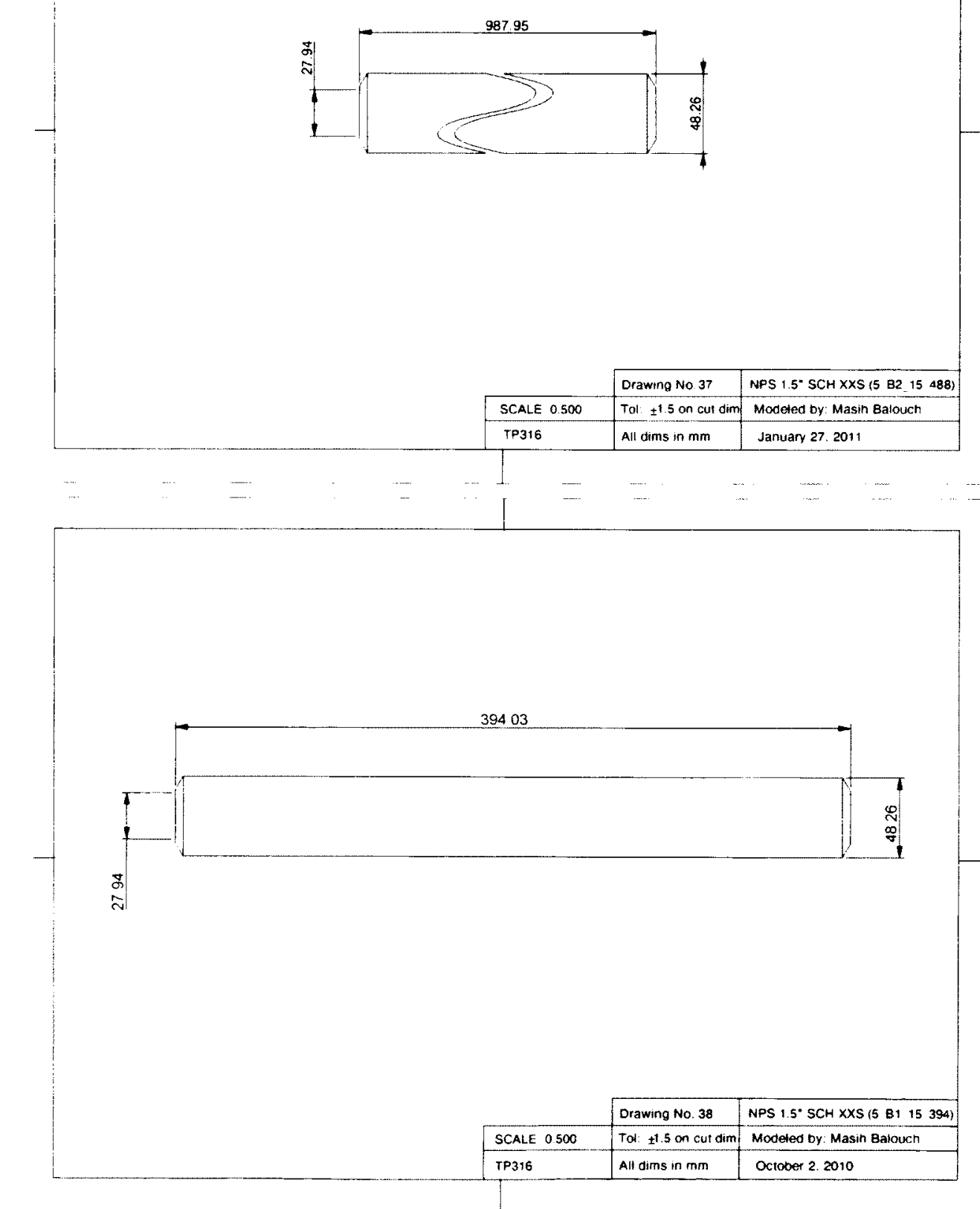


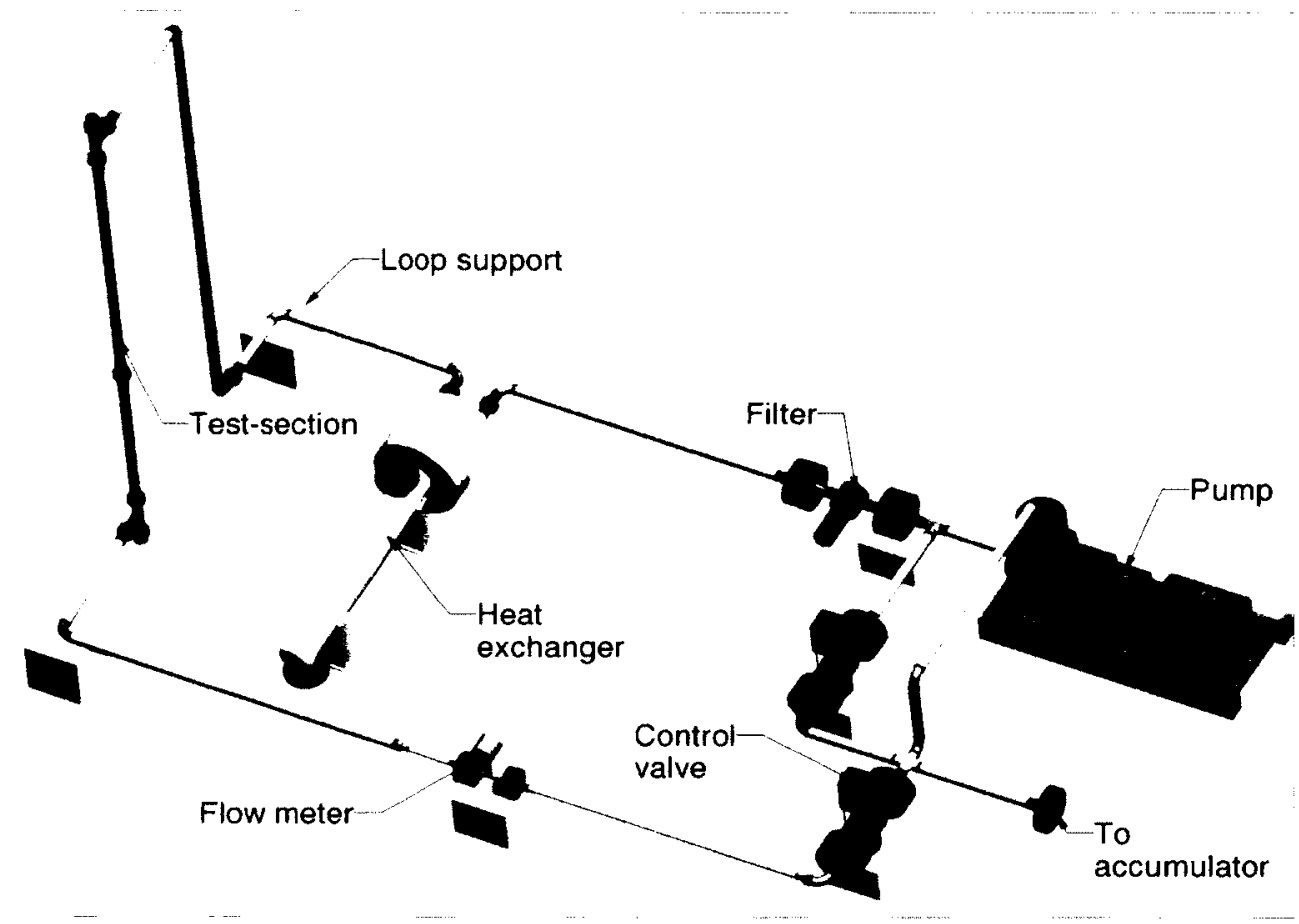




\section{Test Sections}




\section{Tubular}



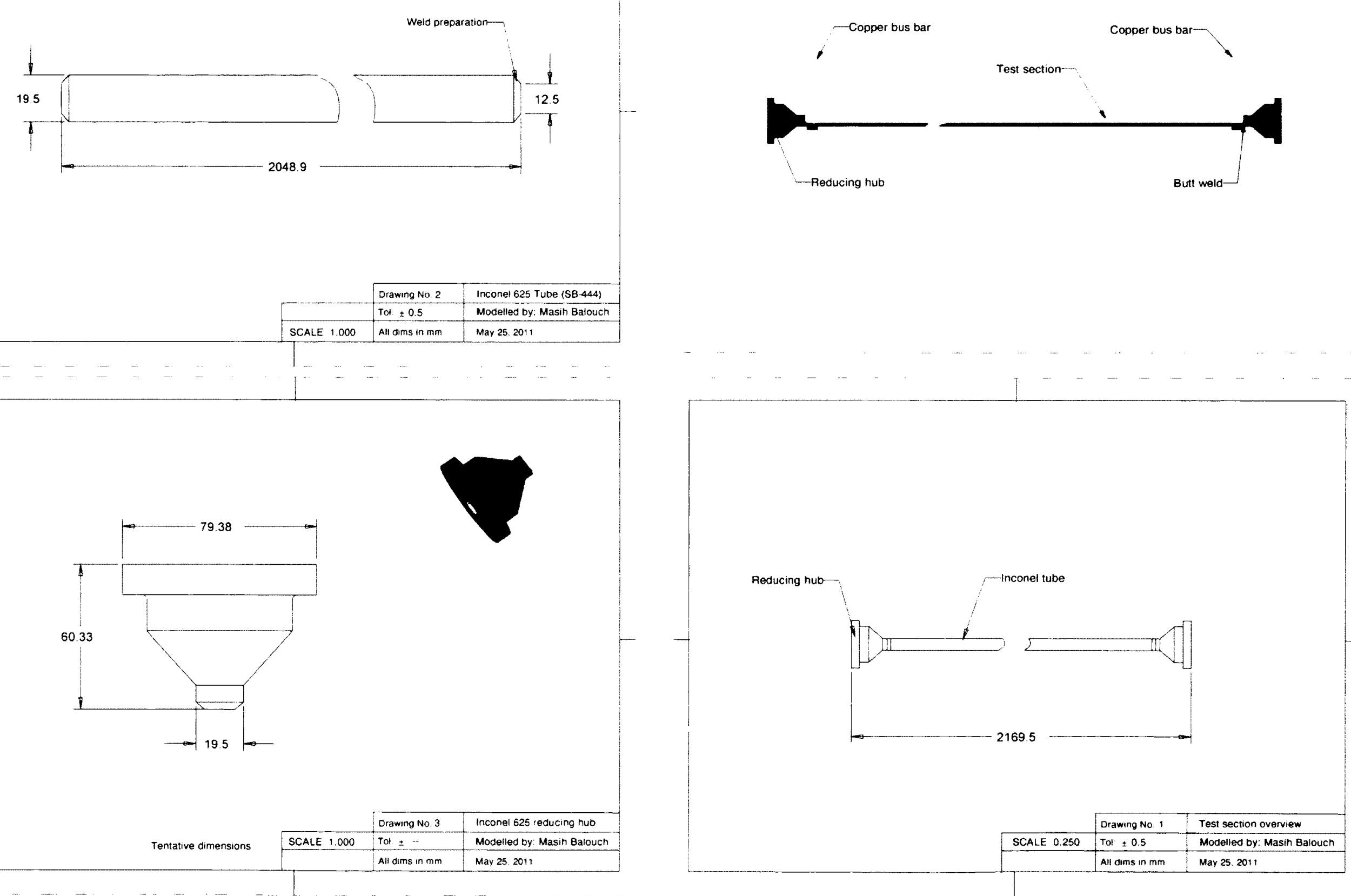
Annular 

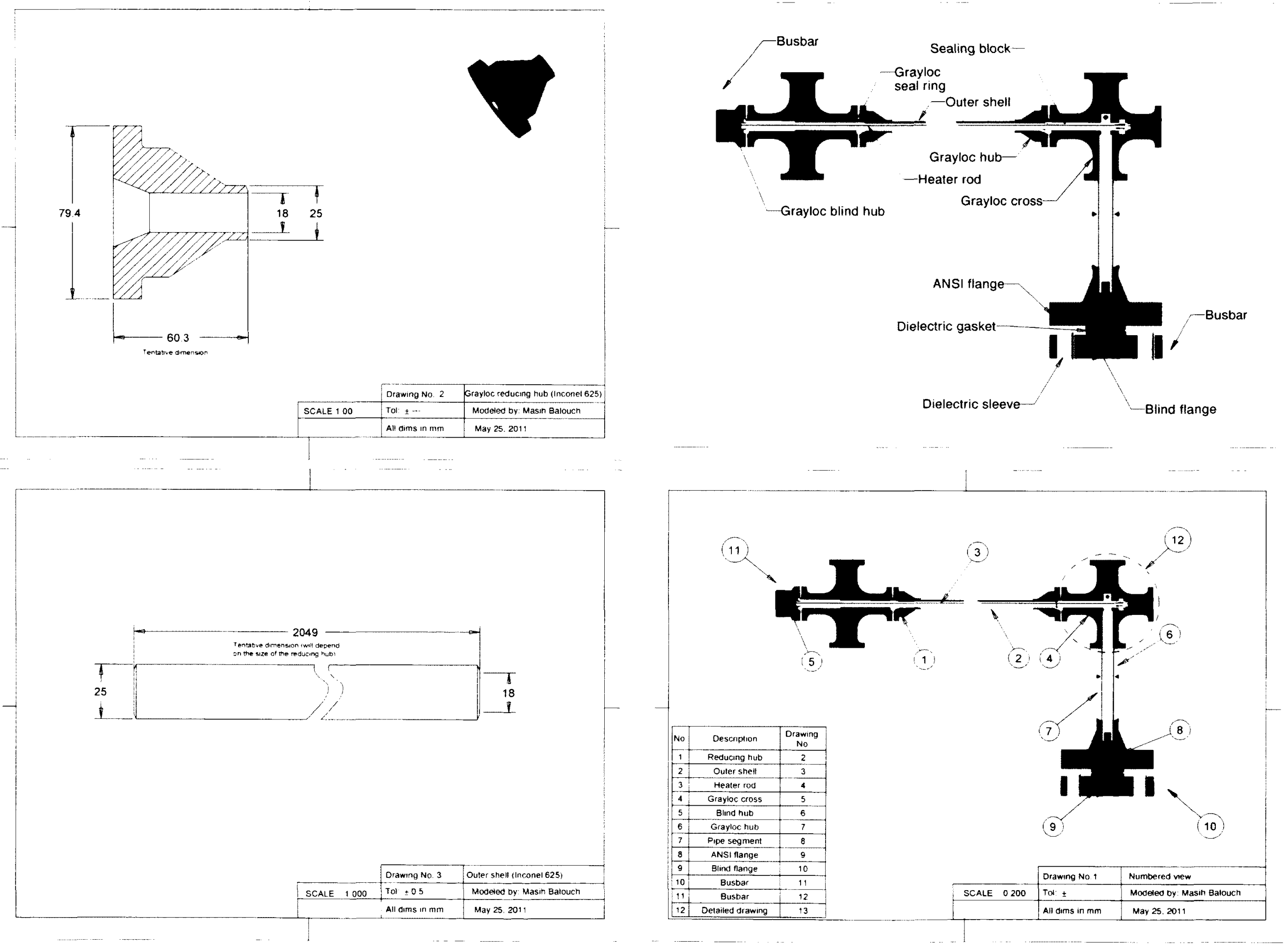


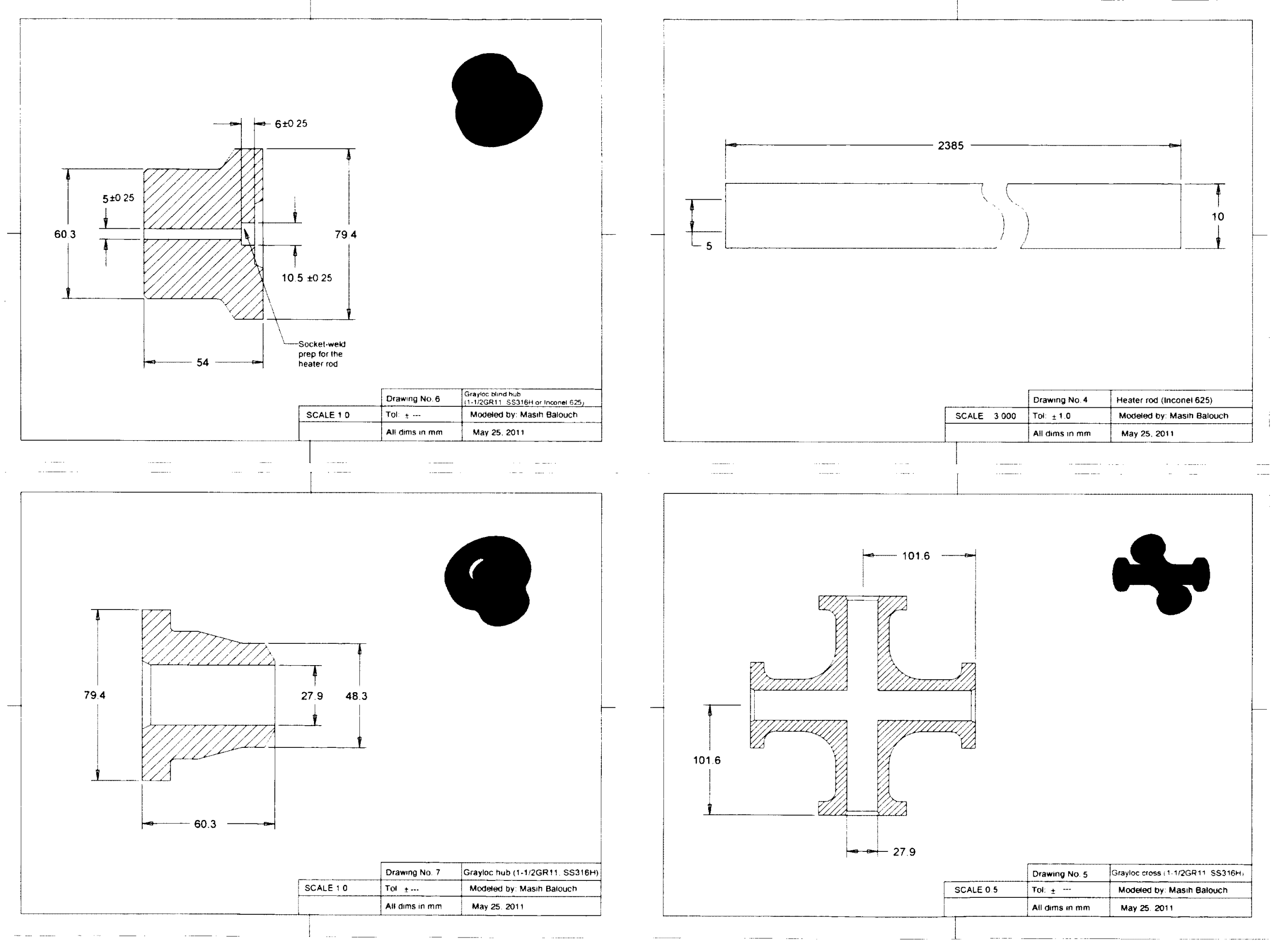




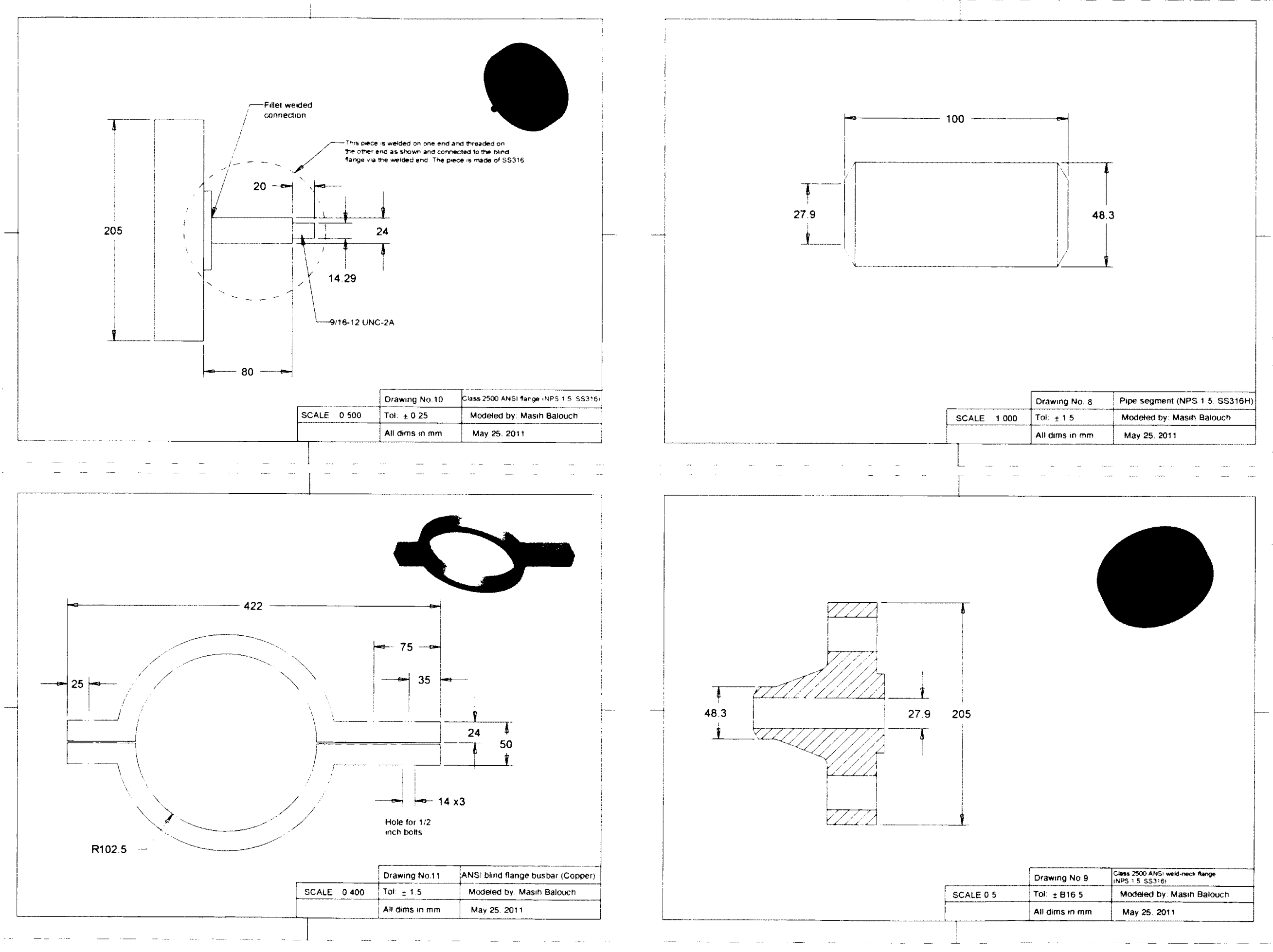




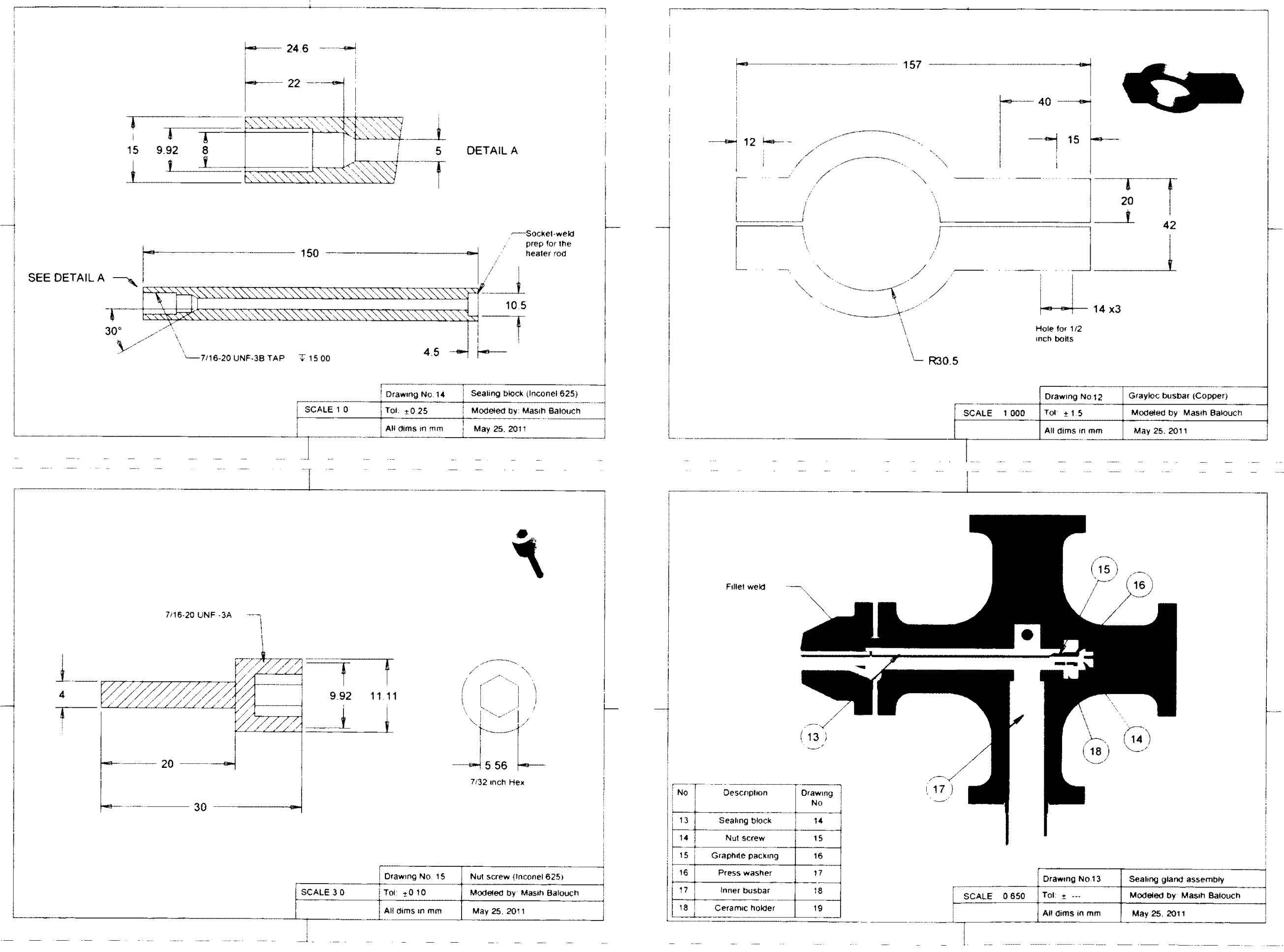



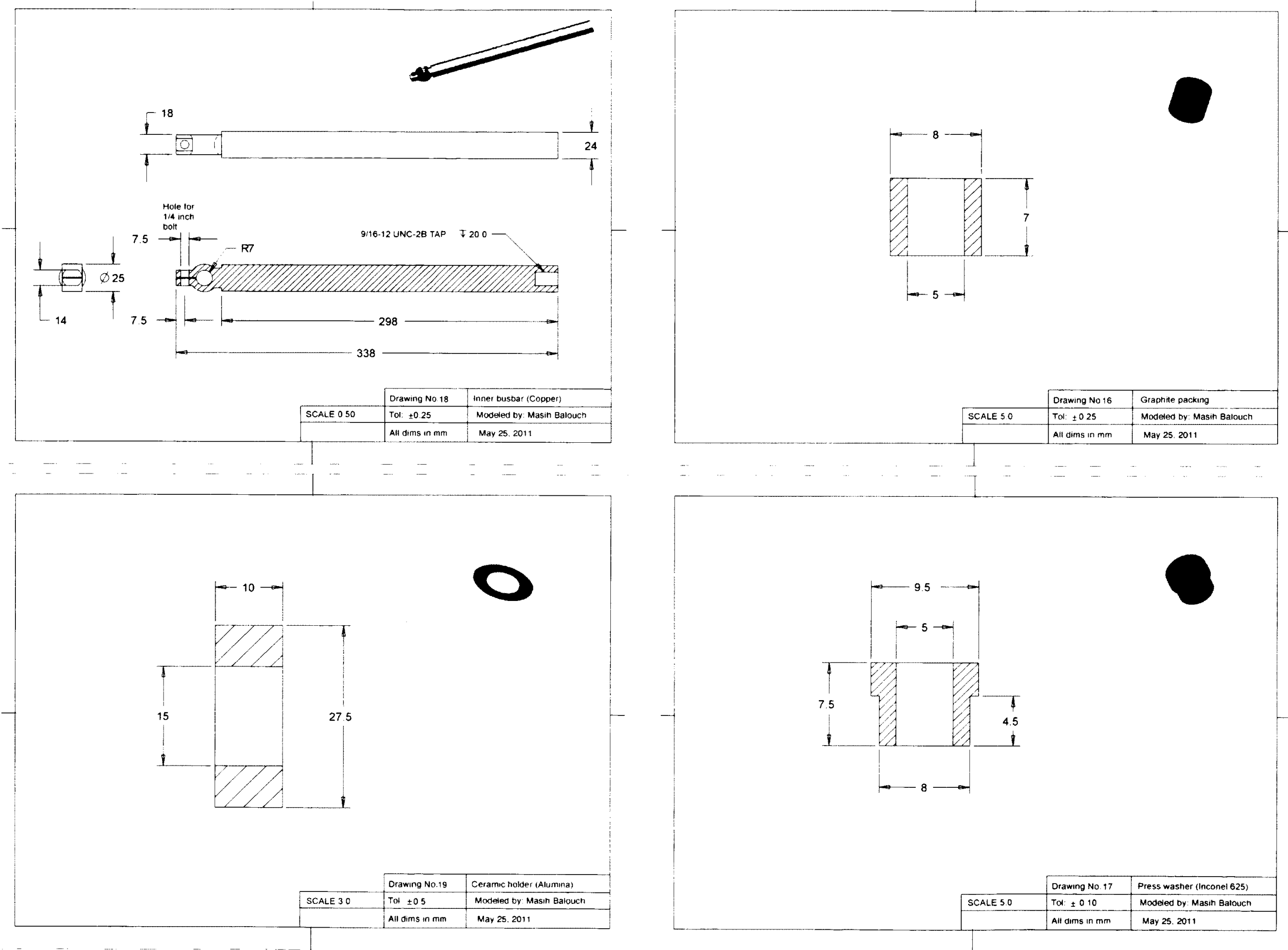


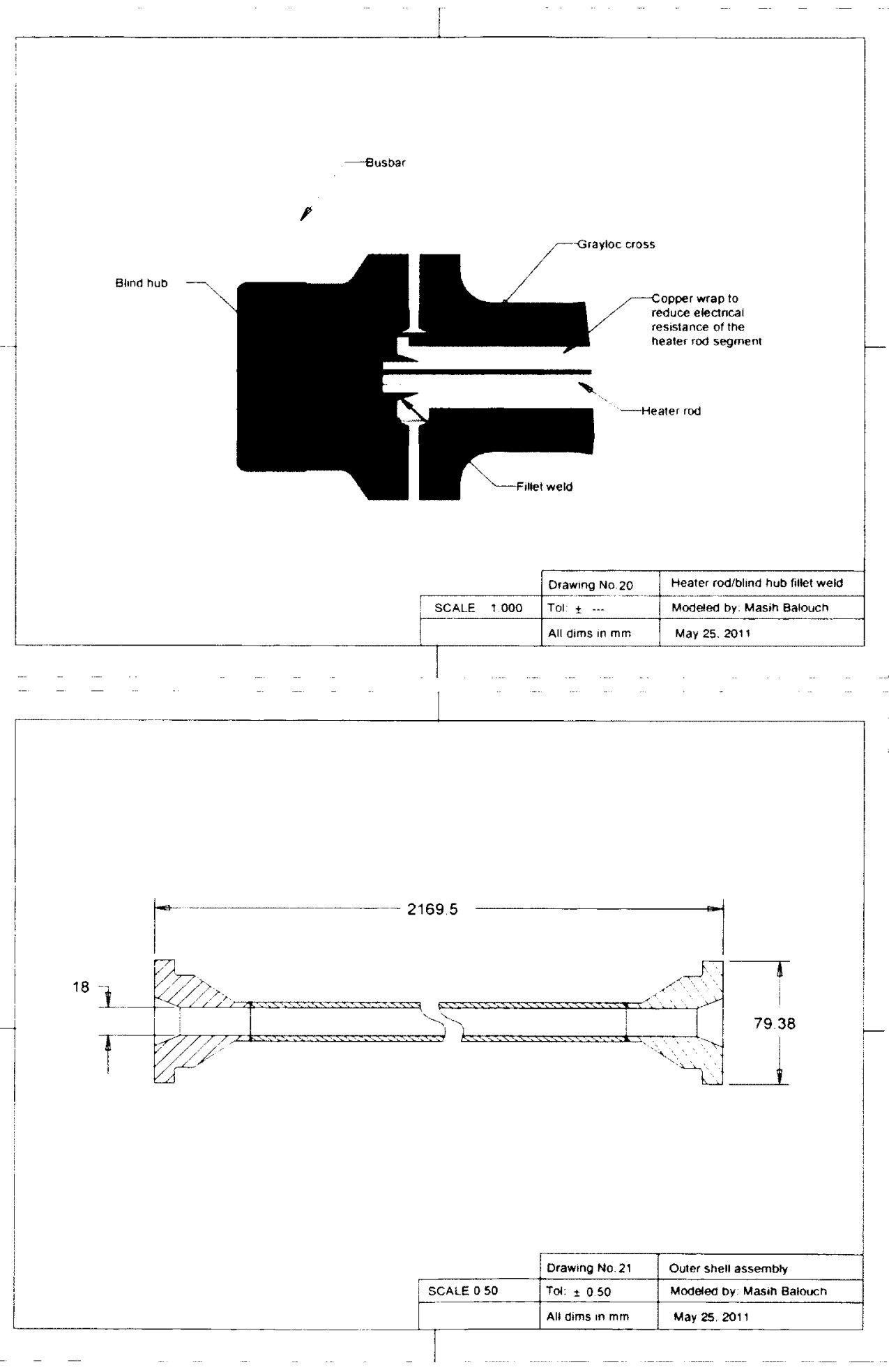


Bundle 

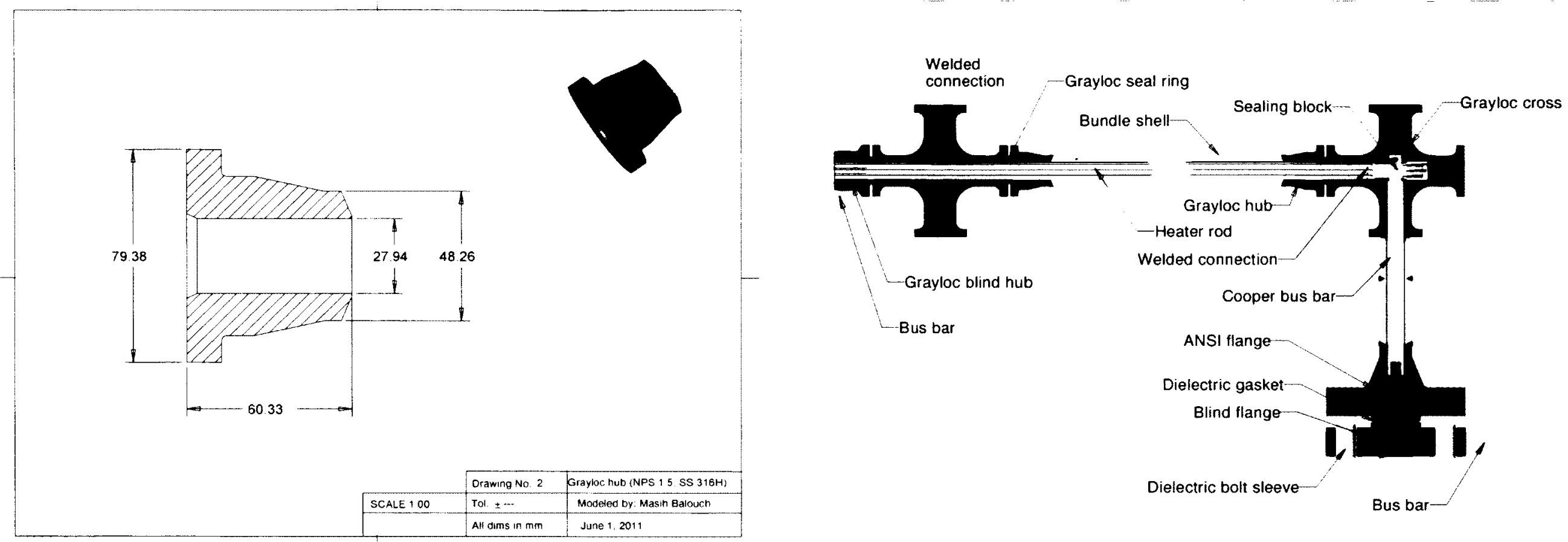

Dielectric bolt sleeve

Bus bar-

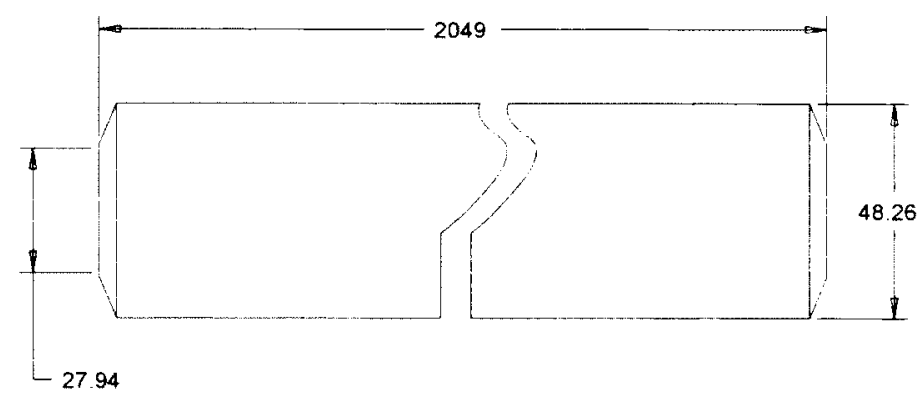

Drawng No. 3 Outer shell (NPS 1 5. SS $316 \mathrm{H}$

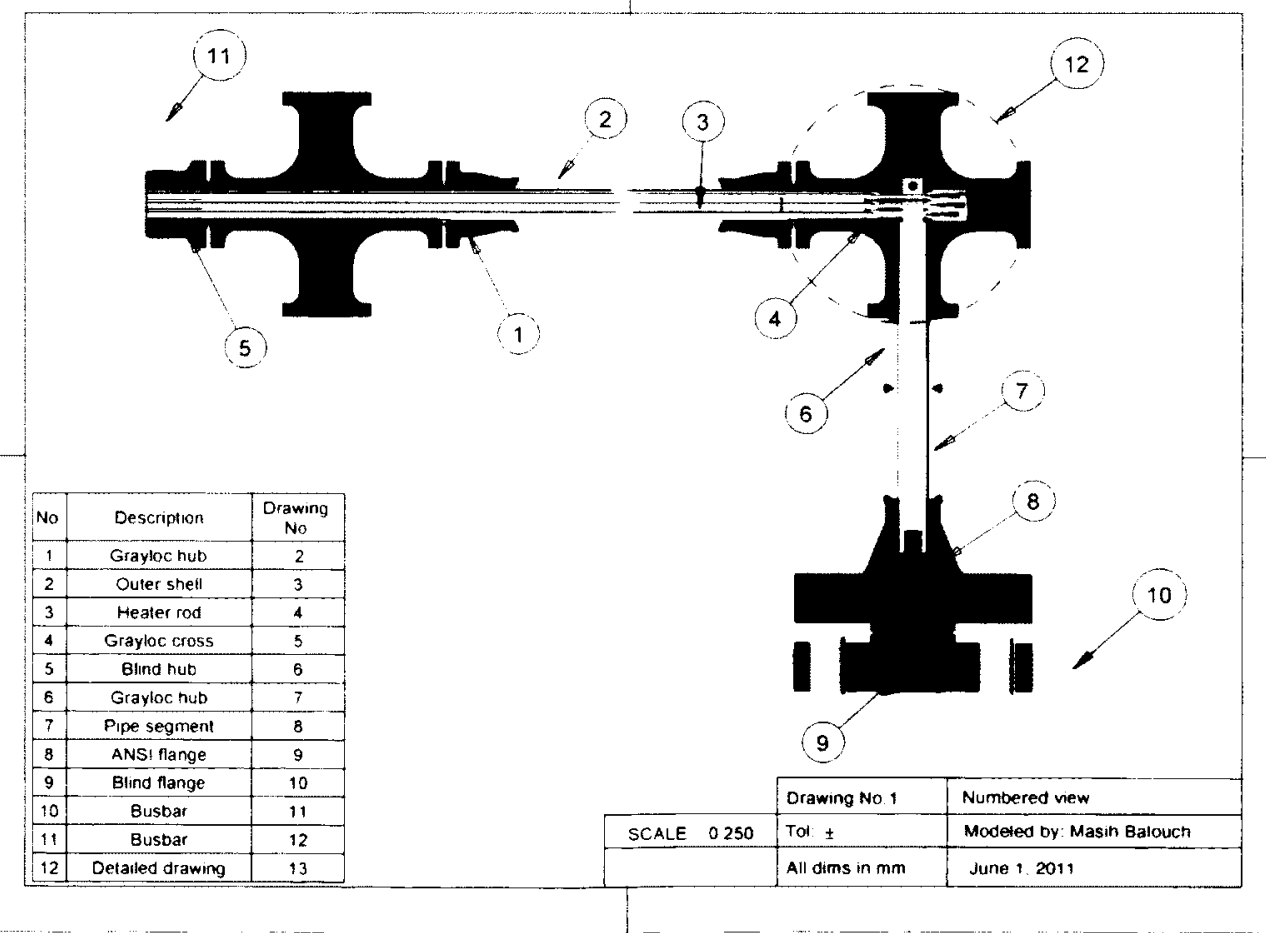



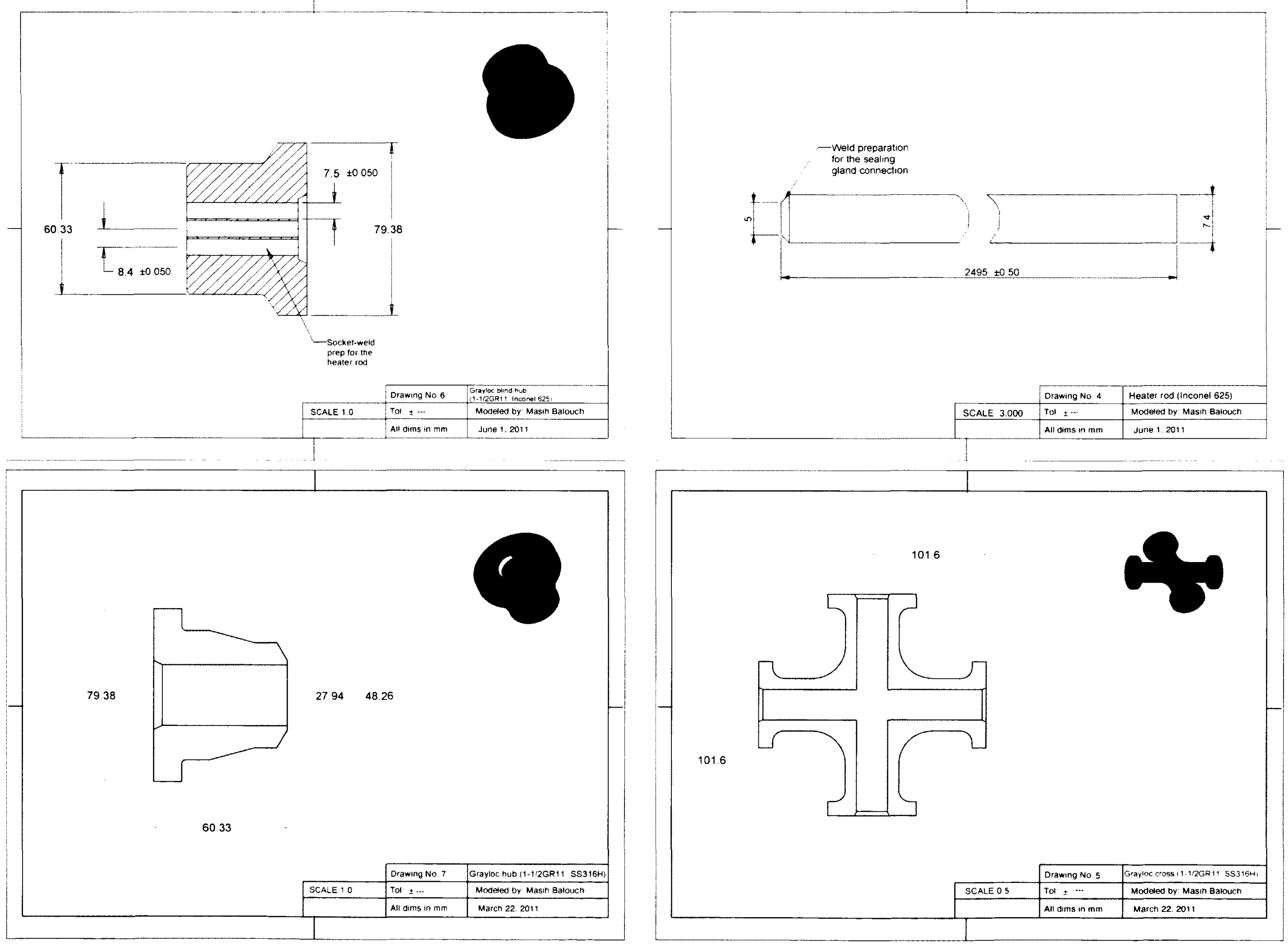

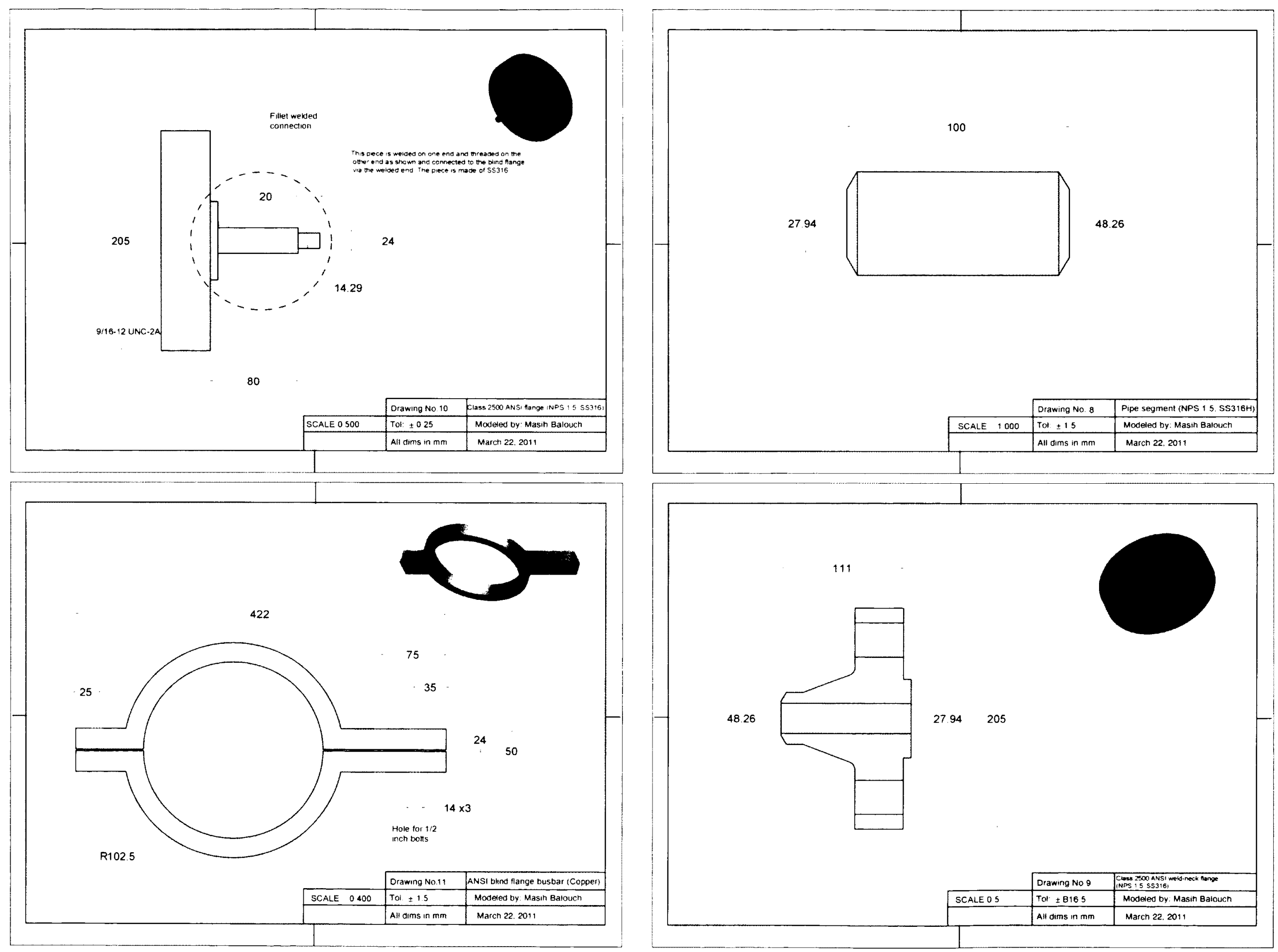

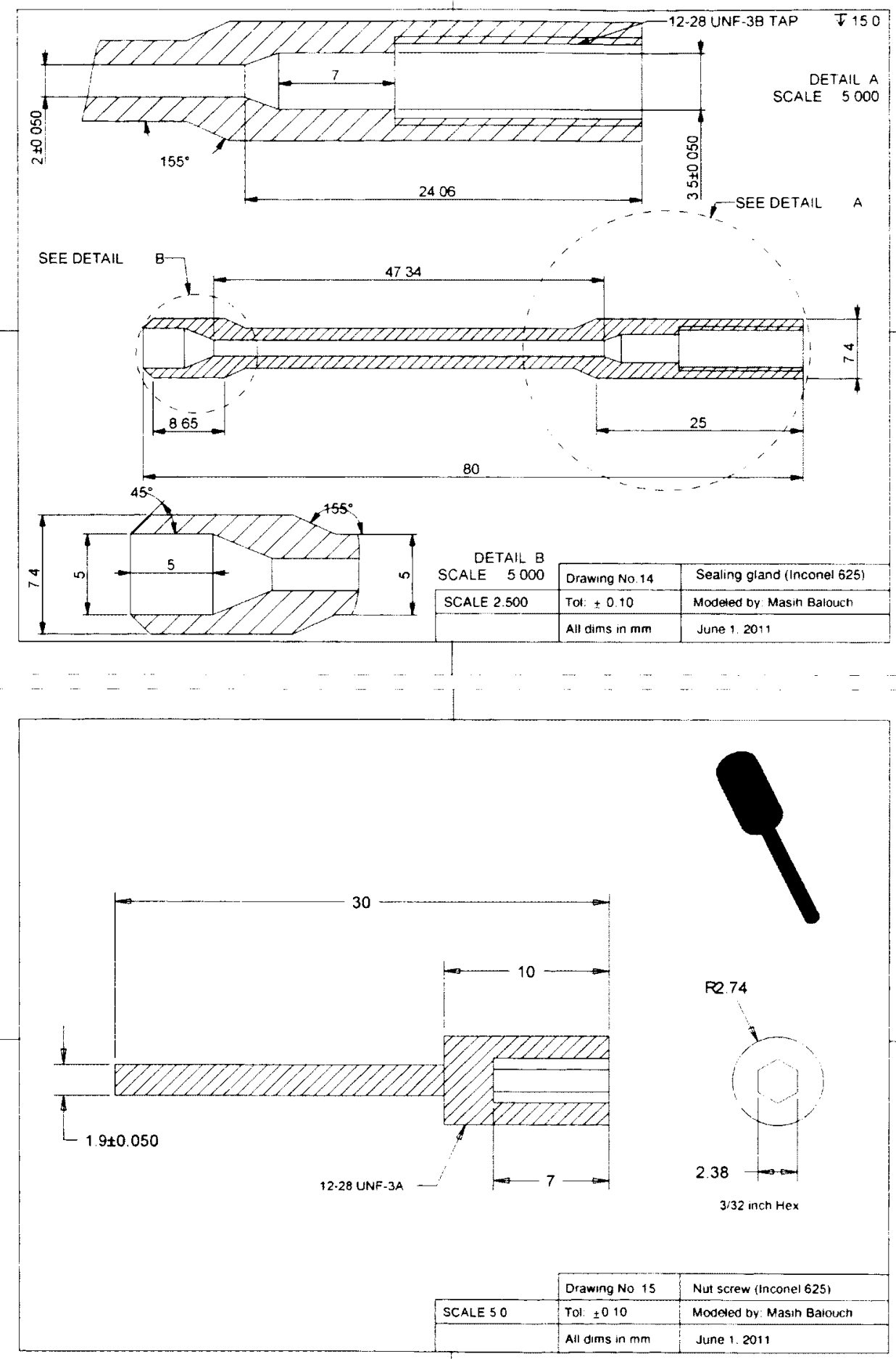

157

40
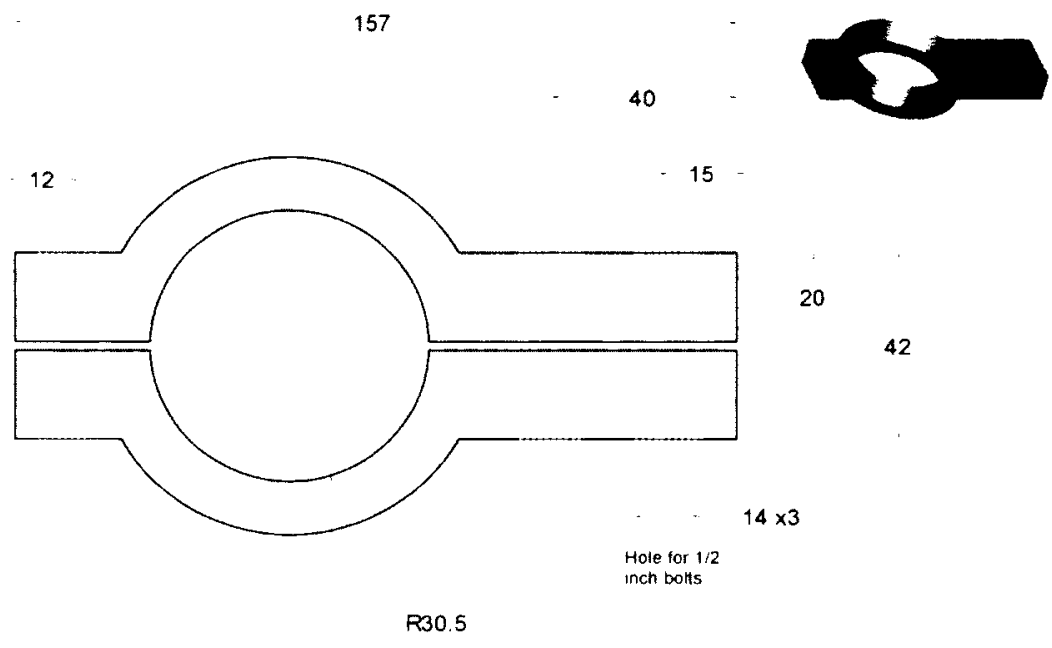

R30.5
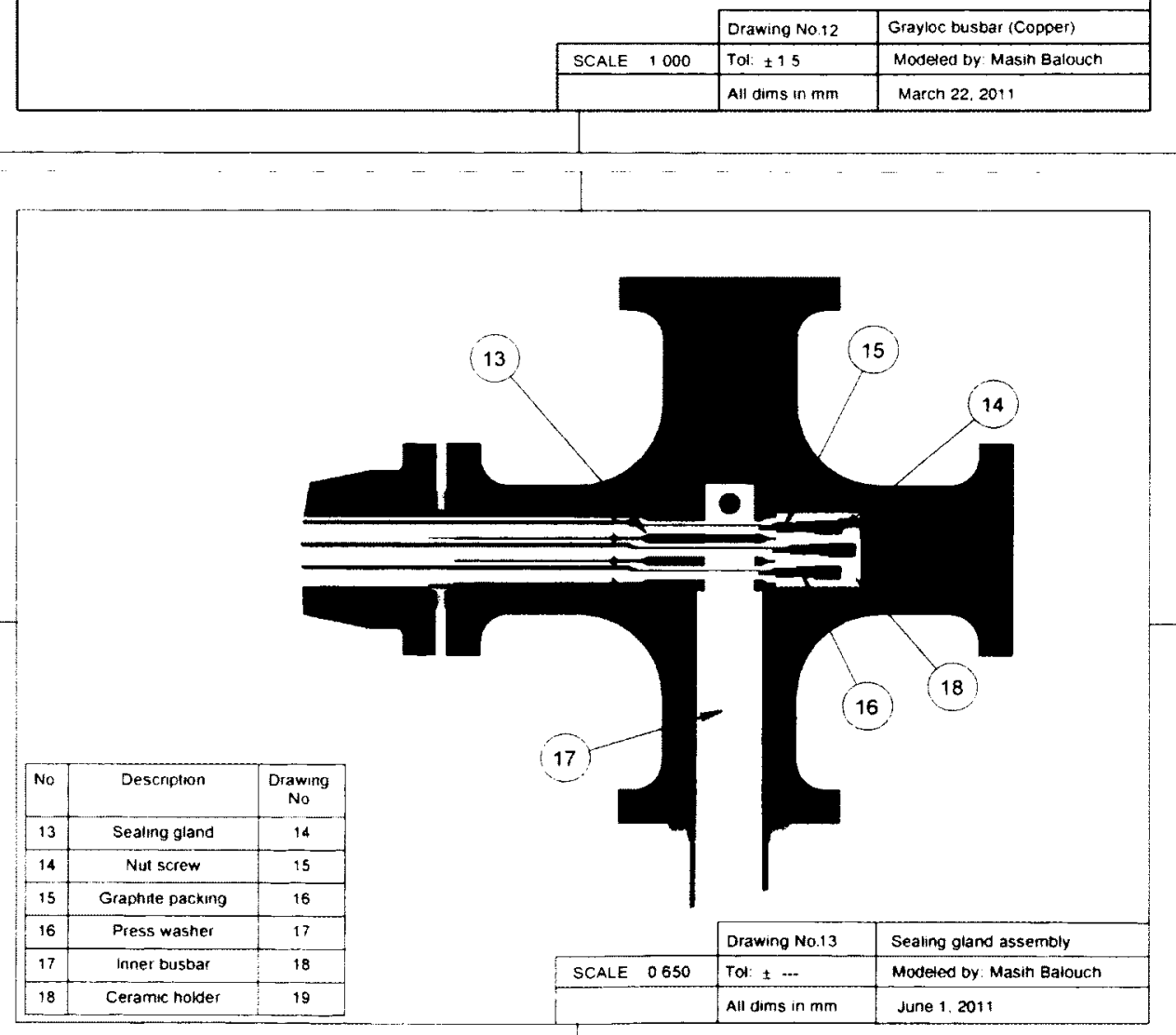


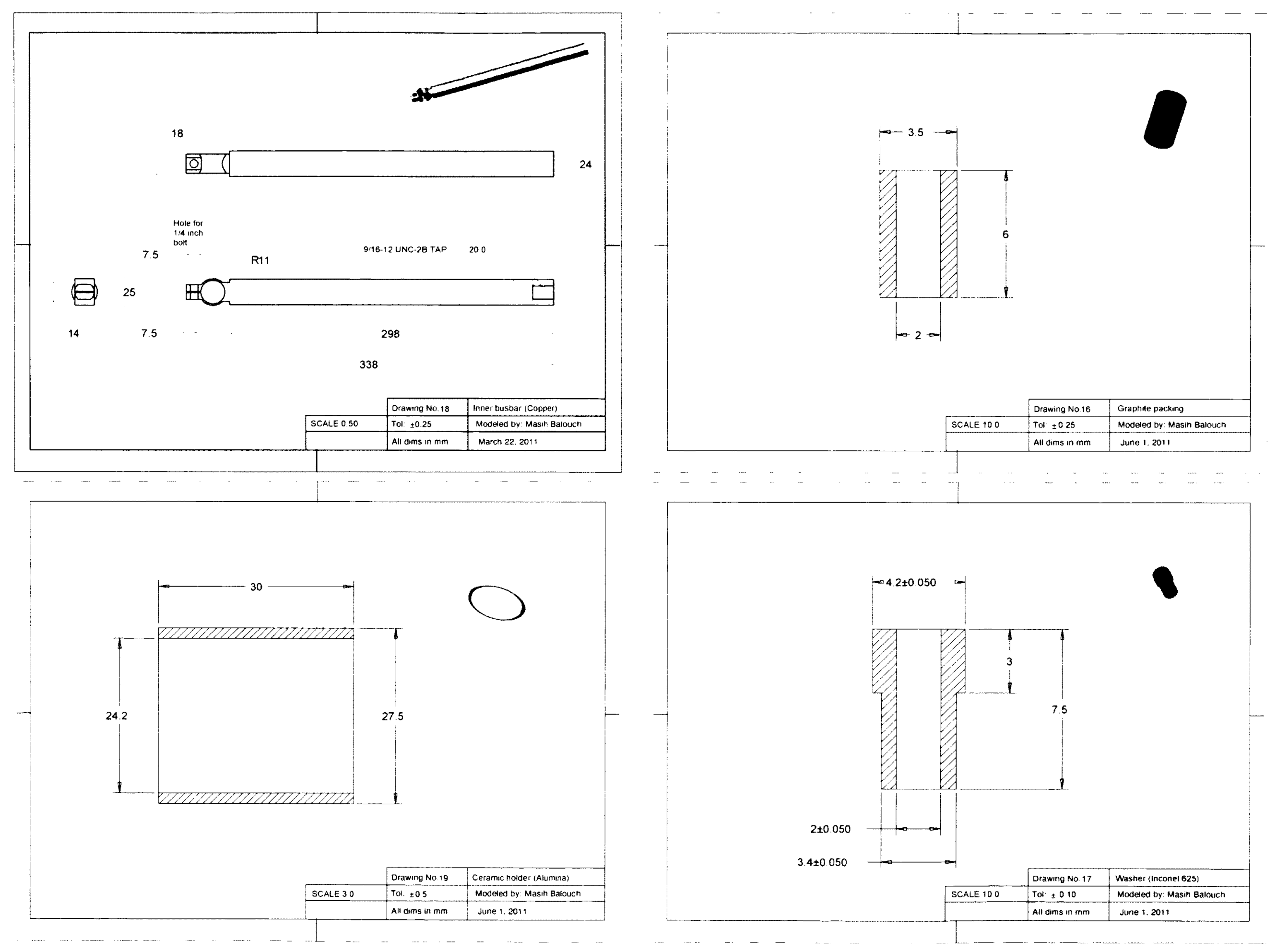



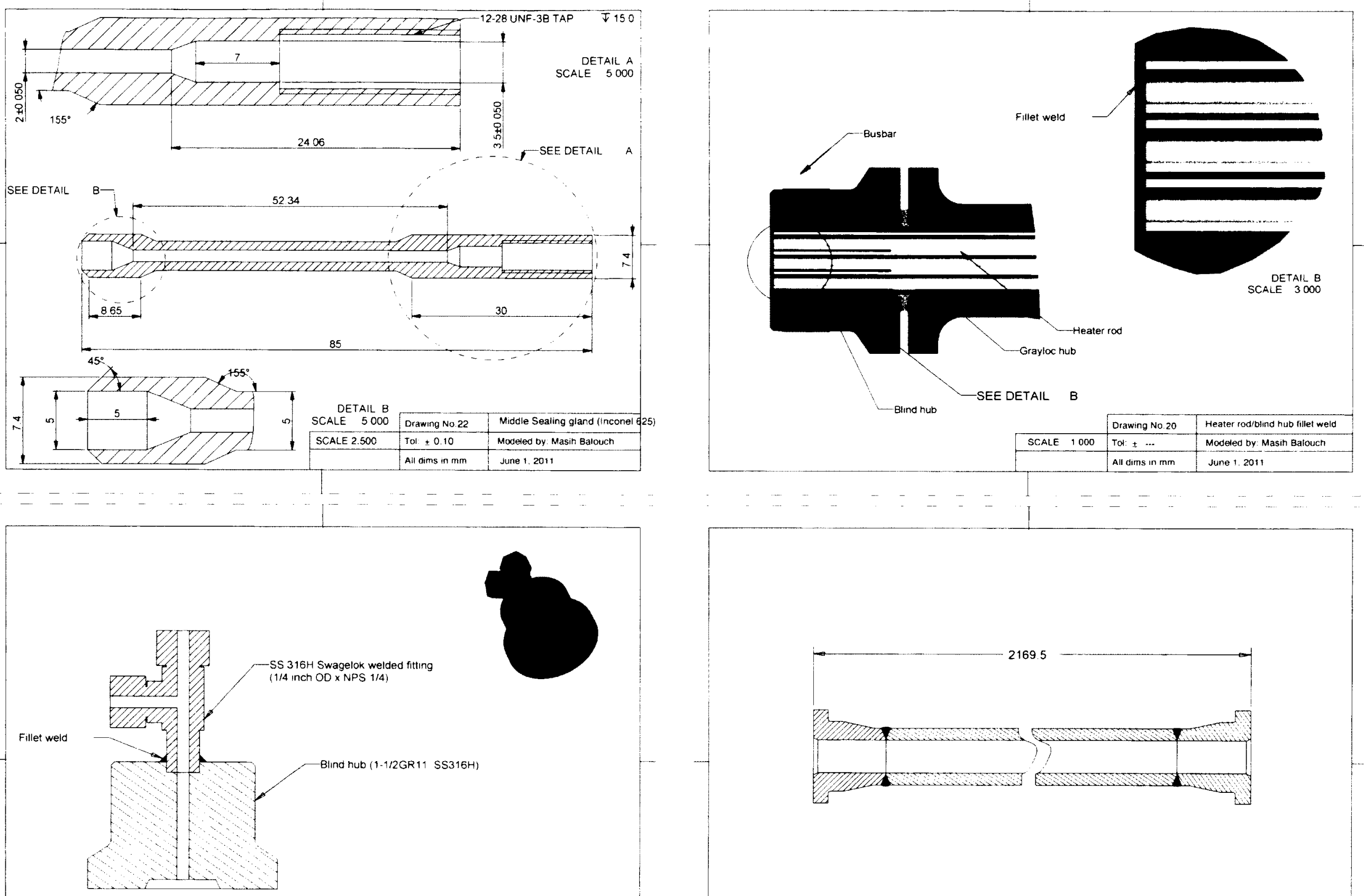

$\times 4$

\begin{tabular}{|l|l|l|}
\cline { 2 - 3 } \multicolumn{1}{c|}{} & Drawing No.23 & Weided Swagelok fftting \\
\hline SCALE 10 & Tol $\pm \ldots$ & Modeled by Masin Batouch \\
\hline & All dims in mm & June 1. 20n \\
\hline
\end{tabular}

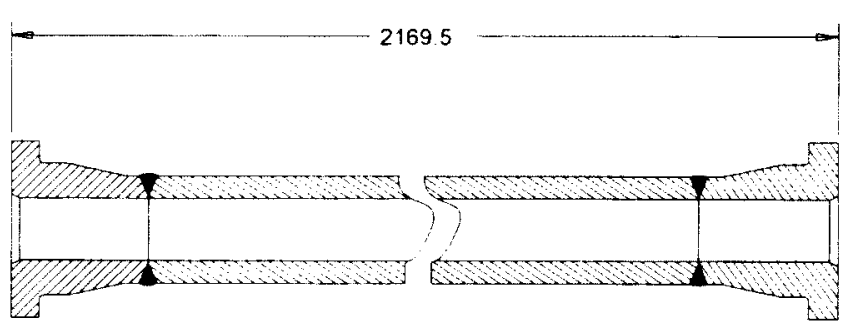

